$$
\text { The }
$$

H.

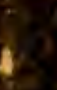

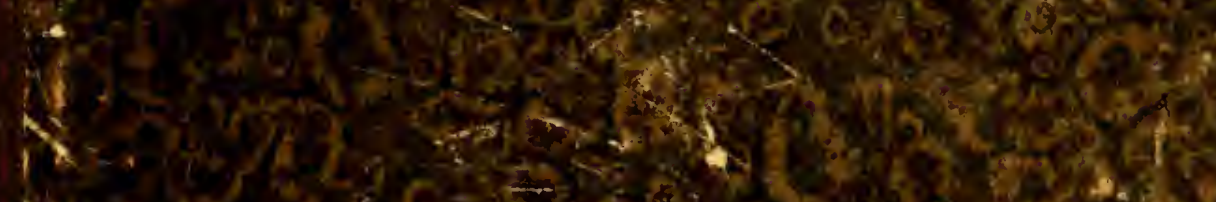

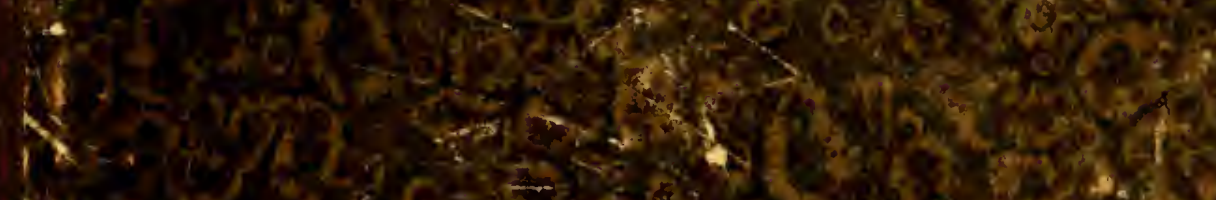

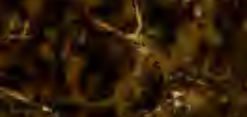

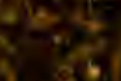

$\sin ^{2}$

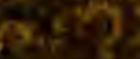

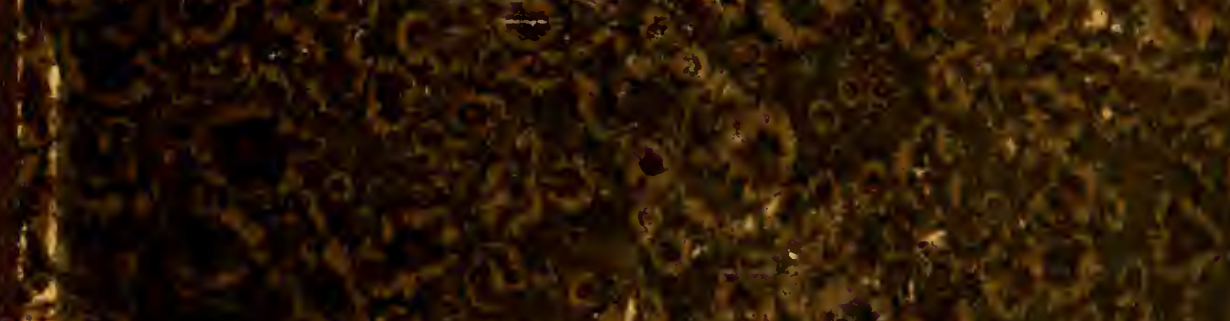

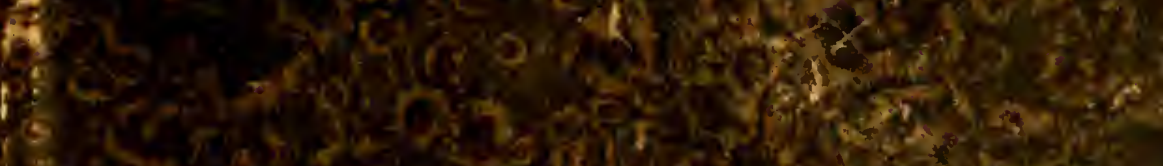

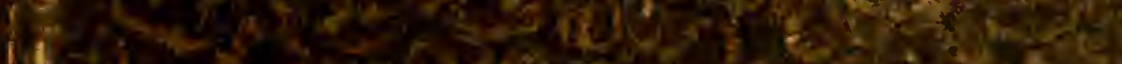

is:

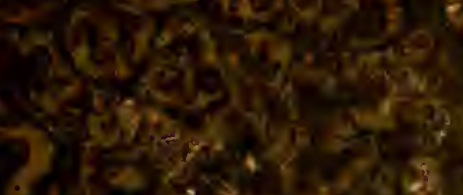

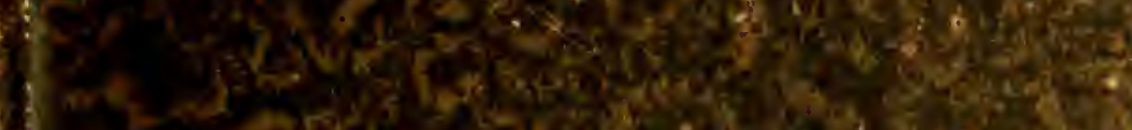


OIIOH 


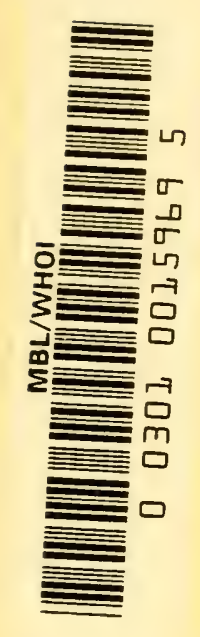





\title{
Ueber den
}

\section{Bau der Korallenriffe}

und die

Planktonvertheilung an den Samoanischen Küsten

nebst vergleichenden Bemerkungen

\section{Dr. Augustin Krämer}

und einem Anhang:

\author{
Ueber den Palolowurm \\ ron Dr. A. Collin.
}

Kiel und Leipzig 



\section{Ueber den}

\section{Bau der Korallenriffe}

und die

\section{Planktonvertheilung an den Samoaniselen Kï̈sten}

nebst vergleichenden Bemerkungen

\section{Dr. Angustin Kräimer}

und einem Anlrang:

Ueber den Palolowurm von Dr. A. Collin.

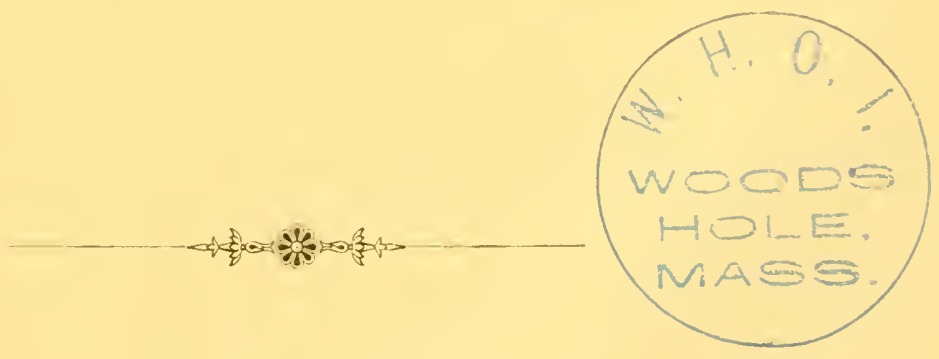

Kiel und Leipzig

Verlag ron Lipsius \& 'Tischer 1897. 
Meinen Kieler Lehrer'n in den Nitur'wissenschaften

$$
\text { Herral Prot. I)r. Kirrl Brandt }
$$

\section{Herrul Prof:. 1)r. Hippolyt Haas}

in Danlibarleneit und Fremulschaft

$$
\text { gewidmet. }
$$





\section{Vorrede.}

Nachfolgende Beobachtungen und Untersuchungen sind während einer zwcijührigen Reise in der Südsee in den Jahren 1893 bis 1895 an Bord Seiner Majestät Kreuzer „Bussard" gemacht worden. Da das Schiff während dieser Zeit nur Samoa, Neu-Seeland und Australien (Viti nur sehr kurz) besucht hat. so kann ich leider über keine ausgedehnte Südseeerfahrung gebieten. Da jedoch von den zwei Jahren volle zwölf Monate anf die samoanischen Gewässer fallen und der „Bussard" bäufig Fahrten zwischen den Inseln dieses Archipels machte, so habe ich wenigstens dies Gebiet ziemlich genau und eingehend kennen gelernt und ich glaube, dass das genaue Studium einer einzelnen Inselgruppe das vorliegende Problem unter Umständen mehr fördert, als das Zusammentragen einer Fluth von immer noch unsicheren Thatsachen, wie dies z. B. in Dana's Buch "Coral and Coral Islands" der Fall ist.

Der jetzige Contrealmiral Hoffmann sagte einst in einem Vortrag in der Gesellschaft für Erdkunde zu Berlin am 7. Mai 1882:

„Ein Vergleich meiner Notizen mit den Beschreibungen, welche wir über Korallenbildungen besitzen, hat mich zu der Einsicht gefïhrt, dass diese Bildungen untereinander viel verschiedenartiger sind, als man in der liegel anzunehmen geneigt ist und dass es nicht zulässig ist, aus Beobachtungen an einer einzelnen Inselgruppe auf das Wachsthum und den Bau der Korallenriffe im Allgemeinen Schlüsse zu ziehen. Die Erscheinungen an jedem einzelnen bringen neve Momente für die Beurtheilung, und die meisten Schilderungen sind viel zu allgemein gehalten, als dass sie die Verschiedenheiten der einzelnen Bildungen zur Geltung bringen köunten."

Den letzteren Eindruck habe ich vielfach anch beim Lesen einzelner $\mathrm{Ab}$ handlungen empfangen; je mehr ich mich aber in das Studium dieser Fragen vertiefte, desto mehr fand ich doch eine Harmonie im Aufban aller dieser wunderbaren Bildungen; es drängte sich mir die Ceberzengung auf, dass es überall dieselben Ursachen und dieselben Hindernisse im wesentlichen sind, welche diese "Momente" bedingen.

Ich bin mir wohl bewusst, dass ich all die verwickelten Fragen, an denen schon Jahrzehnte eine Unzahl von Forschern ihren Geist und ihr Glück versucht haben, nicht zu lösen vermocht und gekonnt habe; weiss ich doch selbst nicht 
aus Erfahrung, ob nicht doch noch an anderen Plätzen andere Factoren für die Riffbildung in Frage kommen lind sind sichere Beobachtungen doch gerade für die Anwendung auf meine Untersuchungen vielfach recht spärlich oder gar mangelud, namentlich in Beziehung anf die Planktonforschung im Riffgebiet.

Aus diesen Gründen bitte ich die vorliegende Arbeit aufzufassen nicht als eine Streitschnift gegen die bestehenden Ansichten und Theorieen, sondern als las, was sie wirklich sein soll, eine Anregung zur Verfolgung bestimmter Beobachtungen und Untersuchungen bei künftigen Riffforschungen.

Aus diesem Grunde habe ich auch diese Abhandlung dem Buchhandel übergeben, damit sie leicht zu erhalten unl handlich sein möge.

Es kömnte ïberflüssig erscheinen, dass ich einer Arbeit ïber Korallenriffe ansgedehnte Resultate ler Planktonforschung*) beigefügt habe; sind es doch gerade diese Studien, welchen diese Arbeit ihre Entstehung verdankt. - Ieh war ferne davon, als ich nach Samoa kam, Korallenriffuntersuchungen machen zu wollen; ich wusste damals kaum un die schwebenden Theorieen und konnte mir auch später nur das nothwendigste an Literatur während eines ZwischenAufenthaltes in Sydney verschaffen.

Der Widerstreit meiner planktonischen Ergebnisse mit den Angaben der Challengerexpedition brachte mich jedoch diesem gefährlichen Gebiet stetig näher und da ich das ganze Thierleben des Meeres so eng mit den Korallenriffen verkettet fand, so schien es mir nicht mehr rathsan, eines allein abzuhandeln und ich entschloss mich, auch meinen Beobachtungen an den Korallenriffen Samoa's Raunı zu geben.

Da ich glaube, dass man künftig bei der Untersuchung von Korallemiffen auch der Verbreitung des Planktous Rechnung tragen muss, so habe ich mich bemüht, die Methode der Messung so auszubilden, dass es möglich ist in kurzer Zeit an Ort und Stelle ein sicheres Resultat über die Vertheilung und die Masse zu erhalten, und sogar über die Zusammensetzung. Die wissenschaftliche Verarbeitumg wird natürlich immer erst zu Hause ausgeführt werden können; jedoch schon an Ort und Stelle scheint es sehr wünschenswerth zu erfahren, was für Thierarten und wieviel nngefähr die Masse ansmachen und wie die Schwankungen an den einzelnen Stellen und wïlrend gewisser Jahreszeiten sind. Die Masse scheint aber hier besonders wichtig.

Von diesem Gesichtspunkte ans liabe ich es vermielen speciell zoologische. Daten und Arbeiten hier zu erörtern, zumal da der grössere Theil meiner Sammlungen noch der Bearbeitung harrt. Letzteres gilt namentlich für die Macrofamna der samoanischen Riffe, welche ich desshalb wesentlich vom ethnologischen Standpunkte aus als eine Nahrungsquelle der Eingeborenen betrachten werde. 1 Uebrigen erfolgt diese Besprechung wie die des Planktons nur von oceanographischen, geographischen und biologischen Gesichtspunkten.

Ich habe im Laufe der Arbeit mehr Citate von Autoren gebraucht, als es im Allgemeinen wünschenswerth erscheinen dürfte; bei der Vieldentigkeit der Meinungen glaubte ich dies jedoch nicht umgehen zu können.

*) Fin tleissiger Assistent erstand mir in dem Oberlazarethgehülfen Pratsch, weleher mir stetig hülfreiche Hand leistete. 
Betreffs der Nomenelatur lualte ich fest an den Namen Viti für Fidji, Pammutu für Paumotu, Pomotu u. s. w., 'Tonga fï̈r Freundschafts-, 'Tahiti- für Gesellschafts-, Hawaii fïr Sandwichinseln u. s. w., da diese Benemungen sowohl geographisch als etymologisch richtiger sind.*) Statt "Stiller" uni „. irosser" Ocean empfichlt sich mehr "pacifischer". "Südsee" ist der sïlliche 'lheil des Pacifischen oceans.

Den örtlichen Beschreibungen und Karten sind die Karten ler englischen Admiralität und die vom Reichsmarineamt im . Tahre 1895 neu herausgegelienen Specialkarten der Nordküste von Upolu (No. 106) und des Apiahafens (No. 107) zu Grunle gelegt. welch' letzterer wälnend des Aufenthaltes in Apia von Lientenant zur See Hollweg neu rermessen worden ist. Ich darf bei diescr Gelegenleit niuht versämmen, meinem einstigen ('ommandanten Herrn Corvetten-Kapitïn Scheder meinen Dank aušusprechen für die grösstmöglichsten Freiheiten, welche er mir in der Verfolgung meiner Studien gewährte, so dass ich meine gauze Zeit, soweit es mein Beruf gestattete, dem Studim der samoanischen Verhältnisse widmen kounte; nicht minderer Dank gebührt den Leitern der deutschen Handels- und Plantagengesellschaft, welche in der Unterstintzung wissenschaftlicher Bestrebungen muermürlich sind, als oh es zu ihreu 'Traditionen gehörte, las Andenken an das commercielle leider zu rasch verblichene Königthum der Godeffroy's zu pflegen.

Zahlreiche Literaturangaben verdanke ich Herru Professor von Martens und Dr. Collin in Berlin, Herrn Dr. Langenbeck in Strassburg und Herrn Professor Krümmel in Kiel, wie Herrn Professor Brandt und Haas lierselbst. Bei der Einsicht und Anfertigung von Karten fand ich das liebenswürdigste Entgegenkommen seiteus des Kartendepots der Kaiserlichen Werft zu Kiel.

Die Abbildungen entstammen grösstentheils, soweit es sich nm Photographieen hanlelt, den in Apia ansïssigen Photographen Davis und Andrews. Je cine verdanke ich auch Herrn Oberstabsarzt Dr. Kleftel und Dr. Reinecke. Die Namen sind bei den einzelnen Bildern aufgeführt. Die Zeichnungen hahe ich selbst an Ort und Stelle angefertigt und war mir ler Maler Herr Fürst bei deren Fertigstellung für den Druck behülflich.

Der Verlagsbuchhandlung bin ich für die schöne Ausstattung des Büchleins besonders zu Dank rerpflichtet.

Die herïcksichtigte Literatur, auf die ich öfters Bezug nehmen musste. ist in eisem besonderen Verzeichniss an Schlusse aufgeführt. Y/ahlreiche Angaben finden sich indessen auch im 'Text verstreut. Die Zahlen in K̈lammern nehmen Bezug anf die Nummern des Verzeichnisses.

Die floristische Untersuchung Samoa's hat in den letzten zwei Jahren durch den Botaniker Dr. Reinecke aus Breslan eine äusserst erfolgreiche Förderung erfahren; es vürde mir eine Genugthung sein, weun icls in oceanologiscllfaunistischer Hinsicht ein Scherflein beizutragen und weiteren Forschungen daselbst dienlich \%u sein vermöchte, damit Samoa mehr und mehr auch in wisseuschaftlicher Hinsicht die ihm gebührende Stelle im tropischen Theil der Südsee eimnimmt, die ihm seine günstige geographische lage und namentlich auch der deutsche Handel längst gesichert hat.

*) Eine Begrïndung an anderer Stelle muss vorbehalten bleiben. 


\section{Nachtrag zur Vorrede.}

When im Begriffe die Arbeit dem Drucke zu übergeben, erhalte ich unerwarteterweise einen Brief aus der Hand des liebenswürdigen englischen Gelehrten John Murray, welcher Aufschluss bringt über den Ausfall der in den folgenlen Zeilen des öfteren erwïhnten Südsee-Expeditionen von P'rof. Sollas und Alexander Agassiz. Leider ist in beiden Fällen das Hauptziel nicht erreiclit worden, und es ist dies um so bedauerlicher, als dieses Resultat geeignet ist einen Rückschlag in der Korallenforschung zu bewirken. Es erhellt daraus, mit welchen Schwierigkeiten solche Forschungen verknüpft sind und dass Erfahrung, Zeit, Ausdaner, Glück und - ansgiebige Unterstït/ung zusammen stehen müssen, um einen Erfolg zu sichern. Zweifellos werden die Untersuchungen von Professor Sollas trotzdem eine Menge des Neuen bringen, wie aus folgendem dem Brief beigelegten Zeitungsausschnitt hervorgeht:

Letters have been received from Prof. Sollas, " the Chairman and Secretary of the Coral Reef Boring Committee of the royal Society, which show that, so far as the main object of the expedition is concerned, the effort has been an almost complete failure. When the party had landed on Funafuti from the Penguin, they selected the most promising site, as it appeared, for a bore-hole. The apparatus was landed and set up, and a bore-hole carried down to a depth of about 65 feet, when further progress became impossible, for material like a quicksand was struck which choked the bore-hole. Very little solid coral rock was pierced. To pass over the steps then taken, it may be enough at present to say that another attempt was ultimately made nearer to the edge of the island, where there appeared some hope of finding more solid coral rock. This boring was carried down to 72 feet, and then similar difficulties prevented further progress. The material struck was a kind of quicksand containing "boulders" of coral. As fast as the sand was got out, fresh material poured in, and the water pumped down the tube, with a view of cleaning it, actually flowed out into the surromnding bed, while the coral boulders made it impossible to drive the tubes through the quicksand. So far as the reef was pierced it appeared to be not solid coral, but more like a "vast coarse sponge of coral with wide interstices, either empty or sand-filled". It is very unfortunate that the efforts of the Royal Society, and the liberal aid of the Admiralty and of friends and authorities in Sydney, should be so ill-rewarded; still, though the expedition has failed in its main object, it has met with great success in all the others. Large collections have been made: Messr's. Gardiner and Hedley have thoroughly investigated the fauna and flora, both land and marine, of the atoll. Dr. Collingwood has obtained information of ethnical interest, and Captain Field a series of soundings, both within and without the atoll, which Prof. Sollas states are more complete than have yet been obtained, and must greatly modify our views as to the nature of coral reefs. Of all these matters it would be premature to speak, 
till Prof. Sollas has returned and been able to give fuller particulars, and Captain Field has reported to the Admiralty.

Es geht aus diesen Worten jetzt sehon zweierlei hervor, nämlich dass der anstehende Riffels keine compacte Masse ist, wie betont, und dass er nicht sehr weit in die Tiefe reicht; ferner dass der Untergrund sandig erscheint, sedimentär, wie es Murray annahm und es auch in den folgenden Zeilen ausgesprochen ist. Man darf auf die näheren Berichte zweifellos gespannt sein!

Kiel, am 1. October 1896.

\section{Dr. Krämer.}

$\because \quad$ Einige Erklärungen.

A: $\mathrm{H} .=$ Annalen der Hydrographie.

P. G. II. = Petermann's geographische Jittheilungen.

ce $=$ eubikcentimeter.

$\mathrm{cbm}=$ cubikmeter.

$q \mathrm{~m}=$ Quadratmeter.

1 Seemeile $=1852 \mathrm{~m}$.

10 Fuss $=3 \mathrm{~m}$.

Aussprache des Samoanischen:

(Accent gewöhnlich auf der rorletzten silbe.)

ma'i $=$ mahi (h unhörbar).

nai $=$ maï.

tagi $=$ tangi (wie in singen).

Die Zahlen im Text rerweisen auf das Literatmrerzeichniss. 


\section{Inhalt.}

Seite

I. Finleitung . . . . . . . . . . . . . . 1

11. Kurzer Cebroliek iber die Rilrbautheorieen und die diesbeziigliche Literatur 4

II. Topograplie, Meteorologie mo Geologie der Sanoainselı . . . . . . . . . 13

1. Topographic . . . . . . . . . . . . . . . . . . . . . . . 13

а) Saraí . . . . . . . . . . . . . . . . . . . . . . 13

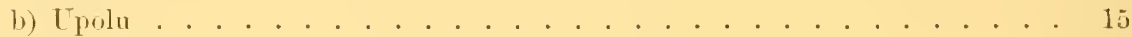

c) Tutuila . . . . . . . . . . . . . . . . . . . . . . 16

d) Mant'a . . . . . . . . . . . . . . . . . . . . . . . 17

e) Rose-1toll . . . . . . . . . . . . . . . . . . . . . . . . . 17

2. Meteorologie and Oceanolugie . . . . . . . . . . . . . . . . . . . . . 17

3. Entstelung und Geologie. . . . . . . . . . . . . . . . . . . . . . . . 22

4. Eralbeben . . . . . . . . . . . . . . . . . . . . . . . 30

5. Keichen rulkanischer 'Thätigkrit und Hebung an andern Orten der Siirlsee nebst einigen Totizen ïber fossile liffe und Korallenkalke . . . . . . . . . . . 31

6. Begriff der säcularen und intermittirenden periodischen Senkung und Hebung (pusitive und negative Terschiebung) . . . . . . . . . . . . . . . 36

IY. Die Korallenriffe an ler samoanischen Kiiste . . . . . . . . . . . . . . . 37

1. Morphologie der Korallenriffe . . . . . . . . . . . . . . . . . . . . 37

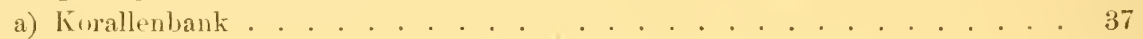

b) Saumriff . . . . . . . . . . . . . . . . . . . . . . . . 38

c) Strandriff . . . . . . . . . . . . . . . . . . . . . . . . . . . . . . . . . . . . . . . . . . . . . . . . . .

d) Barrierenriff . . . . . . . . . . . . . . . . . . . . . . . . . . . . . . . . . . . . . . . . . . . . . . . . . .

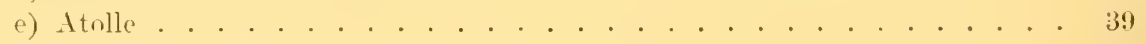

2. Oertliche Vertheilung. . . . . . . . . . . . . . . . . . . 39

a) Savaí . . . . . . . . . . . . . . . . . . . . . . . . . . 39

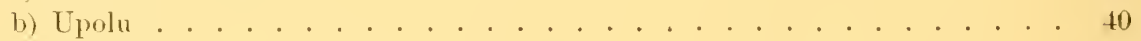

c) Tutuila . . . . . . . . . . . . . . . . . . . . . . . . . 49

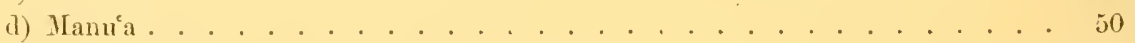

e) Rose-Atoll . . . . . . . . . . . . . . . . . . . . . . . . . . . . 50

3. Vergleich Samoa s mit den Palaumsein. Das Fehlen ausgebildeter Barrieremiffe anf Tutnila und Manúa in der Nähe des Rose-Atolls und die Darwin'scbe Theoric . . . . . . . . . . . . . . . . . . . . . . 51

4. Die Entstehung eines Strandriffs. . . . . . . . . . . . . . . . . . . 54

5. 1) er Iufbau cines samoanischen Strandriffs. . . . . . . . . . . . . . 5tj

a) T'alus (Grundströme) . . . . . . . . . . . . . . . . . . . . . 56

b) Fuss (Dicke der liffe an Riffrande, siche V 1) . . . . . . . . . . 58

c) Liffkante. Luv- und Leekante (Föhlenbildung und Korallensandentstehumg) i2

d) P'lattorm (Triimmerfliche und Schuttkegel) . . . . . . . . . . . . . (is

) Strandlagune (Selnuttfliche mel Strandeanal) . . . . . . . . . . . . 69

f) Sandstraud (Saudsteiu) und Sandkiiste mit Brackwasserlagme . . . . . . 69

3. 1)ie Bestandtheile der ïbrigen Rifflirmen (Barriere, Atoll) und die Definirung der liegrifte Bucht, Mafen. Riffhucht, Rifthafen, Einlass, Lagune, Bootpassage, Barrerencanal. Strandeanal, sowie iiber die natiorliche Regulirmg derselben duch strïmc . . . . . . . . . . . . . . . . . . . . 70

Y. Zusamuenfissung der Bedingungen fiir das Rirrwachsthum . . . . . . . . . 73

1. 'Tiefengrenze des Wachsthums und Dicke der lieffe . . . . . . . . . . . 73

2. Die Finvirkung der Brandung mud starker Ströme . . . . . . . . . . . . 74 
3. Einfluss der Mearesstrimungen als Nahrungsumellen . . . . . . . . . Iti

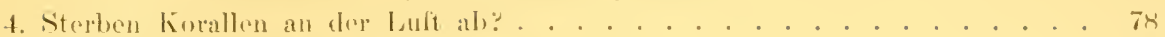

๓. Der Heliotropismus dor Inthezon . . . . . . . . . . . . . . . 78

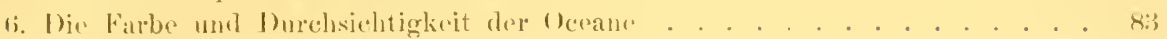

7. Die IIachsthmmsselmelle dir kintallen . . . . . . . . . . . . . . . . sti

8. Temperatur und Salzagehalt . . . . . . . . . . . . . . . . . . . . sti

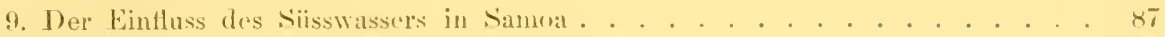

V. line nene Infiassung der butstelmug der Atolle. . . . . . . . . . . . . sir

1. Die Configuration des Meeresbutens im Sitillun ()ean . . . . . . . . . . 8!!

2. Submarine Vulkane und fieyserfelder als Bildner des lintergrundes für Atolle 90

3. Die Meeresströmungen und (iezeitenströme als Auerdner des Sedinents. . . 11

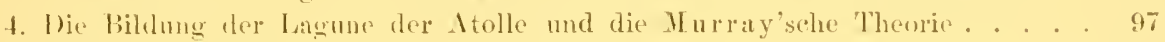

5. Tektonik des l'ntergrmules . . . . . . . . . . . . . . . . . . . . . 9!

6. Hie einstige Iäsmag der Fragr. Bohrungen . . . . . . . . . . . . . . . 100

7. Kurze \%usanmenfassung der gewomnenen Schlïsse an der Hand der Betrachtung der simuanisclen Korallenrifio . . . . . . . . . . . . . . . . . 100

VII. Die Rifrlaun von Samoa, insbesondere in ethnologischer Beziehung . . . 103

1. Kiff- und schiffaht . . . . . . . . . . . . . . . . . . . 1033

‥ Die Korallen und Korallinenalgen . . . . . . . . . . . . . . . . . . . . 101

3. Das Leben in momgebenden Merere. Wale. Delphine. Haie. liochen, Sebildkrïten. Uetopus. Selnlangen . . . . . . . . . . . . . . . . . . 10.і

4. Fische (ia) und Fischfang (fangota) . . . . . . . . . . . . . . . . 107

5. Fingota: Medusen, Echinodermen, Kunster; Muscheln und Śchnecken . . . 110

6. Der Palolownim . . . . . . . . . . . . . . . . . . . 111

VII. Dic Contrifugirung des Pankton. . . . . . . . . . . . . . . . . . . . 114

1. Fang und Netze. . . . . . . . . . . . . . . . . . . . . . 116

2. Besichtigme und Filtrirung des Fanges . . . . . . . . . . . . . . . . . 117

3. Jie Messgläser und die Centrifugen . . . . . . . . . . . . . . . 118

4. Das tentrifugiren . . . . . . . . . . . . . . . . . . . . . . 120

5. Die Verechnung. . . . . . . . . . . . . . . . . . . . . . . 121

1.. Die Kählıng. . . . . . . . . . . . . . . . . . . . . . . . 121

IX. Zur Planktonvertheilung iu pacilisehen Ocean . . . . . . . . . . . . . . 126;

1. Die Resultate der Fänge in Simo . . . . . . . . . . . . . . . . . 1060

2. . . . . . . . Neu-šeeland und Australien. . . . . . . . . . 12!!

3. Vergleichmng der Riesultate unter sich und mit anderen . . . . . . . . . 130

4. Die C'opepolen als constanter Component aller verticalen l'lanktonfänge . . 131

5. Küsten- und heefinge (Verbreitungstiefe) . . . . . . . . . . . . . . . . 135

6. Die Armutl des tropischen pacifischen Uceans . . . . . . . . . . . . . 138

7. Gross- und Kleinplankton. Haeckel und Hensen. . . . . . . . . . . . 146

X. Tabellen und Jiteraturerzeichniss . . . . . . . . . . . . . . . . . . 151

1. 'Tabellen

Tabelle A. C'entrifugirte kïstenfänge ron Simoa . . . . . . . . . . . . . 151

b. Nichtsamoanische Kïstenfänge aus den Tropen . . . . . . . 150

C. Seefänge ron Teu-sooland und Australien . . . . . . . . . . . 15 ti

D. Kïstenfänge ron Xen-seeland und Australien . . . . . . . 157

E. Sïsswasserlänge aus Seu-seeland . . . . . . . . . . . . 160

2. Literatur

a) Korallenriffo, fienlogie. Oecanographie ete. . . . . . . . . . . . 160)

Ђ) l'lankton . . . . . . . . . . . . . . . . . 1103

3. J'reisliste der angewandten Materialien . . . . . . . . . . . . . . 163

Anhang: Bemerkungen ïber den essbaren Palolo-llurm. Cysidice viridis (tiray)

von I)r. Anton Collin . . . . . . . . . . . . . . . . 161 



\section{Einleitung.}

Zum leichteren Verständniss der Arbeit sei einiges über Samoa vorausgeschickt. Es sind diese Inseln weit länger unerforscht geblieben als die nahen Viti- und Tonga-Inseln und das weiter entferntere Tahiti, Hawai und Neu-Seeland, da Cook Samoa niemals berührt hat und die französische Expedition unter dem unglücklichen Lapérouse (1787) die Stätte rasch wieder verliess, nachdem ein selbstrerschuldeter Streit mit den Samoanern anf Tutuila den Tod von 11 Ienten, worunter der Kapitän der "Astrolabe" de Langle und der Naturforscher und Arzt de Lamanon, zur Folge gehabt hatte. Dieses Unglück bewirkte, dass dieses Land fernerhin gemieden wurde, als ob seine Bewohner die blutgierigsten Menschenfresser wären. Wohl wurde es noch zweimal bald darauf angelaufen, von dem Kriegssehiff "Pandora" Kommandant Edwards im Jahre 1791 und von Kotzebue 1824; aber der Besuch war beide Nale nur ein so kurzer, dass nichts erspriessliches geleistet werden komte. Selbst als die englischen Missionare im Jahre 1830 einen glücklichen Versuch gemacht hatten, das Christenthum daselbst auszubreiten, dauerte es doch noch eine geraume Zeit, bis die alte Furcht geschwunden war. Ein 10 tägiger Besuch des franzö ischen Südpolfahrers Dumont d'Urville im Jahre 1838 leitete die neue Aera ein, die im folgenden Jahre mit der „United States Exploring Expedition“ unter Wilkes für Samoa begaun. Obwohl nur einen Monat, vom 7. Oktober bis 10. November 1839 anwesend, hat doch dieser Kommandant eine fliegende Vermessung nahezu des ganzen Archipels vollendet, welche, obwohl mit vielen Ungenauigkeiten namentlich betreffs der Korallenriffe behaftet (wie bei der kurzen Zeit nicht anders möglich), doch heute noch im Grossen und Ganzen gültig und erst in den letzten Jahrzehnten durch grnane Vermessungen namentlich seitens der dentschen Krriegsschiffe theilweise ergänøt und berichtigt worden ist. Dumont d'Urville wurde von Hombron und Jaquinot begleitet und Wilkes von Peale und Pickering, ausserdem aber von lem erst jüngst verstorbenen Nestor der amerikanischen (ieologen, Dana. Dieses Mannes weltbekanntes Buch „Corals and Coral Islands" (3c) war in direkter Folge Darwin's epochemachendem Werk „On the structure and distribution of Coral Reefs" gefolgt, welch letzterer 1831-36 an Bord H.M.S. .,Beagle" als Naturforscher Tahiti besucht und auf dem Keeling-Atoll in Indischen Ocean seine Studien über die Korallenriffe voll- 
endet hatte. Dana hatte schon im Jahre 1839 in Sydney einige Notizen über die Darw in'sche Theorie gelesen und war desshalb in der Lage, noch während seiner Reise diese Theorie prüfen zu können. Sein Buch ist für diese Arbeit desshalb von besonderer Bedeutung, zumal da darin oft der samoanisclieu Riffe Erwähnung gethan wird. In dem ,Geological Report of the Wilkes exploring Expedition" (1849) hat er zuerst seine Erfahrungen über den Bau der Korallenriffe niedergelegt und die geologischen Verhältnisse Samoa's einer eingehenden Besprechung unterzogen. Seit dieser Zeit ist ausser den Arbeiten Graeffe's im Journal des Museum Godeffroy (Heft 1 mnd Heft 6), welche namentlich topographisch viel Neues brachten, nichts besonderes hinsichtlich der samoanischen Riffe veröffentlicht worden. Einige Daten brachten indessen doch die Arbeiten von $\mathrm{H}$ o f fma n n (25d) und die zahlreichen kleineren Berichte der Kommandanten, welche in den Annalen der Hydrographie verzeichnet stehen. (Näheres siehe bei Langenbeck (42).) Erwähnt sei auch hier, dass Studer an Bord der "Gazelle" einige Zeit in Apia geweilt hat.

Man sieht, die Literatur betreffs Samoa ist recht spärlich. Mit der Landfauna steht es nicht viel besser. Auch hier stehen die Berichte der erwähnten Expeditionen oben an, insbesondere die der Wilkes-Expedition, welche hente noch allen Arbeiten über Samoa als Grundlage dienen. Späterhin haben die Abhandlungen des Mnseum Godeffroy viel neues gebracht, weniger allerdings speciell für Samoa, als für die ganze Südsee. Insbesondere ist unter diesen die Bearbeitung der Fische von Günther zn erwähnen und die Arbeiten Graeffe's.

Ueber die Vögol Samoa's handelt das 1867 erschienene Buch von Finsch und HartIaub "Die Vögel Centralpolynesiens", dessen Angaben in dem erst. jüngst erschienenen "Catalogue of birds of the British Museum" vervollständigt sind. "Einige ornithologische Notizen aus Samoa" (Omithologische Monatsberichte Hai 1896) habe ich jüngst in Bezug anf einige biologische Beobachtungen veröffentlicht.

Auch in Bezug auf Landesbeschreibung und Ethnologie giebt es wenig zusammenfassendes und gründliches. Am besten ist hier tas Buch des Missionars 'T'urner "Samoa a liundred year's ago and long before" (London 1884), abgesehen natürlich von den kompilatorischen Arbeiten (II einicke's Inseln des Stillen Oceans, 2. Band, Jung, der Welttheil Australien u. s. w.). Interessant. fül den Kenner sind aber besonders die erwähnten Reiseberichte und ein Buch des Konsul Pritchard vom Jahre 1851 „Polynesian Reminiscences" (aus. nenerer Zeit Churchward "Mry consulate in Samoa".)

Um einigermaassen vollstïndig zu soin, will ich nur noch der Arbeiten. liastian's üher die samoanische Mythologie gedenken, und der zahlreichen Aufzeichnungen des Generalkonsuls Stübel, welche in den Abhandlungen des ethnographischen Museums zu Berlin erscheinen.

lis wäre nngerecht, wenn ich nicht auch noch die nuzäbligen kleineren und grösseren Veröffentlichnngen der englischen und französischen Nissionare erwähnen wollte, insbesondere die wichtigeren Arbeiten des Sammlers Whitmee und der Linguisten Pratt und Violette, weIche indessen, abgesehen vou dew. 
Sprachbüchern der beiden letztoren, so in \%eitschriften u. s. w. zerstrent sind, dass sie nur äusserst schwer beschafit werden können.

Wer endlich sich dafür interessirt, was für schöne Zeiten man an Bord S.M. Kriegsschiffe in Samoa verleben kaun, dem sei las Buch des Kontreadmiral a. D. von Werner "Ein dentsches Kriegsschiff in der Südsee" angelegentlichst empfohlen, nicht minder die letzten Zeilen von Ehlers "Samoa, die Perle ler Südsee".

Es wird eine dankbare Aufgabe sein, wenn auch eine sehr schwierige und mühevolle, all dieses zerstreute Material $z u$ sichten und durch eingehende Studien zu vervollständigen. Nur noch weniger Jalurzehnte bedarf es und die Südsee ist nicht mehr jenes eigenartige Gebiet, abgeschlossen vou del Welt und der Civilisation, ein stilles Paradies. Heute wird Apia schon monatlich von mindestens 4 Dampfern angelaufen, die Eingeborenen sind alle Christen und täglich schwindet die Originalität mehr und mehr dahin. Noch hente sind die grossen Fragen über die Abstammung und Verbreitung der Polynesier so gut wie ungelöst; wohl leben noch in Samoa Greise aus der vorchristlichen Zeit, welche wenigstens noch einigen Aufschluss zu geben vermögen, wenn es auch scheint, dass der Zeitpunkt auch hier schon verpasst ist.

Nicht viel besser steht es mit ler Fauna und Flora, und dabei sind diese Inseln Arbeitsplätze, wie man sie selten in den Tropen findet, gesund, mãssig warm, schön, gefahrlos und dabei noch reich an Nahrung, Lustbarkeiten und Vergnügen. - Nur selten rïhrte sich hier und da eine Hand!

Wenn einst der letzte Hanch aus den alten Zeiten geschwunden sein wird und die jetzige Zeit wird kein besseres Erbe hinterlassen haben als zerstrente. zum Theil sich widersprechende Berichte, dann müssen wir zufrieden sein, wenu unsere Söhne sagen werden, dass wir nur lässig gewesen sind. 


\section{Kurzer Ueberblick über die Riff'batutheorien und die diesbezïgliche Literatur.}

(Ueber die Vor-Darwin'sche Zeit siehe Böttger, Geschichtliche Darstellung unserer Kenntnisse und Meinungen von den Korallenbauten. Dissert. Leipzig 1890.)

Seit Darwin seine Rifftheorie anfgestellt hat, velche darin gipfelt, dass ein Strandriff' durch allmälige „säkulare“ Senkung des Landes zu einem BarrierenRiff und schliesslich zum Atoll wird, kurzum dass diese 3 Hauptriffformen nur verschiedene Stadien in der Entwicklungsreihe seien und seit diese Theorie von dem berühmten amerikanischen Geologen und Zoologen Dana gutgeheissen worden ist, hat man trotz vieler gewichtiger Einwürfe doch vielfach daran festgehalten. Darwin hatte 1836 seine Weltumsegelung beendet. Aber erst 1842 erschien sein Buch "On the structure and distribution of Coral Reefs" und es ist interessant zu erfahren, dass er seine Theorie teleologisch ausgedacht hatte. ehe er ein Atoll zu Gesicht bekam. In einem interessanten Fragment seiner Autobiographie schreibt er: "Kein anderes meiner Werke wurde in so einem dednktiven Sinne begonnen, wie dieses; denn die ganze Theorie wurde an der Westküste von Sïdamerika ausgedacht, ehe ich noch ein wahres Korallenriff gesehen hatte. Ich hatte daher nur meine Ansichten zn verificiren und auszudehnen durch eine sorgsame Untersuchung der lebenden Riffe." Ausser Dana. welcher, wie schon in der Finleitung erwähnt, zufällig in Sydney im Jahre 1839 von der Darwin'schen Theorie las und dieselhe sofort zu seiner eigenen machte, gewann der junge Naturforscher im Jahre 1837 kurz nach seiner Rückkehr seinen Lehrer L yell für sich, als er diesem die Ergebnisse seiner Studien vortrug. Obwohl dieser Mamn wenige Jahre zuvor (1832) in seinen "Principles of Geology" der Entstehung der Atolle auf submarinen Kratern ein ausführliches Wort gewidmet hatte, soll er doch bei dem schlichten Vortrag seines Schülers so überwältigt gewesen sein, dass er im Zimmer anf- und abtanzte. Auch der Professor Jukes, welcher sich an Bord des englischen Kriegssehiffes "Fly" von 1842-46 während der Vermessung des grossen australischen Barrierenriffes aufhielt, erklïrte, dass ihm die Senkungstheorie sehr angemessen für die Bildung der Riffe erscheine. Kein Wunder, dass es 3 Jahrzehnte danerte, bis gewichtige Gegenstimmen laut wurden. 
Darwin war vom 15. bis 26. November 1832 in 'Tahiti gewesen und vom 1. bis 12. April 1833 auf dem Keeling-Atoll; ansserdem hielt er sich noch vom 29. April bis 9. Mai desselben Jahres in Mauritius auf. Es bedurfte seines Geistes, mu in solch' kurzer 'Zeit eine Theorio zu formen und zu begründen, dis lieute noch ihren Standpunkt trotz harter Angriffe behauptet. Dana latte mit der Wilkes-Fxpelition die Pammutn-, Gilbert-, Phönix-, Samoa-, VitiInselı и. s. w. besucht und hatte Gelegenheit, beim Vermessen viel einsehlïgiges zu hören und zu erfahren. Dar win und Dana erkannten, dass das Lehen der riffbildenden Korallen in einer verhältuissmässig geringen 'Tiefe aufhöre, wälırent Reinhold Forster ungeführ einhalb Jahrhundert frühler angenommen hatte, dass die Atolle aus len unendlichen Tiefen des Oceans heraufwüchsen oder Krönungen submariner Krater oder Sedimentbänke seien. Das begrenzte 'Tiefenwachsthum und die steilen Bëschungen, sowie die Tiefe und merkwürdige Form vieler Atolllagnien und Barrieren-Rifflkanäle begründeten im wesentlichen die DarwinD an a'sche Senkungstheorie. Allerdings nimmt, Dana an, dass durchaus nicht alle Atolle und Barrieren-Riffe im Senkungszustande beharren, sondern stationär geworden seien oder gar sich jetzt in Hebungszustande befünden. Umgekehrt will er nicht alle Gebiete, wo Strandriffe oder gar keine Riffe vorhanden sind, und welche Darwin in Ermangelung tiefer Kanäle für stationär oder gar sich hebend hält, als stationäre gelten lassen, sondern meint, dass anch diese sich in Senkungszustand befinden köunten. Da in Samoa alle Riffformen vorkommen, anch für Hebungs- und Senkungsgebiete Aubaltspunkte genügend vorliegen, sowie Zeichen recenter vulkanischer Thätigkeit vorhanden sind, so dürften diese Inseln für die Bemrtheilnng und das Studimm der Riffarten von hervorragendem Interesse sein, zumal da Anordnung und Lage der Riffformen mit den von Semper beschriehenen Palau-Inseln in gewissen Beziehnngen übereinstimmt. Semper war der erste, welcher (1868) gewichtige Einsprüche gegen die Darwin'sche Theorie erhob, nachdem er sich längere Zeit auf genaunten Inseln anfgehalten hatte. Von seinen Beobachtungen wird noch des öfteren hier die Rede sein.

Zwei Jahre später berichtete Rein im gleichen Simne vou den Bermudas, da er nirgend Senkungen, sondern Hebungen dieser Inseln fand.

Ebenso mrtheilte der Graf von Pourtalès und bald darauf Alexander Agassiz über die Floridariffe.

Sie alle hatten indessen im wesentlichen keine neuen Theorieen aufgestellt, sondern nur berichtet, dass ihre Beobachtungen sich mit der Senkungshypothese nicht vertrügen.

Erst John Muray, der bekannte Herausgeber des Challengerwerkes, nahm an, dass, wenn submarine Plateaus und Krater in nicht zu grosser Tiefe gelegen seien, dieselben durch die Kalkablagerungen der Glohigerinenschalen. Muscheln u. s. w. bis in ken Bereich der rittbildenden fiorallen aufwachsen, wo diese alsdann den Aufbau der Riffe bis zur Meeresoberfläche übermehmen. Er wies zugleich nach, dass dieser ,organische Regen“" in grösseren Tiefen den Meeresboden nicht beeinflussen könne, da lie feinen Kalkschalen der Globigerinen daselbst durch das liohleusäurereiche Meerwasser aufgelöst werden, und erklärte daraus die steile Böschung der Atolle. Die Lagune entstehe durch die Vorliebe. 
der Korallen, dem freien Meere zuzuwachsen, während sie nach innen zil abstürben und durch das Meereswasser aufgelöst und abgeführt würden. Lhenso sollen die Barrieremiffe entstehen. Wenn nun auch letztere Ansichten nicht zutreffen dürften, so steht doch die Bildung der Globigerinenbänke ausser Zweifel, da neben anderen früher entdeckten (vergl. Guppy, Sempers Sinoporusfelsen u.s. w.) in den letzten Jahren solche von über $100 \mathrm{~m}$ Mächtigkeit auf Eua in den TongaInseln (von Lister) nachgewiesen worden sind, wovon noch weiter unten die Rede sein wird. Da nach Darwin, gemäss seinen Schlüssen, Barriere-Riffe und Atolle sinkendes Gebiet, Strandriffe dagegen stationäres oder gar sich hebendes Land anzeigen, so sind nach Murray vor allem die Viti-Inseln ein Gegenbereis, da hier alle 3 Riffformen neben eimander vorkommen.

Ein Erweiterer der Muray'schen Theorie erstand in Guppy, welcher 1882 - 84 auf den Salomons-Inseln ausgiebige Stndien gemacht hatte, und dabei zu dem absurden Schluss gekommen war, dass Atolle sich nur auf hebendem Gebiete bilden könnten. Der Darwin-Dana'schen Theorie steht heute die von MI uray-Guppy gegenüber; beide kämpfen um den Vorrang, ohne unanfechthare Beweise für ihre Richtigkeit anfbringen zı können.

Langeubeck unternahm es 1890, indem er sich auf Sues' Werk „Das Antlitz der Erile“, auf Neuma yr' s „Erdgesehichte“ und auf S u pan's "Lehrbuch der physischen Erdkunde" stützte, die Senkungstheorie wieder zu Ehren zu bringen. In einem fleissigen Buche von 190 Seiten „Die Theorieen über die Entstehung" der Koralleninseln und Korallenriffe" bespricht er die ganze Literatur (bis 1890); nit Sues spricht er von nicht nachweisharen Senkungen und Hebungen als "positiven und negativen Bewegungen" und endet am Schlusse der Einleitung betreffend die Sues'sche Meeresniveauschwankungstheorie: „Für die Darwin'sche Theorie ist es ja im Grunde gleichguiltig, ob man eine Senkung des Festen oder ein Anschwellen des Meeres annimmt".

Auch Heilprin hatte 1889 in seinem Buche "The Bermuda Islands" der Senkungstheorie das Wort geredet und ihm pflichtet in allerjüngster Zeit Krümmel bei Besprechung der neuesten Arbeit von Agassiz bei. Weun man sich nochmals ins Gedächtniss zurüekruft, dass der erst jüngst verstorbene D ana bis zu seinem Lebensende über 50 Jahre lang seinen Ansichten und Hrfahrungen treu geblieben ist, so wird man es nicht für überflüssig finden, Brfahrungen geltend zu machen, welche gegen Darwin's Theorie sprechen. Unter den neueren Autoren haben sich Wharton, Saville Kent und vou Lendenfeld gleiclfalls fïr Darwin bekannt. Saville Kent's grosses Werk über das grosse australische Barrierenriff steht in Beziehung anf seine Abbildungen der Rifffauna unerreicht da. Besonders gelungen sind die Photographien der lebenden Lorallenpolypen und des Riftes bei Ebbe. Leider fehlen indessen Abbildungen der Rifflkante nahezu gänzlich. Kent erklärt die grossen Einlässe im australischen Barrierenriff dureh die Süsswasserströme Anstraliens entstanden, welehe vor der Senkung lier gemündet haben sollen. Da die Fauna und Flora Australiens, Nen-Guineas und Nen-Seelands so nahe verwandt ist, beniitzt er diese Thatsache zu folgendem Schlusse: "Da die genannte Thatsache vertrauenswerth und wahr ist, so ist der Aufbau des grossen australischen 
Barrierenriffes muter Bedingungen von Senkung und im linklang mit der ursprünglichen Hypotlese Darwin's bewiesen".

Nan sicht, die Zahl der Darwin'schen Anhäuger ist nicht zu unterschätzen. Die der Gegner ist allerdings anch nicht gering. Dat waren in letzter Zeit Bourne. Irvine, Ross, Hickson, welche sich Mluray anschlossen mit dem Vorlehalt, dass ihnen die Entstehung der Atolllagunen durch Auflösung der todten Korallen in Seewasser nicht wahrscheinlich dünke.

Vor allem ist es aber Alexander $\Lambda$ gassiz, seit Dana's 'Tol wohl der erste Riff'kenner, welcher auf seinen zahlreichen Besuchen iler Rifle von Westindien und Hawaii die Unzulänglichkeit der Darwin'schen Theorie erkannte und ausführte.

In den .Talıren 1877, 1878, 1879 und fermer 1890 führte Agassi\% zahlreiche Dredschzüge anf dem "Blake" aus, 1891 operirte er an Bord des "Albatross" an der Westküste von Mexilio, ('entral-Amerika und hei den (ialapagosInseln und 1893 endlich an Bord der Dampfyacht „Wild Duck“. Letztgenannte Kireuztour wurde benutzt zu einer eingehenden Untersuchung der Bahama-Riffe; die Ergebuisse sind in einem umfangreichen Buche von 203 Seiten und 47 Tafeln und Bildern "A reconnaissance of the Bahamas and of the elevated reefs of ('uba"*) nielergelegt, in welchem der neneren Literatur über Riffbildung einige Worte geweiht sind. Wenn man weiterhin in Betracht zieht, dass $\Lambda$ gassiz die Sandwichinseln besucht hat, $1 m$ Dana's Angaben über die daselbst stattgefundenen Bohrungen einer Prüfung zu unterziehen, dass er 1894 die Bermuda-Inseln besuchte, um $\mathrm{Heilprin} \mathrm{erfolgreich} \mathrm{entgegentreten} \mathrm{zu} \mathrm{können,} \mathrm{und} \mathrm{dass} \mathrm{derselbe}$ Mann in allerletzter Zeit endich sich zu einer nenen Fabrt nach Australien gerrïstet hat, um sich über Saville Kent's Angaben betreffenl die Entstehung des grossen Barrierenriffes an Ort und Stelle ein Urtheil zu bilden und womöglich anch die Inseln des stillen Oceans zu besuchen, so wird man zugestehen müssen, dass Urtheile und Ergebnisse, welche auf Grund solch' eingehender Studien gemacht sind, eine besondere Berücksichtigung verdienen.

Agassiz ist ein entschiedener Gegner der Senkungstheorie, wemn anch seine Gegengründe vorsichtig ruhig und frei von Streitsucht vorgebracht werden. So sagt er Seite 177 der Reconnaissance of the Bahamas: "In der That, was ich bei den Untersuchungen der Korallenriffe in Westindien gefunden habe, zeigt, dass, wo immer Korallenrifte vorknmmen und von welcher Form, dieselben nur eine verhältnissmässig dünne Schicht auf der unterliegenden Basis bilden, und von keiner grossen Dicke sind." Eine eingehende Besprechung erführt hier fernerhin besonders, was über die geologisehen Riffe bekannt ist. Es wird betont, dass Richthofen's und Mojsisories' Ansicht, dass der alpine Suhlerndolomit eine Korallenriffloildung sei, durch die Arbeiten ron Gümpel nnd Miss Ogilvie widerlegt wurde. Die letzten Zweifel sind aber dureh die Arbeit ron Rothpletz. (Ein geologischer Quersehnitt durch die Ostalpen. Stuttgart 1894)

*) Die wissenschaftlichen Ergulunisse sämmtlicher Reisen von Agassiz sind in den durch ihn heriihmt gewordenen Bulletins of the Mnseum of Comparative Zoology at Harrard College, Camhridge. Massachusets erschienen. wrolbst die einzelnen Bände bezw. Abhandlungen küuflich zu hahen sind. 

zerstreut worden, welcher nachweist, dass dieser Dolomit eine sedimentäre, marine Bildung ist, wãhreud nur den Raibler-Schichten ein grösserer Reichthum an Korallen zukommt, welche aber bier als "wahre Korallenwesen" nur in geringer Mächtigkeit anftreten.

Noch bleiben einige gewichtige Stimmen zu erwähnen, welche sich in den letzten Jahren gegen die Senkungstheorie erhoben haben. Vor allem ist es der ausgezeichnete englische Geologe Sir Archibald Geikie, welcher wiederholentlich die Frage erörterte und am Ende seiner Ausführung im Textbook of Geology (S. 492) sein Urtheil dahin zusammenfasst: "Dass die weitverbreitete oceanische Senkung, welche Darwin's Theorie fordert, nicht durch Korallenriffe wassers entstanden ist und nicht durch die fortschreitende Vertiefung während der Sonkung, mit welcher das Aufwärtswachsthum des Riffes Schritt balten müsste." Man sieht, dass Goikie, wenu er auch abweisend sich verlält, doch nicht schroff ist; aus dem Ganzen dringt die Ucherzeugung des Gieologen hervor, dass eine allgemeine Senkung nicht durch Korallenriffe heriesen werden kaun; freilich sieht man auch das grosse Rätlisel der tiefen Atolllagunen eine Unsicherbeit herbeiführen, die den Anhängern Darwin's willkommen sein wird.

Lister spricht sich entschiedener in dieser Hinsicht aus und da seine Beobachtungen während eines längeren Aufenthaltes auf den Samoa so nahe

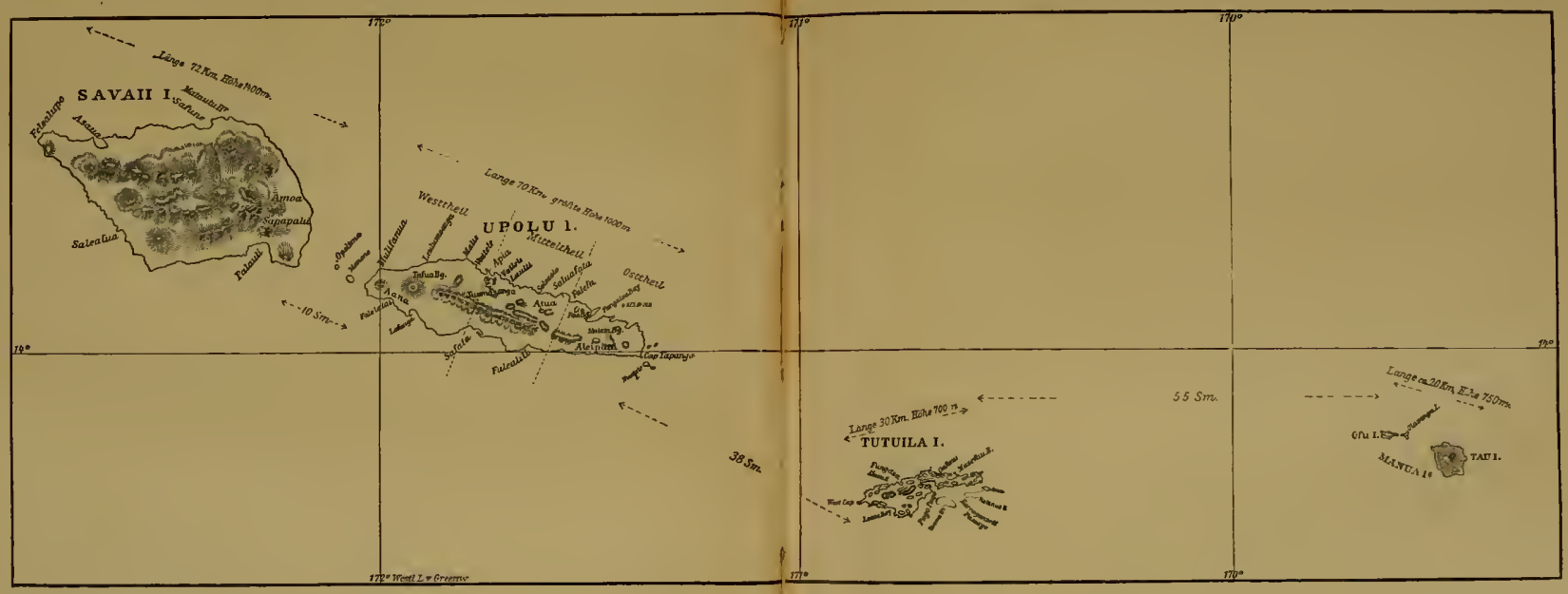

bewiesen werdeu kann, muss jetzt, denke ich, zugegeben werden. Das Zusammenvorkommen von Strand- und Barrierenriffen und von Atollen in derselben Nachlarschaft, mit Beweisen von andauernder RuLe des Bodens oder selbst mit Reweisen von Hebung, ebenso die aufeinanderfolgenden Stadien, wobei ein wahres Atoll ohne Senkung gebildet werden kann, ist in der Westindischen Region so klar bewiesen worden, dass wir die Möglichkeit zugeben müssen, dass dieselbe Bildungsart in allen Korallenmeeren vorkommt. Gleichfalls muss jedoch zugegeben werden, dass die nothwendigen Bedingungen für die Bildung von Barrierenriffen und Atollen manchmal durch Senkung geschaffen werden können. Solange, als passender Bodeu für Korallenwachsthum vorhanden ist, ist es gleichgültig, ob dieser durch Hebung oder Senkung gescliafien worden ist. Dass Senkung in einigen Fällen vorgekommen ist, scheint durch die Tiefe einiger Atolllagunen bewiesen zu werden - 40 Faden weun nicht angenommen werden muss, dass diese Tiefo durch Auflösung des See- gelegenen Tonga-Iuseln gemacht sind, so sind sie für diese Arbeit ron besonderem Werthe, wie überhaupt die gauze Abhandlung viel des neuen und interessanten bietet. Er fand auf Eua Kalkfelsen von nahezu $100 \mathrm{~m}$ Mrächtigkeit, in welchen M urra y 15-20 Arten Globigerinen nachzuweisen vermochte, daneben gehobene Korallenriffe. deren Profile or mittheilt. Das flache Inselmeer giebt ihm ferner Anlass, die Darwin'sche Theorie zu lengnen und er bemerkt (45 S. 611) treffeed: "Ls ist interessant, dass sowohl iu Vavau als auf Eua die Riffe, welche während Zwischenräumen in der Erhebung gebildet worden sind, in einigen Fällen Atolloder Barrierenform angenommen haben."

Endlich will ich noch Sluiter's Arbeit (40) hier erwähnen, welche allein schou dadurch Beachtung verdient, da sie von Bohrungen durch die Korallenriffe auf Java berichtet. Diese, behufs Brunnenanlage unl Hafenbau ausgefülrt, halsen zwar gemäss der Art der Riffe und des Landes keinen Gegeubeweis, jedoch Auf- 
schlüsse ïber den Untergrund gebracht. Man fand nämlich das $300 \mathrm{~m}$ breite Strandriff in der Braudewijns baai bei Padang nicht auf einem Andesitfelsen lagernd, wie erwartet wurde, sondern in $11 \mathrm{~m}$ Tiefe anf Thon und mehrere Meter in diesen eingesunken. Aehnlich fand man auf einer Insel Onrust (1875) das 2) $\mathrm{m}$ mächtige Riff $9 \mathrm{~m}$ im Schlamm stecken. Die übrigen Beobachtungen Sluiter's in der Bucht ron Bataria und am Krakatau denten daranf hin, dass die auf untergesunkenen Bimssteinstücken angesiedelten Korallen der Anfang eines Korallenriffes sein kömnen, und dass dazu nicht in allen Fällen ein Felsen als Untergrund nothwendig erscheint. Betreffend die Riffgenese sagt Sluiter: „Diejenigen Naturforscher, welche in den Tropen die Korallenriffe genauer beobachtet haben, müssen wohl allmälig zur Ueberzeugung gelangen, dass, wie genial, einfach und anregend auch die ätere Darwin'sche Theorie sei, diese einerseits in vielen Fïllen ganz und gar nicht mit den beobachteten Fakten in Einklang zu bringen ist und andererseits anch die Annahme der grossen Senkungen, wie sie die Darwin'sche Theorie annimmt, zur Erklärung der eigentlichen Gestalt der Riffe sehr wohl entbehrt werden kann." Diese Angaben von Sluiter betrefts des Korallenwachsthums auf weichem Grunde bestiitigte $0 \mathrm{rtmann}$ in der Beschreibung der Riffe von Dar es Salam (48). Wesentlich auf demselben Stantpunkte steht Walther (31 a u. b), welcher die lebenden und fossilen Korallenriffe der Sinaihalbinsel und späterhin der Palkstrasse bei Ceylon untersuchte und dessen Untersuchungen ich einigemale z.u erörtern Gelegenheit haben werde. Beide stehen auf einem mässig anti-darwinistischen Standpunkt, ersterer nimmt sogar Hebung für die Bildung der Riffkante an.

Da Walther der Bildung der Korallenriffe im Hinblick auf die Tektonik des nahen Küstengebirges besonders gedenkt, so habe ich seine diesbezüglichen Worte im Abschnitt VI, 6, besonders erwähnt.

Fassen wir das Gesagte zusammen, so finlen wir im Darwin-Dana'schen Gefolge Jukes, Couthouy, Lyell, Heilprin, Kr ümmel, Suess, Supan, Langenbeck, Neumayr, von Lendenfeld, Wharton, Saville Kent u. s. w., während im feindlichen Lager sich Semper, Rein, Agassiz, Pourtales, Muray, Guppy, Bourne, Irvine, Ross, Hickson, Geikie, Sluiter, Lister, Sollas, Ortmann, Wal ther u. s. w. befinden.

Wie schon oben erwähnt, hat unter diesen nur Murray neue zusammenfassende Gesichtspunkte aufgestellt, auf Grund der wissenschaftlichen Resultate der Challenger-Expedition, Gesichtspunkte, welche wohl auch unter dem Namen der Mrray'schen oder mit Berïcksichtigung von Guppy der Murray-Guppyschen Theorie zusammengefasst worden sind. Dies geschieht wohl mit Unrecht, denn die Sätze beider Forscher gleichen sich nur darin, dass sie die Darwin'sche Theorie verwerfen und indem Guppy las Vorkommen des Globigerinenkalks bestïtigte. Zur Uebersicht lasse ich die Sätze folgen:

I. Murray. (21a).

"Es wurde gezeigt

1. dass Untergrund für die Barrierenriffe und Atolle geschaffen worden ist durch die Verwitterung vulkanischer Inseln und den Aufbau submariner 
Vulkane durch Niederschläge von organischen und andern Sedimenten auf ihren Gipfeln;

2. dass die Hauptnahrung der Korallen besteht in dem reichen pelagischen Leben der tropisclien Regionen und die ausgedennte lösende Aktion des Meerwassers wird gezoigt dureh die Lntfernung vou Kalkschalen von diesen Oberflächenorganismen in allen grösseren 'Tiefen der Oceane;

3. dass, wem die Korallen von submarinen Bänken aufwachsen, sie eine Atollform ammehmen, indem nach aussen hin ein grösserer Reichthum an pelagischem Leben rorwaltet und nach immen hin der abgestorbene Korallenfels durch Ströme und durch die lösende Alition der Kohlensäure im Neerwasser entfernt wird:

4. dass Barrierenriffe rom Ufer ans gebaut haben anf einem Grund von vulkanischen 'Trümmern oder anf einem „talus" von Korallenblöcken, Korallensediment und pelagisehen Schalen und die Lagunenkanäle werden im selben Simne gebildet wie eine Atollagune:

5. lass es nieht nöthig ist, die Senkung zu Hülfe zu nehmen, um irgend eine ler charakteristischen Formen der Barrierenriffe und Atolle zu crklären und dass alle diese Formen ebenso sich bilden. ob langsame Hebung oder langsame Senkung vorhanden ist.

II. Guply (24a).

1. Rifle crscheinen durch Wachsthmu bis ungefïhr zur Meeresoherfläche oder durch Hebung:

2. die vielen detaschirten Korallenbänke sind nicht im Stande. sich ohne Hülfe ron Hebung innerhalb der starken Brandung zu erheben. Zurückgehalten in Tiefen zwischen 5-10 Faden, entweder geschützt oder ungeschützt, bilden sie flache Bänke von keiner bedentenden Grösse;

3. Atolle von geringer Grösse (d. h. ungefähr 1 Meile) nehmen ihre Form erst an, wenn sie die Oberfläche erreicht haben. Eine kleine flache Bank kommt durch Hebung zur oder über die Oberfläche. Seitlich wachsen die Flügel an in Gestalt eines Hufeisens, indem durch die Oberflächenströme und die Brandung diese Form entsteht:

4. die grösseren Atolle haben zweifellos ihre Form unter der Oherfläche angenommen;

5. die wahre liffkante ist der Abfall gegen die See zu, welcher zwisehen $4-5$ und 12-18 Faden schwankt. Wo die Bösehung mehr als $10-12^{n}$ ist. was meist der Fall ist. wird der Sand und Kies in die den Korallen unschädliche Tiefe hinausgetragen. Wenn die Böschung weniger als $5^{0}$ ist, dann liegt der Sand innerhalb der Zone der riffhildenten Korallen und belästigt also diese, wodurch Barrierenriffkanäle entstehen. Bei verschiedenen Barrieren hintereinauler kommt Hebung in Frage;

6. Riffbildende Korallen sind nicht an $30-411 \mathrm{~m}$ gehunden. Sie können unter günstigen Bedingumgen bis $100 \mathrm{~m}$ geleihen und so kann man die grossen Tiefen der Lagunen erklären;

7. Riffe wachsen auf ilrem eigenen Talus. 
Die Widerlegung einzelner von Murray und Guppy ausgesprochener Thesen soll in den nächsten Abschnitten versucht werden. Um die Hauptresultate meiner Untersuchungen vorweg zu nehmen, so soll bewiesen werden, dass die Korallenriffe anf stationären Gebieten ihre typischen Gestalten erlangen, indem die tektonischen Landverluältnisse bierfür maassgebend sind, dass die Nahrung der See zu eine ärmere ist als im Hafen und innerhalb der Riffe, und dass aus diesem Grunde und wegen der Brandung das Wachsthum der Riffe seewärts ein schlechteres ist als in den Häfen und Kanälen. Hier erfolgt die Regulirung durch andere Verhältnisse, welche jedem Riffe ein bestimmtes Gepräge verleihen. Der Entstehung der Atolle werde ich, von denselben Gesichtspunkten geleitet, ein besonderes Kapitel widmen. 


\section{Topographie. Meteorologie mnd Geologie der Inseln.}

\section{Topographie.}

Die Samoainseln liegen zwischen $13^{1}$. und $14^{1}{ }^{\prime \prime}$ "Südbreite und zwischen 168 und $173^{\circ}$ westlicher Länge von Greenwich. Sie bilden eine Inselreihe, welche von NNW nach OSO zieht und aus 5 Theilen besteht: Savaíi, Upolu, Tutuila, Manúa und Rose-Atoll. Sie nehmen von Westen nach Osten an Höhe und Grösse ab. Das ganze Gebiet beträgt $2787 \square \mathrm{km}$, wovon 1707 allein anf Savaici entfallen. Ganz aus vulkanischem Gestein bestehend, sind diese Inseln vom Strande bis zu den höchsten Bergspitzen (ca. $1600 \mathrm{~m}$ ) mit üppigem Grüu bedeckt, so dass sie vom Meere aus einen überaus lieblichen Aublick gewähren. Es sollen bier nur allgemein orientirende Notizen gegeben werden. Wegen speziellerer Angaben sei verwiesen anf die Arbeiten Graeffe's, auf Meinecke's „Iuseln des Stillen Oceans" und 'Turner's Samoa, ferner auf den geologischen Theil und die örtliche Riffverbreitung.

a. Savai`i, die westlichste der Inseln, ist die grösste und zugleich die lö̌chste, indem die Berge sich im Innern bis zu $1600 \mathrm{~m}$ über die Meeresfläche erheben. Das Land pflegt nahezu überall vom Meere aus direkt mässig stark anzusteigen, so dass der Küstensaum meist nur schmal ist und wenig Raum für Anpflanzungen bietet. Eine besondere Ausnahme macht nur die als fruchtbar gepriesene Ostseite, welche sich Upolu zuwendet und auch ein grösseres Kiüstenriff besitzt, während die 3 übrigen Seiten der Korallenriffe nahezu ganz entbehren. Diese Ostgegend, Facasaleleanga genannt, ist die Heimatl der Malietoafamilie, welehe zur Zeit den Königsthron inne hat. Hier landete dereinst der englische Missionar Williams mit Tahitischen Lehrern im Jahre 1830 und durch den dort ansässigen Malietoa Tavita gelang es ilmm bald, das Christenthum anszubreiten.

Das Innere von Savaii ist von mehreren parallelen Gebirgsrücken durchzogen und ist wegen seiner Wasserarmuth nur schwierig zu besuchen. Verschiedene Kraterseen sind in ungefähr $1000 \mathrm{~m}$ Höhe vorhanden, vor allen der Mataulanu im Süden und der Lepaengà im Norden, welehe Dr. Reinecke in Jahre 1894 besueht hat. Grosse Höhlen und Schlackengänge finden sich bei Matautu und bei Safotulafai, wie an vielen andern Plätzen. Die Nordküste mit seinem grossen Schlackenfeld und dem jungen Krater des Mua findet sich im geologisehen Theil näher beschrieben. 
Savaici ist durch einen 10 Seemeilen breiten und gegen $100 \mathrm{~m}$ tiefen Kanal von Upolu getrennt, in welchem die interessante Kraterinsel Apolima und die Insel Manono gelegen ist. Während aber erstere mitten zwischen den beiden grossen Inseln isolirt liegt, ist Mamono nur ein abgetrenntes Stiick von Cpolu und anch in dessen grosses Aanariff eingeschlossen. Apolima ragt als die Spitze eines steilen Vulkans aus dem Wasser hervor. Der Kraterrand fällt von Süden nach Norden langsam ab und ist hier eingebrochen, so dass das Meer den Krater ausfüllt. Einige $100 \mathrm{~m}$ nach Norden hin ragt ein Felsblock ans dem Wasser hervor, als ob er der fehlende Theil des Randes wäre. Contre-Admiral a. D. von Werner segelte mit der "Ariadne" zwischen diesem Felsen und Apolima hindurch, um den Manonoleuten den Glauben an ihre uneinnehmbare Feste zu nehmen. Im Krater ist ein Dorf mit einem Süsswasserbrunnen. Da die Pforte im Krater jedoch durch ein Korallenriff verschlossen ist, welches nur einen engen Kanal besitzt, so hängt die Heimkehr der Bewohner sehr von Wind, See und Gezeit ab und ist nicht gar selten unmöglich. In geologischer Hinsicht bildet Apolima ein Caldera mit einem Barranco.

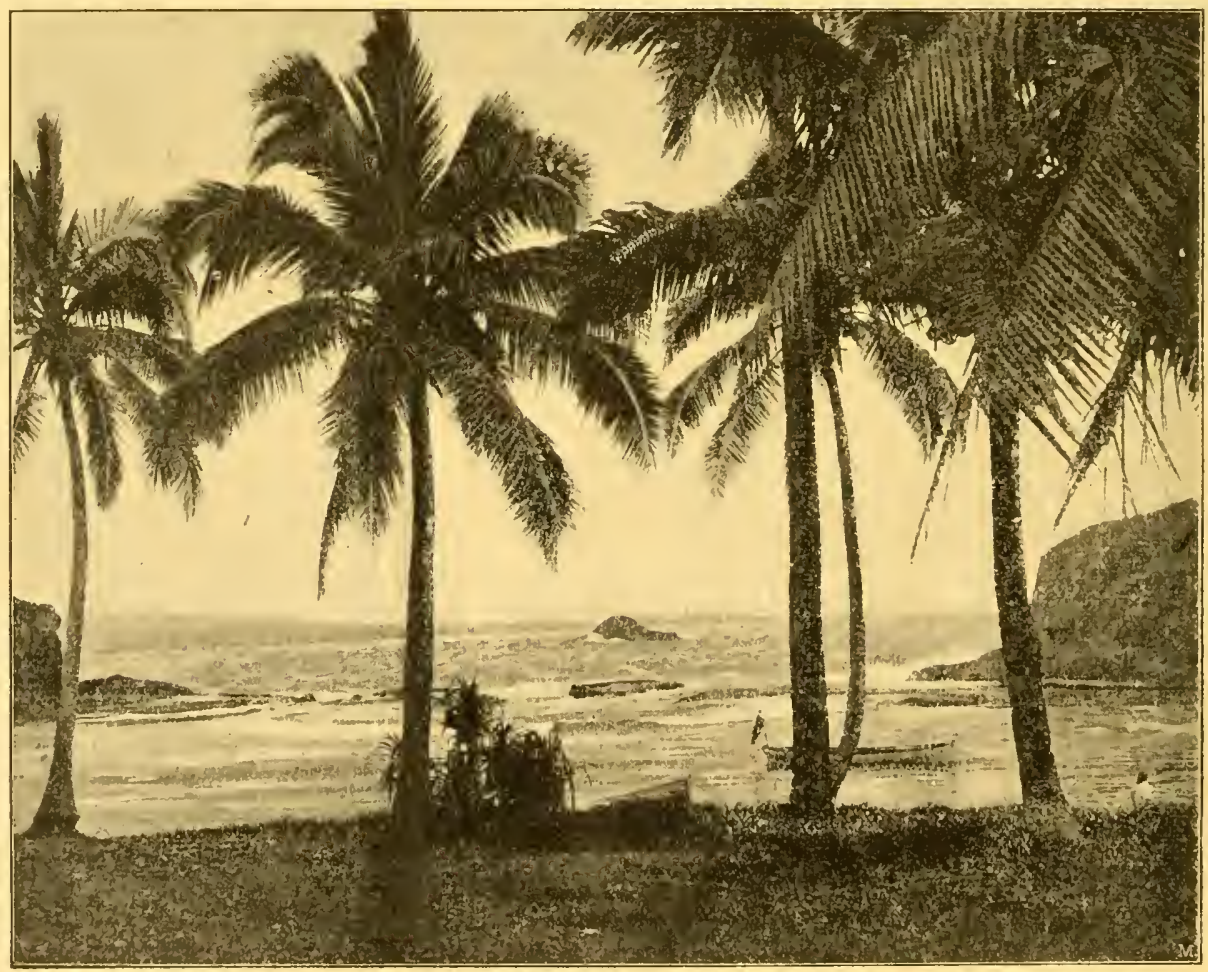

Der Krater der Insel Apolima mit scinem Barranco. Blick aus dem Krater gegen Saraici zu nach XII. Darisphot.

Anders Manono. Die stark bevölkerte Insel, welche lange Zeit um die Hegemonie in Archipele stritt, ist, da sie im Strandrifte von W'est-Upolu eingeschlossen ist, leicht zugänglich. Sie stellt einen niederen Kegel dar und ist 
über und über mit Cocospalmen bestanden. Die Manonoleute gelten nicht allein für vornehm, sondern auch für schön und heute noch sagt man in 'Tonga von einem hübschen Mädchen als höchstes Lob: Sie ist schön wie ein Mädchen von Manono. Westlich von Manono liegt nahe ein einzelner Fels, welchen einige Cocospalmen zieren, Nulopa genannt.

b. Upolu ist die Hauptinsel, mit dem Mittelpunkte Apia inmitten der Nordküste, wo der König Malietoa residirt und die deutsche Handels- und Plantagengesellschaft der Südseeinseln zu Hamburg ihren Sit\% hat. Beschaut man sich von Bord eines mitten im Apiahafen liegenden Schifles aus die schöne Landschaft,

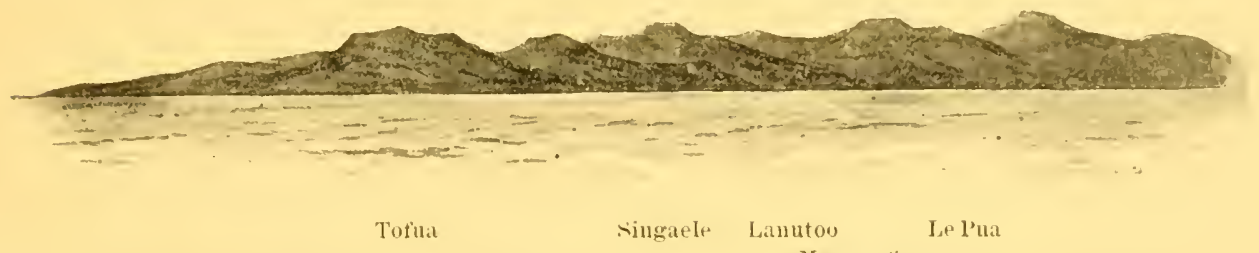

Mamugatiamoe

Das Westende Tpolu's ans Simden geschen.

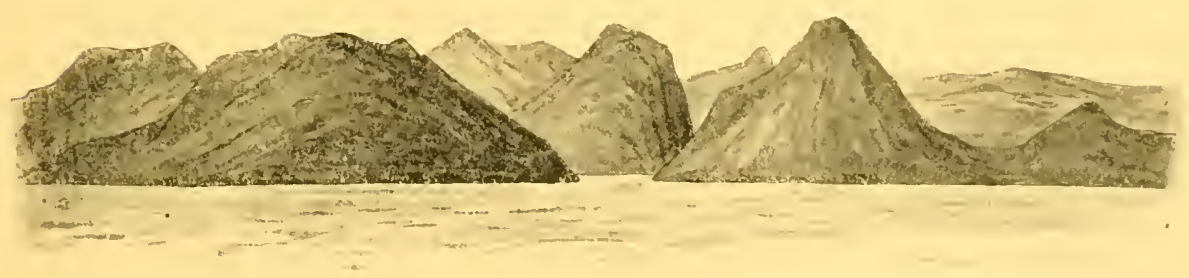

Malataberg Fingang Faberg zuI Fangaloabucht

Sordkïste Upolu's (im Osten der Insel).

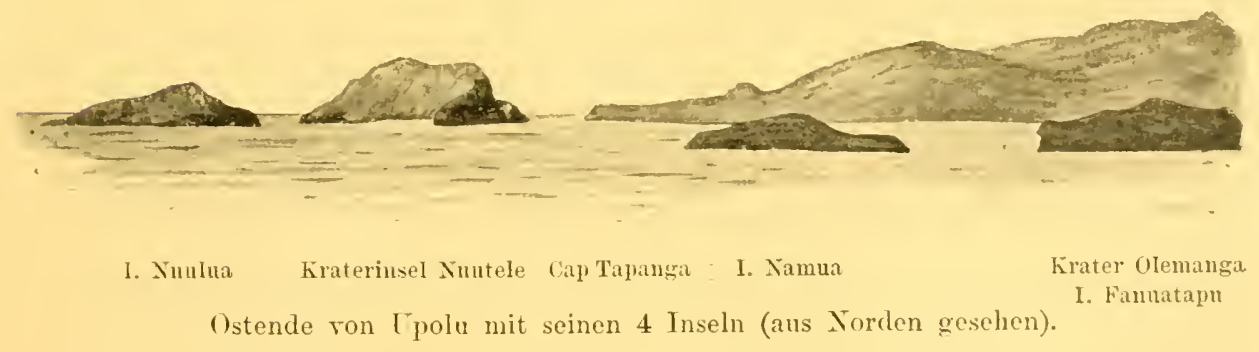

so sieht man fern im Westen an klaren Abenden das hohe Savaici blau verschwommen sich über die Halbinsel Mulinu'u erheben. Ferne im Osten sieht man das flache Aana langsam ansteigen, überragt von dem gegen $600 \mathrm{~m}$ hohen Kegel des Tofua. Auf dem langsam steigenden Kamm gewahrt man fernerhin ostwärts neben vielen kleineren die Krater des Singaele, des tiefer liegenden Lanoatata und Laloanea und dann den höhergelegenen langgestreckten Krater des Lanuto 0 , in welchem ein lieblicher See einsam liegt. lis folgen durch den $350 \mathrm{~m}$ hohen Apiaberg im Vordergrunde verdeckt die Kirater des Maungafiamoe, dann links rom Apiaberg der Tiavi, der isolirte Le Pua und damn der höchste $1000 \mathrm{~m}$ hohe Fa'alata, vor den letzten drei die tiefen Schluchten, durch welehe 
der romantische Vaisinganofluss über zahlreiche grössere und kleinere Felswände herabstürzend im kühlenden Schatten der immergrünen Wülder dem Meere zueilt. Vom Facalata ab füllt der Kamm, gespiekt mit zahlreichen kleinen KraterErhebungen langsam nach Osten hin ins Atuagebiet ab. Die Küstenberge von Vailele und Luatnanu'u, überragt von dem mäehtigen Berg des Saluafatahafens, begrenzen die Landschaft nach Sonnenaufgang. Wenn man denselben Weg im Hinblick auf die politisehe Eintheilung Upolu's macht, so gelangt man aus dem flachen fruchtbaren Aana im Westen, wo zur Zeit der junge Tamasese lebt, in das mittlere Gebiet der Tuamasanga, den Anbüngern des Malietoa, um nach Osten hin in das Atua-Gebiet zn gelangen, dem Verbündeten Aana's, wosellst die uralte Tupua-Familie zu Hause ist, welcher Tamasese entstammt und auch Mataafa mütterlicherseits angehört. Das Ostende der Insel heisst Aleipata und gehört zu Atua. Der Kürze halber werden diese Distriktsnamen fernerhin öfter's zur Ortsbezeichnung Anwendung finden.

Upolu ist im Gegensatz zu dem rhombisehen Saraici langgestreckt und etwas niedriger. Die sanft abfallenden Gehänge bieten namentlich an der Nordküste treffliches Land zum Anban von Pflanzungen. So liegt auf der grossen AauaEbene im Westen die Mulifinua-Pflanzung und ostwärts nahe am Apiaberg die Pflanzung Vaitele. Die Ebene zwischen dem Apiaberg und dem Küstenberg von Vailele nimunt die gleichgenannte Pflanzung ein. Eine weitere grosse Ebene zwischen Saluafata und Falefā in Atua ist noch unbebaut. Auch an der Südküste barren die Niederungen von Lefangāa, Safata, Falealili und Salani noch der ausgiebigeren Benutzung. So ist Upolu nicht allein durch seine centrale Lage und seine Häfen, sondern auch durch den Werth seiner Ländereien zum Mittelpunkt der Samoa-Inseln von der Natur bestimmt.

Am Ostende Upolu's liegen vier kleine unbedeutende Inseln Fanuatapn, Namua, Nu'ulua und das Apolima ähnliche Nucutele.

c. Tutuila, 40 Seemeilen von Upolu in östlicher Richtung entfernt, ist schroff und steil, wenig zugänglich, indesseu früher namentlich voll den amerikanischen Dampferı liäufig besucht, da es den einzigen wirklichen Hafen im Archipele besitzt, welcher von der See vollkommon abgeschlossen ist, wesshalb die daselbst zu verschiedenen Zeiten ausgeführten Plinktonfïnge ein besonderes Interesse verdienen. Im Südwesten ist die offene Bai von Leone, der Sitz eines englisehen Missionars. Zwischen Leone und Pango-Pango (ungefïhr in der Mitte der Südseite) dehnt sich die einyige grössere Niederung auf T'utuila aus, welche ihrer hügeligen Beschaffenheit halber eine Ebene nicht genannt werden kann. Den Aussehen der Küste und des Landes nach gleicht sie einigermaassen der Niederung zwischen Safata und Falealili auf der Südseite Upoln's. Die Lavafelsen der niederen Steilküste sind durch die Passatbrandung stark zerfressen und man sieht hier grosse Höhlen und isolirte Felszacken, an denen der Gischt der Brecher in bedeutende Höhen hinaufspritst und im Somnenschein prïchtige Bilder hervorzaubert. Die Unterminirung des Bolens durch die See ist besonders anschanlich in der genaunten Leone-Bai, woselbst das Hans des Missionars anf einem weiten Gewölbe steht. Zahlreiche $2-4 \mathrm{~m}$ hohe und breite Gänge sieht man bei Niedrigwasser hier ins Land hineinzichen, bei Fluth sich füllend und dem einstürzenden 
Wasser an einigen Stellen durch Ventile Austritt gewährend, so dass auf diese Weise ein Park mit interminirenden Fontänen hier von der Natur angelegt ist. Hier ist das Gestein auch nicht solide Lava, sondern sedimentärer grauer und rostfarben gebänderter Tuff, welcher dem Einfluss des Wassers nur geringen Widerstand bietet.

Der Eingang zum Hafen von Pango-Pango ist leicht kenntlich durch zwei Berge, welche die Thorpfeiler bilden, der $700 \mathrm{~m}$ hohe schroffe spitze Matafao zur linken und der niedrigere, breite Peiva zur rechten. Steile Bergwände, mit ïppigen Wäldern bedeckt, spiegeln sich hier in dem glatten Wasser des schuhförmigen $4^{1} / 2 \mathrm{~km}$ langen Hafens, doppelt schön, wenn dieso Wülder im Mai im üppigsten Blütenschmuck prangen und das ganze Thal von Vogel-

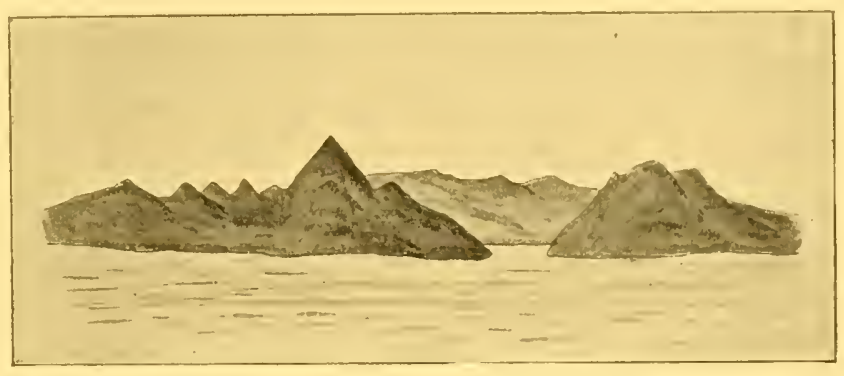

Eingang zur Bucht von Pango-Pango. Südkiiste ron Tutuila. stimmen widerhallt.

An der Süloststrecke Tutuilas liegt die Insel Anun, welche inmitten auf geringer Erhebung einen sumpfigen Krater trägt. Von Anuu aus zieht nach Westen hin bis Pango-Pango parallel mit der Küste Tutuilas ein sogenanntes gesunkenes Barrierenriff, welches weiter unten eine besondere Besprechung erfahren wird.

d. Manua, aus drei Inseln bestehend: Tau, Olosenga und Ofu, liegt 55 Seemeilen von Tutuila entfernt. Wührend Tau einen isolirten $700 \mathrm{~m}$ hohen schroffen Kegel bildet, welcher horizontale Lagerungen zeigt, ist Olosenga und Ofu ein nur durch eine geringe Vertiefung unterbrochener Höhenzug. Manua hat eine eigene Königin, welche unabhängig ist; Manuatele gilt in der samoanischen Sage als das zuerst entstandene und bevölkerte. Hier fand 1866 der submarine Ausbruch statt, von welchem weiter unten die Rede sein wird. Es ist wunderbar, dass die geologischen Schlüsse und die samoanische Ueberlieferung zugleich darauf hindeuten, dass diese Inseln zuerst entstanden sind.

e. Das Rose-Atoll (nach Freycinets Frau, Rose, 1819 so benannt), ist 72 Seemeilen von Tutuila entfernt, trïgt auf dem Korallenring zwei kleine Inseln, eine davon mit hier angepflanzten Cocospalmen berrachsen, ca. $1 \frac{1}{2} \mathrm{~km}$ lang, unbewohnt.

\section{Meteorologie und Oceanologie.}

Die Samoa-Inseln liegen im Bereiche des Südostpassates, welcher indessen nur von April bis November ständig zu wehen pflegt und trockenes Wetter mit sich führt, während zur übrigen Zeit häufiges Aussetzen beobachtet wird, abwechselnd mit nördlichen Winden, welche von Januar bis März nicht gar selten zu heftigen Stürmen und Orkanen ausarten. Diese Zeit, der Va i Palolo der 
Samoaner, da die Regenzeit zugleich die Zeit der Essensfülle ist, wird eingeleitet durch das Erscheinen des Palolowurmes. Die trockene Zeit heisst Va i toelau, die „Passatzeit". Während dieser pflegt der Passat gewöhnlich Vormittags zwischen 8 und 10 Uhr nach einer kurzen Windstille einzusetzen, nachdem Nachts oft ein leichter ablandiger Wind geherrscht hat; dies gilt wenigstens von Apia, welches eigentlich, weil es an der Nordküste Upolus gelegen ist, ausserhalb des eigentlichen Südostpassates liegt. Aber der Wind wird an der Ostkante der Insel in zwei Theile geschnitten, welche längs der Insel von Osten nach Westen laufen. Auch kommt der Passat häufig mehr aus OSO oder gar aus östlicher und nördlicher Richtung. Mit dem Winde setat auch ein Strom von Ost nach West, welcher an der Nordseite durch das vorspringende Sawaii abgelenkt, die Apolimastrasse ron Norden nach Süden durehbricht, und an der Südküste Upolus sogar einen Gegenstrom erzeugt, wie die "Gazelle" beobachtete (auch „Falke“ 1894). Eine besondere Stärke scheint übrigens der Passatstrom hier nicht zu haben, wenigstens für gewöhnlich nicht viel stärker als eine halbe Seemeile in der Stunde. (,,Bussard" fand 0,6 an der Südseite bei Falealili.) Dies hängt offenbar mit der geringen Passatstärke zusanmen, welche hier selten 4 (nach der Beaufort'schen Scala) überschreitet, meist sich nur etwas über 3 hält*). Die Temperaturen des Seewassers sind: Februar $27^{\circ}$ August $27^{\circ}$

\section{Mai $28^{0}$ November $27-28^{\circ}$.}

Wichtiger und bedeutender als die Passatdrift sind an der samoanischen Küste die Ströme, welche durch die Gezeiten erzengt werden. Die Höhe der Springfluth, soweit von einer solchen überhaupt gesprochen werden kann, ist zur Zeit der Aequinoktien (20._22. März und 23.-26. September) ungeführ $1,3 \mathrm{~m}$ (Höhe der Gezeit). Der Zenithstand der Sonne tritt um den 30. October und 11. Februar ein. Die Hafenzeit ist ungefähr $6^{1 / 2}$ Stunden, so dass das Niedrigwasser zur Zeit der Syzygien, also des Nen- und Vollmondes, ziemlich genan Mittags einzutreten pflegt und man um diese Zeit die Korallenriffe weithin in der Sonnengluth frei liegen sieht, während dieselben zur Zeit der Quadraturen (Nippzeit) kaum sichtbar werden. Meteorologische Beobachtungen werden seit vielen Jahren in Apia von dem dortigen Arzte Dr. Funk ausgeführt und der dentschen Seewarte in Hamburg mitgetheilt, welche sie in den „Ueberseeischen meteorologischen Beobachtungen" verwerthet. (Siehe auch A. H. Bd. 18 S. 195.) Dem kleinen Buche Dr. Funk's ,Kurze Anleitnng zum Verständniss der samoanischen Sprache nebst einem Anhange: Meteorologische Notizen" (Berlin 1893. Nittler) entnehme ich folgende Daten:

Durchschnittliche monatliche Beobachtungen.

\begin{tabular}{lcccc} 
& Temperatur C. & Barometerstand & Regenmenge in $\mathrm{mm}$ & Regenlage \\
April & 25.4 & $758.4-764.8$ & 315 & 20 \\
\hline IIai & 26.2 & $765.4-760.1$ & 156 & 13.5 \\
\hline Juni & 25 & $760.1-766$ & 187 & 14.2 \\
\hline Juli & 24.7 & $758-767$ & 89.2 & 10.1 \\
\hline August & 23.9 & $761,7-7665$ & 152 & 13 \\
\hline September & 25.6 & $758.3-766.4$ & 147.9 & 17.5
\end{tabular}

*) Siehe Köppen. Windstärke auf dem Stillen Ocean, Annal. Hydrogr. 1895. 


\begin{tabular}{|c|c|c|c|c|}
\hline October & $\begin{array}{c}\text { Temperatur C. } \\
25.3\end{array}$ & $\begin{array}{c}\text { Barometerstund } \\
759,8-765.7\end{array}$ & $\begin{array}{c}\text { Remenmenge in mun } \\
1+0.9\end{array}$ & $\begin{array}{l}\text { Regrenlatre } \\
18,0\end{array}$ \\
\hline November & 25,5 & $753.4-764.9$ & $361 ; .8$ & 24.5 \\
\hline December & 26.4 & $755.1-76.4 .9$ & $4: 31 i .7$ & 23 \\
\hline Januar & 27 & $755.2 \quad 76(i 3.4 i$ & 455 & 25.5 \\
\hline Februar & 26.9 & $755.7-7633.2$ & 527 & 22 \\
\hline M:irz & 26.9 & $746.5-765.7$ & 316 & 22 \\
\hline Jahresdurchschnitt & 25.7 & $\frac{757}{761.1}-765.2$ & $3119 \mathrm{~mm}$ & 1916.3 \\
\hline
\end{tabular}

Die Amplitude der 'T'emperatur während 24 Stunden beträgt bis zu $10^{\circ} \mathrm{C}$ und darïber. Eimmal beobachtete ich selbst im August 1894 an Land in Apia $17,5^{0}$ C. An Bord ist die Amplitude der Wasserwärme halber weit geringer.

Betrefls der Insolation gehe ich eine kleine Untersuchungsreihe, welche der Steuermann Krautz für mich ausführte. Die Ursache dazu waren die stechenden Somnenstraklen, welche Vormittags um 8 Uhr so empfindlich sind, so dass es schien, dass um diese Zeit wegen der geringeren relativen Feuchtigkeit der Atmosphäre die Insolation eine grössere sei. Das Resultat war negativ.

\begin{tabular}{|c|c|c|c|c|c|}
\hline Datum & $\begin{array}{l}\text { Sichwarze Kingel } \\
\text { a. } \mathrm{m.} 8 \mathrm{~h} .\end{array}$ & $\begin{array}{c}\text { Trockene Kugel } \\
\text { a. m. } 8 \mathrm{~h} .\end{array}$ & $\begin{array}{c}\text { Sclnwarze Kugel } \\
\text { p. m. } 4 \text { l. }\end{array}$ & $\begin{array}{c}\text { Trockene Kugel } \\
\text { p. m. } 4 \mathrm{~h} .\end{array}$ & \begin{tabular}{l|l} 
Ampl. Ampl. & Amp \\
a. m. & p. m.
\end{tabular} \\
\hline 29. V. 95. & $31.0^{\circ}$ & $27.55^{\circ}$ & $36.0^{\circ}$ & $27.7^{0}$ & $1+3.5+8.5$ \\
\hline 30.1. & 31.0 & 25.5 & 37.0 & 28.0 & $+5.5+9.0$ \\
\hline 31. V. & 32.0 & $24.6 \mathrm{i}$ & 38.5 & 28.8 & $1+7.4+9.7$ \\
\hline 1. VI. & 38.5 & 26.3 & 41.0 & 29.7 & $+11.2+11.3$ \\
\hline 2. VI. & 33.2 & 25.9 & 36.0 & 27,7 & $+7.3+8.3$ \\
\hline 3. VI. & 34.5 & 24.5 & 38.4 & 28.7 & $+10.0+9.7$ \\
\hline 4. VI. & 39.0 & 27.8 & 38.0 & 27.7 & $+11.2+10.3$ \\
\hline \multirow[t]{2}{*}{ ธ. ТT. } & 27.6 & 25.0 & 28.5 & 27.0 & $\pm 2.6+1.5$ \\
\hline & & & & & $+7.3+8.4$ \\
\hline
\end{tabular}

Es erhellt, dass die Lufttemperatur in Samoa im allgemeinen für ein tropisches Land eine verhältnissmässig geringe ist. Namentlich zur Trockenzeit ist dank der insularen Lage und dem bestänlig webenden Passat die Hitze leicht erträglich, zumal da nahezu überall am Stranle die Cocospalmen und inlands die Wälder erquickenden Schatten spenden. Samoa verdient desshalb dank diesen günstigen Bedingungen, dank dem liebenswürdigen Charakter und der Reinlichkeit seiner Eingeborenen, dank der üppigen Natur und dem Mangel an bösen Fiebern und gefährlichen Thieren unter den Länderu an erster Stelle genannt zu werden. welche einem Paradiese auf Erden, wenn es ein solches gäbe. verglichen werden könuten. Freilich die Seelente denken anders und aus den folgenden Zeilen erhellt, dass sie ein gewisses Recht darauf haben.

Da Gezeiten und Stürme so ausserordentlich einflussreich auf die Gestaltung der Riffe wirken (was bei der Morphologie. der Ritfe näher zu besprechen sein wird). so will ich hier nicht versäumen, einige Daten zu geben, welche dem Ella'schen Berichte (siehe bei Erdbeben), den Annalen der Hylrographie und mündlichen Berichten an Ort und Stelle entnommen sind: 
Von einer Gezeitenwelle im Gefolge des grossen Erdbebens zu Valdivia in Chile im Jahre 1837 berichtet die Wilkes-Expedition. Die Notizen entstammten einem Missionar im Pango-pangohafen. Daselbst stieg am 7. November 1837 um 2 h. $20^{\prime}$ p. m. das Wasser 2 Fuss über Springfluthmarke und fiel in 10 Minuten zu Niedrigwasser. In 5 Minuten stieg es wieder zur vorigen Höbe, um in 5 Minuten wieder eben so tief zurückzufallen. Dann stieg es plötzlich 5 Fuss über Springfluthmarke und fiel 2 h. 52' wieder zu Niedrigwasser. Geringe Undulationen wurden noch 24 Stunden lang beobachtet.

Am 29. September 18499 h. a.m. fiel das Wasser plötzlich, so dass die Riffe $1 / 2 \mathrm{~m}$ hoch aus dem Wasser hervorragten; in 3 Minuten stieg das Wasser wieder zu halber Fluthhöhe (Ausschlag 5 Fuss). Fernerhin trat Fallen und Steigen ungefähr 3 mal in einer Stunde bis gegen Mittag auf.

Um 3 und 4 Uhr Nachmittags bei halb Ebbe stieg die See plötzlich wieder über die Hochwassermarke, überfluthete die Ufer und fiel dann langsam wieder. Aehnliche Beobachtungen zur selben Zeit auf Aneitum und Neu-Hebriden u. s. w.

Ferner wurde eine Gezeitenwelle im Jahre 1863 beobachtet, welche die Ufer überfluthete und Schaden anrichtete.

Von besonderer Bedeutung sind aber die Stürme, welche Samoa stetig heimzusuchen pflegen.

Das Minimum beginnt gewöhnlich nicht weit nördlich ron Samoa und zieht, erst nach Westen ausbiegend, meist in einer Kurve nach Sülen und Südosten.

Der Monat März ist für Samoa, Viti und Tonga der gefährlichste.

Vollständig verschont scheinen nur die Ellice-, Gilbert-, Marshallinseln, Karolinen und das Meer von Neu-Guinea zu sein.

Für Samoa seien folgende Daten hier gegeben:

1840 war ein Sturm.

Weihnachten 1848 Sturm an der Nordseite Upolus. Ein Samoahaus wurde abgerissen und in die Lüfte getragen.

4.-6. April 1850 Orkan mit kurzen Intervallen, während welcher der Regen in Strömen niederschoss. Viele Büume wurden entwurzelt. Ein Missionshans wurde abgedeckt und theilweise eingeblasen. Mehrere Todesfälle sollen vorgekommen sein. Im Hafen wurden 3 Schiffe auf's Riff getrieben, 1 strandete beim Verlassen des Hafens und ein zu Anker liegender Kutter wurde von der See einfach zugedeckt.

Januar 1865 hauptsächlich Apia betroffen und Manono verwüstet. Die deutsche Bark "Alster" trieb auf's Riff, nur ein Mann wurde gerettet.

Januar 1870 grosse Stürme auf Tutuila. Upolu verschont.

März 1879. Das Minimum des Sturmes ging nicht durch Apia. Schiffsverlust trat nicht ein.

März 1883 starker Sturm. Viele Häuser und Bäume auf Upolu zerstört, mehrere Schiffe gescheitert (10 Mann ertrunken).

Nur 6 Jahre waren vergangen, als jene denkwürdige Sturmzeit des März 1889 hereinbrach, welche noch in aller Gedächtniss fortlebt. Schon vom 9.-17. 
Februar desselben Jahres hatte ein Cyclon die Nähe der Samoainselı passirt; ein zweiter folgte am 7. und 8. Mär\%. Sie hatten indess Samoa nicht direkt getroffen; erst rom 15.-23. desselben Monats datirt jene berüchtigte Zeit, während welcher 6 Kriegsschiffe und mehrere Handelsschifle strandeten und verloren gingen. Dass zwei Stürme schon zuvor beobaclitet waren, gab Veranlassung, das Minimum des 15. März als Regen anzeigend zu deuten.

Köppen schreibt darüber in den Annalen der Hydrographie (1892 S. 267): „Obwohl als allgemeine legel für die tropischen Orkane gelten kann, dass sie verlıältnissmässig selten auftreten und ein und dasselbe Gebiet erst wieder nach einer längeren Pause heimsuchen, kommen doch bisweilen Ausnahmen von dieser Regel vor. In gewissen Jahren und Gegenden scheinen nämlich die Bedingungen für die Bildung der Orkane besonders günstig zu sein, so im Anfange des Jahres 1889 bei den Samoainseln, denn in der Umgebung derselben traten innerhalb eines Monats nicht weniger als 3 Orkane auf."

Konsul Knappe schillerte jene Zeit in seinem Berichte an das Auswärtige Amt mit den Worten: „Während in früheren Jahren die Regenzeit bereits im November einzusetzen pflegte, hatten wir in diesem Jahre bis Ende Januar schönes Wetter."

Es wird also hier ein ursächlicher Zusammenhang bekannt. Der Verlauf des Sturmes und der Katastrophe ist kurz folgender:

15. März früh 4 Uhr Barometer $749,4 \mathrm{~mm}$.

6 h. Die deutschen Schiffe SMS. "Adler", „Olga" und "Eber" Dampf auf (Mittags HMS. „Calliope", Nachmittags die Amerikaner "Trenton", "Vandalia" und "Nipsie").

12 -4 h.p. m. allmäliges Abflauen des S-Windes bis zu Windstille. 4 h. p. m. Barometerstand $742 \mathrm{~mm}$. Minimum.

5-6 h. NO-Wind, starke Dünung.

11 h. p. m. B. $749 \mathrm{~mm}$, starke Böen.

16. März 12-4 h. a.m. Wind NNO-N. Windstärke 12, hohe, direkt in den Hafen einlaufende Seeen.

2 h. a.m. Dentsche Bark "Peter Godeffroy" auf's Riff geworfen.

4 h. "Adler" erreicht das Riff.

6 b. Barometer $746 \mathrm{~mm}$. "Olga" mit "Nipsie" zusammengestossen. "Eber" nach Bedrängung durch "Olga" und "Nipsic" und nach Verlust des Ruder's auf"s Riff getrieben, nach Stenerbord übergekantet und zerschmettert vor das östliche Mittelriff gesunken. "Adler" durch "Olga" bedrängt, da Auflaufen auf den Strand nicht mehr möglich, nach Schlippenlassen der Ankerketten auf das Mittelriff geworfen, wo er heute noch liegt, den Kiel der See, das Deck dem Lande zugekehrt.

Um dieselbe Zeit lief dic "Nipsic" auf den östlichen Sandstrand, nachdem sie „Olga" und „Eber" in harte Bedrängniss versetzt hatte. - Gegen 7 Uhr karambolirte die ,Calliope“, welche den günstigsten l'latz im Hafen inne hatte, mit der "Vandalia", trieb damn auf die ,.Olga" zı, ohue ihr indess verderblich zu werdea. Dass es ihr gelang, kurz darauf mittelst ilırer guten Maschinen und 
mittelst der Westportkoble, wie die Nenseeländer behaupten, aus dem Hafen zu gelangen, dankte sie indessen nicht zum mindesten, wenn nicht völlig, ihrem günstigen Ankerplatz. „Vandalia“ trieb der Ostseite zu, kam auch glücklich von den Riffen frei, sank aber bis zur Reeling, so dass die Mannschaft in die Takelage flüchten musste, wo sie während der folgenden Stunden schreckliche Qualen erdulden sollte, bis am Spätnachmittage die dicht daneben aufgetriebene "Trenton" für einen grossen Theil Entsatz brachte. Viele von der „Vandalia“" ertranken bei dem Versuch, dem nur wenige Schritte entfernten Strande zuzuschwimmen; der Strom, weleher nach Schätzungen 15-20 Seemeilen in einer Stunde betragen haben soll, riss jedoch die Ringenden erbarmungslos fort und trug die durch die Seen Erstickten in die See hinaus. - Der Mittag des 16. war glücklich vorbei; alle Stösse hatte die „Olga" glücklich ausgehalten und schien sicher vor 4 Ketten dampfend zu liegen. Da drehte sich der Wind nach Westen, so dass das letzte Schiff der Amerikaner, mit dem Admiral an Bord, die ,Trenton", direkt in Luv von ihr zu liegen kam. Mit gebrochenem Rndersteven und durch die See ausgeschlagenen Fenern trieb sie verderbenbringend gerade auf die „Olga" zu, so dass diese sich nur durch Auflanfen auf den Strand retten konnte. Das Manöver gelang; die „Olga" blieb das einzige Schiff, welches den Orkan im Hafen überstand und, wenn anch mit schweren Havarien, den Heimweg über die See anzutreten vermochte. - Als am 17. März Morgens der Wind allmälig nachgelassen hatte, gelang es auch, die Letzten des „Adler“ zu retten, welche Tags zuvor trotz des Opfermuthes der Samoaner nicht aus ihrer peinlichen Lage hatten befreit werden können. Obwohl im Kriege mit Dentschland, haben diese Eingeborenen durch Entfaltung solch' edler Gesinnung (mehrere biissten dabei das Leben ein) einen Theil ihres Unrechts wieder gut gemacht, das sie wenige Monate zuvor an dentschen Matrosen begangen hatten. Diese - Wilden haben sich hierbei als ,bessere Menschen" gezeigt, als gewisse Vertreter eivilisirter Nationen, die diese Kämpfe und Feindseligkeiten förderten und schürten.

Das weisse Marmordenkmal in Mulinu'u, woselbst die Gefallenen und Gebliebenen in ewig grünem Garten schlafen, und das Wrack des "Adler" auf dem Riffe mahnen stündlich daran, was die deutsche Marine für diese Inseln geopfert hat.

Fiat institia, pereat munlus!

\section{Die Entstehung und Geologie der Samoa-Inseln.}

Als gegen das knde der 'Tertiärzeit eine gesteigerte vulkanische 'Thätigkeit die Erdoberfläche veränderte, indem allenthalben die Basalte, Trachyte und Phonolithe dem Erdinnern entströmten, sind, soweit zu schliessen, auch die Samoainseln entstanden. Es scheint im Norden und Süden dieser Inselgruppe damals eime starke Depression stattgefunden zu haben, welche mit beftigen Lavaergüssen aus hunderten von Kratern einherging. Der östliche Theil des Inselzuges scheint dabei zuerst entstanden zu sein, wenigstens ist hier die vulkanische Thätigkeit früher erloschen als im westlichen Theil, was ans der starken Verwitterung der Berge von 'Tutuila und des östlichen Upolı dentlich genug hervorgeht. Während nun aber das westliche Upolu und Savaíi bis in die letzten Jahrhunderte hinein 
noch vulkanisch thätig war und sich hoh, sank der östliche Theil allmälig ein, so dass von Manúa nur noch 3 Bergspitzen über den Meeresspiegel hervorragen, während ein unterseeischer Berg 78 Seemeilen weiter ostwärts von dem Rose Atoll gekrönt wird. Fs ist eine richtige Abnahme der Höhe und Grösse dieser Insellinie von Westen nach Osten zu bemerken, welche Dana in seinem Geolological Report (3 b.) eingehend beschrieben hat. Ein Längsdurehschnitt iurch die Inselreihe würde sich ungefähr folgendermaassen gestalten, wobei Höhen und Tliefen zur Veransehanlichmig un-

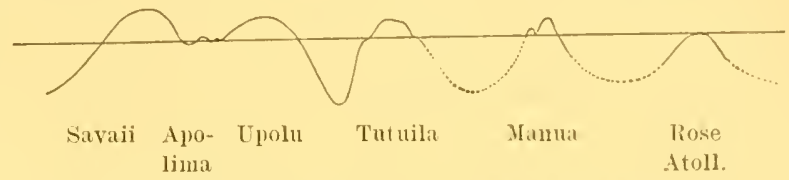

Durchsehnitt durch die Samoainseln.

(Hölı́n und Tiefen sind im Terhältuiss zn den Entfernnngen zu gross augegehen.)

rerhältnissmässig grösser als die Längen angesetzt worden sind.

Dana hat nun nenerdings eine Depression des Meeresbodens in Abrede gestellt (siehe Characteristies of Volcanoes with contribution of facts and principles of the Hawaian Islands 1890). Er kam zu denı Sehluss, dass, abgesehen von enghegrenzten Depressionen, ein ursächlicher Zusammenhang der Vulkane mit den Zonen grosser Tiefe nicht besteht. Er betrachtet vielmehr letztere als wahrscheinlich sehr alte Züge in der Gestaltung der Lrdkruste, welche ihre Ursachen in Vorgängen tief im Innern der Erdkruste habeu.

Ich verweise in dieser Hinsicht anf die Worte von Haas, welche er in dem bekannten Werkchen "Aus der Sturm- und Drangperiode der Frde" gebrancht. (S. 164.)

„Die Meere sind die Depressionsgebiete unseres Planeten, eingesunkene, oder theilweise vielleicht noch im Einsinken begriffene grosse Schollenkomplexe der Erdfeste, die Festländer dagegen die erhöhten Stellen derselben."

An selber Stelle führt er weiterhin aus, dass „dort, wo die faltende Kraft ihre stärksten Wirkungen hervorgebracht hat, sich in erster Linie die Spalten in der Erdrinde finden werden, die Vorbedingungen für das Auftreten der Vulkane. Betrachteu wir, nu uns das recht zu verauschaulichen, eine Landkarte Südamerika's. An der Westküste dieses Continents ist ein gewaltiges Gebirge aufgeworfen. dessen Entstehung auf die vorerwähnten Ursachen zurïekgeführt werden muss, ein Faltengebirge im vollen Sinne des Wortes, die Cordilleren. Hier verlaufen in nordsüdlicher Richtung mehrere grosse Bruchlinien. und hier hat vulkanische Thätigkeit auch die riesigen Fenerberge anfgebant. Entsprechend dem steilen Abfall des Continents zeigt auch der Ocean an dieser Stelle der Erdoberfläche verhältnissmässig grosse Tiefen. Die Ostkïste Südamerika's ist verhältnissmässig flach und das Neer, welehes dieselbe bespült, nur seicht und wenig tief. Steile Bruchränder des Festlandes gegen den Ocean zu sind hier nur an verhältnissmässig wenigen Stellen vorhanden, die Depression der Erdfeste ist hier eine nur geringe, zux Bildung von Spalten ist's also nicht gekommen, und daher lässt sich auch der fast gänzliche Nangel an Fenerbergen auf dieser Seite des Continents leicht erklären. Nicht immer liegen die tektonischen Verhältnisse so klar und deutlich zu Tage, doch sind wir meist in der Lage, aus 
einer Reihe anderer Umstände auf das Vorhandensein von Bruchstellen überall da zu schliessen, woselbst Vulkane vorhanden sind."

Dana vertrat ferner die Ansicht, dass die fjordartigen Bildungen, wie sie den Gambier- und Marquesasinseln, Borabora und Raiatea bei Tahiti, der östlichen Vitigruppe, Vanikoro u. s. w. eigen sind, eine stattgefundene Senkung anzeigen und da mehrere solcher fjordartiger Bildungen auch auf Samoa angetroffen werden (vor allem die Fangaloa-Bucht im östlichen Upolu und der Hafen von Pango-Pango auf Tutuila), so nahm er eine solche Senkung auch aus diesem Grunde für diese Gegend in Anspruch. In der That lassen sich die Samoa-Inseln in zwei Hälften theilen, welche durch deutliche Unterschiede gekennzeichnet sind. Die Trennungslinie geht senkrecht mitten durch Upolu, und liegt auf der Strecke Apia-Falefā, welche einen gewissen Uebergang bildet, indem hier auch 5 Küstenberge auftreten. Es macht fast den Eindruck, als ob hier eine Abknickung

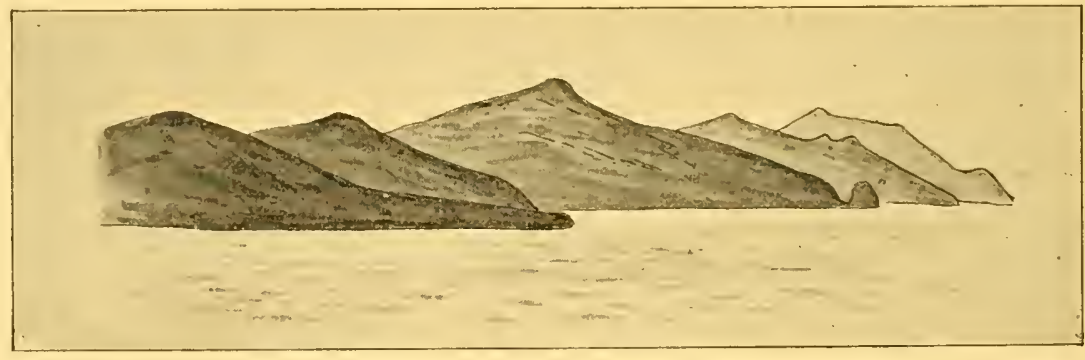

V. Salnafata- IV. Solosolo-
berg. $\quad \begin{gathered}\text { III. Luatuanum- } \\ \text { berg. }\end{gathered} \quad \begin{gathered}\text { Laulii- I. Apia- } \\ \text { berg. }\end{gathered}$

Die 5 Küstenberge zwischen Apia und Falefă. (Nordküste Upolus) in der Höhe von Falefā rom Meere aus gesehen.

stattgefunden hätte, indem der stärker sinkende Osten von dem schwächer sich hebenden Westen abbrach. Die Unterschiede zwischen diesen beiden Theilen sind folgende: Im Westen breites Land von fortlaufenden Gebirgskämmen durchzogen, welche in sanften Gehängen zum Meere abfallen und selten steile Schluchten bilden. Die flache Küste ist mit breiten Strandriffen besetzt, durch welche die Häfen gebildet werden (diese fehlen nur zum Theil Savaíi aus sogleich näher zu erörternden Gründen). Kahle Stellen ohne Baumwuchs als Zeichen junger vulkanischer Thätigkeit zahlreich vorhanden. Guterhaltene Krater häufig. Mangel an Flüssen. Im Osten schmales Land, fortlanfende Gebirgskämme seltener, die unregelmässig verlaufenden Berge meist schroff in's Meer abfallend und zwischen sich steile Schluchten bildend. Die Steilküste entbehrt nahezu ganz der Korallenriffe und die Häfen werden durch das Land gebildet. Kahle Stellen ohne Baumwuchs und guterhaltene Krater seltener. Flüsse zahlreich.

Ich glanbe, dass diese Charakterisirung genügt, um die Untersehiede deutlich hervortreten zu lassen. Man wird sich kaum der Annahme verschliessen können, dass es sich hier um eine starke Senkung des Ostens handelt, was ja auch aus den grossen Meerestiefen zwischen Upolu, T'utuila, Manúa und dem Rose-Atoll erhellt, wïhrend Savaici und Upolu nur dureh eine geringe Einsenkung von einander getrennt sind. 
Diese Senkung des Meeresbodens, welche als Gegenreaction auftretend mit einer Erkaltung der Erdrinde in der posttertiären Zeit Hand in Hand ging, hat auch zweifellos die Brïcken zerstört, welche Samoa mit den Ellice-, Gilbert-, Marshallinsehn und Karolinen nach den Philippinen hin verband. Als vulkanische Centren blieben diese alle neben 'Ionga, Raratonga, Tahiti, Hawai'i u. s. w. stehen, während der Meeresboden zwischen ihnen in ungehenerliche Tiefen versank. Dass alle diese Punkte bis Madagaskar hin eine so eng verwandte Fauna und Flora besitzen und von demselben Volksstamme mit einer Sprache bewohnt sind, legt die Annahme einer zeitweiligen wenn auch unvollkommenen Verbindung nahe. Es interessirt dies indessen hier nur soweit, als es zur Erklärung des Alters dieser Inseln und deren Fauna dient. Während also im Osten der Samoainseln

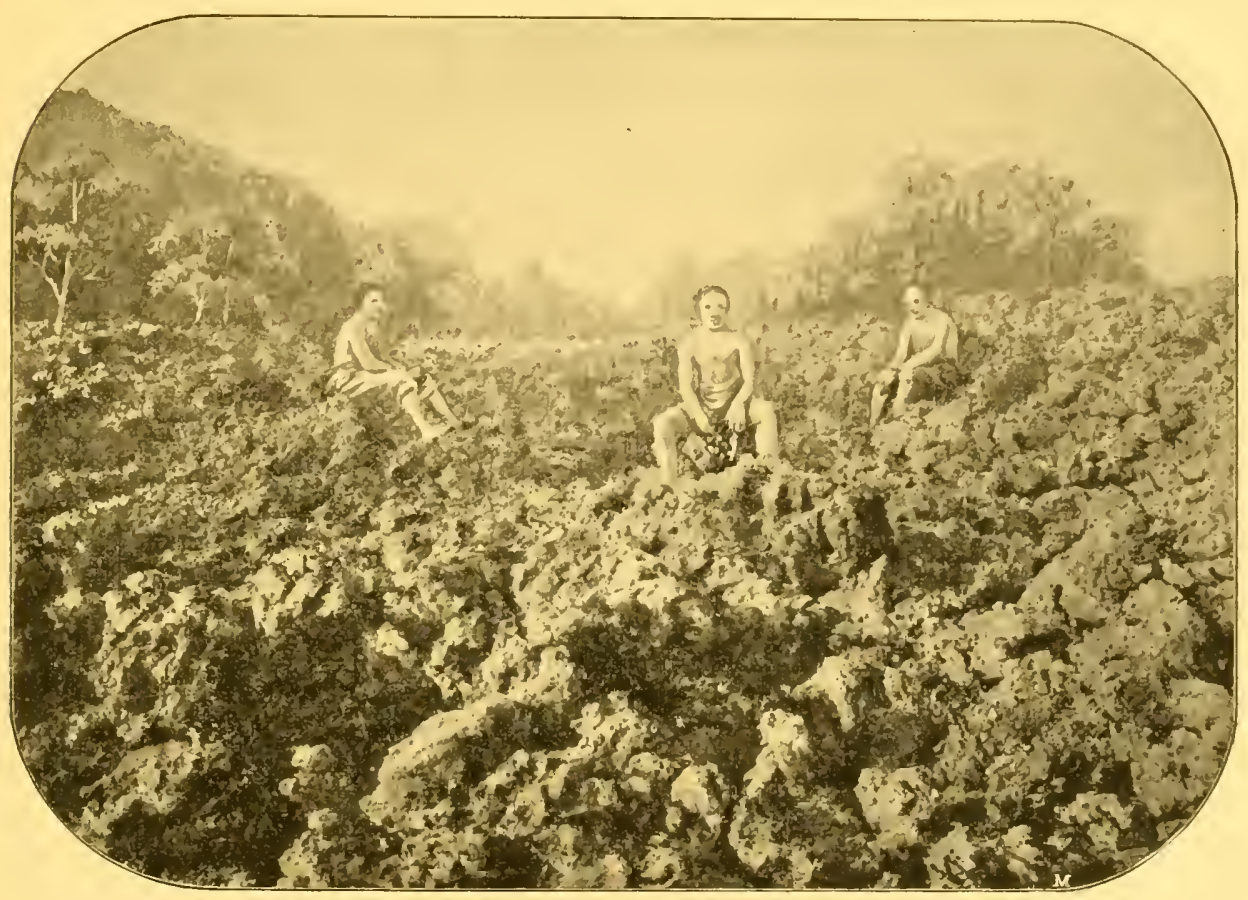

Dr. Reinecke phot.

Junge unverwitterte Schlackenlara ron Suraii.

periodische intermittirende Senkungen eintraten, welche nummehr längst zum Stillstand gekommen zu sein scheinen, dauerte im Westen die vulkanische Thätigkeit länger an und führte eine langsame geringe Hebung herbei. Vor allem betrifft dies die grösste Insel Savaì, wo über einen grossen Theil des Noriabhanges noch völlig junge unverwitterte Java zu Tage liegt. Die Samoaner nennen diese gefürchtete wasserlose Gesteinswüste co le mū, das Glühende. wie ihrer. Sprache ïberhaupt auch der Ausdruck für ,fenerspeiender lBerg, maunga mū" nicht frem ist. Pritchard giebt in seinem Buche "Polynesian Reminiscences" an, lass um die Mitte dieses Jahrhunderts alte Samoaner sich noch gut daran erinnert hätten, dass diese Fläche einst glühent gewesen sei. Man muss aber 
bedenken, dass dieses Gestein heute noch wie ehemals unter den sengenden Strahlen der Sonne sich so erhitzt, dass es dem nackten Fusse der Eingeborenen wie glühend erscheinen muss. Herr Dr. Reinecke, welcher diese Stätte besuchte und photographirte, berichtet darüber folgendes (51):

„Der Busch hört vor dem Mū plötzlich auf. Vulkanischer, mit Verwitterungsund Verwesungsproducten bedeckter basaltischer Boden, mit dichtem Wald bestanden, geht unvermittelt in ein fast geradlinig von der Küste aufsteigendes Trümmerfeld über, auf dem weitporöse, scharfrandige Lavablöcke wild übereinander gewürfelt liegen und aufgethürmt sind. Wendet man den Blick landeinwärts, so führt links die fast schnurgerade Waldlisière durch eine tiefe Einsenkung an kahlem Gebiet entlang und in den üppigen Busch, welcher von den östlichen Höhen herniedersteigt, über." „Tiefschwarze unter den Stiefelı und dem Stock metallisch tönende erhärtete Lavaströme stellen ein ausgezeichnetes Parkett dar, auf dem die Tropensonne ihre Kraft nicht nutzlos verschwendet und vorn gegen $11 \mathrm{Uhr}$ bereits eine Temperatur von $82^{\circ} \mathrm{C}$. bei $36^{\circ} \mathrm{C}$. Lufttemperatur erzeugt hatte, so dass Gummisohlen förmlich zu kleben beginnen, sowie man nur einen Augenblick still steht, wie es z. B. eine photographische Aufnahme erfordert."

Westwärts von dem Mū, welcher eine Höhe von 168 m erreicht, liegt jene Gegend ca. $100 \mathrm{~m}$ über dem Meere, zwischen den Orten Satana und der Westspitze Falealupo, welche jene Korallenbildungen zeigt, von denen Reinecke schreibt:

"Die Korallenreste, welche hier ohne Zusammenhang aufzutreten scheinen, bestehen vorzugsweise aus grossen, flachen, an der Oberseite welligen oder warzigen Platten, bis $1 \mathrm{~m}$ im Durchmesser und $20 \mathrm{~cm}$ Dicke. Da sie früher gerade auf dem Wege aufgefallen waren, konnte man zunächst vermuthen, dass sie vielleicht hierher gebracht seien, um das Gehen zu erleichtern. Vielleicht hatten die siegreichen Tonganer einst die unterdrückten Samoaner gezwungen, auf diese Weise Strafdienste zu leisten und, wie an anderen Stellen ler Inseln, auch hier eimen bequemen Weg anzulegen. Sie hätten in diesem Falle allerdings das Banmaterial von Papa, einem kleinen Orte zwischen Sataua und Falealupo, oder von Sataua herbeischafien müssen, denn bei Papa hört nach Westen zu das Auftreten der Korallen auf.

Diese Annahme verliert jedoch durch die Thatsache an Wahrscheinlichkeit, dass lie Korallen nicht nur auf dem Wege selbst, sondern auch ganz allgemein in der Umgebung zerstrent vorhanden sind. Sie liegen vorzugsweise an der Oberfläche und sind von ausserordentlicher Festigkeit. Es hält äusserst schwer, mit einem Basaltstück etwas davon abzuschlagen.

Ebenso auffallend ist das Vorhandensein solcher Korallenreste an der Küste kurz vor Falealupo, wo sie auf dem Steinwalle in besonders grossen Exemplaren häufig sind.

Wemn man nun in Betracht zieht, dass auch über Falealupo sich ein Krater befindet, dessen Bildung und Ungebung auf eine recente Entstehung schliessen lässt, dass also voraussichtlich der letzte Aushrueh in ziemlich gleicher Weise oder gleichzeitig wie auf Westsavai'i (Ost?) stattfand und dort gewaltige Formenverïnderungen hervorrief, und dass hier am Westende Korallen da auftreten, wo 
in der Umgebung jetat solche gänzlich fehlen, so dürfte die Vermuthung berechtigt sein, dass die Westspitze ler Insel ihre Bildung einer Hebung verdankt."

In der 'That können nach dieser Beschreibung die Korallen nur auf zwoi Weisen hierher gelangt sein; entweder durch Hehung des Landes oder lurch einen submarinen Aushruch. Gegen diesen spricht jedoch die grosse Entfernung des Weges rom Ufer umd die Form der Korallenstïcke, die Platten ron 1 m Durchmesser, die wohl doch bei einem solch' weiten 'Transport durch die luft und demgenäss Anffall zertrümmert worden wären*).

Für eine Hebung spricht ja auch die ganze Configuration des westlichen Savaii, vor allem die Armuth an Korallenriffen, wie sie der gehobenen Insel Ngaur auf den Palauinseln ebeu auch eigenthümlich ist (s. IV. 3).

Eine solche Hebung erklärt ja für Savaíi leicht, warım es trotz seiner sanften Hängre so wenig von Riffen geschützt ist. Savaici und Upoln krönen zusammen einen submarinen Berg, dessen Böschung ringsum sehr steil ist. Während nun das sanfte Gefäll von West-Upolu sich nordwärts unter dem Mceresspiegel fortsetzt und den Untergrund für das grosse Aanariff liefert (in einer Entfermung von 6 Scemeilen sind noch $60 \mathrm{~m}$ angegeben, aber in 9 Seemeileu schon circa $15110 \mathrm{~m}$ ), setzt sich das sanfte Gefälle Savai is nicht submarin fort; aus dem Meere gehoben, ist die Kiüste direct an den Rand des grossen Absturzes gerückt; eine grössere Strandriftbildung ist desshalb hier nicht möglich.

Der Einfluss dieser Hebung tritt anch in den Häfen Saraicis dentlich zu Tage. So sind die Buchten ron Safune, Asaua im Norden und die von Palauli im Süden durch Terflachung rollständig zugewachsen, während dies bei den rielen Punkten Upolus (Apia, Saluafata, Falefã, Fangaloa, Falealili, Safata) nicht ler Fall ist; nur die flache Bucht von Lefangā verbält sich daselbst ähnlich. Ein einziger Ankerplatz für grössere Schiffe findet sich auf Savaici, die Rhede von Matantu im Nordosten der Insel bei Safune. Das flache Land bildet daselbst ein mässig breites Straudriff, in dessen Leeseite die Schiffe zu ankern pflegen. Besonderer Beliebtheit erfreut sich indessen dieser Platz bei den Seeleuten auch njcht, so dass das interessante Savaíi. woselbst die Samoaner ibre Sitten noch am reinsten bewahrt haben, von grösseren Schiffen nur selten und kurz besucht zu werden pflegt.

Ausser dem grossen Lavafeld 'o le mu sind in Sarai'i noch viele Punkte, welche daranf hindeuten, dass die vulkanische Thätigkeit vor noch nicht allzulanger Zeit erloschen ist. Auch die Wasserarmuth deutet darauf hin. Deun obwohl diese Insel gross genug ist, um einen kräftigen Wasseram auszubilden, fehlen doch Flüsse und Bitche nahezu ganz, so dass das Innere schwierig zu besuchen ist. Ebenso steht es mit dem naheliegenden westlichen Upolu (die Pflanzung Nulifanua leidet sehr darunter), wïhrend bei Apia und weiter ostwärts zahlreiche Rimsale dem Meere zueilen, welche zur Regenzeit zu mächtigen Giessbächen anschwellen. So liegt der Hauptreiz ron Apia nicht allein in der wechsel-

*) Die dem mineralngischen Institute z.1 Breslan won Dr. Tieinecke greschenkten Handstiicke wurden mir von ersterem liebenswürdiger. Weise ïbersandt. Ein stïck war als Heliastraea bestimnt (Salzgurkengrösse), das andcre ein Scheibenstïck ron rersintertem festem Kalk. Contactmetarmophose nicht rorhanden. 
vollen Landschaft daselbst, sondern auch in den lieblichen Flussthälern, oder besser gesagt Schluchten, innerhalb welcher das Wasser zahlreiche Kaskaden bildet. Der Grund der Wasserarmuth Savai'i's liegt zweifellos in dem noch wenig verwitterten Boden. Die poröse Lava lässt das Wasser alles nach unteu abfliessen, und nur ein sehr heftiger Regenfall vermag an günstigen Plätzen für wenige Stunden einen Wassersturz zu erzeugen. Höhlenbildungen sind desshalb im westlichen Theil Samoa's und vorzüglich auf Savai'i häufig. Die genannten baumlosen Plätze sind bei Apia indessen ziemlich häufig anzutreffen; so sind besonders hinter dem Vaileleberg weit hinauf im Gebirge zahlreiche Stellen, welche nur mit Farnen und niedercm Gestrüpp bedeckt sind. Auch im hinteren Vaisinganothal, östlich vom grossen Wasserfall Afutápu, ist ein grosses, kahles Feld, von Steinen und Schlacken bedeckt. Dana giebt an, dass er am Wasserfall Tanungamanono bei Apia verkohltes Holz in Lava eingeschlossen gefunden habe. Dass dem Krater der höchsten Erhebung des Gebirgskammes hinter Apia, dem Fa'alata, zeitweise Dämpfe entsteigen sollen und dass in der Nähe der Fangaloabai und bei Solosolo warme Quellen seien, will ich nur als unwahrscheinlich erwähnen. Es wäre daran weiter auch ja nichts wunderbares im Hinblick darauf, dass in dem unter ähnlichen Bedingungen stehenden nahen Viti in der SavuSavu-Bai auf Vanua-Levu warme Quellen vorkommen, ganz abgesehen von dem ebenso nahen Tonga, wo vulkanische Kräfte noch ausgiebig wirken. Die zahlreichen Erdheben und der submarine Ausbruch im Jahre 1866 zu Manu'a beweisen jedoch zur Genüge, dass Samoa auch noch nicht in das Stadium der Ruhe eingetreten ist. Dass dieser Ausbruch im östlichen Theile erfolgte, welcher ja doch als der ältere, gesunkene bezeichnet wurde, wird bei der Unberechenbarkeit der vulkanischen Ausbrüche nicht weiter verwundern. Es sei nur an den plötzlichen Ausbruch des völlig erloschenen Taraweraberges im Jahre 1886 in Nen-Seeland erinnert, welcher mitten zwischen zwei thätigen Vulkanen, dem Whakari-Island und dem Tongariro, gelegen ist. Obwohl von Hochstetter prophetischer Weise verkündet, konnte doch niemand wissen, dass durch solch' einen Ausbruch die herrliche Rosa- und Weisse Terrasse am Rotomahana zerstört werden würde.

Im übrigen scheint es auch für das östliche Samoa durchaus nicht unmöglich, dass es sich zur Zeit, wie nahezu alle Punkte der Süllsee, im Stadium leichter sekundärer Hebung befindet, wie aus den folgenden Zeilen erhellt.

In der Vorrede zu seinem Dictionuaire Samoan-français giebt der Mariste Violette an, dass verschiedene stets befahrene Riffssanäle im Jahre 1878 plötzlich völlig unbenutzbar geworden seien, was nur durch Hebung entstanden sein könne. Der Ort ist leider nicht genannt.

Auf Nu'utele, einer der 4 Inseln am Ostende Upolu's, und auf dem gegenüberliegenden Cap Tapanga wurden ron Dana $(3$ b.) Korallenstücke in Tuff eingebettet gesehen, die er auf einen submarinen Ausbruch zurückführte; mit wie viel Recht, kann ich nicht angeben, da ich diese Stellen nie betreten konnte.

Merkwürdig berührt es indessen, dass Dana*) eine Schilderung seines Reise-

*) Dana 3. c.s. 37.4. E. Samor. Keine genïgenden Zeichen von Hebung wurden auf diesen Inseln entleckt. Das ist alles! 
genossen Couthouy vollstïndig und wohl absichtlich ignorirt hat, welche sich auf zu Tage liegenden Korallenkalk auf Manu'a bezieht. Darwin giebt dio Stelle Couthouy's folgendermaassen wieder (2. Seite 99):

„C. fand auf Manu'a viele und sehr grosse Korallenfragnente in der Höhe von 80 Fuss ,,,an einer steilen Hügelseite, eine halbe Meile inlands von einer sandigen Ebene austeigend, welche viele marine Reste enthielt."“ Die Fragmente waren eingebettet in eine Mischung von zersetzter Lava und Sand. Es ist nicht angeführt, ob sie von Muschelschalen begleitet waren, oder ob die Korallen recente Formen sind; da die Reste eingebettet sind, können sie möglicherweise einer entfernten Zeitperiode angehören; aber ich nehme an, dass dies nicht die Meinung von Couthouy war."

Ob es sich um Hebung oder vulkanische Eruption handelt, muss hier leider gleichfalls offen bleiben.

Indessen soll auf Olosenga (Manu'a) eine Hochwassermarke $7 \mathrm{~m}$ über der jetzigen sein.

Wenn ich noch anführe, dass auf der Sanddüne des Rose-Atolls Hebungszeichen beobachtet sein sollen, so wird man sich fragen müssen, ob nicht der ganze Osttheil des samoanischen Archipels sich auch im Zustande recenter Hebung entweder localer oder allgemeiner Natur befindet.

Bei der Unsicherheit aller dieser Angaben vermeide ich es indessen absichtlich, daron für die Korallenriffbildung Gebrauch zu machen, zumal da ich genügend anderweitige Erklärungen für die Art des Aufbanes gefunden zu haben glaube. Es dürfte jedoch eine dankbare Aufgabe sein, diese Angaben über Hebung näher zu prüfen und nach weiteren Anzeichen zu forschen.

Wichtiger erscheint mir für die Atollausführungen die Katastrophe von Manu'a wegen der Nähe des Rose Atolls und der Bildung submarimer Krater von besonderem Interesse, und so will ich nicht versäumen, einen kurzen Abriss der Schilderung eines Augenzeugen, des Missionars Turner zu geben, welche seiner Zeit im Sydney Morning Herald erschien (auch Graeffe im Ausland 1867):

Am 7. September 1866 fortdauerude Erdbeben (3-4 in einer Stunde). In der Nacht des 9. gegen 40 Stösse. Leichtes Zittern und Dröhnen erschreckte alles; es hörte sich wie unterirdisches Seufzen an. Am 12. Mittags sah man ziemlich mitten zwischen den 5 Seemeilen ron eiuander entfernten Inseln Olosenga und Tau die See in Bewegung. Es sah aus, als ob daselbst Brandung wäre. Die Ausbrüche fanden ungefähr stündlich statt, nahmen während des 13. und 14. an Zahl zu und traten am 15. nahezu jede Minute auf. Grosse Massen von Schlamm wurden viele $100 \mathrm{~m}$ hoch in die Lüfte geworfen und bildeten eine solche Wolke, dass die beiden Inseln dem gegenseitigen Anblick entzogen wurden. Das Geräusch des Ausbruches und des Zusammentreffens aufsteigender und herabfallender Steine war schrecklich. Flüssiger Obsidian gab in der Luft ein wunderbares Farbenspiel der Sonne. Flammen wurden nicht gesehen, nur sah man die Steine hei Nacht aufglühen. Die See war im Umkreis einer halben Meile sehr erregt und zeigte sich weithin milchig getrübt (Schwefel). Eine grosse Anzahl Fische und $3-4 \mathrm{~m}$ 
lange Seeungeheuer, welche die Eingeborenen noch nie gesehen hatten, trieben anf Olosenga an's Land und verursachten durch Verwesung einen solchen Gestank (bei dem Schwefelgeruch und der Hitze besonders unerträglich), dass auf die Leeseite der Insel geflüchtet werden musste. Risse und heisse Quellen wurden nicht bemerkt, auch blieben die Süsswasserbrumen unbeeinflusst. Nach 3 Tagen liessen die Ausbrüche allmälig nach, aber nach 2 Monaten waren doch noch 3-4 Eruptionen täglich. welche 10-20 $\mathrm{m}$ hohe Wasser- und Schlammsäulen aufthürmten. Erst am 29. November trat völlige Ruhe ein. Eine geringe Cnruhe mit Erdbeben trat vom Januar bis März 1867 zeitweilig noch auf. H. M. S. ,Falcon" traf bald darauf am Orte ein und lotete in 81 Faden Tiefe einen Kegel aus, welcher 40 Faden $(70 \mathrm{~m})$ hoch den umgebenden Meeresboden überragte." Im Jahre $189+$ besnchte auch H.M.S. "Curacoa" Manu'a und bestätigte das Vorhandensein eines submarinen Kraters.

Was die Gesteine betrifft, aus denen sich die Samoainseln zusammensetzen, so scheint es sich durchweg um Basalt zu handeln.

Dana berichtet von Laven mit Chrysolith und Augit.

Graeffe nennt schwarze bis graue 'Tephrine und Basalte mit Angit; in Savaìi erbsengrosse Analcimkörner.

Die Gesteinsproben, welche ich mitbrachte, hatte Herr Professor Haas die Liebenswürdigkeit zu untersuchen und berichtete er mir folgendes:

„Es siud im Wesentlichen typische Plagioklasbasalte, theils dichter, theils blasiger und schlackiger Structur. Plagioklas, Augit und reichlicher Olivin, Maguetit und spärliche Apatitnadeln sind die wesentlichen das Gestein zusammensetzenden Mineralien. Eine Basis mit allerlei ausgeschiedenen Körnchen und Nädelchen drängt sich zwischen dieselben. Nur ein einziges der mir übergebenen Handstücke ('Tanungamanono-Wasserfall, Vaisinganofluss bei Apia) weist diese Basis in sehr reichlichem Maasse auf, während dieselbe bei den übrigen Proben gegenüber den genannten Mineralien im Gesteinsteig sehr zurücktritt. In den Hohlräumen des Gesteins von Tanungamanono sind verschiedene Neubildungen von Mineralien (Zeolithe) zu beobachten, über welche, sowie über die ganze Suite noch eingehender berichtet werden wird."

\section{Erdbeben.}

Es bedarf noch der Erabeben Erwähnung zu thun. Die Daten sind theilweise dem Berichte des Missionars Ella im Report of the 4. Meeting of the Australasian Society for advancement of Science (1892) entnommen:

Die Oscillationen sind meist schwach und kurz. Die seismische Welle ist selten vertical, meist horizontal. Richtung von NO und SW. (Das einzige, welches ich am 10. Juli 1894 Abends 7 Uhr beobachtete, schien dieselbe Richtung zu haben).

Dass die Erdbeben früher stärker waren als jetzt, ist allgemein überliefert. Der samoanischen Sage nach ist dem Erdbebengott Mafucie durch Tíciti (den Maui aller Polynesier) im Kampf um das Feuer ein Arm gebrochen worden, so dass er jetzt nicht mehr so kräftig zu rütteln im Stande ist (s. Turner, Samoa 
a hundred years ago and long before. London 1884.). Dies sagt man auch auf Niné und 'T'onga.

Ella nenut: 1850 rom 26. September bis 29. December 7 Stösse.

1861 am 22. Februar um 2 h. $45^{\prime}$ p. m. Doppelschlag, der zweite kräftiger, "23. $\quad " \quad 2$ h. $20^{\prime}$ a. 11. heftiger Stoss. zwischen 2 Stössen soll vorkommen.

Im September 1889 wurden einzelne heftige Stösse verspürt, die Unruhe unter der Bevölkerung verursachten. Das Zittern und Stossen dauerte 3 Minuten lang, Häuser und Bämme wankten. Die Ankerketten der Schiffe im Hafen kamen steif. Kleinere Stösse werien in jedem Jahre beobachtet. Ein hefitigerer Stoss soll auch im December 1895 beobachtet worilen sein.

Besonderer Notizen über Erdbeben anf anderen Inseln der Südsee bedarf es nicht; sie sind so allgemein verbreitet und häufig, dass dies bei der Luwichtigkeit dieser Erscheinung für diese Arbeit zu weit führen würde.

Ein grösseres fand im März 1875 auf Uvea in den Loyalitätsinseln statt, wobei viel Eigenthum und Leben verloren ging.

\section{Zeichen vulkanischer Thätigkeit und Hebung an anderen Orten der Südsee nebst einigen Notizen über fossile Riffe und die Korallenkalke.}

Wie das Torkommen von Erdbeben, so sind anch Beobachtungen von Hebung von nahezu allen Theilen der Südsee berichtet; so von Süd-Amerika (Darwin), Süd-Australien, Neu-Guinea,. Salomons-Inseln, Neu-Seeland, Tonga, Viti, Hawai i u. S. W.

Es sei nur erimnert an die Berichte von Semper über die Palauinseln, Wallace und Finsch über Nen-Guinea, Schleinitz über Neu-Irland, Guppy über die Salomonisinseln, Clı m b r e y o über Nen-Caledonien und Nen-Hebriden, Lister über Tonga, Hutton über Neu-Seeland. Näheres darüber bei Sues (38. II. Bd. S. 649-659). Betreffs Neu-Guinea auch Stre h l "Negative Strandverschiebungen im Gebiete des südwestlichen Pacific, insbesondere anf Nen-Guinea: (Zeitschr. für wiss. Geogr. Erg. Heft Nr. 3. 1890).

Alle diese Hebungen lürfen betreffs Korallenkalk als jung aufgefasst werden, wenigstens nicht älter als tertiär.

Die Höhen sind ungefähr (Korallenkalk):

Nordküste ron Neu-Guinea nach Wallace $70-100 \mathrm{~m}$,

an der Südostecke nach Moresby $30 \mathrm{~m}$ (Strehl giebt Höhen von 400 und $500 \mathrm{~m}$ [Hoch-Kei] an; Gra f P feil $150 \mathrm{~m} \mathrm{P.} \mathrm{G.} \mathrm{M.} 189$ S. 220).

in Neu-Irland $10-20 \mathrm{~m}$,

in Uvéa, Mare Lifu ca. $50 \mathrm{~m}$,

Salomonsinseln, Santa Amna $140 \mathrm{~m}$, Malapauina $20 \mathrm{~m}$,

Eua (Globigerinenkalk) $325 \mathrm{~m}$, Westterrasse (Riffbucht) $100 \mathrm{~m}$,

Vavau $150 \mathrm{~m}$,

Palau $100 \mathrm{~m} \mathrm{u.} \mathrm{s.} \mathrm{w.}$ 
Dan a giebt Seite 382 seines Buches (3c) eine Tafel mit allen ihm bekannt gewordenen Erhebungen im Pacifischen Ocean; darunter sind verzeichnet:

\begin{tabular}{|c|c|c|c|}
\hline Tahiti & $1 / 2 \mathrm{~m}$ & Ellice ca. & $2 \mathrm{r}$ \\
\hline Metia (Paumutu) & 80 & Sandwich & $1-100$ \\
\hline Maugaia (Hervey) & $100 "$ & Gilbert & $1-2$ \\
\hline Plurutu $\quad "$ & $50 \%$ & Carolinen & 20 \\
\hline Tongatabu & $20 "$ & Ladronen & 200 \\
\hline Savage Island & $30 \%$ & Loyalty I. & 80 \\
\hline
\end{tabular}

nebst zahlreichen kleineren Inseln; bestimmt ausgenommen ist eigentlich nur Samoa und das östliche Viti.

Man hat so bestimmt Hebungen über den ganzen pacifischen Ocean und vielfach recht ansgiebige beobachtet, dass man eigentlich schon aus diesem Grunde anch eine Hebung der Samoainseln anzunehmen berechtigt wäre. Dass Dana trotzdem die Senkungstheorie aufrecht erhält, muss eigentlich danach Wunder mehmen.

Zum Ueberfluss will ich hier noch des Falcon-Island gedenken, welches seiner recenten vulkanischen Thätigkeit halber in der Nähe Samoas sicherlich Interesse verdient.

Das englische Kriegsschiff „Falcon“ sah im Jahre 1867 als erstes im TongaArchipel nicht weit vom Vulkan Tofua eine Klippe dem Meere entragen, welche zu Ehren des Schiffes Falcon-Island getauft wurde. Zehn Jahre später sah H. M. S. "Sappho" an derselben Stelle von einer flachen Bank Rauch aufsteigen. Im October 1885 wurde ein submariner Ausbruch an derselben Stelle beobachtet, welcher ziemlich gleichzeitig mit dem Ausbruch der grossen Terrasse am Rotomahana-See in Nen-Seeland stattfand, ein Jahr vor dem folgenschweren Ausbruch des Tarawera. Ein französisches Kriegsschiff besuchte im Jahre 1887 die Stätte, und die Abmessung der durch die Eruption gebildeten Erhebung ergab $87 \mathrm{~m}$. Captain Wharton (Nature 1890) an Bord H. M. S. "Egeria" fand die Insel im October 1889 noch 153 Fuss hoch und über eine Seemeile $(1850 \mathrm{~m})$ lang, aus Asche bestehend und in rascher Abspülung begriffen. Ein Jahr später wurde sie (1890) von dem französischen Kriegsschiff "Duchaffault" gesichtet und nur noch 25 Fuss hoch befunden.

Im Januar 1895 fand ich im „New-Zealand-Herald" (Auckland) folgende Notiz :

„Da die Regierung hörte, dass Falcon-Island allmälig weggewaschen würde, sandte sie jüngst eine Expedition behufs Vermessung dorthin. Der officielle Bericht ist noch nicht veröffentlicht, aber man kann jetzt schon sagen, dass es scheint, dass eine nene Hebung jüngst stattgefunden hat, da die Insel auf einer Soite 50 Fuss $(15 \mathrm{~m})$ hoch geschätzt wurde, während der Kapitän Ross von der "Ysabel" 3 Monate zuvor berichtet hatte, dass das Aussehen der Insel in einer kleinen Entfernung davon einer Limie von Felsen glich."

Den officiellen Bericht habe ich nicht erlangen können. Er thut auch nicht noth. Das was ich zeigen will, dass Erhebungen anch in nenester Zeit sich bilden, ist ja damit bewiesen. (S. auch Pelorus Riff. A. H. 1888.) 
An und für sich ist dies anch nicht wunlerbar in einem Gebiet wis der. Tonga-Archipel. cines der noeh thïtigsten in pacitischen Ocean; ich branche nur auf die intermittirende Thätigkeis des Tofua hinzuweisen, ferner auf den Ausbruch des Kia, auf die schrecklichen Aushrüche des Late im .Jahre 1854, des Toku und Amargura 1845-46, der Insel Niuafu 185:3 und 1867 u. s. W.

Lister, welcher in demselben Arehipel die über 300 m betragenden Hebungen von lua im Süden und die etwas geringeren vou Tavau im Norden näher besclıieben hat, giebt folgende Vulkanlinie an:

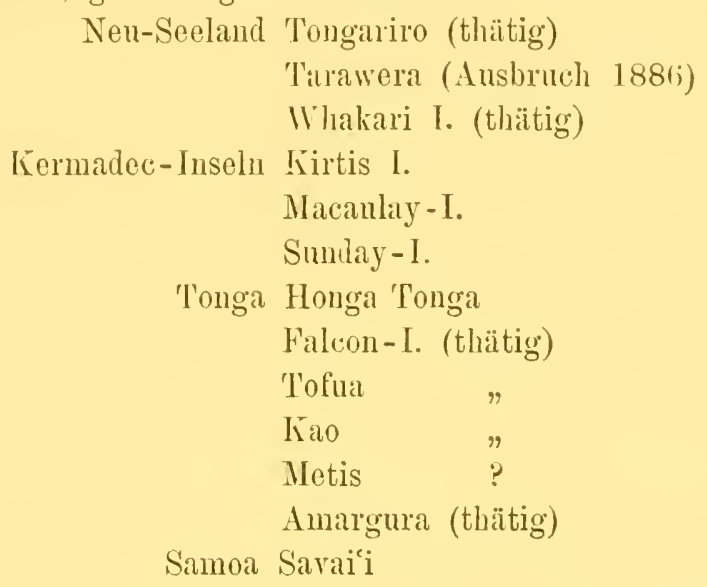

Dabei fehlt noch der Boseawen, ein isolirter grüner Vulkankegel zwischen Tonga und Samoa, und viele andere Krater in mmittelbarer Nachbarschaft. Verlängert man die 1800 Seemeilen lange Linie (Neu-Seeland bis Samoa) um weitere 2000, so schneidet man anch noch Hawaici.

Wenn solch' eine Uebersicht auch nur topographisches Interesse besitzen mag, so glaubte ich sie wenigstens der Merkwürdigkeit halber erwähnen zu müssen.

Wie steht es nun mit dem übrigen gehobenen Korallenkalk auf der Erde? liein (10 b. S. 91) führt die Aeusserungen eines Geologen, des Professors von Fritseh in Halle an, welche ich hier wiedergebe:

„Dana zïhlt in seinem wiederholt citirten Werke über Korallen und Koralleninseln viele dureh jungvulkanische Thätigkeit in der Südsee gehobene Riffe auf. Haben auch genanere Messungen ihrer Dicke bei den meisten nicht stattgefunden, so erkenut man doch, dass dieselben bei allen weit unter $100 \mathrm{~m}$, bei manchen sogar unter 6-7 m bleibt. Ebenso bleiben aber auch alle hekannten Korallenkalkmassen Emopas und anderer untersuchten Gebiete weit hinter den Mächtigkeiten zurück, wolche für die Koralleninseln gewöhnlich angenommen werden.

Ablagerungen, welche fast ausschliesslich aus gesellig lebenden Korallen der Vorzeit bestehen, kenne ich nur bis zu Mächtigkeiten, die meist viel unter 100 m bleiben. Berücksichtigt sind:

1. Die Korallenbänke des Miocän, welche ich bei Plewna als sehr auffallende Stufe der Gehänge entwickelt fand, aber wohl nie auch nur $10 \mathrm{~m}$ mächtig sah. Auch die ebenfalls miocänen Korallenbänke von Sao Vincente auf Madeira erreichen kaum 20 m Mächtigkeit. 
2. Die oligocänen Korallenkalke verschiedener Abtheilungen dieser Formation そ. B. im Vincentinischen werden als höchstens $20 \mathrm{~m}$ mächtig geschildert.

3. Die eocänen Korallenkalke am Südhange der Alpen sollen Bänke von nicht mehr als $25 \mathrm{~m}$ Stärke bilden. Die Gesammtmächtigkeit der Nummulitenkalke auf Bornen und auch der analogen Bildungen von Sumatra bleibt unter $100 \mathrm{~m}$ zurück, und doch bestehen nur einzelne Partien und Lagen oder Bänke aus wahrem Korallenkalk.

4. Kreidekorallen, die als Riffbildner zu gelten haben, bäufen sich in verschiedenen Districten an. Ich erinnere an den Faxökalk, an einen Theil des sogenannten Kalktuff's vom Petersberg bei Maestricht, an die Gosauschichten, und die äquivalenten Korallenlager der Provence, an the von Toula und von mir beobachteten in den wahren Korallenbänken höchstens $20 \mathrm{~m}$ mächtigen, uryonisch-aptischen ,Caprotinenkalke" am Nordabhang des Balkan, an südfranzösische Gebilde ähnlicher Art u. s. w.

5. Jurakorallen sind seit langer Zeit als riffbildende bekannt, besonders vom Malm. Aher weder Nattheim noch andere schwäbische und schweizer Orte, noch die lothringischen, noch die hannöverschen, noch die englischen Korallenkalke erreichen als solche grössere Jächtigkeiten als die jüngeren Formationen.

6. Triaskalke, namentlich der Dachsteinstufe zeigen sich zuweilen als Korallenkalke, indessen auch diese nachweisbar hauptsächlich ans Anthozoenresten bestehenden Gebilde bleiben bei aller Mächtigkeit ihrer Bänke doch unter $30 \mathrm{~m}$.

7. Ganz ähnlich ist es mit den ans liugosen, Favositen u. s. w. gebildeten paläozoischen Korallenkalken, sowohl denen des Carbon als den devonischen und silurischen. Die Korallenkalke der Eifel, jene des Harzes, die von Gothland und die wir am Ardisithügel in Maroceo fanden, erreichen keine 20 m Mächtigkeit. Bisweilen trifft man mehrere Bänke übereinander, durch schwache Zwischenlagen getrennt. Aber auch dann bleibt der Complex der Korallenkalke unter 100 m."

v. Fritsch schliesst seine Betrachtungen mit folgenden Worten:

„Wie schwach der Grund ist, auf den hin die grosse Mächtigkeit der jetzigen Riffe erschlossen worden ist, die Berechnung nach den Böschungen der Inseln, die das Grundgelage der Riffe bilden, hat ja auch Dana angedentet, doch muss dies wohl noch stärker betont werden. So machen es namentlich die Gambierinseln mit ihren verschiedenen Gipfeln doch wohl sehr wahrscheinlich, dass das alte Grundgebirge noch untermeerische Gipfel hat.

An Senkungen im pacifischen Gebiet glaube ich, nur nicht an so mächtige Korallenbauten, als man gewöhnlich angiebt. Und noch weniger glaube ich, dass die Süitiroler dolomite Riffe, weil man ja nicht eimmal die riffebildenden Korallen näher kennt. Dass dort Korallen in der 'Triaszeit (mehr vereinzelt) gewachsen sind, ist ja nachgewiesen."

v. Fritsch spielt hier am Schlusse auf die Dolomitenkalke an, welche in neuerer Zeit zu solch heftigen Fehden Veranlassung gegeben haben. Ich habe der neueren Arbeiten über diese schon bei Besprechung der Arbeiten von Agassiz Erwähnung gethan. Wie dem auch sei, es ist mindestens zweifelhaft geworden, ob man es hier mit wirklichem Riffkalk zu thun hat. 
Soweit ich aus allen Arbeiten geologischer Natur in dieser Beziehung erfahren habe, ist man sich noch nicht vollkommen klar darüber, was man mnter Korallenkalk alles zu verstehen hat. Man sollte die Begritte ,.!ittkalk, Korallenkalk, Glohigerinenkalk" u. s. w. hetrefts ihrer Genese und Composition erst einwandsfrei klarzustellen versuchen, elıe nan in solch weittragende Discussionen eintritt.

1)ie Metamorphose der (iesteime bietet ja freilich grosse Schwierigkeiten, aber sie werlen doch überwindhar sein.

Lehreich in dieser Bezichung sind insbesondere die Arbeiten von J u kes $B r o w n e$ and $\mathrm{H}$ ar r ison über Barbadoes und $\mathrm{L}$ ister über 'Tonga (beide in einem Band, 45 und 46).

Die erstere Arbeit sagt über die zalılreichen gehobenen Riffe daselbst (S. 200): ,Der Korallenkalk, welcher so einen grossen Theil der Oberfläche der Insel bildet. ist nur eine Kruste oder Decke ron sehr verschiedener Dicke“.

Ferner (Barbadnes):

„,Die Dicke des Kifffelsens, gebildet in einem Stadium der Hebung, überschreitet nicht häufig 200 Fuss, aber kann 260 Fuss dick sein. Wir müssen indessen nicht daraus schliessen, dass die Korallen in 40 Fadeu Wasser zu wachsen begannen, weil immer eine gewisse Dicke von Korallenkrus, Sand oder Breccie an Fuss ron Riffen ist.

Der Detritusfelsen an lem Fuss der alten Riffe scheint an dem Gehänge auswärts von einem alten Riff angehänft zu sein. Die Dicke desselben wechselt von 1-10 Fuss oder 50 Fuss und wahrscheinlich mehr in manchen Fïllen, zweifellos abhängig vou der Steilheit der Böschung."

Wir nü̈ssen uns hierbei erinnern, dass, wenn ein Riff sich auf weichem Boden bildet, es allmälig in diesen einsinkt (s. Sluiter-40-).

Hill, weleher in nenester Zeit die gehobenen Rifie von Cuba im Auftrage von Agassiz mutersucht liat (s. M. of. Comp. Zool. at. Harv. Coll. ]895) machte mehrere Schliffe vou den Barbadoeskalken, welche sich natürlicherweise in ihrer Structur sehr verschieden erwiesen (im Anhang zu 46).

Er unterscheidet 3 Arten:

1. Reefrock (Riffkalk). Homngener Fels, bestehend aus Kiorallen und Korallentrümmern, zusammengebacken mit Sand und mehr oder weniger gehärtet dureh Calcitinfiltration.

2. Lagmen oder Canal-Deposit (Korallenkalk). Nach Componenten und Art des Korns selı verschieden, schliesst neben Korallen immer noch andere Thiere ein, namentlich Mollusken, Echinodermen und Foraminiferen und manchmal machen diese Schalen und ihre gebrochenen Fragmente das ganze Gestein aus. Ursprïnglich loser als liorallenfels kamn diese Art infiltrirt und sehr hart werden.

3. Beachrock Strandfels, aus Korallenstiicken und Korallenfelsstücken zusammengesetzt, die am C’er aufgehäuft werden, mit Vermischung.

Die Analyse des Reefrock ergab:

$\begin{array}{lc}\text { kohlensaurer Kalk } & 98 \\ \text { kohlensaure Magnesia } & 1,5 \\ \text { Phosphorsäure } & \text { Spuren }\end{array}$




\section{Oxyde ron Eisen und Alaun 0,2}

\section{Kieselsäure}

0,2 .

Lister fand auf 'T'onga, wie schou erwähnt (Literaturuachweis), $100 \mathrm{~m}$ hohe Kalkfolsen, welche sich nach Muray's Angaben als Globigerinenkalk erwiesen. An der Westseite von Eua fand er indessen auch ein gehobenes Barrierenriff (besser wohl eine Riffbucht) in situ.

Solche Untersuchungen in situ verbunden mit petrographischen Untersuchungen an Ort und Stelle sowohl fossiler als zugleich lebender Riffe werden allein Licht in diese verwickelte Riffkalkfrage zu bringen vermögen. Nothwendig ist es aber, dass dieselben an Ort und Stelle gemacht werlen. um allen sich bei solchen Untersuchungen aufdrängenden Fragen und Zweifeln sogleich mit Thatsachen entgegentreten zu können.

Wohl werden jetzt Bohrungen auf Funafuti in der Ellice-Gruppe seitens Englands ausgeführt; sie werden uns dienlich sein, wenn man z. B. in $20 \mathrm{~m}$ Tiefe überall vulkanischen Boden findet; aber was werden sie uns bringen, wenn dies nicht der Fall ist? Werden die Gesteinsuntersuchungen zur Zeit uns sichere Aufklärung verschaffen könuen?

\section{Begriff der säcularen und intermittirenden (instantanen) Senkung und Hebung.}

Darwin selbst hat schon zwischen säcularer und intermittirender Senkung unterschieden. Während jeđ̉och erstere eine Unzahl von Anhängern in ihren Bannkreis zog, ist letzterer verhältnissmässig wenig Aufmerksamkeit geschenkt. worden. Und doch ist es diese, mit welcher wir es vor allem in Betreff der Südseeinseln zu thum haben werden. Es wird niemanden zufallen, positive und negative Verschiebungen der Erdrinde in Abrede zu stellen; unumstössliche Beweise liegen dafür vor. Ebensowenig dürfte es aber auch erlaubt sein, alle diese Senkungen und Hebungen als säcular, allmälig erfolgend, zu betrachten. Niemand wird bezweifeln, dass Neu-Seeland und Neu-Guinea einst mit dem australischen Continent verbunden war; die neueren paläontologischen Funde haben dies wenigstens für Neu-Seeland sicher dargethan. Was giebt aber Saville Kent. das Recht, diese Trennung durch säculare Senkung entstanden anzunehmen und desshalh die Entstehung des grossen australischen Barrieren-Riffes nach der Darwinschen Theorie zu erklären? Da die Trennung aus famistischen und floristischen Grïnden spätestens kurz nach der Tertiärzeit erfolgt sein muss, so ist eine säculare Senkung um so unwahrscheinlicher, als in jener Zeit wilder vulkanischer 'Thätigkeit ausgiebige Bewcgungen zweifellos die Südsee beherrschten. Heute scheint diese positive Bewegung der Erdrinde nicht allein hier zum Stillstand gekommen, sondern sogar in eine umgekehrte allgemeine negative übergegangen "u sein, was aus dem vorigen Abschnitt erhellt. Aber auch bier wirl man periolische Hebungen annehmen müssen, wofür Lister's Beschreibung von Eua cin Beweis zu sein scheint. Jedenfalls möchte ich die Senkung der östlichen Samoainselu meinerseits in diesem Sinne aufgefasst wissen. 


\section{Die Korallenriffe an der samoanischen Küste.}

Ehe ich in die Beschreibung der samoanischen Riffe eintrete, möchte ich kurz die versehiedenen Riffarten scizziren, damit eiu Missverständniss betreff's der Benennuug ausgeschlossen wird. Es lassen sich im Allgemeinen 5 Riffarten unterscheiden, welche natürlicherweise mehr oder weniger in einander übergehen können. Dies wird durch die weiter unten zu erörternden Entstehungsbedingungen begründet.

\section{Morphologie der Riffe.}

a. Korallenbank, bei den Engländern pateh oder shoal, Kegelriff, bei Walther "pelagisches Riff" genannt, bei Ortmann "Flachseeriff", ist ein isolirter Korallenfelsen, oft nur wenige Fuss im Durchmesser haltend, säulenförmig, welcher im stillen Hafenwasser meist nur da gedeiht, wo eine grössere Riffanlage wegen der Sandabfuhr der Strandriffe unmöglich ist. Baumförmig emporwachsend und sich ausbreitend, nach oben zusammenstossend und verklebend, sind diese im Allgemeinen die Bildner jeglicher Riffanlage (siehe Keller's Ansichten beim Capitel Heliotropismus.) In See kann eine kleine Bank die Oberfläche nie erreichen; sie bleibt daselbst stets mindestens $2 \mathrm{~m}$ unter derselben. Im Hafen kommt sie bei mittel Niedrigwasser nur dann zur Luft, wenn sie noch von geringer Dünung bespült wird. Grössere Bänke und Schuttflächen können, wenn im Sehutz der Küste gelegen, als Barrieren aufgefasst werden, in offener See sind sie als kleine unvollkommene, versandete Atolle zu betrachten. Hafenbänke sind an zahlreichen Orten bemerkt und beschrieben worden. So schreibt Heilprin über die Riffe im kalifornisehen Meerbusen bei Vera Cruz (p. 41b, 312): „Die Riffe gehöreu offenbar zu jener Gruppe, welche Darwin erkannte als aufgebaut auf Haufen oder Botten ron Sedimenten ", ,liegend ein wenig unter der Oberflïche und geeignet als Basis für Korallenwachsthum zu dienen" "Struct and distribut. of c. r. p. 58), eine Classe ron Riffen, welche die Gegner der Darwin'schen Theorie als im Widerspruch mit dieser stehend, ausgeben. Sie sind gemäss einer stricten Classification weder Atolle, Barrieren- noch Strandriffe und mögen als eine vierte Classe, vielleicht mit Vortheil Patch-Riffe benannt werden." 
Darwin sagt ferner in der Introduction vou ilmen: „Riffe kommen anch um submarine Sediment-Bänke und Felsen vor; und andere sind ganz umregelmässig an Orten ausgestreut, wo die See sehr flach ist; diese sind in den meisten Fällen den Strandriften zugehörig, aber sind von geringem Interesse."

Beispiele im Apiahafen, namentlich östlich bei Matautu, vor allem auch im Saluafata-Hafen, in der Riffpassage beim Orte Saluafata.

b. Das Saumriff. Typisch tritt das Saumriff in Häfen resp. Buchten mit Steilküste auf. Es ist daselbst nur wenige Meter breit, spriugt balkonartig rom felsigen Ufer aus ror und säumt in dieser Weise solche Häfen ein. Betreffs des zu Lufttretens gilt dasselbe wie hei der Korallenbank. Je stiller das Hafenwasser oder je mehr der Brandung ausgesetzt, so weniger tritt es zur Luft. Auch hier ist eine leichte Dünung die Bedingung dafür. Im Innersten des Hafens pflegt das Sammriff ganz auszusetzen oder wenigstens in Bänke aufgelöst zu sein. Gegen See zu entschwindet der Rand allmälig den Blicken, indem das Riff der Brandung halber gleich den Korallenbänken nur in Tiefe von einigen Metern unter der Oberfläche zu gedeihen vermag. Das Saumiff stimmt im Bau genau mit der Leeseite der Strandriffe ïberein, ror allem betreffs des steilen Abfalls, der Beschaffenheit der Leekante und des Mangels der Plattform und des Schuttkegels.

Beispiele im Hafen von Fangaloa und Pango-Pango.

c. Das Straniriff. Eringing reef, shore reef, auch Küstemriff genannt, ist ein Korallenriff, welches im Laufe seiner Entstehung einen secundären Strand gebildet hat und auf diesen gestützt seinen Aufbau bewirlite. Bedingung für die Bildung eines Strandriffes ist eine Küste mit geringem Giefäll und einigermaassen gleichmässigem Abfall. Je nach der Beschaffenheit der Küste kam ein Saumriff, ein Strandriff oder ein Barrierenriff sich ausbilden; das typische Strandriff ist für sich allein charakterisirt durch die Bildung eines Sandstrandes, vou dem aus man zu Fuss bei Niedrigwasser bis zur Riffkante wandern kann, ohne viel über die Ḱnie in das Wasser zu gerathen. Desshalb sollte der Name, ,Strandriff" hierfür beibehalten werden. Wie schon erwähnt, zeigt die Leeseite, welche meist hafeubildend wirkt, und die Lurseite, welche dem offenen Meere zu liegt, bestimmte Interschiede, deren Besprechung beim "Aufbau" erfolgen wird. Das grosse Aanariff, die Riffe von Matautu und von Saluafata sind die classischen Strandriffe an der Nordküste Upolus. Sie erreichen in Samoa die grösste ununterlrochene Flächenausdehmung unter den Riffformen.

d. Das Barrierenriff, barrier-reef, auch Dammriff und Caualriff genannt, ist gewöhnlich eine Combination von einer Barriere und einem Strandoder Saumriff, welche ron einander durch einen tipfen Canal getrennt sind. Je nachdem die Barriere auf einer Seite mit dem Strandriff zusammentängt oder vollständig isolirt ist, kann man peninsulare oder insulare Barriere unterscheiden. Bedingung für die Entstehung der Barriere ist der Schutz der Küste, also las nur einseitige Einwirken der Brandung. In Rücken der Barriere muss Stillwasser sein. In Samoa sind von insularen Barrieren nur kleine vorhanden, z. B. bei Táalele, bei Salnafata, Falealili und Safata. Die submarinen Barrieremriffe 'Tutuilas bedïrfen einer besonderen Besprechung. Es ist oft schwer, zwischen Barriere und Korallenbank zu unterscheiden, ebenso wie es oft schwierig ist zu 
sagen. was noch ein Felsenriff uni was eine Insel ist. Der Lniergrund für Barrierenrifte mird lurch Bodenschmellen geliefert. Welche den hüsien rorgelagert sind und eine der siirke der see fropmrtonale Breite baben mussen. Die Barrieren sind in gewissem sinne nurollsaäniere dtulle. sectoren run iiesen.

e) Die tiolle, Kran\%rifte. acills. encircling reefs, lagoon-islands. sin lie eigenartigsien Gceanbiliungen. Welche am meisten iazu heigetragen bahen, aie

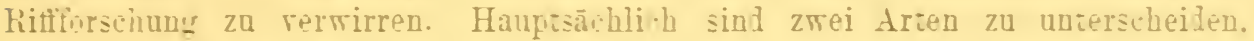
welihe nicht allein topgraphish. sonjern auch genecisch übereinstimmen, tietlagunige un! Alachlagunige. Wäbreud nämlich leszere aut submarinen Berskuppen entstehen uni lesshalb die Lagune. je nach irisse uni Tntergrunl. mair oler meniger rersaniet. Kōnnen letzere nur auf submarinen hratern entstanien sein. Jeren specifisebe Entsiehung zu erörtern bleib. Kleinere diolle honnen rollstănhig greschlossen sein. grüssere rühren immer minlestens eine Cnterbrechuns. Auch die Beschatenhei: ier Lagune zeig noch weitere Cntershiele. indem dis-

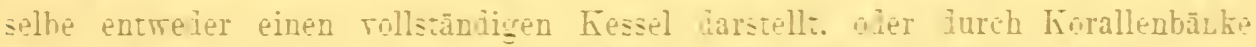

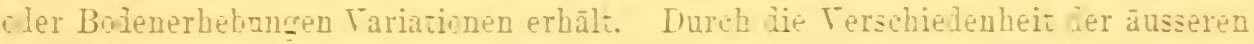

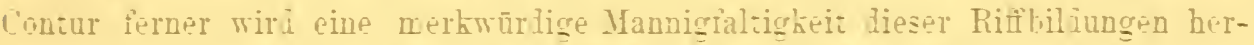
vorgerufen. Welche nur iurch lie Teknnik ies Catergrunies erklär merien hann. Diese Tehonik. dio Iocale Budenbescutenbei. lie feriolis he Tersanlung uni sandabfulu sin 1 ile massgebenien Facoren für lie Gesaltung uni Erhalmug der Rifitormen.

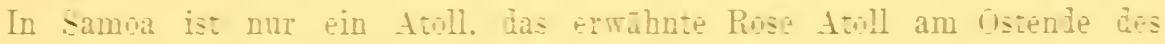
Archiriels.

Ein Atnl. Jessen Lagme allnälig ron oben ber zun absi und ladurch in 3 Theile getheile is:. ist las Valmrra-tioll $1 \hbar^{\circ} \mathrm{N}$. B., 1211: T. L.). ein Zeichen Gafür. Gass ausgiehiges horallenmicsthum auch in her Lagune ron dtollen siatifinden kann.

\section{Oertliche Vertheilung.}

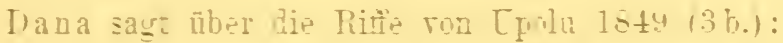

..Lie Inst [pwlu is: rou einem Riti begrenzt. nabezu 1 Meile breit. an

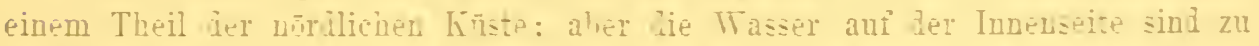

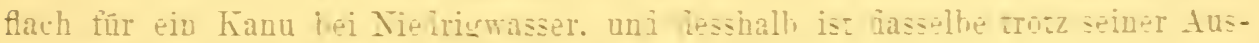
dehnung eher ein siraul- als ein Bairiereniti.."

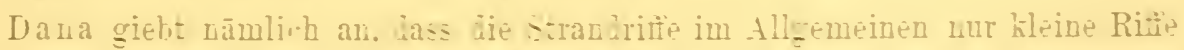

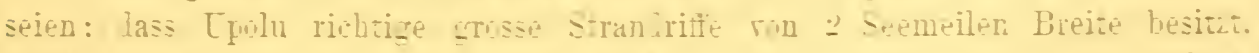

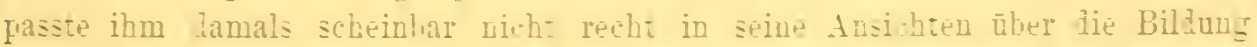

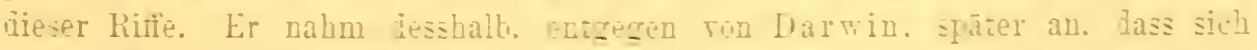
strandritie auch in sinhenjem lebiet lilium kinntin.

$$
\text { (a) }=\text { a } r \text { a i }{ }^{c} \mathrm{i} \text {. }
$$

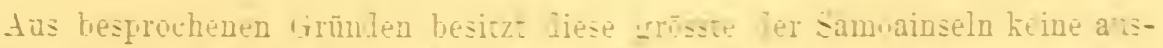

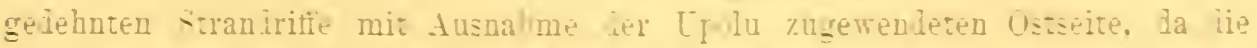
Apolimasirasse nur eime rerhälinissmásig freribe Einsentung zwischen beilen 
Inseln bildet. Desshalb senden beide Inseln Kiorallenriffe in dieser Richtung vor. Das Savai'i zugehörige Strandriff besitzt eine Länge von ungefähr 12 Seemeilen, bei Puapua beginnend und beim Tofuacap endend. Bei Sapapalii, ungefïhr halbwegs, befindet sich der Hauptriff-Einlass, welcher den Kïustenschonern einen guten Ankerplatz gewährt, bei Amoa und Iva sind kleinere Bootpassagen. Dieses ausgedehnte Strandriff liegt dem fruchtbaren und wichtigsten Bezirk Savai'i's vor, Facasaleleanga genannt, der Heimath der Malietoafamilie.

Die Nord-, West- und Sïdküste entbehrt der Riffe nahezu ganz. Nur an einzelnen Plätzen, z. B. bei Matautu, Safune, Asaua im Norden, Gangamalae im Westen und in der schlammigen Bucht von Palauli im Sülen kommen beschränkte Riffbildungen vor. Die zwischen Savaici und Upolu gelegene Kraterinsel Apolima wurde gleichfalls schon oben besprochen, wie Manono.

b) Upolu.

Die Nordseite des westlichen Upolu besitzt die grössten Riffanlagen. Hier ist es insbesondere das grosse Strandriff voll Aana, welches sich von Manono bis Apia in nahezu ununterbrochener Linie über 25 Seemeilen hinzieht und bei Afenga eine Breite von 2 Seemeilen erreicht, während an der Südküste dasselbe Riff bald durch die Steilküste von Falelatai einen Abschluss erfährt. Kleinere Einschnitte finden sich am Nordrande nur bei Malua und Faleula, eine etwas grössere bei Vaitele, welche indessen nicht unterbrechend wirkt. Die der See zu gelegenen zahlreichen Untiefen zeigen deutlich, dass das Land auch unter dem Meeresspiegel hier nur sehr langsam abfällt.

Mit der Veränderung der Landschaft bei Apia verändert sich auch die Gleichmässigkeit des Riffes. Zahlreiche Einschnitte durchbrechen die Strandriffe, streckenweise fehlt die Riffbildung ganz, wo nämlich die Küstenberge an den Strand herantreten. Wo sich aber eine Niederung zeigt, sieht man auch wieder ein Strandriff vorgelagert. Diese Abwechslung endet jedoch gänzlich bei Falefā, von wo ab fernerhin die See den Fuss des schroffen Gebirges unmittelbar bespült. Erst das sanfter abfallende Ostende der Insel wird wieder von einem grösseren Strandriff umschlossen, das die Inseln Fanuatapu und Namua theilweise in sich einschliesst.

Um den Wechsel der Landschaft und der Riffe und die Uebereinstimmung beider genauer zu verfolgen, bitte ich einen Spaziergang mit mir von Apia aus nach Osten zu machen. Ehe wir indess diesen Weg antreten, wollen wir erst dem Apiahafen selbst eine kurze Betrachtung widmen, welcher, da er so gut vermessen ist, besondere Beachtung verdient. (S. Karte.)

Es bildet dieser Hafen ein nach Norden offenes Hufeisen. Mit einer längeren westlichen Seite, der Halbinsel Mulinu'u, welche von dem Ausläufer des hier endenden Aanariffes noch umschlungen wird, und einer kürzeren östlichen, der "Vorspringenden Landspitze" Matautu (in samoanischer Uebersetzung und Nomenclatur). Auch die Ostseite wird von einem Riff umschlossen, das im Innern des Hafens endet, zwischen den beiden Rillendigungen liegt in dem innersten Hafen noch ein drittes Ritf, las Mittelriff, auf welchem das Wrack des "Aller" weit- 
hin sichthar in seinem lisengeriple liegt. Dieses Mittehill schaut mit seinel Stirn direct anf die oflene See hinans und bietet ror sich einen Hafenlitum rou ungefïhr 400 m im Geviert (ausserhalh der 10 m Grenze). Auf diesen Raum waren die 7 Kriegssehitio im Sturn des Mäı\% 1889 \%usammengepfercht, der ummittelharen (iewalt des Windes und der See ans Norlen preisgegreben.

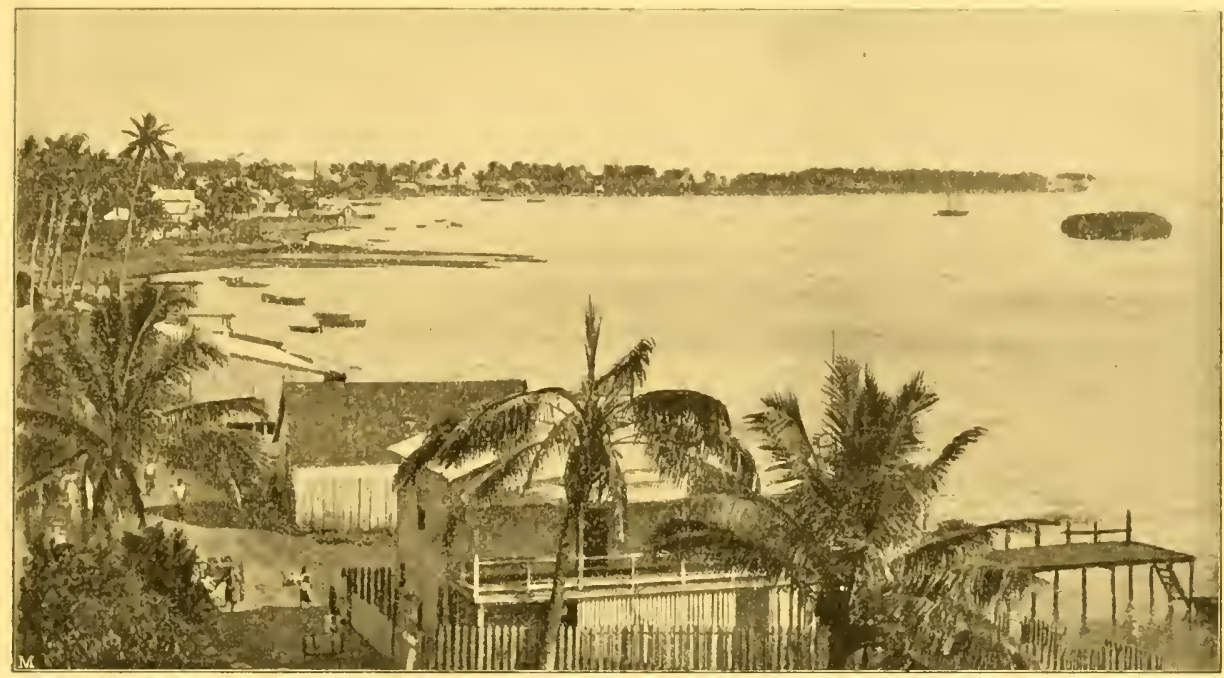

Matafele Mulivai

Apia

Mulinuu

Davis phot.

Apiahafen mit Adlerwrack rom Ort Apia aus gesehen gegen $\mathrm{X} . \mathrm{W}$.

Zwischen dem Ostriff (bei Matautu) und dem Mittelriff bleibt eine $600 \mathrm{~m}$ lange Strecke offen, inmitten derer der Vaisinganofluss zur Regenzeit seine braunen Wasser ergiesst. Diese Strecke zeigt nur spärlichen Korallenwuchs, südlich nahezu gar keinen, nördlich gegen das Ostriff hin einzelne „Bänke“. Ein offener Sandstrand charakterisirt diese Strecke. Südlich von dieser Strecke, im Grunde des Hufeisens liegt der Ort Apia, welcher dem ganzen Hafen seinen Namen giebt Hier ist die Bootsanlegestelle der Kriegsschiffe. Das Mittelriff beginnt hier, erst aus zahlreichen „Bänken" bestehend, aber gegen Osten zu einem Riff'rand sich festigend, je mehr die einlanfende See auf das Riff zur Wirknng knommt. Diese ist selten stark, sodass das ganze Riff, mit Ausnahme vielleicht des westlichsten und meist vorspringenden Punktes, des im Seemannsmunde sogenaunten Cap Horn, den Charakter der Leeriffkante trägt. Mitten anf dieses Riff müudet das Flüsschen Mulivai und der Mündung direct nach Norden vorgelagert, las Deck gegen Land gekehrt, liegt das Adlerwack. Zwischen dem Mittelriff und dem Westrift (Mulinu u) bleibt ein 300 in breiter Canal often, kurzweg Bootshafon genannt, da in demselben die Handelsschooner der Deutschen Handels- und Plautagengesellschaft zu ankern pflegen. Gegen das Westrift, nach Norlen zu, siud auch hier zahlreiche . Korallenbänke", zwischen denen der Sanl lagert, welcher hierher ron diesem Riff durch den Ebbestrom getragen wird unl zur Ablagerung kommt. Desshalb 
ist der eigentliche Bootshafen nur ca. $200 \mathrm{~m}$ breit. Die Gezeitenströme pflegen sich iun Apiahafen für gewöhulich nicht unangenehm geltend zu macheu; nur bei stärkerem Wind und Seegang pflegt zur Zeit der Ebbe am Strande des Mittelriffes ein Strom von Westen nach Osten zu setzen, sodass das Anlegen der Boote bei Apia mühsam wird, indem dieselben kaun gegen den Strom anzupullen vermögen. Dieser Stron war es auch, welcher den Lenten von der "Vandalia“ im Orkan so verlerblich wurde. Die Entstehung dieses Stromes erklärt sich leicht, wenn man die Karte des Apiahafens betrachtet und die Abflussrerhältnisse der Riffe berücksichtigt.

Einiger weniger Worte bedarf noch die Halbinsel Mulinu'n: Parallel dem Riffrande verlanfend und der directen senkrechten Wirkung des Passates ansgesetzt, ist sie mit grosser Wahrscheinlichkeit ein Erzengniss dieses Windes, indem wenigstens ein Theil von ihr ähnlich einer Atollinsel entstanden ist. Die Rücklehne dieser Halbinsel bildet ein grosser Mangrovesumpf, welcher indessen, da er keine Malariaplasmodien zu beherbergen scheint, nur ästethische Nachtheile besitzt. Früher war Mulinu'u mehr weniger eine Insel. So war die Stelle, wo heute die Gebäude der Gesellschaft stehen, ein Sumpf, mud wurde dieser zum Zwecke des Baues zugeschüttet. Mulinu'n, der vielumstrittene Sitz des Königs, verkörperte eiust die deutsche Seite im Gegensatz zum englisch-amerikanischen Matautu. Vou dem vorspringenden Mulinu'u aus geniesst man einen herrichen Ausblick anf die Bergwälder und die luftigen Höhen, besonders schön im letzten Glanz der sinkenden Somne.

Auch das Ostritl bedarf noch einer Frwähnung: denn einige $100 \mathrm{~m}$ gera le nordwärts von der Matantulandspitze befindet sich mitten in Riff eine kiusenkung, welche als kiffhucht aufufissen ist, die sogenannte Lelepabucht, indem sie mit dem oftenen Ocean in freier Terbindung steht. Fine 13 m tiefe Stelle, das Palolotief, vereinigt Ente October oder Anfang November im Morgengranen die Palolophilen Samoaner, um dem Fange dieses schwärmenten Borstenwurmes zu huldigen, rovon noch weiter unten die Rede sein wird.

Wemn man an der Landspitze in Matantu steht, so sieht man gegen Osten hin ein weites Strandriff sich ansdehnen; weit draussen die weisse Brandungslinie als Grenze gegen das blane Meer. gerade vor sich einen von Palmen beschatteten, bilderreichen Strand und im Hintergrunde den Küstenberg von Laulii. Man durchwanlert die Ortschalten Matiutu mit dem englischen Lonsulatshans, Silopo, Lelepa, Vaiala, wo das sternfunkelnile Banner weht und gelangt nach einer ${ }^{1}$ Stunde nach dem Orte Fuisa'a, wo ein Fluss eimmïndet, den man ant' einem liümmerlichen Fusssteg überschreitet. Nach einem kleinen Landflecken Taumeasina gelangt man an die Vailoaflusslagune, welche man watend durchschreitet. Unmittelhar darauf gelangt man in die Dörfer von Matafangatele uni kurz darauf in die Bucht von Fangalii, in welche zwei kleine Flüsse münten. Das Riff, ras man stets weit draussen mitlaufen sah, springt hier jüh zurück, indem es einen 10-20 $n$ tiefen Einlass hildet. An der Osthante dieses Einlasses sieht man einen Stein wohl 2 m hoch über das Wasser herausragen und einen zweiten etwas kleineren mehr in der Tiefe des Einschnittes. Schwarz wie Basalt ans- 
sehend, erweisen sich tie beiden hei näherer Betrachtung ans Korallenkalk bestehend und sind wohl durch Stürme losgerissene hiflstücke der Leekante.

Wenn man in einer halhen Stunde die Bucht umschritten hat, welche als das bude zweier Flussthäler (des Vaivase- und Fangaliiflusses) zu betrachten ist, golangt man um einen 5-10 m hoheu Hügcl herum, welcher nahe au das Ufer herantritt, in das Dorf Tailele, anf schmaler Niedermng, dem im Hintergrunde steigt das hand rasch zu einer $10 \mathrm{~m}$ hohen Hochehene (Pllanzung Vrailele) an. Das Riff ist wieder in's Meer hinausgeeilt. Nach Passiren des Dorfes gelangt man um ein steiles Calp herum, Sunga genannt, wo die Gebäule der l’flanzung Tailele liegren. in ein hühsches Flussthal, in welchem am Fusse des zweiten Küstenberges las Dorf Letongo liegt. Das kiff ist wieder jüh zurückgeeilt. In dem freien Wasser sicht man eine isolirte kleine Barriere, wclche der Iruth der

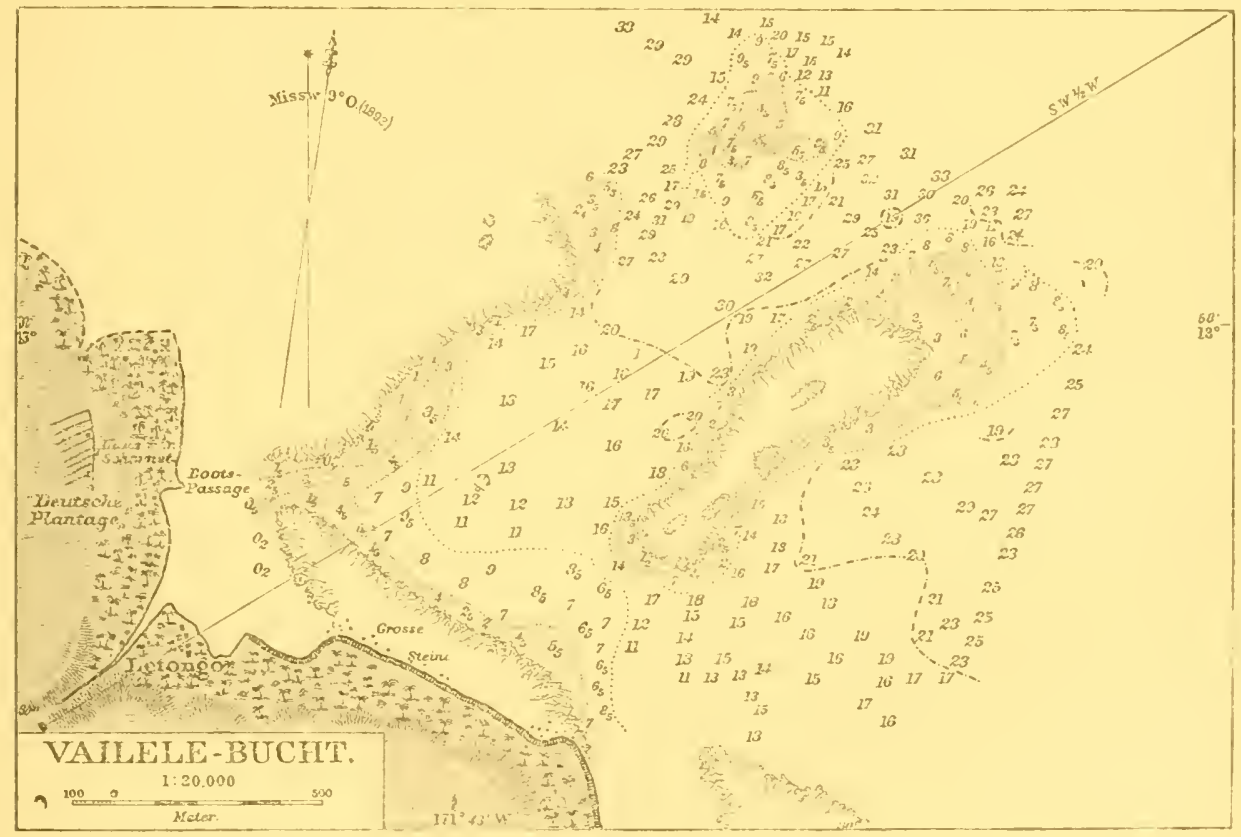

Isolirte Barricre bei Vailele.

Brandung erfolgrnich trotzt, und an der Nordostseite des Riftes eine Bank, welche in den letzten Jahren gewachsen zu sein seheint.

Die gauze Lagune hier ist ein grosses Sundfeld, welches liei Ebbe den englischen Officieren Gelegenheit bot, das Reiterpolospiel zu betreiben.

In der Ferne im Osten ragt Uer einzelstehende Ltumaufels aus dem Wasser hervor, der Auslïufor des dritten Kü̈stenberges von Luatuan'u.

lis gilt jetzt den zweiten Küstenberg zu umgehen. Bis zur Iandspitze bietet der Berg noch einem Sandstrande Plat\%. Ein schmales Riff läuft mit. das allmälig mit diesen an der felsigen Landspitze endet. Hier hört das lielren am Iffer auf. Man steht ant dem Fuss eines Lavastromes. Welchen die nuanfhörliche Brandung blossgelegt und zurückgeulnängt lat. Der weitere Weg ist wïhrend einer Viertelstunde recht beschwerlich, aber schön. Stetig geht es auf 
und nieder über haushobe schwarze Lavafelsen. Von ler Höhe sieht man hinunter durch das Grün in kleine Schluchten und Höhlen, in welche die Brandung sich mit Getose stürzt, weil die Steilheit der Ufer einem Küstenrifie keinen Platz zu bieten vermochte. Unten aber wandelt man unter den hohen, immergrünen Barringtonien (futu) mit ibren grossen, weissen, magnolienartigen Blüthen, inmitten derer ein Büschel rothbespitzter, langer Staubfäden prangt; der Boden ist bedeckt von den weissen Blüthen und den vierkanten, faustgrossen Früchten. Wieder hinauf und wieder hinab in die lieblichen Schluchten, wobei die Hand dem ungeschickten Gleitfuss (se'evae) des Fremden oft zu Hilfe kommen muss, bis man plötzlich in eine liebliche Bucht gelangt, im Hintergrunde von nahen Höhen begrenzt, am Strande die Dorfschaft Lanli i. Auf den steilen Sandstrand rollen unaufhörlich die Seen, ein Zeichen, dass kein Riff hier vorgelagert ist. Ein kleiner Wasserlauf, genährt durch eine Brackwasserlagune im Hintergrunde, verliert sich im Sande des Ufers. Wir eilen weiter. An der östlichon flachen Landspitze der Bucht beginnt das Riff wieder und zieht sich als schmales Strandriff (höchstens $300 \mathrm{~m}$ breit) entsprechend dem mässig steilen Ufer über $4 \mathrm{~km}$ weit bis zum Utumaufels hin, wo es plötzlich wieder aufhört. Einmal erfährt es auf diesem Wege nur eine kleine Einbuchtung, da nämlich, wo das schroffe Felsenthal ausmündete, welches die Grenzscheide zwischen Tuamasauga und Atua bildet. Hier auf den beiden Höhen am Meere pflegen sich die feindlichen Samoaparteien monatelang gegenüberzuliegen und nur selten wagt es die eine, die andere anzugreifen.

Wir sind am dritten Küstenberge, dem von Luatuanu'u (des am Fusse gelegenen Dorfes) angekommen, mit dem vorliegenden Utumaufels. $12 \mathrm{~km}$ sind wir von Apia entfernt und sind nun halbwegs etwa in unserem Spaziergang nach Falefā.

Die Wegverhältnisse sind ähnlich wie beim Lauli'iberg: vor der Landspitze guter Weg am Sandstrand und dieser mit dem Riff sich bis zur Landspitze verringernd, jenseits aufgeschlossene, zerschlissene Lavafelsen. Während jedoch dort alles von Vegetation bedeckt ist, ist hier der Fels nackt und die Felsen sind bis zum schroffen Abhange so zerfressen, unterwaschen und durchlöchert, dass sie bei stürmischem Wetter und Fluth nicht passirbar sind. Dies jedoch nur auf einer Strecke von ungefähr einem $\mathrm{km}$. Man gelangt alsdann an eine kleinere Landspitze, die westliche Grenze der $3 \mathrm{~km}$ breiten, offenen Bucht von Solosolo.

Zunächst fesselt unser Auge, wenn wir an den Strand heruntersteigen, ein wunderbares Bild: ein blendendweisser, wenige Meter breiter Strand, landwärts von frischem Grïn, seewärts rom blanen Meere begrenzt. Man sieht kein Korallenriff und doch gewahrt man bei näherer Betrachtung, dass dieser Strand aus reinen, grossen Stiicken von geschliffenen Korallenstücken besteht, welche ihre ursprüngliche Form nur noch schwach orkennen lassen. Da sieht man fingerähnliche Madreporenstücke, Kugeln und Scheiben aus Porites und Astraeen, kurz, alle Variationen durch die aufrollende See gemahlen und von der Sonne gebleicht. Man wird nicht satt, all' dio Formen zu betrachten, mit zahllosen Muscheln untermengt, welche den $2-3$ m breiten Strand bis zum Rande des Grünen bedecken. Geht man weiter, so hört dies nach wenigen Minuten auf. 
Die Höhen treten zurück mul man gelangt in eine deltantige, flache Nielermug; alsbald begimnt auch ein kleines korallenriff dem Strante sich vor"mlegen und zwar gerade an der Stelle, wo ein kleiner Fluss ausmindet, der seinem zerrissenen ansgewühlten Bette nach zu schliessen in der Regenzeit oft viel Wasser führen muss. Das kleine Strandriff ist ungeführ $800 \mathrm{~m}$ lang und erreicht vor der Mündung seine grösste Breite von $100 \mathrm{~m}$. Weitere $100 \mathrm{~m}$ in die Bucht hinaus ist eine Tiefe von $12 \mathrm{~m}$ notirt.

Nach Ueberschreitung des Flusses, welcher mir in angenehmer Erinnerung ist, da ich dort beim erfrischenden Bade zur heissen Nachmittagszeit eines der hübschesten samoanischen Mälchen kennen lernte, Fusi aus Solosolo, die meinem Begleiter so sehr gefiel, - verschwindet das Riff alsbald wieder. Die Höhen treten wieder näher zmu Ufer heran, indessen noch genug Platz für einige Hütten und Bananenpflanzungen lasseml. Aber der Koralleustrand erscheint nicht wieder;

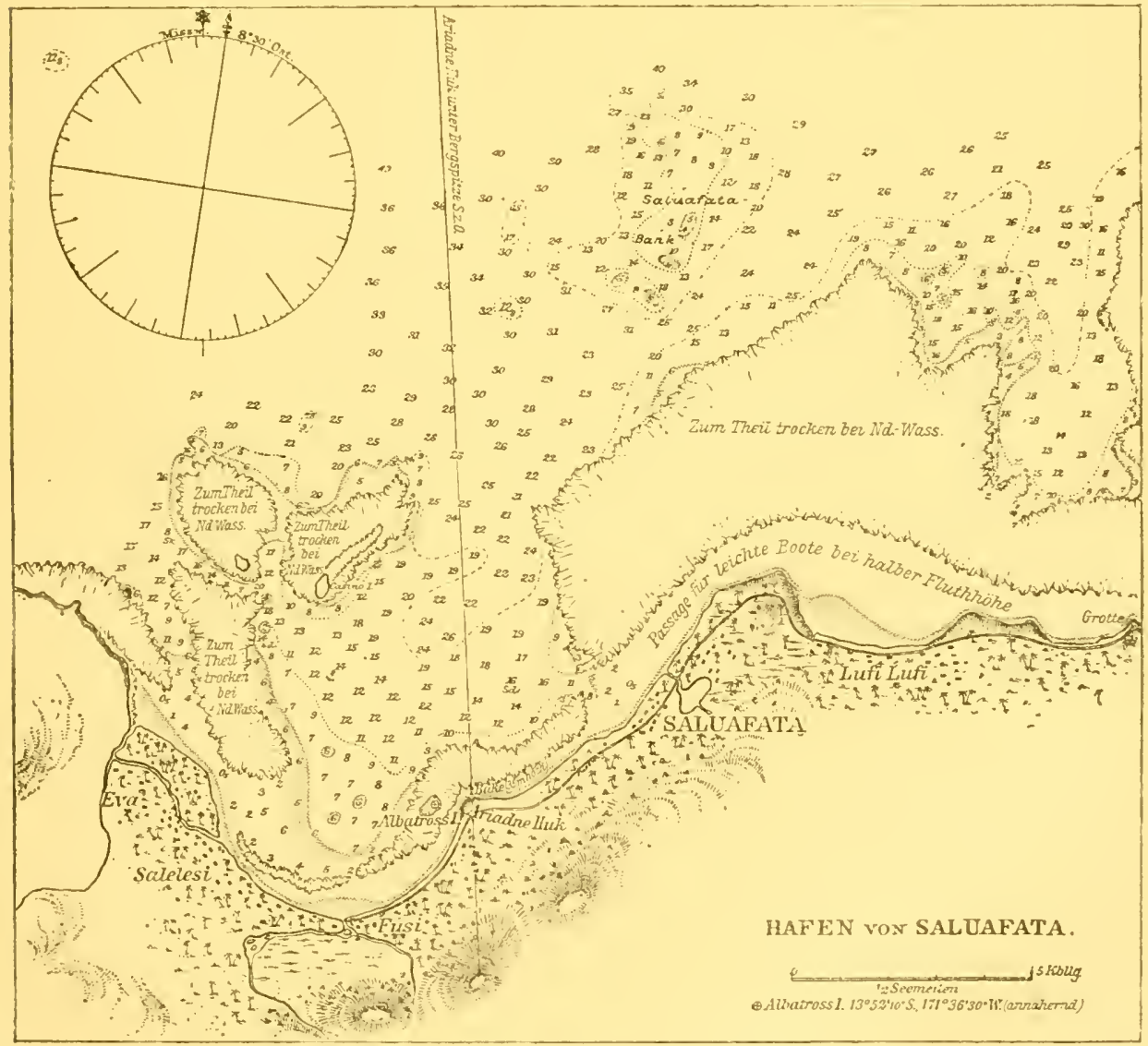

eine schwarze, weiche Masse tritt an seine Stelle, welche sich bei näherer Betrachtung als Basaltsand mit Olivincrystallen gemischt, zu erkennen giebt. Im nahen Osten der Bucht sieht man auch mehrere flache Larafelsen dem Wasser entragen, ein Anzeichen, wie der Untergrund hier im Wasser beschaflen ist.

Wenn man das an der vorspringenden Landecke hübsch gelegene grosse Dorf Solosolo passirt hat, gelangt man an den 4. Küstenberg, muss jedoch zuror einen 
kleinen Flusslanf passiren mit einer rückständigen Lagune wie bei Laulii. Auch dieser kleine Wasserarm ergiesst sich auf eiu schr schmales Strandriff, welches wieder - zum drittemmale - bis zum Cap des Küstenherges mitläuft, um dort zu endigen. Aher es bietet sich hier etwas neues. Dem Cap vorgelagert seben wir drei isolirte Korallenbänke, von denen die beiden seewärts gelegenen, offenbar einzeln entstanden, nahezu verschmolyen sind und eine wirkliche Barriere bilden. Auf jeder der beiden äusseren ist ein grosser Schuttkegel, über einen Meter hoch die Trümmerflüche überragend, aher von keiner grossen Ausdehnung (s. u. Abb. Karte S. 45). Die dritte Bank liegt im Schutz von diesen beiden, und ist dureh einen tiefen, aber sehr schmalen Canal (theilweise nur 2-3 m breit) von diesen getrennt, gegen Land zu durch eine flache Brücke mit dem Strandrift verbundeu. Es ist uicht abzusehen, wann und ob überhaupt der erstgenannte Barrieren-Canal überbrückt werden wird. Unter der Brüeke wird alsdann eine grosse Höhle bleiben*).

Wir sind im lieblichen Hafen von Salnafata angekommen, welcher einst als dentscher Vertragshafen gesichert wurde.

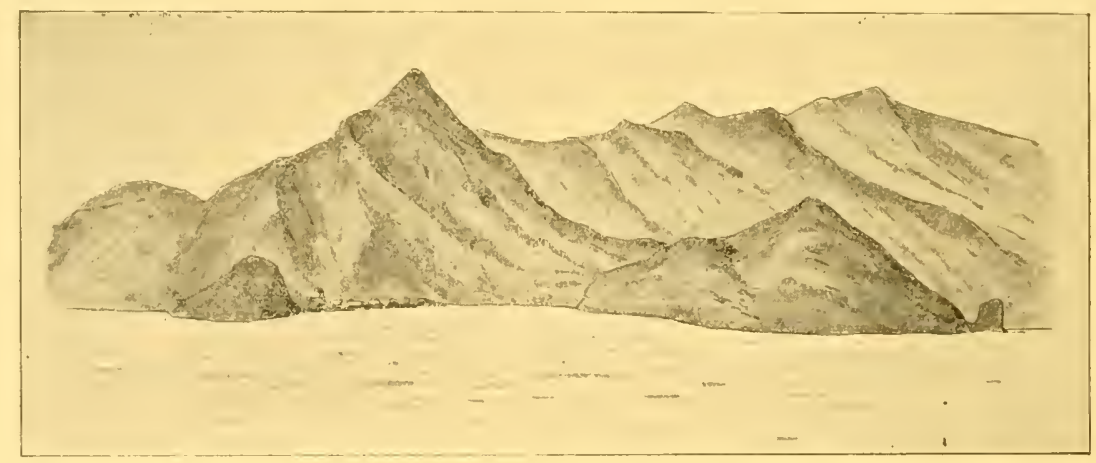

Saluafita-Bucht Dorf Solosolo

4. Kiistenberg sialuafate-Pik

Scizze der Kiiste bei Solosolo.
3. Küstenlerg von Luatuanum

Utumatufels

Die genanute Barriere bildet den Westschutz des Hafens, ein kleines Mittelriff ist wie heim Apiahafen auch hier vorhanden und im Osten legt sich das grosse Atuarift schützend vor das Land; diese Riffe schliessen sich so eng zusammen, dass sie nahezn einen Kreis bilden mit einer nur 300 m breiten Einfahrt gegeu NNO., welche durch Vorlagerung der Saluafata-Bank auch gewisser-

*) Langenbeck schreibt ron diesen Barricren in scinem Buche (42 Seite 70): „Die von West nach Ost langgestreckte Insel Lpolu lat anf der Siid- und Nordseite Riffe. Vorwiegend sind es auch hier Kiistenriffe, doch treten daneben auch Barricrenriffe auf, so namentlich gegenïber dem Hafen Saluafata, wo das Aussenriff einc ścemeile von der Küste entfernt ist. ein paar kleine linralleninsehn trägrt, die beständig an (irösse zunelumen, und zwisclien sich und rem Lande tiefes Faluwasser freilïst. (A. H. 1A79 S. 329. S. 340. 1883 S. 325.) Anch dieses Riff diirfte wohl nur der Flachlıcit der gegenüherliegenten Kïste seine Entstchung rerdanken." Ws seleeint, dass hier die West- und Ostseite rerwechselt wird: Westwärts ist die Barrice und steiles Land, ostwärts das Strandriff und thaches Land, wie aus der karte herrorgeht. 
massen geschützt ist. Desshalh wird dieser Hafen von den C'ommandanten del' Kriegsschifle in der schlechten Jahreszeit dem Apiahafen vorgezogen. In Westen der Solosoloküstenberg, im Osten ler von Saluafata (der letzte fünfte) und im Hintero'sude der steil aufsteigende, wohl ïber 600 m hohe schroflo SaluafataPik, über und üher nuit grünen Wäldern bedeckt, ist dieser Hafen von grosser landschaftlicher Schönheit.

Wil mmwandern die Bucht auf hübschem Strandpfale, erst ehen durch die Ortschaften Eva, Salelesi und Fusi, wobei zwei Wasserläufe mit rückstälnigen Brackwasser-Lagumen passirt werden müssen, alslam an der Flanke des östlichen Küistenberges langsam ansteigent bis zu einem kleinen Cap, dem driahnehuk. auf welchem einige dentsche Matrosen begraben liegen; der Huk rorgelagert liegt eine kleine Felseninsel, nach S. M. S. ,.Albatross", welches 1885 den Hafen vermessen hat, benanut. Die Insel ist ganz in das Mittelrifl eingeschlossen. Steigt man von der Ariadnehuk wieler noriwärts langsim ab, so gelangt man auf eine freie sanlige Wbene, mit Kokospalmen bestanden, unter denen das Dor't Saluafata ansgestreut liegt, malerisch gruppirt um ciue grosse Brackwasserlagune, welche einigen kleinen Süsswasserquellen ihre Entstehung verdankt. Nach Umgehung des steiuigen Landvorsprungs (der Ostecke der Bucht) gelangen wir an einen 2 m breiten flachen Wasserlauf, nach dessen Durchwatung wir uns im Dorfe Lufilufi befinden, dem Sit\% der regierenden Häuptlinge von Atua. Ein weiter sandiger Platz, der Malae, mit Brotfruchtbämmen bepflanzt, lädt uns zu kurzer Rast ein. Man zeigt uns das grosse blendend weisse Grabdenkmal des einst von dentscher Seite als König eingesetzten Tamasese, welcher hier am 19. April 1892 verlassen starb. Ueber sein Grabdenkmal flogen die englischen und dentschen Granaten im August des Jahres 1894, um die Atuapartei zum Frieden zu zwingen.

Auf das Meer hinausblickend sehen wir das Strandrifl weit sich ausdehnen und ostwärts eine Breite ron $2 \mathrm{~km}$ erreichen. Wenn wir weitergehen, müssen wir indessen einen Hügel ïberschreiten, falls wir es nicht vorziehen, bei Ebbe den beschwerlichen Weg am Strande zurtïckzulegen. Der Hügel scheint ein flacher Auslänfer des Gebirges zu sein, ein Lavastrom, welcher nicht ohne Einfluss auf die Rifibildung geblieben ist, denn ihm gegeü̈ber befindet sich ein scharfer, tiefer Einschnitt in das Strandriff, wie wir diesen Einfluss auch in allen vorhergehenden Fällen gesehen haben. Wo eine Steilküste oder eiu Bero nahe an das Ufer herantritt, pflegt das submarine Gefälle demgemäss grösser zn seiu.

Auf dem Hügel liegt die wesleyanische Missionsstation und an seiner Stirn ostwärts am Rande des Meeres die liebliche Grotte Fatumea; wohl $20 \mathrm{~m}$ lang: und an der Mündung $5 \mathrm{~m}$ breit und $3 \mathrm{~m}$ hoch, entströmt ihr das crystallklare Quellwasser, in dessen küblenden Flnthen schwimmend man die Hitze des Tages vergisst. Ein vorgelagertes Bassin ist dem Meere zu durch Steine abgeschlossen. Dem Zauber dieses Platzes hat auch der vielgereiste, leiler so frïl untergegangene Ehlers nicht zu widerstehen vermocht.

Noch eine halbe Stunde Weges und wir sind am Ziele unserer Wranderung. Wir kommen durch das Dorf Faleapuna mit einer rückständigen grossen Brackwasserlagune, und nach Lmgehung der Landspitze biegen wir nach der Bucht 
von Falefä ein, das wir nach Ceberschreitung eines aus einer grossen Brackwasserlagune stammenden Wasserarmes erreichen. Mit uns läuft das grosse Strandriff, das an der NO.-Kante einen hohen Schuttliegel trägt, in die Bucht hinein, nachdem es eine Gesammtlänge ron nahezu $6 \mathrm{~km}$ erreicht hat. Bei Falefä, dem Heimathorte des auf Jaluit in der Verbannung lebenden Mataafa, mündet der grösste Süsswasserfluss Samoas, $3-4 \mathrm{~m}$ breit, seine reissenden Fluthen über eineu ca. $15 \mathrm{~m}$ hohen senkrechten Felsabsturz direct in einen Meeresarm ergiessend, der bekannte Wasserfall Vaitafa.

Es ist merkwürdig, dass das Ende des Korallenriffes sich gerade vor die Flussmïndung legt, so dass das Fhusswasser, allerdings reichlich mit Seewasser untermischt, nach Osten hin abzufliessen gezwungen wird. Diese Ostseite des Hafens trägt der Steilbeit der Ufer halber nur ein Saumriff. An der Landspitze Naneivi ist es natürlich den Augen entschwunden. Von hier ab beginnt die rifflose Ostseite des Nordufers, denn hier treten überall die steilen Berge direct an das Ufer heran. Nur in den kleinen Buchten und in der Fangaloa-Bucht vermögen kleinere Strandriffe und Sammriffe an die Oberfläche zu treten, bis an dem sanfter abfallenden Ostende Upolus sich wieder ein grösseres Strandriff zu bilden vermag, das, "wie schon erwähnt, die Inseln Fanuatapu und Namua zum Theil mit einschliesst.

Sehen wir nochnals zurück, so haben wir 3 grosse Strandriffe gesehen: 1. das $45 \mathrm{~km}$ lange Aanariff an das Aanagelände sich anlehnend,

2. das $51 \% \mathrm{~km}$ lange Apia-Vaileleriff an die Vailelepflanzung sich anlehnend,

3. das $6 \mathrm{~km}$ lange Atuariff an der Niederung von Saluafata bis Falefā sich anlehnend.

Fünf Küstenberge haben wir auf dieser Strecke gesehen, welche folgende Unterbrechungen in der Rifflinie mit sich brachten:

1. der Apiaberg, die Apiabucht,

2. der Vaileleherg, die Vailelebucht und die von Laulii,

3. der Luatuanu'uberg, die Solosolobucht,

4. der Solosolo- und der Saluafataberg, die Saluafatabueht.

Dieses sind nur die in die Augen springenden Punkte; für die geringeren Veränderungen sind die Karten noch z,u ungenau, um sie nachweisen zu können. Ueberall kann man indessen an Ort und Stelle sehen. wie mit der Tektonik der Tïuste anch die 'Tektonik des Meeresbodens sich ändert, wofür die Korallenriffe die sichtbaren Zengen sind. So kann man aus dem Anblick der Formation der Korallenriffe auf der Karte untrügliche Schlüsse auf die Natur des Küistenlandes riehen.

Nur kurz soll nochider Korallenriffe der Südküste Upolus Erwähnung gethan werden:

lis wurde schon erwähnt, dass mit dem Auftreten der Steilkiiste von Falelatai im Westen Upolus das Riff verschwindet. (Der Ausläufer des Aanariffes nach Süden hin.)

Die folgende flache Bucht von Lefangä wird durch ein Strandriff geschlossen, thas einige Bootspassagen führt. 
Von Lefanga ah beginnt die grosse Safata-libene sich auszudehnen; langsam schiebt sieh ein Strandriff vor, das nach einigen kleineren Unterbrechungen erst durch die grosse Safatabucht, einen grösseren Finschnitt erführt, nachdem das Riff eine Breite von ungeführ $3 \mathrm{~km}$ erreicht hatte. In der Bucht sellsst liegt eine grosse Korallenbank, eine Barriere bildend, welche dieser Bucht einigen Schutz verleiht. Jenseits eilt das Riff wieder in die See hinaus, verjüngt sich allmälig wieder, um mit dem Auftreten einer viederen Steilküste wieder ganz zil verschwinden.

Es kommt die Niederung von Falealili.

Die Riffbildung interessirt nus hier etwas mehr, da dies der einzige Platz in Samoa ist, wo sich eine grössere Barriere ansgebillet hat. Ein grösseres Strandriff hat sich wieder vor die flache Kinste gelegt, welches hei dem Dorfe Yaovai eine starke Unterbrechung erfïhrt. indem hier ein ca. $150 \mathrm{~m}$ breiter Canal dem Lande zu often bleibt. Der Mündung dieses Canales direct gegenüber liegt ein wohl $1 \mathrm{~km}$ langes liiff, isolirt, mit einer hübschen kleinen, cocos-

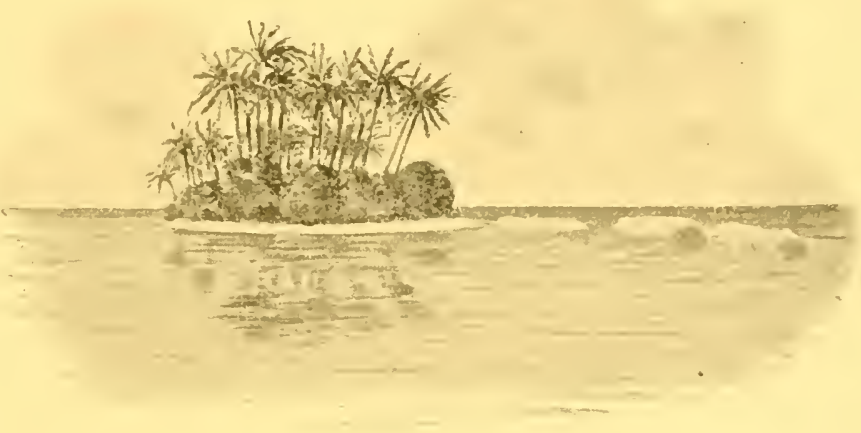

- () le muin sil tée

Die Barriereninsel "() le nu'u sa fee hej Falealili an der Siidkïste ron L polı. bestandenen Insel landwärts, dem bekannten Núu sa fee (dem Dämon des Tintenfisches geweiht) (s. Abbildung). Dieses Barrierenriff ist von dem Strandriff dureh einen mindestens $100 \mathrm{~m}$ breiten Canal getrennt. [Eine Vermessung dieses Platzes hat noch nicht stattgefunden, wesshalb genauere Augahen nicht gemacht werden könuen. S. M. S. „Bussard" hat diesen Canal passirt, die innere Strandriffbucht ihrer relativen Enge halber indessen nicht angelaufen.]

Von Falealili bis zum Cap Tapanga an der Ostspitze sind die Rittbildungen von geringem Umfang und untergeordueter Bedeutung. Doch sind hier auch Strandrifle streckenweise vorhanden, welche die Breite von $1000 \mathrm{~m}$ erreichen dürften, vor allem dem Osten zu.

\section{c) 'Tutuila.}

Gemäss der Steilheit der Kü̈sten fehlen die Korallenrifte an der Nordküste ausser in den kleineren Buchten Aluan, Fungasa, Vatia, Oafonu und der grösseren Masefau nahezu ganz.

An der Südküste ist jedoch ein grösseres Strandrifi" vorhanden, und zwar auf der Strecke vom süllichsten Punkte, dem Sail Rock Point der Karte bis gegen den Eingang des Pango-Pangohafens hin, einer Strecke von mehr als zwei 
Seemeilen (ca. $4 \mathrm{~km}$ ). Die Pango-Pangobucht selbst ist von typischen Saumriffen ansgekleidet.

Hier sind es jedoch die beiden sogenannten versunkenen Korallenriffe, welche Aufmerksamkeit verdienen. Die cine, die 'Taemabank, liegt der Einfahrt von Pango-Pango gegenüber, $1^{1} / 2$ Seemeile von dieser entfernt und durch eine Tiefo von ca. $60 \mathrm{~m}$ getrennt. Ihre Länge scheint $3-4 \mathrm{~km} \mathrm{zu}$ sein, die Breite 200 bis $400 \mathrm{~m}$ und ihre Tiefe 8-12 m. Von der anderen, der Nafanuabank, welche ebenfalls mit dem Lande längs läuft und von Anu'u ihren Ausgang nimmt, scheint sie durch eine Tiefe von über $100 \mathrm{~m}$ getrennt $z$ u sein.

d) Manu'a.

Die Korallenriffe daselbst sind der Steilküste halber nur von untergeordneter Bedeutung. Am NW.-Ende Olosenga's sollen indessen eigenthümliche Riffbildungen vorkommen, die auf Hebung deuten.

Ueber den von Couthouy beschriebenen zu Tage liegenden Korallenkalk s. bei 4 (die Entstehung und Geologie der Samoainseln).

e) Das Rose-Atoll.

Das Atoll bildet nahezu einen Kreis von 21/2 Seemeilen Durchmesser. Der Südostseite, dem Passat zu, befinlet sich eine über $1 \mathrm{~km}$ lange und nahezu ebenso breite Insel und nördlich davon eine Sanddüne. Der Insel gegenüber liegt die Ausflussöffinung des Atolls, welche

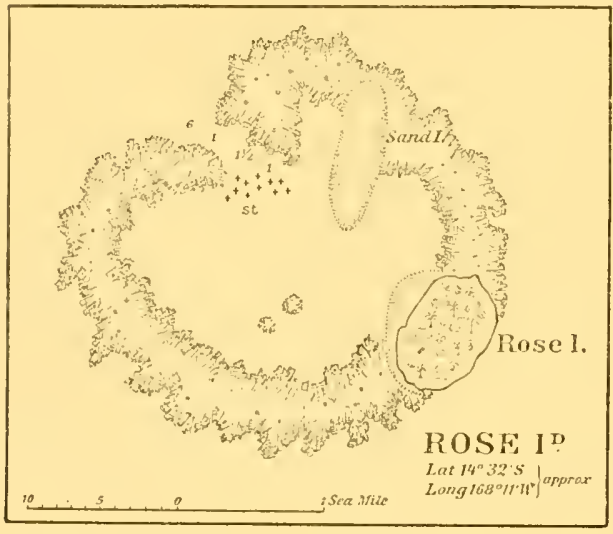
nur 1-2 $\mathrm{m}$ tief sein soll, während die Lagune eine Tiefe bis zu $20 \mathrm{mı}$ zu erreichen scheint. Das Atoll wurde von der Wilkesexpedition besucht, welche auf der Sanddüne zahlreiche Seevögel brütend fand, vor allem Seetölpel (Sula) und Seeschwalben (Sterna). Anch sollen hier die Schildkröten zu gewissen Zeiten ihre Eier ablegen. Auf ler Insel fanden die ersten Besucher einige Pflanzen, Pisonia- und Portulacea-Arten. Der Consul Weber in Apia kaufte die Insel später und wollte hier eine Fischereistation gründen; bei dieser Golegenheit sollen hier Cocospalmen angepflanzt worden sein. Das Unternehmen schlng jedoch fehl - wegen Mangels an Fischen und guten Fischmethoden.

Auf ier Insel liegen verschiedene grosse Basaltblöcke verstreut (3 c p. 317). Ihre Herkunft ist noch dunkel. Dana meint, dass dieselben durch 'Treibhölzer oder als Bootsballast hier zur Ablage gekommen seion. Was ist jedoch näherliegender, als an den Kern dieser Insel zu denken, welcher wie Manu'a aus Basalt bestehen muss?

Auf der Sandlüne sollen Zeichen von Hebung beobachtet worden sein, was ich nur der Vollständigkeit halber anführe.

Leider hatte ich nicht Gelegenheit, die Insel zn sehen. 


\section{Vergleich Samoa's mit den Palauinseln.}

Das Fehleu a usgehilueter l3arrierenriffe a uf Tutuila und Manu'a in der Nithedes Rose-Atollsund die I) ar in'sche Theorie.

Semper (9a) begiunt seinen Aufsat\% ïber die Palauinseln folgendermaassen: "Die nörllichste Spitze der truppe iler Pelewinseln oler Palaos bilden ächte Atolle: lie Hauptmasse, welche ler ganzen ciruppe ihren Namen ïbertragen hat, ist zum grössten 'Theil ron Barrierenriflen, im Süden von Kü̈stenritten umgeben, unl die südlichste Insel ist röllig ohne eigentliches Riff."

Ceber Samoa lässt sich mit ähnlichen Worten sagen:

Die östlichste Spitze der Samoainseln bildet ein ächtes Atoll; die mittlere Gruppe zeigt Anlagen ron Barrierenritien, der Westen Strand-(Küsten-)Rifie; und die westlichste Insel ist nabezu ohne eigentliches Riff.

Nun sind aber doch wichtige Unterschiede, welche die beiden Inselgruppen unterscheiden:

1. Die Samoainseln bestehen vollständig aus basaltiseher Lava. Die Palauinseln im Torden aus Trachyten, die sïdlichen gehobenen Inseln aus Korallenkalk (Peleliu, Eimeliss. Urulong und $\mathrm{Ngaur}$ ).

2. Die Barrierenriffe sind in Samoa nur schwach rertreten, während sie bei den Palauinseln die grosse Hauptmasse ausmachen.

3. Die Barrierenriffe treten im Wesentlichen mit den Barrierenriffen bei den Palauinseln zugleich anf, indem die weitaus grösste in der Mitte gelegene Insel Babelthaub, welche ca. 25 Seemeilen lang ist (so lang ungefübr wie das Aanariff), im Osten theilweise recht breite Strandriffe trägt, währenl im Westen mächtige Barrieren der Küste vorgelagert sind, welche nach Süilen sich über eine gleiche Länge weiter auslehnend, die gehohenen Kalkinseln in sich einschliessen.

4. Die südlichste Insel Ngaur, welche rifflos ist unl auch aus gehobenem Kalk besteht, ist nur nielrig im Verhältniss zur grössten mittleren Insel Babelthanb, wälrend in Samoa die entsprechende rifflose lnsel Sawaíi die grösste und lö̈chste des Aruhipels ist.

5. Die Palauinseln sind alle ron einander dureh verhältnissmässig schmale und wenig tiefe Meerstrassen getrennt, während die Samoainseln mit Ausnahme. von Sawai i und Upolu durch sebr breite und sehr tiefe Meere ron einander geschieden sind.

Es bleibt nun also nicht viel anderes übrig als die Thatsache, dass in beiden Inselgruppen an einem Ende dentliche Hebung und demgemäss Aruuth an Küstenriffen, am anderen Eude Atollbildung und in der Mitte Barrieren- und Straudriflbildung vorhanden ist.

Diss aber die beiden Inselgruppen gerade nur darin, im wichtigsten Punlite, übereinstimmen, erscheint für die Entstehmng der Rif̈̈e der Samoainseln vou besonderer Beleutung.

Es lag natürlicherweise nahe, anch für die Palau-Inseln eine Hebelbewegung anzunehmen. wie ich sie für die Samoainseln als wahrscheinlich bingestellt habe. (Dana nimmt Stillstand im Westen und Senkung im Osten an.) 
Semper ist dieser Ansicht bei der Bespreehung der Palaninseln in seinem bekannten Buehe "Die Existenzbedingungen der Thiere" (9c S. 45) energisch entgegengetreten; er sagt daselbst:

„Man kömnte aber auch versuehen wollen, die Schwierigkeit anf eine andere Veise zu entfernen, indem man nämlieh annähme, es hätte imnerhalb der Inselgruppe der Palaos eine von allen übrigen Sehwankungen des Niveaus im Stillen Ocean unabhängige Hebelbewegung stattgefunden. Fs möchte dabei vielleicht nördlich von Peleliu oder in dieser Insel selbst der Punkt zu suchen sein, von welchem aus nordwärts eine immer stärker werdende Senkung, südwärts cbenso eine immer stärkere Hebung stattgefunden hätte. Dies würde in der That seheinbar erklären, dass Ngaur gar lieine Rifie, Peleliu aber sowohl Küsten- als aueh sehwach, aber deutlich entwickelte Canalriffe aufzuweisen hätte: gleichfalls würde dadurch erklärt sein, warum die Riffe im Norden von diesem Hebelpunkte sich je mehr nach Norden, um so mehr in die Tiefe senken, bis endlich im höchsten Norden nur noeh Atolle oder atollälmliehe Rifle auftreten. Nun will ich absiehtlich kein zu grosses Gewieht daranf legen, dass die Annahme im höchsten Grade unwahrseheinlich ist, es möchte wirklich auf einem so wenig ausgedehnten und ganz isolirt im Ocean liegenden Gebiete, wie es diese Inselgruppe darstellt, ein Ruhepunkt in der Mitte, und nördlich davon eine Senkung, südlich aber eine Hebung stattgefunden haben. Aber selbst diese Möglichkeit zugegeben, so glaube ich doch so zahlreiche Beweise ihrer Unriehtigkeit trotz ihrer theoretischen Möglichkeit in den von mir beobachteten Structurverhältnissen jener Rifle gefunden zu haben, dass die Aufgabe, sie zurückzuweisen nicht gar schwer werden dürfte."

Semper beschreibt nun das Vorkommen ron Globigerinenkalk (Tinoporusfelsen) auf der Atollinsel Krreiangel, spricht von grossen mächtigen Korallenblöcken anf dem Riff, welche dureh die See nicht hinaufgetragen worden sein kömnen, zumal da sie nicht an der Sturmseite lägen, ferner die sanfte Böschung an der Sturmseite im Osten und die steile an der Seeseite im Westen (die uns bei Beschreibung der Entstehung des Fusses der Riffe erklärlich wird), wie den obliterirten Bootscanal, der von den Spaniern um das Jahr 1830 (30 Jahre vor Semper's Besuch) gegraben worden war, lessen Ränder er weit über der Hochwassermarke liegend fand und seine Sohle, sowie die Lagune, zn der er führte, an der tiefsten Stelle nur wenige Fuss tief.

Auch bei dem Cossolatoll führt Semper Gründe an, die gegen eine Senkung sprechen. (Die Hufeisenform von Cossol und Aruangel werde ich weiter unten bei der Entstelıung der Atolle erörtern.)

Sehon erwähnt wurde, dass anf der nur wenige Seemeilen von dem Atoll Cossol entferuten Insel Babelthaub auf einer Streeke südwärts ron über 25 Seemeilen an der Ostkïste zum Theil reeht breite Strandriffe, an der Westküste in gleicher Ausdehnung entsprechend ansgedehnte mäehtige Barrierenbildungen auftreten.

Die geringen Tiefen (höchstens $150 \mathrm{~m}$ ), welche diese Inseln von einander trennen, deuten jedoch besonders im Gegensatze zu Samoa deutlich daranf hin, dass es sieh hier um solehe Senkungen, welehe die Darwin'sehe Theorie für sich in Anspruch nimmt, nieht handeln kann. Semper hat durch Beschreibung. diescr Inseln den ersten und heftigsten Stoss gegen diese Theorie geführt. 
Wem also Senkungen in einen Gebiete, dessen liffrertheilung so sehr an Sámoa erimnert, ausgeschlossen werden dürfen, da im Gegentheil auf beiden Seiten gewichtige Gründe für Hebung sprechen, so ist das für Beurtheilung der liiflbildung in Sanoa ron grosser Wichtigkeit, da man hier annelmen muss, dass dem jetrigen Stillstand bezw. der nachgefolgten Hebnng cine ausgiebige Senkung vorliergegangen ist.

Es möge nochmals kur\% an die Riffreihenfolge in Samoa orinnert sein (von West mach Ost):

Savaici ohne ausgedehnte Riffbildung (bis auf Ostküste)

(West Strandriffe

Upolu Mitte Strandriffe und vereinzelte sehr kleine Barrieren

Ost ohne ausgelehnte Riffbildung (bis auf Strandriff am Ostende)

T'utuila $\left\{\begin{array}{r}\text { ohne ausgedehnte Riff bildung } \\ \text { bis auf } 1 \text { Strandrift an der Süi }\end{array}\right.$

Manu'a ohne ausgedehnte Riffbildung

Roseatoll ein Atoll.

Nun muss ich betrefts Samoa folgende Fragen stellen an die Anlänger Darwin's:

1. Wenn es sich im Osttheil des Archipels um säculare Senkung handelt, warum ist Mauı'a und Tutuila ohne Barrierenriffe?

2. Warum sind nicht wenigstens die submarinen Barrieren Tutuilas an die Oberfläche gelangt, was doch der Fall sein müsste!

3. Gesetzt den Fall, dass diese Barrieren etwas zu rasch gesunken wären, warum befindet sich in unmittelbarer Nähe ein wohlausgebildetes, ausgedehntes Strandriff, das zweifelsohne an der aufgeschlossenen Küiste eines sehr laugen Zeitraumes zur Bildung bedurfte?

t. Zugegeben auch ferner, dass ein Strandriff sich nach Dana in sinkendem Gebiet bilden könnte, warum ist das Westende Tutuilas frei von jeglicher Riffbildung, da doch hier ein submarines Plateau in durchsehnittlich $50 \mathrm{~m}$ Tiefe vorhanden ist, welches erst in 10 Seemeilen Entfernung von der Küiste in die grosse Tiefe von $3300 \mathrm{~m}$ mit einer Böschung von ca. $25^{0}$ abfällt?

5. Warum ferner trägt das Ostende Upolus (Tutuila zugekehrt) ein grosses Strandriff, während an àer Nordseite bis Falefā jegliches Küustenriff fehlt und an der Südseite kleinere Strandriffe streckenweise auftreten, former einige kleine Barrierenriffe?

6. Warum fehlt endlich an der Südscite eine grössere Riftbildung (Barrierenbildung), da doch durchweg Tiefen von ca. $50 \mathrm{~m}$ noch in $1-2$ Seemeilen von der Riffkante bezw. Küste gefunden wurden?

Alle diese Daten sprechen zu dentlich gegen die Annahme einer säcularen Senkung der Samoainseln.

Komnt doch Graeffe selbst, der beim Anhlick der vielen Atolle in der Südsee geneigt war, der Dar win'schen Theorie beizupflichten, betrefl's der Samoainseln zu den Schluss (12 l): 
„Der Umstand, dass die steilen Küsten den Riffgürtel ganz entbehren, zeigt hinreichend, dass auf den Inseln Savai'i und Upolu kein echtes Dammriff ein sinkendes Land umgieht, sondern dass ein franzentes Riff alle Biegungen der äusseren Kante des Landfusses in der für Korallenbildung günstigsten Tiefo folgt."

\section{Die Entstehung eines Strandriffes.}

Eine Erklärung der Entstehung eines Strandriffes schien bislang nicht für nothwendig erachtet worden zu sein (Darwin sagt: With respect to fringing or shore reefs, there is little in their structure, which needs explanation; and their name expresses their comparatively small extension), da die Annahme, dass die Korallenpolypen der Brandung zu oder in derselben am besten gedeihen, so gut wie eine Erklärung ist. Da ich indessen aus den zu erörternden Gründen dieser allgemeinen Annahme auf Grund meiner Untersuchungen nicht beipflichten kann, will ich auch eine solehe Erklärung bringen, wie sie sich mir bei der örtlichen Besichtigung der Riffe anfdrängte. Ich gehe dabei von der alten Erfahrung aus, dass eine See bei flachem Strande sich lange vorher erschöpft, ehe sie den Strand erreicht und dass dieser nur noch leicht bespült wird; die See "rollt sich auf" und verliert dadurch ihre Macht, während sie an der Steilküste als Brandung zertrümmernd und vernichtend wirkt. Jedes Korallenriff bildet gegen die See zu einen zur Stärke der vorherrschenden See oder Dünung proportionalen Abfall, den sogenannten "Fuss" des Riffes, während der Murray-Guppy'sche "Talus" noch weiter seewärts zu suchen ist. Der Fuss besteht aus lebeuden Korallenstöcken, der ,talus" aus abgelagertem Riffsand; der „Fuss" erstreckt sich von der Lur-Riffkante über eine Strecke von $100-200 \mathrm{~m}$ bis zu einer Tiefe von ungefähr $15 \mathrm{~m}$; jenseits dieser 15 m-Grenze liegt der "Talus". Der "Fuss" ist für die Entstehung jeglichen Seeriffes von grundlegender Bedeutung; ohne ihn wäre es der Riffkante nicht möglich, sich bis in die Niedrigwasserlinie zu erheben, weil er sonst durch den Anprall der Brandung vernichtet würde.

Die Schilderung soll vollständig schematisch gehalten sein; Modificationen lassen sich leicht anbringen und einfügen. Die angenommenen Zahlen sollen keine Thatsachen sein, sondern nur zur Erklärung dienen.

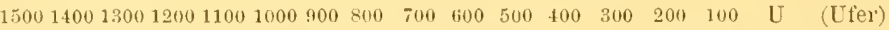

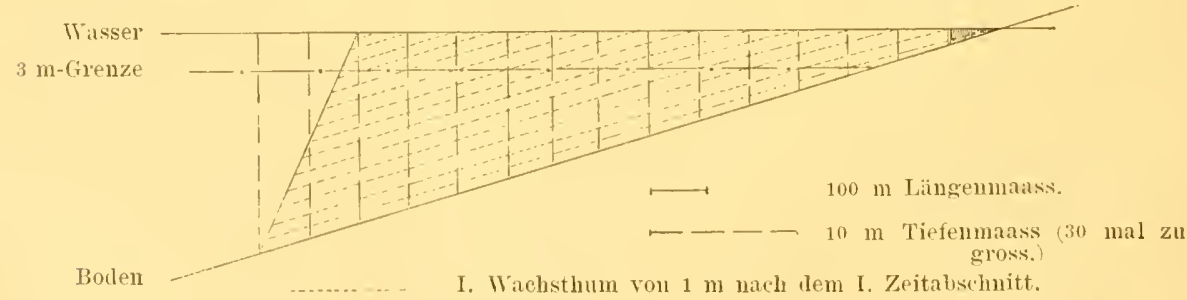

11.

Die Entstehung eines Strandriffs.

Man denke sich ein Gelïnde, welches sanft zum Meer abfüllt mit dem Ciefälle von 1:100 $\mathrm{m}$ und im selben Maasse unter dem Meeresspiegel weiterlaufend. (S. Bild.) 
Vom Ufer (U) aus wïrden in $1500 \mathrm{~m}$ Entfernung $15 \mathrm{~m}$ 'Tiefe erreicht sein, welche als firenze für riffbildende Korallen, wenigstens für deren in die Wagschale fallendes Wachsthum gelten soll.

Der Untergund sei ein Lavastrom, welcher frisch entstanden sein soll und welcher sich allmälig überall mit war\%enförmigen Korallenbänken bedeckt hat.

Es sei angenommen, dass in einem hestimmten, nicht näher zu bezeichnenden \%eitraum dies Korallenwachsthm überall die Höhe von 1 in orreicht hat. (\%eitraum I.)

Ls sei weiter angenommen, dass sich eine mittlere See an einem Felsen zu brechen beginnt, welcher 3 m unter der Oberfläche liegt.

Es sei mittleres Niedrigwasser als Oherfläche gesetzt. Es wird sich also nach dem ersten Zeitraum (I.) die See in $400 \mathrm{~m}$ kntfermung vom Ufer zu brechen beginnen, da daselbst die $1 \mathrm{~m}$ hoch gewachsenen liorallenbünke nur noch $3 \mathrm{~m}$ von der Oberfläche entfernt sind. Ton diesem Punkt ab dem Lfor zu liegen nun die Korallen im Bereiche der langsam sich aufrollenden See und können, wenn auch etwas behindert, doch noch gedeihen, bis zu dem Punkte, wo die zeitweise losgerissenen horallenstïcke alıgelagert werden und sich in grösserer Menge anhäufen. Das dürfte vorerst vor allem die Strecke von $100 \mathrm{~m}$ his zum Ufer sein, welche im Lauf der nächsten Zeitabschnitte mehr und mehr zum Sanistrande wird, jenem „Sandstrande“, welcher im Rücken aller grösseren Strandriffe vorhanden ist nnd einen Theil der Uferlandschaft bildet. Dabei ist eime weitere Strecke von $100 \mathrm{~m}$ inlands noch unberücksichtigt, welche von der bis zu ca. 1 m hohen Fluth bedeckt zu werden pflegt mad welche natülich denselben Bedingungen unterliegt. Hierbei muss zugleich des Einflusses der Flnth auf das Lorallenwachsthum insoferu gedacht werden, als sie bei $1 \mathrm{~m}$ Höhe die in $2-3 \mathrm{~m}$ Tiefe gelegenen Polypen dem directen Einwirken der Brandung längere Zeit entzieht. Da von den 12 Stunden zwischen zwei Niedrigwassern zur Springzeit

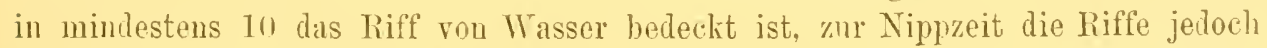
überhaupt nie zur Luft treten, so darf diesem Factor eine nicht zu unterschätzende Bedentung zugewiesen werden, wie ich überhaupt in den meisten der Arbeiten über den Bau der Kiorallenriffe gesehen habe, dass der Oceanographie zu wenig Beachtung geschenkt rorden ist.

Was wird num nach dem Zeitabschuitt II. der Fall sein? Die Korallenbänke sind um einen zweiten Meter in die Höhe gewachsen mul die 3 m-Grenze um $100 \mathrm{~m}$ weiter seewärts gerückt, befindet sich jetzt also 500 in vom Niedrigwasser-Ufer (U) entfernt. Bei $400 \mathrm{~m}$ siud die Korallen noch $2 \mathrm{~m}$ ron aer Oberfläche entferut. bei $300 \mathrm{~m}$ noch $1 \mathrm{~m}$, und bei $200 \mathrm{~m}$ rom Wasser haben dieselben gerade die Niedrigwassergrenze erreicht. Fine Fläche von $300 \mathrm{~m}$ Breite $(500$ his $200 \mathrm{~m}$ ) rollt die See ron der 3 m-Grenze an rollstïndig auf, so dass sie dem sich bildenden Riffrande nicht mehr sehädlich werlen kann. Hier stossen die Korallenbänke allmälig zusammen, die Zwischenäume werden durch Trümmer ausgefüllt, versintert; bei cintretender Fluth werden die Trümmer dem Lanle zugetragen und die Zwischenräume zwischen Riffrand und Sandstrand ausgefült - die erste Anlage der Rifflagune ist. wenn auch in kleinen, elfolgt. 
So geht es nun Zeitabschnitt um Zeitabschnitt weiter; nach jelem ist die 3 m-Grenze um $100 \mathrm{~m}$ weiter hinausgerückt, ebenso der Riffrand, während der Sandstrand seinen Standort behält; noch aber hat die Riffkante ihren schroffen Charakter nicht angenommen; noch schützt der breite Fuss die jungen Bildungen.

Dies verändert sich, je mehr sich die liante der $15 \mathrm{~m}$-Grenze nähert. Nach dem Zeitabschnitt XI ist die Rittkante $1000 \mathrm{~m}$ vom Ufer (U) und die $3 \mathrm{~m}$-Grenze noch $300 \mathrm{~m}$ vou dieser entfernt. Doch nun ändert sich dies. Der Fuss wird kürzer und steiler, Platz um Platz ringen die Korallen dem Meere ab, im harten Kampf mit der stärker und stärker sie treffenden Brandung, bis schliesslich bei $1300 \mathrm{~m}$ (in diesem Falle) vom Ufer das Meer der Riffkante gebietet: „bis lierher und nicht weiter." Ein $200 \mathrm{~m}$ breiter Fuss, welcher bis zu $15 \mathrm{~m}$ abfällt, bleibt die eiserue Stütze, welche die kräftigen Stösse des Meeres parirt. Gelingt es dem Fuss, auf dem seewärts durch Koralleusand sich bildenden "Talus" noch weiter fortzuschreiten, so kann auch wohl die Riffkante in ruhiger Zeit weiter vordriugen. Aber hier ersteht in Sturm und Wetter ein mächtiger Feind; was in guten Jahren sich bildete, reisst ein wilder Orcan in wenigen Stunden wieder zusammen.

Wir haben den Weg vom Strande zum Meer genommen; es soll nuu der Weg wieder zurück gemacht und die einzelnen Gebilde des Strandriffes dabei einer näheren Betrachtung unterzogen werden, insbesondere auch die Bildungen auf dem Riffe, die Plattform mit dem Schuttkegel. Es wird sich dabei zeigen. dass diese Gebilde, wie theilweise auch der Fuss, gewissen Theilen der Strandriffe nicht angehören, nämlich den an der Leeseite gelegenen. Die Vergleichung: insbesoudere auch ler Riffkanten wird zu interessanten Ergebnissen führen.

\section{Der Aufbau eines samoanischen Strandriffes.}

Wenn wir auf dem Boden des Meeres wandernd der Küste zueilen, kommen wir erst über Sandgrund, den

T'alus, steigen daun über lebende Korallen treppenförmig auf dem Fuss hinauf zur

Riffkante.

Daun auf sauft geneigtem, festem Korallenfels hinauf zur Plattform, ïber diese (und den

zur Lagune, erst über die grosse, sanftgeneigte dann durch den schmalen

Schuttkegel)

Sandfläche,

Strandeanal

zum Sandstrand.

a. Der Talus.

Murlay sagt, wie schon erwähnt, am Schlusse seiner Abhandlumg (21 a):

"Es wurde gezeigt, dass Barrieremriffe vom Ufer aus gebaut haben anf einem Grund von vulkanischen 'Trümmern oder auf einem Talus von Korallenblöcken, Korallensediment und pelagischen Schalen."

Murray und cuppy fassen die Billung des Talus so auf, dass seewärts abgetragener Korallensand vor dem Riff abgelagert wirk, und durch Anhäufung* dieses der Meeresboden in den Bereich der riltbildenden Korallen gelangt, also ungefähr innerhalb der 20 m-Grenze, und in diesem Sinue sagt Guppy: ,,Riffe wachsen anf ihrem rigenen 'T'alus." Nun weiss man nach Sluiter's Beobach- 
tungen, dass Korallen sich wohl auf losem Grunde, selbst auf Schlamm, ansiedeln kömnen.

Immerhin muss man aber belenken, lass der schon exwähute ,Fuss“6 namentlich an der luvseite der Riffe sehr breit ist, wie wir sogleich sehen werden. Da aber an Stelle der stärksten Brandung auch am meisten Sand und Stron gebildet wird, so müsste gerade hier der 'Talus näher an die Kante heranrücken, und würde das Leben hier ersticken, anstatt es zu fördern. Ich habe aher selbst weit ab rom Riff in See Korallenwachsthum am (irunde gesehen, ohne Sandinseln. Es scheint desshalb die Bildung des Sandgrunles direct vom Riff her unter regelrechten Bedingungen unwahrscheinlich und ich schliesse mich in dieser Beziehung den Ausführungen Dana's an, welcher annimmt, dass der Sand durch die auflandige See der Gezeiten auf dem Riff angehäuft wird und nicht in die Tiefen der Oceane fällt. Walther spricht sich ähnlich aus, wemn el auch die Wirkung der See nicht anerkennt und die Rolle des Festhaltens des Sandes den ästigen Madreporen zuweist, worauf ich bei Besprechung der Entstehung des Riff́sandes noch näher einzugehen haben werde.

Im Geological Report der Wilkes-Expedition (3b S. 55) gicbt Dana über die Lothungen bei der Insel Clermont Tonnevre folgendes an:

$\begin{array}{rrrr}\text { Entfernug vom Riffrand } & \text { Tiefe } & \text { Grundprobe } \\ 1500 \mathrm{~m} & 350 \text { Faden } & \text { todte Korallenstücke } \\ 100 \mathrm{~m} & 90 & , & \text { Korallensand } \\ 55 \mathrm{~m} & 85 & , & \\ 40 \mathrm{~m} & 7 & ,(12,5 \mathrm{~m}) & \text { lebende Korallen. }\end{array}$

In der neuesten Auflage von Corals and Coral Islands (3 c S. 171) erwähnt er jedoch nur die grösseren Tiefen.

Muray giebt von Tahiti an (s. Dana $3 \mathrm{c}$ S. 281-283): Bis ca. $200 \mathrm{~m}$ weit vom Riff eine flache Gegend, theilweise mit lebenden Korallen; und weiter aussen, wo der Boden steil bis zu $200 \mathrm{~m}$ (45 $)$ abfiel, waren grosse Korallenmassen und feiner Korallensand.

Da genamere Vermessungen und Grundbestimmungen zur Zeit noch recht selten sind, so ist es unmöglich, ein sicheres Urtheil über den sogenannten "Talus" zu gewinnen. Es ist ja zweifellos, dass ein rïckläufiger Unterstrom seewärts zieht; dieser könnte proportional der Stärke der Brandung den Riffsanl entsprechend weit hinaustragen und daselbst zur Ablagerung bringen.

In allgemeinen gilt die seemännische Regel, dass an einem langsann ansteigenden Strand bei der 15 m-Grenze die Grundseen allmälig aufhören, welche als rücklänfige oder Kreis- und Spiralströme durch die auflaufende See gebildet werden. Je stärker die See, je mehr Wassermassen durch die Winde und Gezeiten herbeigeschaftit werden, desto stärker müssen die Ströme sein, welche das Wasser wieder abführen. Ein Oberstrom kann sich rückwärts nicht bilden, folglich muss das Wasser an Grunle nach der See abfliessen. Beim Riffe wird dies anı stärksten nach Niedrigwasser sein, rornehmlich an cler Lurkante.

Die Grundseen an den Küsten sind keine Theorien: es sind bekannte Erscheinungen, welche allenthalben beobachtet worien sind. Es ist neuerdings wiederholt betont worlen, dass der kalte Humboldtstrom an ler Westküste Süd- 
amerikas nicht von den Polen herstammt, sontern als Auftriebwasser zu denten ist, welches den Tiefen des Oceans entstammt. Professor Kr ümmel sagte mir, dass ein solcher Kaltwasserauftrieb auch wahrscheinlich die Ursache ist, warum an der Ostküste und Westküste Afrikas Rifl'billungen an verschiedenen Punkten fehlen, wo sie allen Berechnungen nach doch vorhanden sein müssten. Nun, für Samoa kommen diese grossen verticalen Meereshewegungen nicht in Betracht. Aber die kleineren erwähnten Küstengrundseen sind doch wichtig genug, um ihnen Aufmerksamkeit zu 'Theil werien zu lassen. Ist es doch nicht undenkbar, dass ein starker Grundstrom bei Fluth und Sturm Korallenstöcke oder - Aeste von dem Fusse losreisst und sie seewärts trägt und dass der Fuss nur điesen Strömen seinen allmäligen Abfall veriankt. Wäre dies nicht der Fall, so wäre es ja nicht einzusehen. warum die Korallen nicht alle gleichmässig emporwïchsen bis zu der Linie von $3 \mathrm{~m}$, wo die Brandung sie direct zu treften beginnt; damn hätten wir diese Configuration anstatt des in dem folgenden Capitel gegebeuen Luvkantendurehsehnitts.

Vielleicht giebt es irgendwo anch diese Form.

Es wäre wohl lohnend, diesen Verbältnissen bei späteren Untersuchungen Rechnumg zu tragen.

b. Der Fuss.

Wie schon bei der Entstehung des Rifles erwälnt wurde, ist unter ,Fuss“ der lebende 'Theil des lifles gemeint, welcher von der Luvkante des Riffes aus allmälig seewärts abfällt. In vorigen Abschnitt wurde schon besprochen, wodurch dies möglicherweise verursacht wird. Wie breit der Fuss in den einzelnen Fällen ist, dürfte ron der Stärke und Daner der anlaufenden See, ron den Gezeitenströmen und der Configuration des Bedens abhängen. Bis zu welcher Tiefe er reicht, ist bis zur Zeit noch nicht sicher ermittelt. In allgemeinen dürfte die 20 m-Grenze auch als Fussgrenze gelten, in der That jedoch eine geringere von $15 \mathrm{~m}$ schou in Betracht kommen.

Der Fuss ist der eigentliche Bildner des Riffes; hier sind die wahren grossen Korallengärten in ununterbrochener Reilenfolge, Stock an Stock, in bunten Farhen sich reihend, die zu sehen uu wenig Sterblichen vergönnt ist. Viele leben Jahre auf den Koralleninseln und sind dieses Anblickes nie theilhaftig geworden. Wohl sind in den Häfen und Ritteinlässen, von denen wir sogleich zu reden haben weruen, prächtige Bilder genug vorhanden; sie sind es auch im Wesentlichen, welche die meisten Beobachter schildern. Diese Bildungen sind jeiloch, obwohl gleich an Ueppigkeit, doch meist nur local beschränkt, oder mehr in verticaler Ausdehung an Bänken oder Leckanten der Riffe vorhanden, hier allerdings den Blicken nahezu immer zugänglich. Der breite Fuss delunt sich jenseits der Braudung aus und ist wegen des steten Passates nur selten sichtbar, abgesehen davon, dass Boote gewöhnlich innerhalb der Riffe bleiben und Schifle die Nähe der Riffkante fliehen. 
Mir selbst ist es nur ein einziges Mal währent mamnigfacher Gelegenheit geglückt, dieses seltene Schauspiel zu geniessen:

Als nämlich am 24. Nai 189+ SMS. , Bussarel und HMS. „Curaçoa" Apia mit einer Lnzahl samoanischer Boote im Schlepp verlassen hatten, um die feincliche Atmajartei zum Fieden zu zwingen, wurle auf der Fabrt nach Saluafata die oflene Bucht von Solosolo angelaufen. Es war noch früil an 'Tage, der Passat war noch nicht durehgekommen, und da es seit mehreren Tagen sehr ruhiges Wetter gewesen war, war die See, obwohl von leichter Dünung bewegt, doch so spiegelglatt, wie man sie in der l'assatzone nur selten gewahrte. Beim Verlassen der Bucht bot sich ein wundervolles Schauspiel: das Schiff schien auf rinem erystallenen Teiche zu gleiten, man sah ron der Hütte aus den Meeresbocien in ungefälı $15 \mathrm{~m}$ Tiefe wie einen Blumengarten in allen Farben prangen, einen Teppich ron lehenden Korallen, dessen Schönheit durch die schief einfallenden Strablen der Sonne noch erlöht wurde.

Sogar die alten Häuptlinge, welche sich an Bord befanden, an Korallenanblicke gewöhnt. waren überrascht und gaben ilnem Erstamen so lauten Ausdruek, wie sie es sonst nu beim Anblick eines guten Gewehres zu thun pflegen. Der Anblick danerte kaum eine Viertelminute, da das Schifl bald in tieferes Fahrwasser gelangte.

Der Korallengarten war der Fuss des Riffes, welches am Ostende der Solosolobai zungenförnig in die Sea vorspringt und in ziemlicher Nähe (ca. 200 m) passirt wurde.

D an a gieht ïbrigens auch an, dass er den Fuss der Riffe seewärts in Samoa gesehen habe. schrieb aber sein Torkommen localen Verhältnissen und besserem Wachsthum seewärts zu.

Eine der seltenen lieobachtungen hat anch Semper (9 c S. 58) beschrieben. welche ich inrer Wichtigkeit halber hier mitheilen will. Freilich hat er die Beobachtung nicht richtig gedentet, indem er sie als Gegenbeweis fül die Darwin'sche Theorie ausgah. was sie matürlich an unl für sich nicht ist. Er schreibt:

„Es war auf meiner Fahrt nach dem Atoll Kreiangel. Nachdem ich am frühen Mlorgen, etwa um 9 Ulr., das Riff überschitten hatte, trich ich mich absichtlich riele Stunden lang this zum Nachmittag an der Aussenseite des östlichen Riffs herum, wobei ich vom schönsten Wetter begïnstigt wurde. Die Untersuchung an dieser Stelle lieferte mir ein damals sehr unbequemes Resultat, jeh sah deutlich. dass das hift' durchaus nicht: wie es hier sein sollte, rasch in's Meer abfällt, dagegen wohl, dass sein Abfall ein gan\% langsamer ist. Tausenle ron Schritten komnte ich mich in senkrechter hichtung ron dem Ritfe entfernen. ohne den Meeresgrund aus den Ingen zu verlieren: die einzelnen Korallenblöclie inn Grunde waren deutlich in ihren verschiedenen Formen zu erkennen. Dio See war dabei fast eben; mu das in grossen Oceanen nie fehlende leise Steigen und Fallen, der von den Englündern sogenannte swell*), war vorhanden. Dieser 
aber zeigte ganz die Erscheinung. wie sie an flachen Küsten überall beobachtet wird; das ansteigende Wasser hebt sich nämlich, je nüher dem Lande, um so stärker, aber ganz gleichmässig und kaum dem Auge bemerkbar, bis sich endlich die Woge mit Getöse am Wall des Aussenrifl's bricht. Da aber dieser Wall nicht plötzlich wie am westlichen Riff (der Seekante) aus der purpurnen Tiefe anfsteigt, so tritt auch hier eine Erscheinung ein, wie sie an ganz langsam ansteigenden Küsten beobachtet wird; auf die erste Linie der äussersten Brecher folgt eine zweite weiter nach innen liegende, und auf diese endlich meist noch eine dritte. Diese Erscheinung ist den Eingeborenen sehr wohl bekannt; um der Gefahr zu entgehen, ihr Boot dureh die zweite und dritte Linie von Wogen gefüllt zu sehen, schieben sie dasselbe nach Ueberwindung der ersten Brecherlinie mit sehr langen Stangen so rasch als möglich über die Aussenfläche des Riffs hiu, um anch die weiter hinaus liegenden gefährlichen Linien möglichst rasch zu passiren. An der Westseite dagegen findet sich immer nur eine einzige breite Linie von Brecheru."

Semper bespricht fernerhin, wie er oft frïher gelesen habe, dass an der Wetterseite der Abfall der Riffe ein sehr schroffer sei, während das hier eben gar nicht zutreffe. Dass die Ostseite von Kreiangel in der That die Wetterund Sturmseite ist, geht schon daraus hervor, lass auf dieser Seite alle Riffinseln, im ganzen 5, liegen, während das Westriff frei von solchen ist.

Darwin beobachtete anch, dass die Luvkante nicht steil abfällt, so sagt er (2 S. 17) vom Keeling-Atoll:

"Der Holzschnitt zeigt die Form des Grundes ansserhalb des Riffes: das Wasser vertieft sich eine Strecke zwischen 100 und 200 Yards weit sehr allmälig zn 25 Faden, von wo die Seiten unter einem Winkel von $45^{\circ}$ in den unergründlichen Ocean. Bis zur Tiefe von 10 oder 12 Faden ist der Boden ausserordentlich uneben und scheint aus grossen Nassen lebender líorallen gebildet, ähnlich denen am Riffrande“.

Anch Guppy kennt diesen Rifftheil wohl und nennt ihn das ,growing edge of the reef".

Captain Whartou, der so viele Korallenriffe vermessen hat, sagt (32 a S. 394): „Ich muss hinzufügen, dass es Seeleuten, welche in der Navigation in den Korallenriffen erfahren sind, wohl bekannt ist, dass man geringere Lothungen häıfig an den Kanten von Bänken erhält."

Man sieht, Beobachtungen für das Vorhandensein des Fusses sind genügend vorhanden, aber nirgend wird ihm, glaube ich, die Bedentung beigelegt, die ihm znliommt.

Besonders steil hingegen ist dieser Abfall in den sehr geschützten Barrierencanäleu; M urray sagt darïber:

„,In den Lagunencanälen wurden die Riffe mit lebenden Korallen eingesüumt gefunden, aus- und abwärts erst einige Fuss abfallend, um dann auf eimmal zu einer Tiefe von 10 bis 16 Falen abzustürzen. Viele Theile dieser inneren Biffe waren überhängend und an einigen Plätzen waren rüberhängende Massen nenerdings abgefallen." 
Hoffm a n us sagt von denselben Lagmeneanïlen in T'ahiti (25 il) (Rajatea): ,Am inneren Rande ist dieses Platean scharf ausgezalckt und füllt 20, 30 bis $60 \mathrm{~m}$ tief steil ab zum Canal. - Die abschüssige Innenseite dieses Plateaus und damit des gimzen Korallenrift's ist die einzige Stelle, an welcher man lebende Korallen antrift', tief hinunter, soweit man sehen kann, eine üppige Vegetation in verseliedenster Form und Farbe."

Und von der Kante des secundären Strandrift's:

,Von Lande ans rïekt nun in den Lagunencanal hinein das Strandrifr, sehr verschieden in seiner Ausbildung, oft beeinträchtigt von dem Detritus des Ufers, fast immer aber todt auf der Oberfläche, am Rande erhöht, aber nicht die Wasserlinie erreichent. und die äussere Böchnng; welche steil gegen den Canal abfïllt, bedeckt mit lebenter Korallenvegetation."

Teider komnte der erfahrene Capitän über die Structur der äusseren Böschung und die daselbst lebenien Kiorallen nichts berichten.

Dagegen sagt er rom Apiariff:

, Wenn man ausserlalb des Riffes in einiger Entfernumg von der Brandung: hinfährt. sieht man immer den Grund (erfahrungsgemäss weniger als $10 \mathrm{~m}$ 'Tiefe)*) und die Lothungen ergeben sehr geringe und ungleiche Wassertiefon und oft lebende liorallen".

Weitere Beobachtungen über die Terschiedenheit dieses Abfalls liegen zahlreich vor, aber nirgends scheint es aufgefallen zu sein, dass die Brandung es im wesentlichen ist. welche die Auslehumng des Fusses zu bedingen sclueiut.

Im Allgemeinen darf man sagen, je stärker und stetiger auf einer Riffstelle die See steht, lesto sanft abfallender und breiter ist der Fuss, oder anders ausgedrïckt, je weniger war es der Riffkante möglich, bis an die Tiefengrenze vorzudringen. Dies springt in die Angen, wenn man die Karte eines gut vermessenen Korallenhafens betrachtet und den Verlanf der 20 und 10 m Grenze verfolgt. Der offenen See zu mindestens $100 \mathrm{~m}$ abliegend, nähern sich diese Linien. je mehr es der Leekante des Riftes zn geht, so mehr dieser mnd werden schliesslich eins mit ihr. Nicht dass die lebenden Korallen daselbst seltener wären: ein Blick dur den Meereskiker (ein Blechgefüss mit einem Glasboden, auf das Wasser zu setzen) zeigt jederzeit. dass auch hier das ïppigste Wachsthum herrscht, So sagt Guppy von einem geschützten Barrierencanal de C'Loiseul-Bai: „Hier sind die Korallen in der Brandung zahl- und artemreicher."

Darwin und Dana geben ähuliche Beobachtungen.

Dana kommt jedoch bei der Beschreibung der äusseren und imneren Riffe zu keinem sicheren Schluss. Er sagt (3e S. 137 и. 144): „Der grosse Unterschied in der Schnelligkeit, mit welcher sich das Wasser vertieft, hängt hauptsächlich vom verschiedenen Charakter der submarinen Böschung ab. Flache Wasser können sich meilenweit ausdehnen, hauptsächlich gegenüber den prominenten Punkten und Winkeln; aber es ist gewöhnlicher las gegenseitige Extrem zu finden grosse Tiefen in wenigen hundert Fuss." Von den inneren Riffen: ..Der Rand

*) Das dïrte nicht unbedingt richtig für die Tropen sein. da ich in Apiahafen oft den Grund bei $13 \mathrm{~m}$ (durch Lothung bestaitigt) gesehen habe. Siehe anch I)urchsichtigkeit des Meerwassers (Abschn. I. 6). 
ist gewöhnlich weniger steil: Aber hier kommt jede Variation von Abfall, vom mässig geneigten Korallenbett bis zum senkrechten Absturz, vor."

Dass letzterer nie am äusseren Riff vorkommt, erwähnt er nicht, nur dass daselbst, ,in wenigen 100 Fuss" eine grosse Tiefe sein könne.

Im Hafeneingang, wo meist nur leichte Dünung herrscht, kann der Riffrand soweit answachsen, bis er sogar überhängeni wird. Dasselbe ist natïrlich im Barrierenriffcanal der Fall, wo das sec!ndäre Strandriff eine Leekante darstellt. Dies hört im innersten Hafen natürlich auf, wo die Sandabfuhr von den Riffen ber nur das Aufwachsen einzelner Korallenlaänke gestattet.

Diese Verhältnisse vom "Zurückweichen des Fusses oder vielmehr rom Vordringen der Riffkante werden durch die neu vermessene Karte des Apiahafens gut veranschanlicht (s. d.), sowie durch zwei Durchschnitte, einer durch die Luvseite und einer durch aie Leeseite des West- und Ostriffes daselbst.

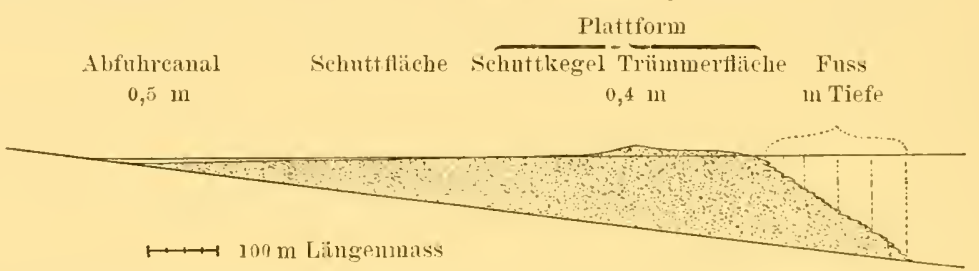

Die Tiefe in m 10 mal grösser angegehen.

Durchschnitt durch das Westrifl des Apiahafens: Lurkante bei Niedrigwasser.

Vom Haus des Chief.Justice in Mulinúu aus ô NO. z. O. missweisend.

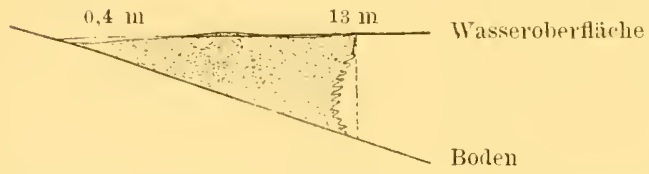

Durehschnitt dureh das Ostriff des Apiahafens: Leekante bei Niedrigwasser.

Von der Flaggenstange am Matautu-Cap aus nach der Bake of $\mathrm{W}$. missweisend.

Lïnge- mnd Tiefenmaass ebenso.

Es könnte eingewandt werden, dass der Hafenabfluss es ist, welcher hier das Auswachsen des Fusses verhindert.

Aber es zeigen auch offene Rifftheile, die geschützt liegen, vor allem die kleinen Riffbuchten, bei denen eine Abfuhr nicht in Frage kommt, den steilen Abfall. Die 'Tiefe wirkt hier Hemmung gebietend und die Stürme sorgeu dafür, dass diese Riffkanten nicht z.ı selır überwachsen. (Beweise dafïr sind auch die isolirten Barrieren von Vailele und Saluafata. S. die Karten daselbst.)

$\begin{array}{llllll}0 & 25 & 50 & 75 & 100\end{array}$

Die Lmwante im richtigen Verhältniss gezeichnet. Das schwarze ist das Iiitr.
Deutlich kommt der Unterschied anch zur Schan

bei Besprechung des Baues der Luv- uni der Leekante.

\section{c. Die Riffkante.}

Luv- und Leekante, Höhlenbildung und Korallensandentstehung.

Unter Riffkante ist die Strecke gemeint von dem Raude des Korallenriffs an (bei Springnienrigwasser) bis zur Plattform. Sie ist gewöhnlich $10-20 \mathrm{~m}$ breit.

Wie beim kuss, so ist es auch bei der Ritfkante von grossen Belang, ob sie luvwärts oder leewärts liegt. Anch hier sind diese Unterschiede nicht genügend 
auseinander gehalten worden, wie überhaupt die Morphologie der Rifie bis jetzt im Argen lag, welche doch für das Verständniss des Rillaut'baues sn sehr wirhtig ist.

Die Einwirkung der Brandung tritt am deutlichsten zu 'Tage, wenn man den Uebergang von der Kante zu der landwärts gelegenen Plattfol'u berücksichtigt.

Während nämlich die Luvkante convex im Bogen diesen Uebergang bewerkstelligt, geschieht dies bei der Leekante oft geradezu umgekehrt in concaver Aushöhlung.

So kommt es, dass wir an der ausgeprägten Luvkante eine scharfe Ritlkante gar nicht besitzen: man sieht bei Niedrigwasser die Brandung einen Buckel herauflaufen und wieder zurückfliessen, auf dem nennenswerthes Korallenwachsthum nicht stattfindet. $10-50 \mathrm{~m}$ seewärts von der Kante findet man um diese Zeit nur 'liefen von $1-2 \mathrm{~m}$, so dass man die See lange sich öherstürmen sieht. che sie den Riffrand erreicht. Hier mit der Dünung fallend und steigend bricht ihre letate Kraft zusammen, den steilen Rücken mit ibren Fluthen überschwemmend, wie man dies am Meeresstrande stets wahrnehmen kann. Trockenen Fusses wandert man, kleinere Pfützen vermeidend, in denen kümmerliches Leben waltet, hinauf zur ungefäh' $1 \mathrm{~m}$ böher liegenden Plattform. Sechs Stunien später ist alles mit Wasser überdeckt; die Korallen unter dem Riffrande haben nun mindestens 1 m Wasser über sich und können mübsam ihre Nabrung suchen. Die in den Pfützen jedoch, welche zuvor friedlich ihre Tentakeln ausbreiten konnten, müssen jetzt vorsichtig arbeiten. So herrscht hier ein steter Kampf mit der (rewalt der See, Neubildung und Untergang wechselt hier mit Wind und Wetter beständig.

Anders die Leekante. Scharf abgeschnitten, wird sie nur von der leichten Dünung bei Niedrigwasser bespïlt. An dem abhängigen Rande stehend sieht man beim Zurückweichen der See, wenn das Wasser sich einen Augenblick glättet, unbehindert auf die bunten Korallenstöcke, wenn tas Riff nicht geradezu ïberhängend ist. Meist sieht man den "Fuss" in einigen Metern Entfermung in die Tiefe verschwinden, als ob man auf dem obersten Absatz einer Treppe stände. Um die Gegensätze scharf zum Ausdruck zu bringen, will ich zwei Durchschnitte hier folgen lassen:

Die Unterschiede sind deutlich genug.

Natürlicherweise kommen je nach

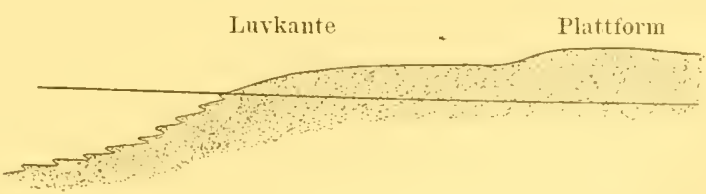
Stärke der See. Gezeitenstrom, Sandabfuhr u. s. w. alle Uebergänge und Vermischungen beider Formen vor, für welche man an ort und Stelle nach Maassgabe obiger Ausführungen leicht die Grünle findet.

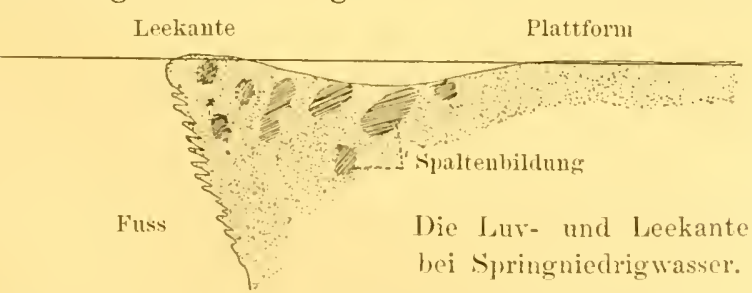

Besonders eigenthümlich ist bei der Leekante aber noch eine Bildung, welche der Luvkante aus naheliegenden Gründen in wesentlichen fehlt, eine atollartige Lagunenbildung, beruhend auf der starken Durchklüftung dieses Rifftheils. Während dieser Theil an der Lurseite mit Trümmer. und Sand ausgefüllt und vercementirt wird, gemäss der starken Tbätig- 
keit ier See, findet hier eine Trümmerbildnng natürlicherweise nur in sehr beschränktem Maasse statt.

Desshalb ist die eigentliche Kante, der Balcon sozusagen der Leeseite, oft nur 2-3 $\mathrm{m}$ breit und nur sehr wenig über Springniedrigwasser liegend. Zahlreiche Risse und Löcher machen das Gehen auf diesem Wall mangenehm. Noch schlimmer aber wird dies, wenn man sich querab landwärts wendet. Eine nahezı ${ }^{1 / 2} \mathrm{~m}$ tiefe, $10-20 \mathrm{~m}$ breite Lagune trennt gewöhnlich den Rand von der soliden Plattform, und diese Aussenlagune mit zahlreichen lebenden Korallenstöcken geziert, erweist sich als so zerklüftet, dass ihr Passiren oft geradezu unmöglich wird, will man nicht riskiren, dass man öfters bis zur Hüfte einsinkt und sich beim Fallen die Hände zerschneidet. Eine solche Stelle ist im Apiahafen bei der Bake am Ostriff vorhanden, wo es mir trot\% mannigfacher Versuche an einzelnen Stellen nicht gelang, die Schuttfläche zu erreichen. Diese Schuttfläche, welche, soweit hier überhanpt vorhanden, natïrlicherweise sehr flach ist und kaum dem Wasser entragt, muss im Wesentlichen als ein Ausläufer der Luvplattform

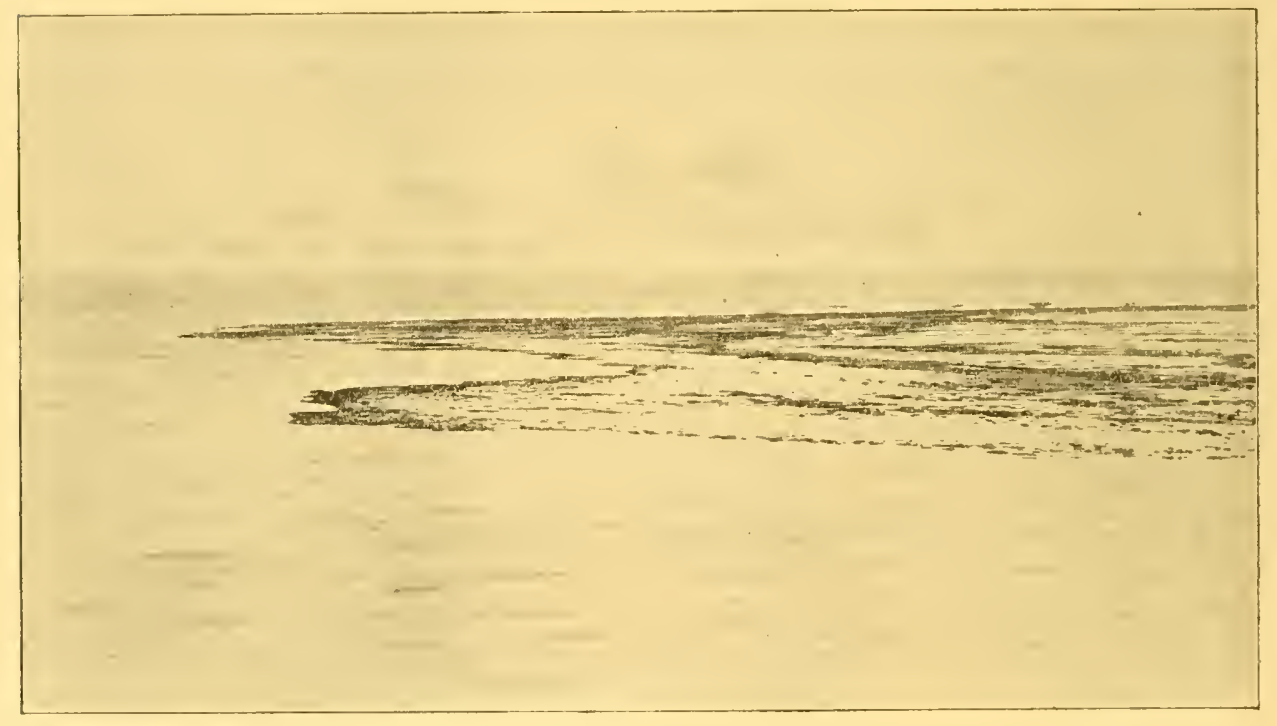

Das Ostriff im Apiahafon bei Matautu vom Innern des Hafens aus gegen Norden. Die Photographie stamnt aus den Jahre 18s0. Oberstabsarzt KJeffel.

betrachtet werden, oder als eine Bildung der Stürme und Gezeiten. Eine $A b-$ bildung dieses Rifftheiles im Apiahafen, welche ich der Güte des Herrn Oberstabsarztes Dr. Kileffel verdanke und die um so werthvoller ist, als sie ans dem Jahre 1879 stammt, will ich nicht versäumen, hier einzufügen, da sie diese Verhältnisse sehr schön wiedergibt.

Einen genaueren Einblick in diesen Riffrand mit den vorgelagerten Korallenstöcken gestattet das nebenstehende Korallenbild.

Man sieht hier bei zurücktretender See auf einige Augenblicke die für die samoanischen Riffe so wichtigen Madreporenbeete. Nur dureh wenig Wasser noch von einander getrennt, werden sie bald zusammengeflossen sein, len Riff- 
rand nach aussen hin verbreiternd. Je länger sie an die Luft treten, lesto mehr werden absterben, bis schliesslich der nackte Korallenfels auch hier übrig bleibt, nur noch von einzelnen niedrigen Stöcken geziert - wenn nicht ein Sturm dieser vielversprechenden Colonie ein jähes linde bereitet.

Es ist hier der Ort, der Höhlenbildung in den Riffen noch einige Worte zu widmen. Mit einem Meereskicker bewaffnet kann man anf der Leekante der Riffe sich bei Ebbe eine der genussieichsten Stunden verschaffen im Betrachten der Thierwelt, welche mit Vorliebe diese Schlupfwinkel aufsucht. Man kann sich aber auch überzengen, wie zerklüftet hier das anseheinend so mauerfeste Riff ist. Ich erimnere mich hierbei eines launigen Zwischenfalls im Atuakriege:

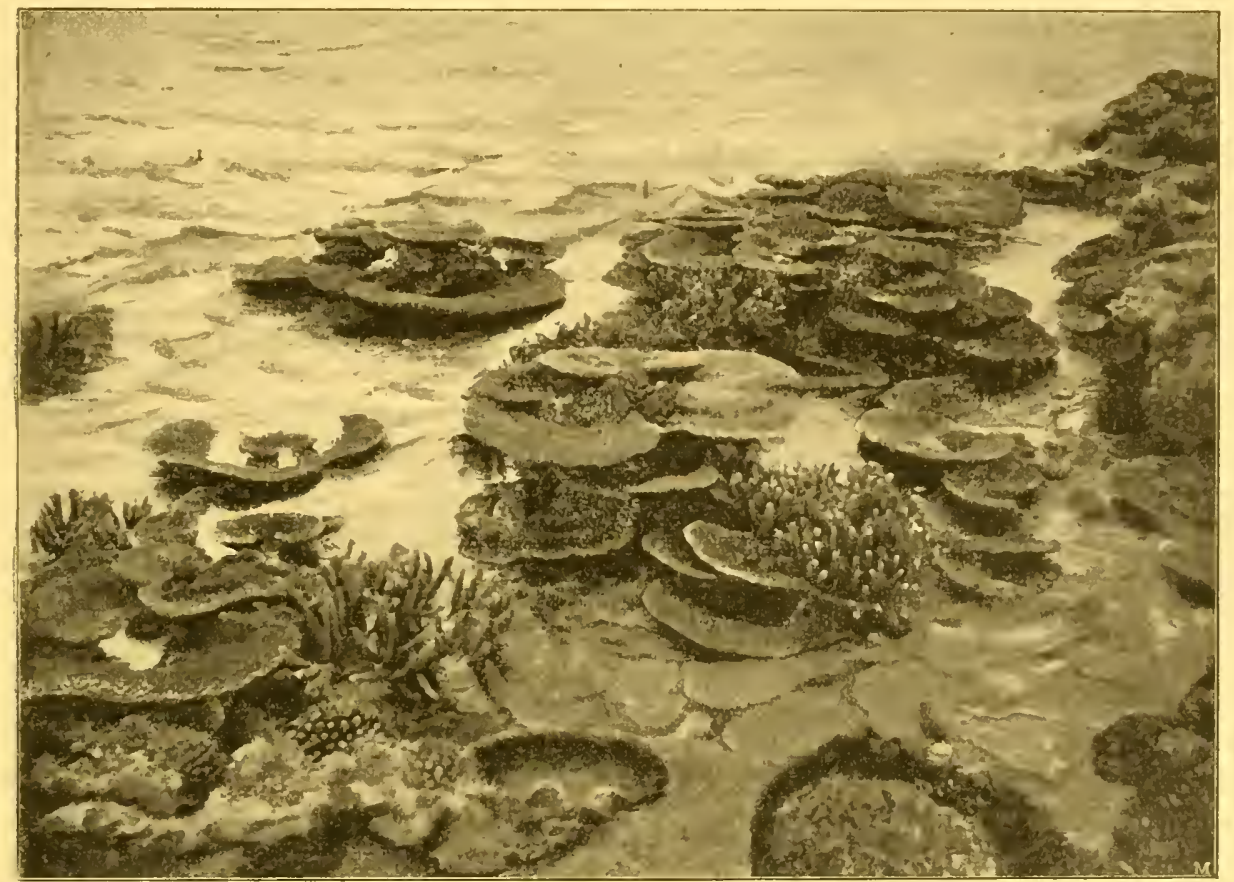

Madreporenwachsthum an der Leekante. Apia. Andrew phot.

Die Friedensunterhandlungen mit der Atuapartei waren beendigt. Die Boote des deutschen und englischen Kriegsschiffes, welche bei Hochwasser am Strande von Lufilufi angelegt hatten, hatten wegen eintretender Ebbe nach der erwähnten Riffbucht gegenüber der Grotte Fatumea verholt und harten daselbst am Riffrande im Tiefwasser. Mit den deutschen verliessen einige englisehe Ofinciere den Sandstrand und wateten mit Sübel und gutem Zeug angetban erst durch die Lagune, daun über die kleine Sehuttfläche durch die Aussenlagune den Booten zu. Kurz vor diesen hörten wir plötzlich eine englisehe Stimme und als wir stillstehend vorsichtig aufblickten, sahen wir einen englischen officier bis unter die Arme eingesunken, lebhaft gestikulirend. Die herzugeeilten Samoaner und Matrosen befreiten ihn bald aus seiner misslichen Lage.

Krämer, Ueber den Ban der Korillemritle. 
Diese Höhlenbildungen innerhalb der Riffe sind von Darwin, Dana, Semper, Rein u. s. w., kurz von allen gesehen worden, welche Korallenriffe besucht haben. Aber nirgend finde ich eine Angabe, dass ihr sichtbares Vorkommen, wie in Samoa, im wesentlichen an die Leeseite der Riffe gebunden ist, ja man ging geradezu soweit, ihr Vorhandensein der Brandung zur Last zur legen.

Eine treffende Schilderung aus dem rothen Meere verdanken wir Klunzing er (17 a S. 2-4):

„Die Brumen sind tief, schluchtenartig, überhängend. Sie communiciren vielfach mit einander und mit dem Meere und dieser Theil der Klippe zeigte sich zumeist nur als die durch Spalten, Löcher und weite gyröse Krater gegen die Oberwelt geöffinete Steindecke eines grossartigen Höhlensystems. Nirgends lässt sich das Korallenleben ruhiger und gemüchlicher anschanen als hier; aber solche Tage, wo die Klippen bis zum Abhange entblösst sind und zugleich die Winde ruhen, sind sehr selten".

Es scheint, als ob Klunzinger hier vom äusseren Riff, also von der Luvseite spräche. In einem Meere, das oft teichartig still ist wie das rothe Meer und. wo die Gezeiten nicht einmal so ausgiebig sind wie in Samoa, lässt sich dies leicht begreifen. Die See im Meerbusen von Suez kann weder in der Ruhe, noch im Sturme mit jenen gewaltigen langen Seeen verglichen werden, welche der pacifische Ocean auf die Korallenriffe in ununterbrochenem Wechsel wälzt. Diese Verschiedenheit geht anch aus dem Riffaufbau hervor, welchen Klunzinger an selber Stelle folgendermaassen eintheilt:

1. Ufer oder Seegraszone,

2. Stilophorenzone,

3. Vorkorallenzone (wasserbedecktes Uebergangsgebiet),

4. Alhangszone, steil abfallend.

Von denselben Gesichtspunkten geleitet, urtheilt im wesentlichen Walther, welcher erst das rothe Neer besuchte (31 a) und späterhin die Korallemriffe der Palkstrasse, jenem flachen Binnenmeer, welches zwischen dem nördlichen Ceylon, Vorderindien und der Adamsbrücke eingeschlossen liegt. In der Abhandlung darüber (31 b) widmet der Jenenser Geologe ein besonderes Capitel der Höllenbildung auf dem Riff. Die von meinen Ansichten ahweichenden Schlüsse, welche der treffliche Erforscher der Sinaihalbinsel zog, kann ich mir nicht anders erklären, als dass dieselben anf Grund der Beobachtungen in solchen verhältnissmässig stillen Meeren gewonnen sind.

Walther sagt ( 31 b S. 31$)$ :

„Die Entstehung solcher Höhlen wird leicht rerständlich, wenn man sich der Baumaterialien erimnert, aus denen. wie wir in den vorhergehenden Abschnitten gesehen haben, ein Korallenriff gebildet wird. Wir sahen, dass zwei von einander nur indirect abhängige biologische Factoren den Bau eines Korallenriffes ausführen. Auf der einen Seite die ïstige nder massige Kalksubstanz, welche durch die Thätigkeit der Riff korallen organisch ansgeschieden wird, welche den Zusammenhalt, ja wir dürfen sagen, die Existenz des lift's bedingt. Zwischen die beim Weiterwachsen der Korallenstöcke entstehenden Lücken wird ein Kalk- 
sand gefüllt, welcher durch lírebse und Raubfische, vielleicht auch turch Holothurien aus den Sceletten der kalkbildenden Foraminiferen, Helinodermen, Mollusken, Bryozoen, Brachiopoden u. s. w. gebildet wird.

Nun ist ja die Existen\% und der Individuenreichthum der korallophilen Fauna, welche diesen Kalksand liefert, gehunden an die kxisten\% ller Riff korallen, allein die speciellen biologischen Bedingungen, welche auf einew Riff eine grössere Henge solcher Thiere erzengen, könuen unabhäugig sein von den Bedingungen, welkhe das Wachsthum der Riftkorallen veranlassen und begünstigen, laher wird es uns nicht schwer, zu verstelen, dass die korallophile Fauma auf einem hiff oder Kiftheil reicher ist als auf einem andern. In Folge dessen wird an der eimen Stelle mehr Kalksand gebildet als an einer andern; dort werden alle beim Weiterwachsen der Korallenstöcke gebildeten Lücken mit Kalksand ansgelüllt, hier bleihen grössere oder kleinere Lücken otten."

Diese Sandbildung aurch niedere Thiere spielt gewiss im rothen Meere eine Rolle, aber auf den Insehn ler Südsee, wenigstens in Samoa, ist sie doch nur von untergeordueter Bedentumg.

Bevor ich nüher darauf eingehe, will ich nur mit wenigen Worten der Ausfülungen Walthers nameutlich in der letzten Arbeit gedenken.

Die Entstehung der grossen Haufen Sandes auf den Kiffen des rothen Meeres wurle durch $\mathrm{K}$ eller beobachtet, dor den Scheeren der Ocypolen diese Aufgabe zuwies (30). Walther hat diese Angabeu bestätigt und giebt an, dass aller Riffsanl durch diese Krebse gebildet wird, indem sie mit ihren Scheeren die Schalen der Mollusken u. s. w. öftnen und zerbrechen. Fr führt ferner die Beobachtungen Verill's vom Meeresgrunde an und Darwin's nebst Allan's Angaben über die korallenfiessenden Scarusarten und Holothurien, die im übrigen durch verschiedene gegentheilige Beobachtungen läugst mindestens zweifelhaft geworden sind.

Da na sagt über die Entstehung des hifisaules (3 \& S. 232):

„Eine unfehlbare und reiche Quelle dieser Art Material ist in dem sellıst sich zerreibenden Sand der Ritte zu erblicken, welcher durch die Kraft des Wassers bewegt wird. An der Seeseite vou Koralleninseln und an den Cfern der grösseren Lagunen, wo die Oberfläche aufsteigt zu hohen Wrellen, werden die feineren Theile fortgetragen, während der gröbere Sam liegen bleibt, um das Cfer zu bilden. Dieses Sandentstehen ist gerade so wie jede anlere Sandoder Schlanmbereitung".

Wo aber die eigentliche Saudbilung sein unss, giebt Dana nicht an. Wer einmal auf einer Plattform der Südsee gestanden hat, wenn das Wrasser zu steigen beginnt, der wirl sich darüber nicht zweifelhaft sein. Man steht auf einem, sagen wir einmal $100 \mathrm{~m}$ im Geviert haltenden, 'Trïmmerfeld aus blendend weissen Korallenstöcken: da liegen vor allem die zahlieichen Madreporenarten, melche für die Randzone ler samoanischen Forallenritte so charakteristisch sind. grosse Platten der M. eytherea, lange śtiele der M. acuminatil u. s. w. in [nmassen herumgestreut.

Dis Wasser steigt und wirft anf dem Abhang liegen gebliebene todte, und wenn schlechtes Wetter vorhergegangen war, frisch abgerissene Korallenstöcke in stetem Spiele hin und her und endlich anf das Trümmerfeld herauf. Wir 
haben uns vor der ansteigenden Fluth, die die hell klingenden Platten durcheinander wirft, auf den Schuttkegel geflüchtet und sehen nun die Seeen näher und näher kommen, bis die Ausläufer die Trümmerfläche überfluthen und das Wasser, je stïrker die Fluth und See, desto getrübter nach der Lagune hin abfliesst. Wir müssen unsern Standpunkt rerlassen, eilen in das Boot und treiben, sobald es tief genug, mit dem Strome dem Lande zu, das wir bald erreichen. Zweimal wiederholt sich täglich dieses Schauspiel, wobei die brennende Sonne zur Zeit der Syzygien auf die lange Zeit freiliegenden Korallentrümmer ausserdem noch verwitternd wirkt. Ewig danert diese mahlende, zertrümmernde Bewegung des Wassers. Was vermögen die Scheeren der verhältnissmässig wenigen Krebse gegen die stetige, elementare Gewalt der Wassermassen, welche die Gezeit zweimal täglich heranwälzt. So wird es auch erklärt, dass, je näher der Luvkante zu, desto geringer das Korallenwachsthum in der Strandrifflagune ist, und je weiter von der Trümmerfläche ab, der Korallensand um so feiner wird. Ein rückläufiger Strom kann nur kurze Zeit lang nach Hochwasser auftreten, da das Wasser durch die immer andavernde Brandung und das höhere Aussenriff abgelenkt, schliesslich alles seitlich ïber die Riffe abfliessen muss. Dass die „ästigen Arten vieler Korallengattungen das zwischen ihnen gebildete klastische Sediment bewahren" und dass ladurch die Kalksande auf dem Riffplatean liegen bleiben, wie IV alther ferner meint (31 b. S. 27), trifft für Samoa ebensowenig zu, wie die Bildnng dieses Sandes durch Thiere, an denen (vor allem an Krebsen) das eigentliche Riff verhältnissmässig arm ist. Rein mechanische und physikalische Gründe scheinen hier in Action zu treten, wenn auch nicht abgelengnet werden darf, wie Agassiz und Guppy sagen, dass die bohrenden Mollusken, Anneliden, Echinodermen etc. hier in vielen F'allen eine vorbereitende Rolle spielen, welche ich auch namentlich durch Anneliden an todten Poritesstöcken des öfteren zu beobachten Gelegenheit hatte. Der bohrenden Wirkung der Diadema wird noch weiter unten Erwähnung gethan werden. (Abschnitt VII. 5.)

\section{d. Die Plattform.}

\section{(Trümmerfläche und Schnttkegel.)}

Dana hat den Namen so oft gebrancht, dass ich ihn nicht gerne fallen lassen möchte. Es ist darunter die grosse Trümmerfläche verstanden, welche iiberall an der Luvseite der Riffe sich bilitet und welche als erste Anlage der Riffinseln aufzufassen ist. Ueberall wo die See besonders stark auf das Riff aufläuft, also in Samoa besonders an der ONO.- resp. OSO.-Seite der Riffe, bildet sich auf dieser Trümmerfläche ausserdem noch ein Scbuttkegel, welcher meist die Breite vou 3-4 $\mathrm{m}$ erreicht und dieselbe um ungefäh $1 \mathrm{~m}$ überragt. Gebildet wird die Plattform durch die von der Brandung losgerissenen Korallenstöcke, welche hier zusammengehäuft werden. Die 'Trümmerfläche ist bei Hochwasser meist von Wasser bedeckt, erscheint jedoch gewöhnlich schon bei MittelNiedrigwasser über der Oberfläche. Natürlicherweise ist die Form dieser Bildungen sehr Wind und Wetter unterworfen, vor allem der Schuttkegel. Eine geringere Inselbildung gewahrt man im Saluafatahafen und an der NO.-Ecke des 
Strandriffes bei Falefa; grössere Inseln sind die Barriereninsel bei Falealili, le Nucusa fee genannt, und die Insel anf dem Rose Atoll.

Wie schon erwäint, besteht die 'Trümmerfläche aus abgestorbenen todten Korallenstöcken, häufig 1-2 Fuss im Durchmesser haltend, wenn an einer exponirten Stelle liegend. Je mehr die Luvkante in die Leekante ühergeht, desto geringer ist sowohl die Höhe der 'Irümmerfläche als auch die Grösse der Korallenstücke, welclie alsdam nur noch Fingergrösse aufweisen oder gar

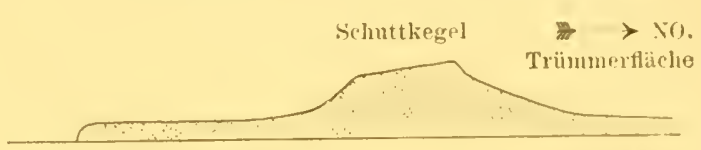

Durchschnitt durch die ('asinoinsel bei Saluafata.

ganz verschwindeu. Die Breite der Plattform überschreitet oft $200 \mathrm{~m}$, wechselt jedoch sehr; die Länge ist unbeschränkt.

Die Angaben Hoffmann's, dass diese, ,kleinen Plateaus in der Regel an tiefen Einschnitten der Upoluriffe liegen und nach der tiefen Wasserseite auffallend steil abfallen", kann ich nicht bestritigen. Jedenfalls hat ihre Genese damit direct nichts zn thun. Von den im .Jahre 1880 gepflanzten Cocosnüssen auf der Saluafata-Riffinsel, welche ein Jahr später $1 \mathrm{~m}$ hoch gewachsen waren, fand ich nichts vol:

\section{e. L a g}

Ton der Plattform ans sieht man landwärts bei Niedrigwasser cin grosses Feld ror sich ausgebreitet, oft mehrere Kilometer, oft $110 \mathrm{r}$ einige $100 \mathrm{~m}$ breit.

Kaum merklich ahfallend und mit fingergarssen Stïckchen (Schuttfläche) hedeckt, vertieft sich sehr allmälig der Boden und hedeckt sich dem Lande zu mit immer feinerem Sind. Einzclne Korallenstöeke treten nun auf, aber nie kommt es zu einer grösseren zusammenhängenden Bildnng. Solten geht man bei Niedrigwasser tiefer als his zum Knie im Masser. meist ist dasselle dem Lande zu höchsteus einen Fuss tiof. Kine Tertiefung ist gewöhnlich un ummittellar am Strande vorhanden. in dessen Nähe im allgemeinen der sogenamnte bontscanal verlüuft. welcher als Abfuhreanal für das Riffwasser dient. Da er gewöhnlich am Strande liegt, will ich ihn Strandeanal nemnen.

In Lehrigen wechseln die Terhältnisse hier sehr und hringen die Sitürme oft grosse Veränderungen hervor.

Häutig sieht man in der Lagune Steine dem Wisser entragen, todte Korallenblöcke. welche von der Stumfluth hierher gewïlzt worden sind. Selten sind sie höher als $1 / 2 \mathrm{~m}$. Häufig werden anch Steine von den Simnoanern zusammengetragen, um als Anziehungspunkte für die Fische z.n dienen, denen sie hier nachstellen. (TII. 4.) Die Lagune ist für die Buote der sicherste Terkehrsweg: ohne welchen es mit den Buotfihrten an ilen Kïsten schlecht liestellt wäle.

\section{f. Iner Sandstrand.}

Der Sandstrand bedarf nur noch weniger ITorte; seine Bildung ist hei der Entstehmng der Riffe hesprochen. (IT. 4.) Eigenartig ist hier in der ... Sa ndküste.* das Vorkommen oft an mehr als 100 m lireiter und limger Brackwasserlagunen. 
welche Sïsswasserquellen oder Flüssen ihre Entstehung rerdanken. Besunders reich an solchen Lagmen ist die Gegend um Saluafatil. Am Sandstrande ist eine Sandsteinhildung ron I)ana erwihnt (beachock). welche rein sedimentär entsteht. Am Strande ron Mulinu'n. Tailele n. s. w. ist er allenthalhen vorhanden, bei Ehbe freifallend. Es handelt sich um eine gegenwärtige Bildung ans grobem Korn. Korallenstücke und kleine Muscheln finden sich häutig eingeschlossen.

\section{Die Bestandtheile der übrigen Riffformen (Barriere, Atoll) und die Definirung der Begriffe Bucht, Hafen, Riffbucht, Riffhafen, Einlass, Lagune, Bootpassage, Barrierencanal, Strandcanal, sowie über die natürliche Regulirung derselben durch Ströme.}

Wir sahen bei dem Strandriff. dass es ans bestimmten Bestandtheilen in seiner vollen Aushildung hesteht.

Yon den übrigen Riffformen lïsst sich sagen. dass sie nur theilweise diese Bestandtheile hesitzen: als nener kommt hei den Barrieren und Atollen nur die tiefen Canäle und Lagunen hinzn.

Die Korallenbänke sind die Bildner jeder liffform. indem durch ihr Znsammenwachsen diss anstehende Riff gebildet wird.

Das Sanmriff ist gleich der Leekante eines Strandriffs. es kann alles im Miniaturmaassstabe rorhanden sein: meist jedoch fehlt die Plattform und die Lagune.

Die Barriere besitzt eine Plattform. An Stelle der Lagune ist jedoch der Barrierencanal vorhanden. Innerhalb der Barriere können Kurallenbänke. Saumriffe und Strandriffleckanten rorhanden sein. wofür die Tektonik des Landes maassgeliend ist.

Das A toll endlich enthehrt wie die Barriere des Sindstrandes. Eine StrandJifflagune kann andentungsweise rorhanden sein. dimn ist das Atoll eben ein Strandriff ohne Stramd. Meist jedoch ist die Atolllagune tief. dann ist sie ilentisch mit dem Barrierencinal.

Die Plattformbildnng ist bei den Atollen am stirksten rorhanden, da die in freier See gelegenen Wind und Wetter am meisten preisgegehen sind.

Es bleibt noeh ührig, die Benennung einzelner Rifttheile etwas zul definiren.

Bucht und $\mathrm{H}$ afe n sind Bildungen, die durch Anshuchtungen des Landes erzengt werden. Nehnuen jedoch nur Korallemrifie an ihrem Entstehen theil. so werden wir von emer Riffhucht und einem Rifhafen zu sprechen haben. was bezeichnen wïrde. dass dieselben hlind enden. also nirgends einen Sindstrand anfweisen. Dies ist der Fall hei der Ledepalund bei Apia. der Fangaliibucht, der von Vailele n. s. W. die man gewöhnlich anch Riffeinlässe henemnt.

Kleinere Linschnitte in der Rifflkante. welche man nur mit einem Boot palssiren kamn. werden allgemein als Borotpassagen bezeichnet. Sie haben den Tweck, das Boot ans tem tiefen Wasser. sei w ans der Sere dem Hafen order der Riffbueht in die Hache lalgume zu hringen. 


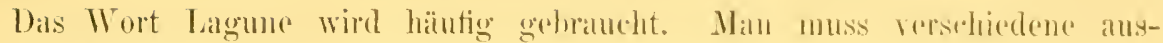
einander halten, vor allem

die Atolllagnue.

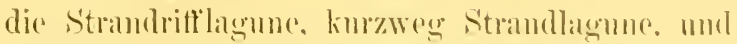

die Brackiwassorlatgme and der Silndkïste.

lalgume heisst eben Stillwasser.

Ehensowenge aber als man das ruhige Wassere im Hafon Latemne menut. solite man das Stillwasser der Rifthuchten su henemnen. Sie heissen chen Finlässe (inlet) mol bei den Bamrieren ('imïle.

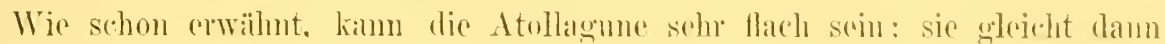
der Strandlagme, welehe immer dureh grosse Flarhleit ausgezeichnet ist, so dass bei Springniedrigwasser Bunte nieht mehr passiren kïnnen, selbst nicht im Strandeamil.

Ich möehte den Namen Stran dranal für diesen Theil vorsehlagen. da seine Bildmo mit dem Simdstrand so rng velinüpft ist mol dies eine hestimmte Enterschejelung bewirkt. namentlich gegenïber den Barrierencanälen. Ehenso Strandlagune im Gegensatz zn allen anderu.

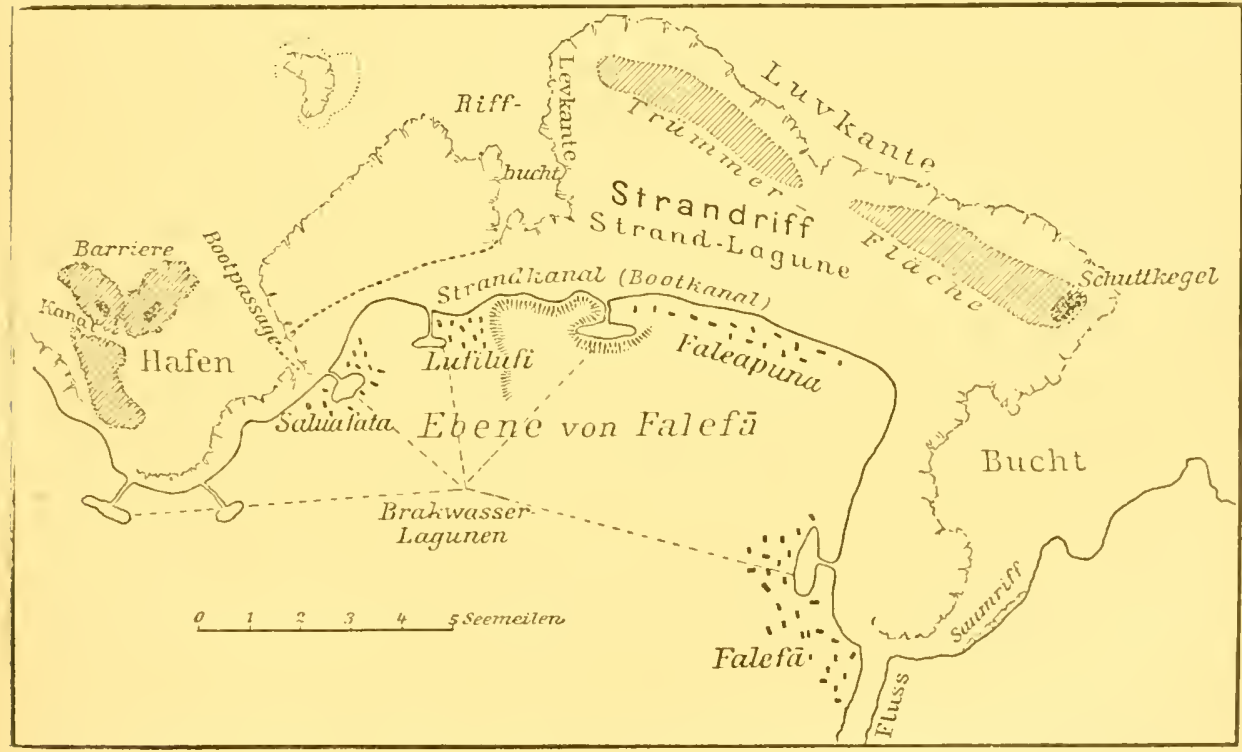

I)as Atuariff mit Beispielon der Bezeichnung der einzelnen Rifftheile.

Der Strandeamal ist in der That dem strande oft so nilheliegend. dass man

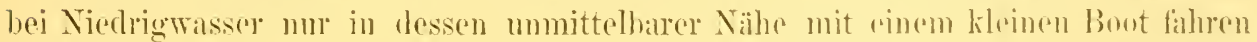

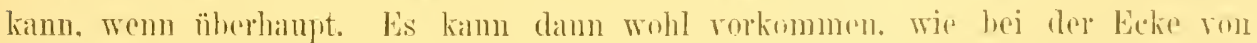
Matautu im Apialnafen, dass man mit rinem Rirmen im Siande des Strandes, mit dem andren in dem dere ladgrme pullend, fülıt.

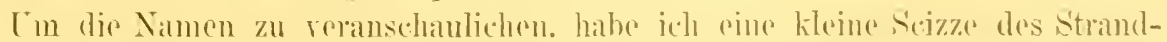

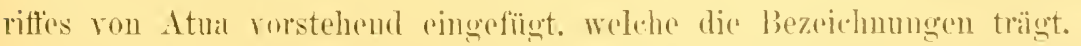

Wie schon erwihnt. wird der Strom hei rintretender Fluth anflandig. Dies

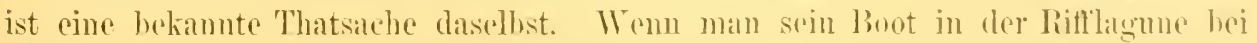


Niedrigwasser liegen lïsst und man entfernt sich ohne es festzumachen, so treiht es, sobald die Fluth eintritt und das Wasser über das Riff strömt, mit dem Strome weg dem Strandeanal zil. Da das Riff von der Plattform aus gegen Land zu at)fällt (oft über $1 / 2 \mathrm{~m}$ ), so strönt bei eintretender Ebbe alles Wasser landwärts und eilt ron dort am Strande durch die Canäle und die Seitenablässe (Bontpassigen) ah, wodureh ein Strom entsteht, der den Sand mit sich führt und in den Riffeinschnitten und Innenhäfen ablagert. wodurch daselbst das Korallenwachsthum hintangehalten wird und nur in einzelnen Korallenbänken fortznkommen vermag. Im Aussenhafen findet sich desshalh gewöhnlich nur noch Schlick. Besonders eingreifend wirken indess die Stürme, welche Ströme innerlalb der Riffe an Strande erzengen, reissenden Giesshächen gleich. Ich habe schon bei der Beschreihung des Apiahafens (IV. 2b) und des Orcans rom März 1889 (III. 2) solcher heobachteter Ströme lirwähnung gethan. Auch ron anderen Inseln (namentlich ron I) ana) liegen zahlreiche Angahen vor, so dass es nicht benöthigt darüber noch weitere Worte zu verlieren.

So ist es den Winden und Gezeiten zu danken. dass die Riffe offene sichere Wasserstrassen bilden, welche den kleinen Bootsverkehr imnerhalb der Küstenorte amöglichen. Ohne sie würden die Bootspassagen bald ansgefüllt und in den Buchten und Häfen würden Veränderungen eintreten, welche wir vorerst nicht absehen kömnen. Tor allem sind es die Gezeiten. welche durch ihre Stetigkeit den Riffen ihre charakteristische Form geben und daher ist es auch zu erklären, dass an Orten, wo diese fehlen oder gering sind, scheinhar nene Riff formen aultreteu, welche man indessen leicht auf die genannten Formen wird zurü̈ckführen kömnen. 


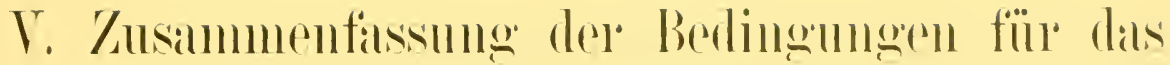 Riffiwaldstlım!n.}

\section{Tiefengrenze des Wachsthums und Dicke der Riffe.}

1)ieselhe ist immer noch nicht sieher festgestellt: eigene sichere Beobatehtumgen kann jeh auch nicht beibringen. Doch ist das sicher. dass his zu 15 m der Fuss der Riffe sich ausdehnt. Jenseits der go m Grenze ist meist in Simoa Schlick gefunden worden. Jerlenfalls ist die Genze varialoel und liegt zwischen $\overline{1} 5$ und $20 \mathrm{~m}$ Tipe.

Guply und Smith (Nature 1889 S. 223 ) hahen lehemele Steinkurallen his zus $80 \mathrm{~m}$ gefunden und zwar letzerel ron $36 \mathrm{~m}$ al noch 18 general mit 40) species. Dass dies nicht von Belang fül die anstehenden Ritte ist, scheint nahezu allgemein allğenommen.

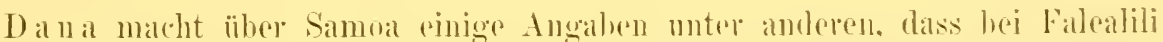
in $40 \mathrm{~m}$ nur noch nackter Fels gefunden worlen sei. Agassiz fand hej den Tortugas-Riffen 6-7 Faden $(11-13 \mathrm{~m})$. Was zwrifellos otwas zu gering ist: ahere dies heweist doch. dass die Grenze in diesere Linie mugefiiln liegen muss.

Gesetzt jedoch. dass auch unch tiofer (üher 2.j m darf ausgeschlossen werken) der Fuss hinabrejeht. so ist doch wahrseheinlich das Wachsthum daselhst so eingeschränkt. dass es nicht mehr in Betracht kommt. Sïheres siehe hei Heliotropismus und bei Talus-Bildung (IT. 5a).

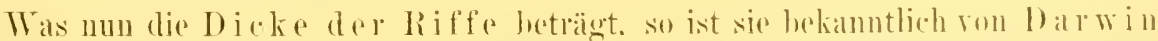
und Dana als recht heträchtlich ..herechnet." worden anf Grund del Senkungs-

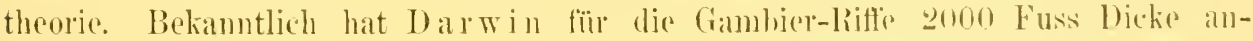
gegeben. Für Tahiti gieht D) a na 250 Fuss an. mul fül l julu 440 Fuss und bei $3^{0}$ Inclination 260 an äusseren liande (3e. S. 158). Nun hat aher Il of fma $n$ u schon 1882 auf Grund seine Lothungen darauf hingewiesen (e) find 70 m in 3. Sme Abstand), dass die Inclination nur 3 Minnten heträgt $(150$. 233). I)ies ist D) a na offenhar nicht hekannt geworken.

Jukes Browne and Il areison machen num rou barbadoes folgende Angaben (46 S. 208):

.. Ton ohigen Berienten üher die Korallenrifte, die um Barbadoes zur Zeit wachsen, können wir mehrere Thatsilehen ersehen. welchr licht auf den Bau und 
die Formation der gehohenen Riffe mol Kilksteine werfen, welehe einen so grossen Theil der Insel bedecken. Vor allem zeigt sich, dass Korallenrifte sicher aus Tiefen von 25 bis 30 Faden aufwachsen kïmmen. sodass, rorausgesetzt sie wïchsen für eine gewisse Koitspanne beständig fort olme jegliche Bewegung des Landes, sich ein liff von ungeführ 180 Fuss $(50 \mathrm{~m})$ bilken könnte."

Dies ist an und für sich für Simna einfach dadurch widerlegt. dass weit ansegedelnte Plateaus ron dieser Tiefo sich submarin ron den Korallenriffen anshreiten, die. wenn dies möglich wäre, alsdann ron Riffen bedeckt sein müssten. Ausserdem zeigen die Rifflunchten rom Leclepar. Fangalie. Lufiluti u. s. W. deutlieh. dass cine plötzliche Vertiefung ron $20-25 \mathrm{~m}$ im Intergrunde genügt. den Riffrand $\%$ unterbrechen (s. Karte mel 15 . Eh).

Den beiden Autoren ist wohl die Arbeit rom Sluiter unbekannt gehliehen. wonach die Riffe riele Meter tief in rlen weichen Cutergund einsinken kïmen. Diese gehobenen Riffe hedürfen zweifellos eincr ermenten Durchsicht hehufs Topographie und Petrographie. Ist es aber doch so, so muss man eine temporäre Senkung für die Erklärung zn Hilfe nehmen.

Bei festem Boden wird man annehmen dïrfen, dass die Lurkante der Riffe 10-14 m dick ist. die Leckante. wenn nicht zn weit in Hafen liegend. 14-20 11 .

Wird bei einer Buhrung tiefer Korallenkalk gefunclen, su wird erst seine Composition bestimmt werden müssen. Es wird sich natürlicherweise anch an einzelnen Orten aroignen. dass man eigentlichen Riffkalk in grösseren Tiefen findet. demn niemand fällt es ein. temporäre Senkungen zu lengnen: wundern wird sich aber auch der ausgehildetste Antidarwinist, wenn er bei der Mehrzahl der Atolle in geringen Tiefen schon anf anderes Gestein stïsst, demn die sïculare Senkungshypothese sitzt einem doch gewissemaassen in den Knochen.

\section{Die Einwirkung der Brandung und starker Ströme.}

An der Hand der Fusshildung wurde gezeigt, dass die Brandmmg sehr hindernd auf das Vordringen der Riffkante wirkt. Anch die Trünmerflächen zeigen deutlich den Schaden, den die stark bewegten Wasser amichten. Es ist dies ja atch an mon für sich sehr natïrlich. Trotzdem hat sich bei den meisten Beobachtern die Ansicht ausgeprägt. dass die Korallen in der Brandung besser wachsen als im stillen Wasser.

So sagt sehon Ehrenberg (1 b. S. 49). dass im Rothen Meer die stäristen Korallen an Riffiand vorkommen mol die Brandung zu lichen seheinen. End C'ham isso erzïhlt ron ihnen: .. Die Korallen wachsen am hesten in der Wogenhrandung und der Ring (der Atolle) entsteht darlureh. dass sie dem Meere entgenenwalchsen."

I) ar w in sigt (2. S. 53) nach Besprechung verschiedener Beobachtungen: .. Aus diesen Thatsathen rhellt. dass die stärksten und massigsten Korallen da gredeihen. Wo sie am meisten exponiet sind."

Ferner 1$)$ al 11 a: (3 (:. S. 229)

.. Lis wurile gezeigt. dass die Korallen. die die Riffe bilden, nicht in den ruhigen und stillen Tiefen der Oceane wachsen. Sie werden in den Wogen gefunden und kommen gewöhnlich nicht tiofer als 100 Fuss vor. was weit im Be- 


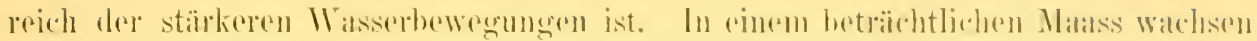

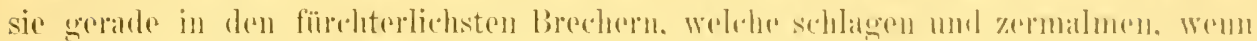
sic übure das rith treiben."

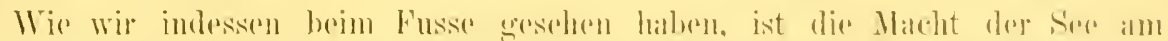

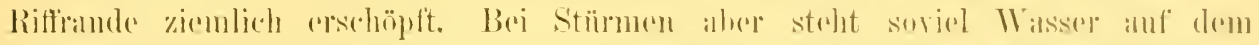

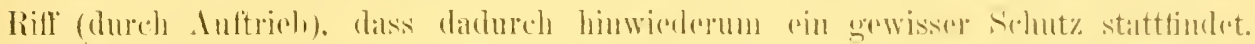

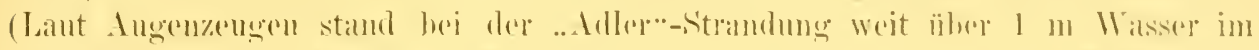

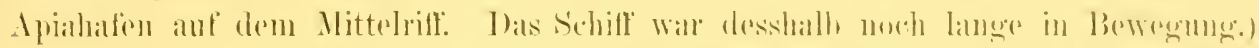

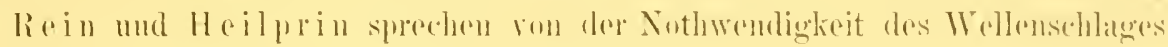

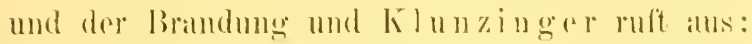

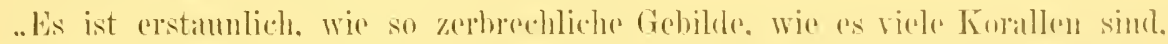

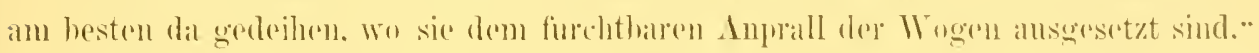

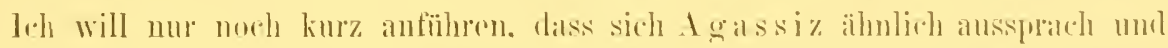

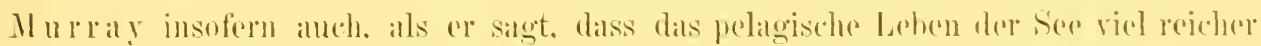

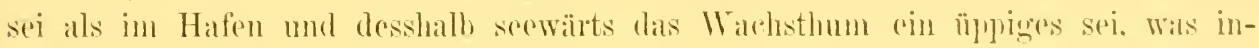
dessen für simmoa alled nieht richtig ist.

lis sime jedoch nicht alle Boobachter dieser Meinmeg. Vur allem laben

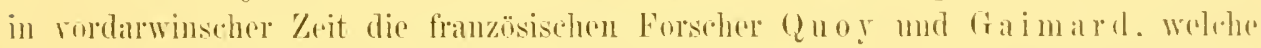

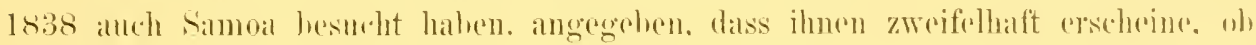
iroend eine Korallenart hestehen. oder selhst gadeihen kïmne in den Brechern der

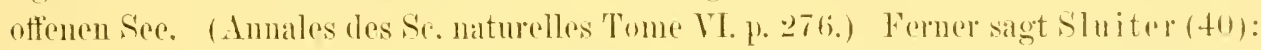

.. Dass. wie rom Dar win und Murray herrorechohen wird. der Ramd des

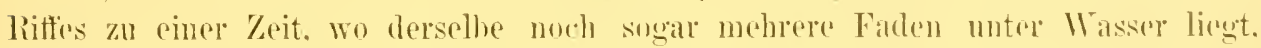

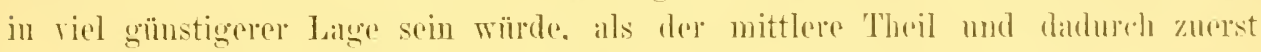
in die Höhe wathsen med ain Atoll bilden wïrde. triftt jedenfalls bei den hiesigen Rittion nicht zu."

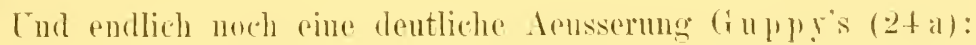

.. Wie schon angeführt. sime die grossen massigen Korallen selten in der Brandung zu sehen. Sie ziehen die weniger zngäinglichen Theile des liftes ansser

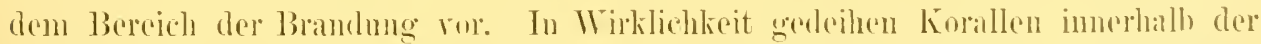
Passathrandung nicht. Sie werden nur in Teppigkeit gefunden am abfillemdru Hange in Tiefen ron 5-15 Eaden. der Ahlang, welche als .. growing edge. des Riffs hezeichnet werelen kïnnte.*

Einen Beweis dafiir. dass in den jwirklichen Brochern die korallen nicht

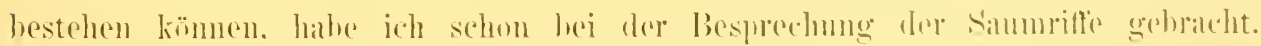

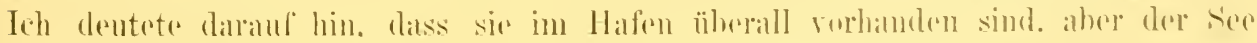

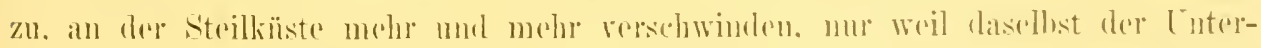
grumel die Ausbildung aines busses nicht gestattet. Gamz follen sie indesion anch

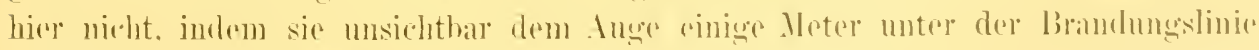

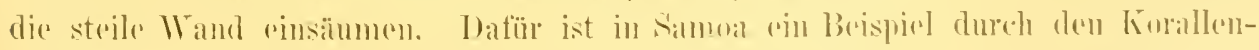

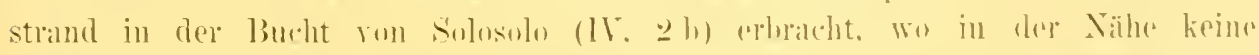

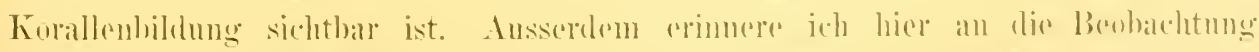

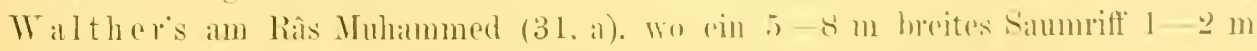
muter Wassere liegt. 
Aber nicht allein die Brandung ist nachtheilig für die zartgefügten Anthozonen. auch ein starker anhaltender Strom wirkt wachsthumbehindernd. Ich führe hier nur die Angaben Semper's ron den Philippinen an (9 c. 2. Theil S. 36):

.. Beide Lfer des Canals sind gehildet ron Korallen. die aber doch an der Nordseite, also an der Küste ron Malaunari an stärksten entwickelt sind. Es sind die gewöhnlichen riffhauenden Arten, Astraeen, Porites, Madreporen u. s. W. Nun hesitzen diese. wie alle grössere Blöeke bildenden Arten. die Tendenz. nach allen lichtungen hin sich anszubreiten: hier aber tritt ihnen der starke sie tangirende Strom hindernd entoregen. welcher, wie schon hemerkt, die grösste Zeit des Jahres constant in einer Richtung durch den Canal fliesst. Wäre er schwächer als die Wachsthumsstärke der Korallen ist. so wïrden diese den Widerstand leicht ïberwiuden: er ist aher vielmehr stark genug. sie zu völlig verticalem Wachsthum zu zwingen. So ist das liff namentlich an der Seite von Malannavi nur wenige Schritte breit: aher dann stürt es völlig senkecht in die allerdings nicht hedeutende Tiefe ab."

Auch von Möhius führe ich hier eine Angabe an (20 S. 29) vom Fouquetritt' auf den Serchellen:

.. Diese starke Strömmng reinigt offenbar fortwährend den Canal zwischen den Küistenriffen und dem Dammriff ron den Schlammmassen, welche die Flüsse vom Lande her in ihn hineintragen und die Wogen rom Aussemiff her hineinwerfen. und verhindert die Vereinigung des Dammrift's mit der gegenüberliegenden Küste zu einem einzigen Kïistenrift."

Brandung und Strom sind schlimme Feinde der Korallen: aber sie wissen diesen Fährlichkeiten zu trotzen nnd die Kraft iluer Feinde zu schwächen und wenn nicht neue Feinde sich hinzugesellten. so würden sie in siegreichem Zuge rorwärts dringen.

\section{Der Einfluss der Meeresströmungen als Nahrungsquellen.}

In vorhergehenden Abschnitt wurde schon der Muray' schen 'Theorie biähmung gethan, welehe darin gipfelt, dass die Atollform entsteht dureh das Wachsthum der Korallen nach anssen wegen des grösseren pelagischen Reichthums der See und nach innen hin die Lagune gebildet wird durch Auflösmug des Kalkes im Seewasser. M ur r y sagt darïher (21 a S. 508): .. Die meisten dieser Organismen lehen von der Oherfläche his zu 100 Faden abwärts: hei warmem Wetter sehweben sie nahe der Oberfläche, aher wem es rauh ist, sind sie einige Faden darmere. Sie werden in den grossen ocemnischen Strömen längs getragen. welche dureh die Winde geschaffen sind: und wemn sie ein Korallenrift treffen, versorgen sie die Forallen an der äusseren littseite mit reichlicher Nahrung. Der Grund, warum die Lurseite eines Riffes lehhafter wächst. scheiut dieser ledehliche Nahrungszufluss zu sein und nicht die reichere Zufuhr ron Sauerstoff, wie allgemein hestätigt wurde. Die challenger- Cntersuchumgen zeigten, dass Sauerstofl' hesonders reich in allen Tiefen vorhanden war, in denen Korallen gedeihen."

Die sonst so ghrreichen Errungenschaften der Challengerexpedition haben in dieser Richtung Verwirrung angerichtet. Icll werde weiter unten heim Plankton die Daten heibringen, welche beweisen, dass das Plankton der 'Tropen weit ärmer 
ist an Quantitït, als das der gemëssignten Yone. wenigstens in der Südsee, und dass ron Mecresströnen als Thierstratssen dasclost keiue hede suin kimn. Fhenso unrichtig ist die Annahme, class im offenen Meer mehr l'lunkton soi als an der Küste resp. in den Lagunen. Natürlicherweise sind die Daten dieser herïhmten Expedition für alle folgenden Beobathter leitend gewesen.

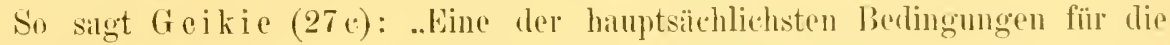
Rifthildung ist Ceherfluss an Nahrung für die Rifflihlner und diese scheint am hesten durch die grossen Aequatorialströme zugeführt zu werden."

Semper nimmt den Einfluss eines solehen Stromes fiir die Palauinseln und Agassiz den des Golfstroms für die westindischen Riffe an.

End ron letzterem sagt $\mathrm{Br}$ row ne and $\mathrm{H}$ arrison $(46$ S. 206): .. Ein Grund für das kräftige Wachsthum an diesem östlichen Ende der Insel (Barbadoes) ist wahrscheinlich. dass die Polypen hier eine überrejehe Nahrungsversolgung durch den Golfstrom erfahren, welcher hier das Eiland bespüilt."

Ls soll num nicht gesigt seiu, diss für die Korallen ein Wasserwechsel nicht nothwendig wär. Bei der Luzahl von grerigen Nägen, welche am Abhang eines Korallenriffes zusammengedränert sind, scheint eine solche nothwendig sehon aus hỵgienischen Grïnden. Es wäre ja alleh denkbar, dass bei mangeluder Wasserbewegung ein gewisser Nahrungsmangel ointreten kïnnte, ohwohl die lehhaft beweglichen Copepoden überallhin nachdringen. wo cine Leere entsteht. Diese Krehse müssen als ein Hauptnahrungszweig der Korallen angesehen werden, da sie in jedem Planktonfang relatir reichlich rertreten waren. während die ührigen Planktoncomponenten in Samoa in Verhältniss zul Zahl der consumenten rerschwindend gering sind. Ind die Copepoden wollen doch anch ermïht sein! Man denke sich nur, dass eine der zallhreichen hreiten Madreporenschalen an 100000 Polypen trigen kamn. und $1 \mathrm{chm}$ Seewasser diselbst nur einige tausend copepoden besitzt. Wenn man anch nicht annehmen darf. dass jeder dieser Polỵen tïglich etwas zu fressen hahen muss (denn es sind jil doch mur viel Mäuler und ein Körper). so bleibt doch die Schwierigkeit. dass mehrere solcher Platten auf 1 ym kommen.

Ich will hier nicht länger bei del Plankitonfrage bleiben, denn weiter unten in Ahschnitt IX sind alle diese Fragen eingehend besprochen.

Die Strömungen sind für die Neere im wesentlichen nicht mehr als die Winde für die oberfläehe der Erde. Sie beide sorgen für die Wegsehatfung der Stoffwechselproducte, damit keine Stagnation eintrete. Es führen die Winde ebensowenig eine besondere Menge von Sanerstoff mit sich, wie die Ströme eine hesundere Menge ron Plankton. Wie die grosse Zahl ron Köpfen in den Metropolen den Sauerstoff der Luft nieht zu verringern vermögen. so rermögen die wenn auch viel zahlreicheren, aber so kleinen Korallenpolypen die mugehemen Mengen ron Plankton. welche der Ocean birgt*), merkhar zu decimiren. Fïr den Nahrungszusehub leisten die Gezeiten ïbergenug. Der Ströme des Meeres können wir, fïl Samoa wenicgstens. vollstïndig entrathen.

*) Nach einer sehr niedrigen Berechnung sind in einer Seemeile Lmkreis um das Rose Atoll gregen 1000 Tonnen (à $1000 \mathrm{~kg}$ ) Copepodenplankton rorlanden. 


\section{Sterben Korallen an der Luft ab?}

D arwin sagt (2 S. 10): ..Ich muss zuerst bemerken. dass die riffbildenden Korallen, da sie keine Gezeitentliere sind, beständig mtergetancht oder von den Brechern üherenaschen sein müssen. Ich wurle ron Mr. Liesk versichert. einem sehr intelligenten Bewohner der Inseln. ebenso von einigen Häuptlingen von Otaheite. dass eine Aussetzung an die Strahlen der Somne anch nur während einer sehr kurzen \%eit stets ilıe \%erstörmg veranlasst."

Die neuren Brolachtungen haben dies längst widerlegt.

So saget Möbius ron den Seychellen $(20$ S. 45): ..Bei niedriger Ehbe stehen manche Korallen ohne Nachtheil in der Luft, z. B. Goniastraca retiformis und Leptoria gracilis. Während dessen bleiben dic Polyjen zurïckgezogen und die ganze entblässte Oherfläche des Stockes ist mit Schleim bedeckt. der das Tertrocknen hindert."

Und Ortm a 11 . einer unserer besten Korallenkenner. sehreilit ron Dar es Salan (48 S. 635): ..Ieh konnte constatiren, dass - wie schon von anderen Forschem beobarhtet wurde - gewisse Korallenarten stundenlang den directen Somnenstrahlen ohne Wasserbedeckung ansgesetzt sein kïnnen. ohne dass ihre Lebensfähigkeit dadurch geschärligt wird. Lnter solchen Verhältnissen fand ich 3 Arten: Porites lutea. Coeloria sinensis mol Goniastraea se pchellonsis."

Auch Walther macht daüber eine Angabe aus der Pallistrasse (31 S. 18): .. Es war bei tiefer Ehhe, als ich mit meinem Camm und 9 Bootsleuten und Tanchem bei ..Kurrysudly." ankam und eine etwa 300 Sehritt breite Rifftlïche theilweise rom Wasser entblöst fand. In Inurchschnitt stand 20_-30 cm Wasser n̈ber den lebenden Korallenstöcken. aber gross war mein Erstamen. als ich Schime ron Madrepora und Pocillopora $4 \mathrm{~cm}$ aus dem Wasser heransschauen sah. Wwar spülten die kleinen Wrollen oft über disse heransragenden Korallenäste, aher mehrere Minuten lang blieben sie oft unbenetzt und demnoch schienen sie ruhig weiturzulehen."

Ich selbst habe wiederholt Madreporenstöcke nancutlich an der Leekante dor Riffe üher Wasser gesehen, allerdings stetig ron der Dümung in kleinen Zeitintervallen lespïlt. binzelne Stïcke davon habe ich als Belege mitgenommen.

bimen solehen Iugenhlick des Zurïcktretens der Dünung hat auch der Photograph 1 ndrows in Samoa benutzt. mm das erwähnte Korallenbild ron der Leekante zn gewimnen.

Ueber Lederkorallen besitze ich ähnliche Beobachtungen. wie sie Sarille Kent in seinem Werke photographisch festgehalten hat. Das von Wasser strotzende sehwammige Gewebe remag natürlich eine stundenlange Exposition in der Sonne zul ertragen.

\section{Der Heliotropismus der Anthozoen.}

toh habe darzulegen versucht. dass die Brandung, kurz, starke Wasserbewegung und die Terunreinignng des Wassers es sind, welche das Wachsthmm der Riflkorallen so sehr beeinflussen. Einen nemen Factor haben wir indessen noch nicht in Erwägmng gezogen. wolcher namentlich ersterex stetig entgegenatbeitet. ieh moine den Heliotropismus. 


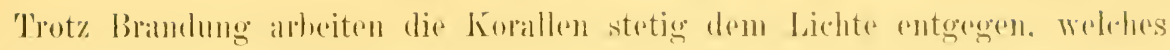

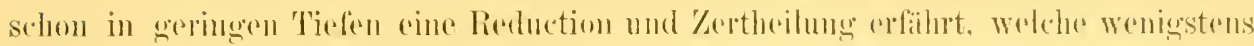

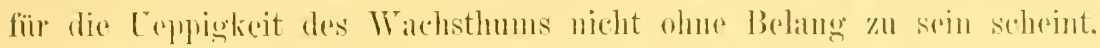

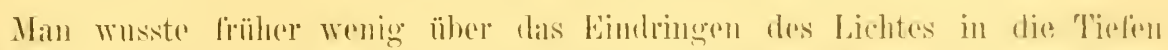

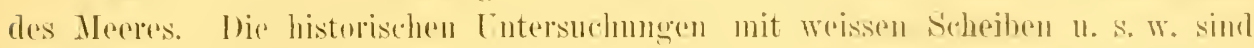

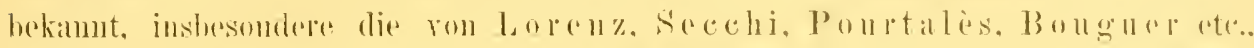

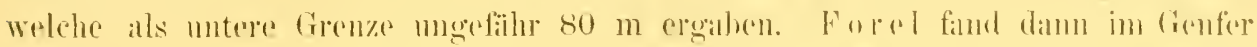

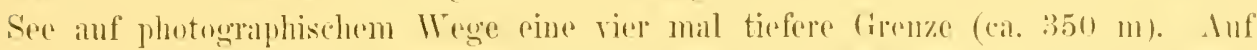

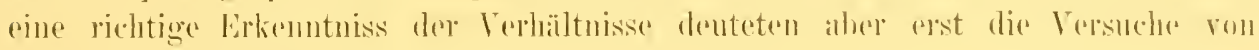

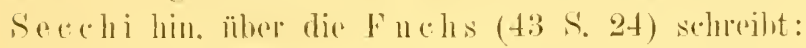

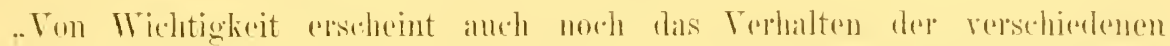

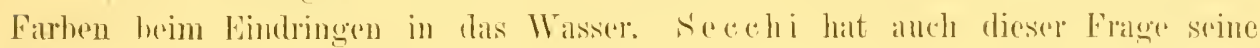

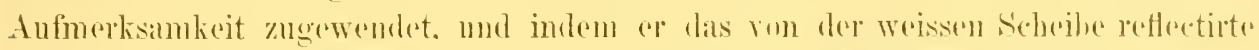

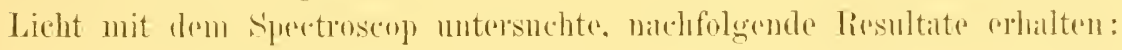

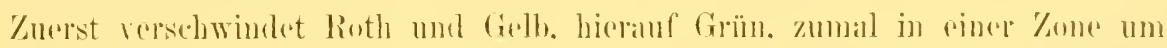

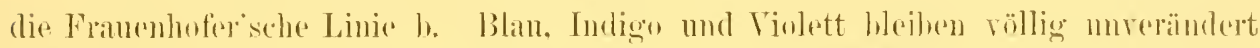
und ziemlich lehhaft. wodurch sich atuch die Fathe des Mecres, ein schömes, otwas in Violett neigendes blau erklärt.:

Man hat in früheren \%eiten vielfach angenommen. diss die rothen Strahlen des Spectroms an tiofsten in Mreerwasser cindringen und daraus alluh die häutign

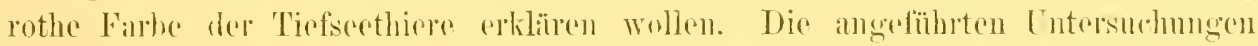
zeigen jedoch, dass dies vollstïndig irrig sei und in der Tiefe violmeht aine bline und vinlette Farho lerrschen müsse."

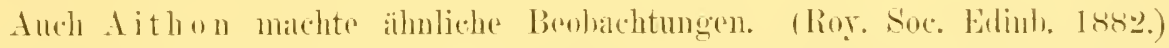
Diese relativen Angaben sind mun in nenerer \%eit ron meinem einstigen Lohrer.

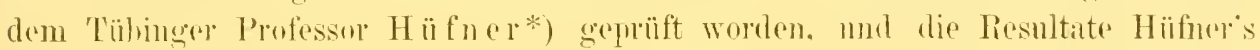
hinwiedermm hilben durch die Cntersuchungen rou E. Aschkinass. Welehe biologisch loider nichts menes brachten. ihre rolle Bestitigung erfihren. so diss man nun mit Sieherheit die Extinctionscoefficienten des Viassers fül die vinzelnen Strahlen des spectrmms kemnt. allerdings nur in destillirtem Milssel. Wis wäre sehr zu wänschen. dass diese Versuche mit Salzlösmgan. rersehieden temperirtem Wasser und bei rersehiedencem Finfall der Strahlen fortgesetzt würden. damit sie auch der angewanden Physiki diensthal sinel.

Aher obwohl alle diese Lntersuchungen im Laboratorim gematht sind, und

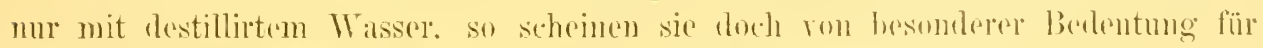
die Photologie les Mleres zu serin. H ï fue found, lass dureh eine 180 am lange Sä̈ule frisch destillirten Walssel's (17-18" (') von den rothen Strahlen des Spec-

;) Die austiihrliche Besehreihung befindet sich in den Annalen der Physik und ('hemie 13d. 42 S. 1-17, die Resultate in Arehis fïr Anatonio und Physiologie. physiologische Abtheilung 18:1. wo insbesondere die Biologie beriicksichtigt ist.

E. Aschkinass. Teber das Mbsorptionsspectrum des flïsigen Wassers und ïber die Durchlïssigkeit der Augenmedien fïr rothe und ultrarothe Strahlen.

(Wiedemann's) Amnalen fül Physik nnd ('hemie. Bd. 55 S. for 1895. 
trums (671-658 $\mu$ Wellenlänge) nur 49,25 \% durchgelassen wurden, während von den Indigostrahlen $(452-446 \mu) 95,06$ passirten. Er fand den Extinctionscoefficienten für erstere $=0,001709$. für letztere $=0,000122$. Fr berechnete ferner. dass die gelben Strahlen im allgemeinen in der Tiefe von $34 \mathrm{~m}$ nur noch dem Vollmondslichte entsprechend vorhanden sind, dass aber schon in $10 \mathrm{~m}$ Tiefe durch Absorption dieser Strahlen. durch Entziehung der Complementärfarben ein Licht vorhanden sein mïsse. welehes uns als Cyanblau erscheint. Helmholtz fand das Sonnenlicht aus folgenden 4 Parren Complementärfarben zusammengesetzt: (phỵsiologische Optik Leipzig 1867).

$$
\begin{aligned}
& \text { Roth-Grünlichblau } \\
& \text { Orange-Cyanblan } \\
& \text { Gelh-Indigoblan } \\
& \text { Grünlichgelb-Violett. }
\end{aligned}
$$

Die Extinctionscoefficienten für dieselben Farben sind nach $\mathrm{H}$ ü fnè

$$
\begin{gathered}
0,001709-0,000160 \\
0,001226-0,000119 \\
0,000494-0,000122 \\
0,000328-
\end{gathered}
$$

In $10 \mathrm{~m}$ Tiefe sind unch folgende Werthe vorhanden:

$$
\begin{aligned}
& \text { roth } 19 / 1000 \\
& \text { orange } 59 / 1000 \\
& \text { gelb } 820,1000 \\
& \text { hlau } 760 / 10010
\end{aligned}
$$

und in $100 \mathrm{~m}$ :

$$
\begin{aligned}
& \text { von grian nur noch } 12 / 1000 \\
& \text { und von blall } 64 / 1000
\end{aligned}
$$

Es wird also zuerst das Roth absorhirt und ist schon in $15 \mathrm{~m}$ Tiefe siecher nicht mehr vorhanden. woselbst das Wasser grünlich-blan ist. Nach dem Roth sehwindet das Orange; das Wasser wird eyanblan. Nach Extinction von Gelb muss das Wasser indigoblau erscheinen und in die grösseren Tiefen (500 bis $1000 \mathrm{~m}$ ) dürfte $110 \mathrm{r}$ noch das Violett rordringen. zu geschweigen von den wunderbaren nltrivioletten Strahlen.

Für die grünen Pflanzen ist es nun schon längst sieher festgestellt, dass sie in den geringer hrechlaren Strahlen am besten assimiliren;*) so fand Pfeffer (nach Hüfner). dass die Elodea canadensis im Gelb 5mal stärker als im Cyanblan. 8mal stärker als im Indigo und 14mal stärker als im Violett arbeitet. (Pflanzenphysiologie 1881.) In neuester Zeit hat anch Flammarion der Academic zu Paris Resultate solcher Cntersuchungen vorgelegt, welehe in den Comptes rendues 1895 ( $\mathrm{Nr}$. 25) enthalten sind. Danach fand er das Wachsthum einer Pflanze in rerschiedenem Lichte folgendermalassen gestiltet:

*) Siche auch Engelmann „Wie Farlen hunter Laubblätter und ihre Bedentung für die Kerlegung der Kohlensäure im Licht." Botanisehe Keitung 1887. Absorption und Kohlensäure zerlegende Wirkung des Lichts in den Chromophyllkörpern der Pflanzen sind einander proportional. 
ill rothem

Höhe dor Pflanze an 6. Septhr.

0,220

(),345

0.420 in grïne!!

$0.090 \mathrm{~cm}$

$0.150 \quad$..

$0.152 \quad$. in hlauem Licht

$0.027 \mathrm{em}$

0.027

0.027 .

Diese Dilten sind in die Angen springend. Man weiss jil anch längrst. dass

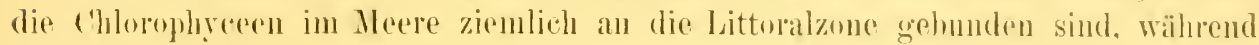

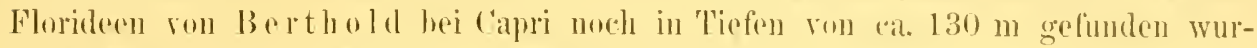
den (Mitth. der zool. Station zu Neapel. Bal. III).

Fïl die 'Thiere sind mir soleh' sichere Resultate nicht hekamnt geworden. immerhin wenigstens genug. um lier darthun zu können. dass auch untel ihmen wenigstens gewisse Formen nicht indilferent gegen rersehiedene Lichtstrahlen und das licht ïhrelkanpt sind.

Gegen Ende des lotzten Jahrhunderts hat Trembley dargethan, dass die Hydrapolypen rinen ausgeprägten Heliotropismus besitzen. Paul Bejt stelle mit Daphnien Versuche an, indem er anf einen Trog ein Spectrum projicirte. und fand. dass dieselhen in Gelb. Grïn und Roth grössere I,chendigkeit zeigten und anch diese Strahlen den blanen und rioletten rorzogen. Lubbock und G raber hathen zahlreiche Versuche in ähnlicher Richtmng gemacht. Ferner Stahl an Euglenen u. s. w. Alle diese Arbeiten sind in Loebs Anfsatz ..10r Heliotropismus der Thiere und seine Cebereinstimmung mit dem Heliotropismus der Pflanzen (Würzhurg 1890 ) besprochen. laeb weudet sich — etwas heftig - gegen den Aus-

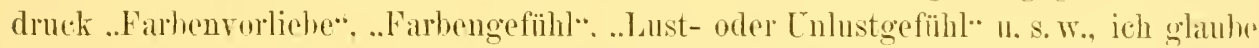
mit gewissem Recht. Aus der Pflanzenphysiologie geht doch zur Genüge herror. dass das rothe Licht für die Assimilation ungleich wirlisamer ist als das hlaue oler gar violette. wie üherhaupt die Assimilation an dis Tageslieht gehunden ist. während ja hei Nacht der therische Process der Athmung hervortritt. Lo b berïdesichtigt den Zusanmenhang der Biogenese mit dem Heliotropismus, heschäftigt sich jedoch in der genannten Alheit nur mit Landthieren. In ciner späteren ,Weitere Lntersuchungen ïher den Heliotrop." (bonn 1890. Arele. f. d. gges. Phys. Bd. 47) hat or anch Seethiere in den Kreis seiner Cutresuchungen gezngen und gefumlon. dass ein Röhrenwurm. die Serpulide Sprirugraphis die lïhre nach dom lichte krïmmte. Interessanter sind die liesultate mit Hydroidpolypen. welche von Driesch und Lueh erzielt worden sind. Lach fand: ..Die polypentragemelen Sprossen sind positiv. die Wurehn negativ heliotropisch"”: Driesch (Youlog. Jahrhücher 1891 Syst. B(l. V.): .. Pie unter ungünstigen Verhältnissen fon Tertularella polyzonias an Stelle ron Personen erzengten Stolonen sind his anf den ersten. ron Anliug an sich rom Licht abwendenden zuerst positir und wrelen nach lizeugung ihrer Tochterstolomen negatir heliotropisch. Sir entstehen an der dem licht zugewemleten Seite des Mutterstoln."

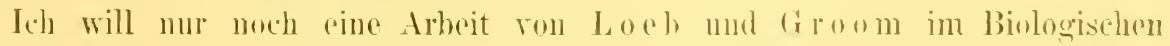
C'entrabblatt Band X 1890 ..Der Heliotropismus von bialanus perforatus und die periodischen Tiefenwanderungen pelagiselere Thiege" crwïhnen. welehe indessen von Gieshlecht nicht als zuverlässig anerkannt wirl (58h. S.807). Die paletischen Resultate. wolehe Kï ekenthal und Walther im ustspitzhergischen Eismeere erzielt haben (s. Deutsche geographische Blätter: Bd. XIII Heft 1 und 2). sind in 
dieser Beziehung wichtiger. Sie tingen bei Tage Medusen nur in der 'Tiefe ron 25-40 Faden. nachts jedoch an der äussersten Oherfläche. Dieses Auftauchen ron Tunicaten und Medusen bei Nacht ist ja bekannt, wemn auch selten so einwandsfrei bewiesen. Hs handelt sich hier allerdings um negativen Heliotropismus. Aher diese Thiere sind ja keine Kalkbildner (vergl. auch ('hun).

Was können wir aus den bisher hekannten Beohachtungen für Schlüsse auf den Heliotropismus der Korallen ziehen?

Keller. dem wir viele gnte Beobachtungen auf seiner Madagaskarreise verdanken. schreibt S. 61 seines Buches (30) üher dic Korallen im rothen Mecre:

.. Im ganzen verlangt die Koralle viel Licht und viel Sanerstoff zu ihrem Gedeihen: in der stürmischen Brandnng ist ihr eigentliches Wohnelement. In der oberen ITasserschicht, (l. h. in einer 'Tiefe von $3-10 \mathrm{~m}$, spielt sich das Leben dieser Geschöpfe ah. Schon in 10-12 m Thefe sind auffallend viel Korallenstörke alogestorben. Fast alle Arten sind eigentlich lichthungrig. ihre Thiere hauen fast nur in der Richtung der starken Belenchtung und lassen einen ausgeprïgten Heliotropismus erkennen. Es scheint bisher völlig übersehen worden zu sein. dass hier die Ursache liegt, warum die Korallenbank von einem ausgedehnten Höhlensystem durchzogen wird und nicht eine compacte Nasse darstellt. Eine Koralle beginnt zu bauen und breitet sich nach ohen möglichst ans. Eine benachlorte Koralle macht es ebenso und schliesslich erfolgt eine Berïhnung. während dio Basen getrement sind. Zwei sich erhebende Korallenfelsen verhalten sich ebenso und schliesslich führt dies zu cince lacunösen Structur der ganzen Bank."

In der That lassen sich an den Teekanten der Riffe zahlreiche Beispicle ron Heliotropismus finden. Jeder hat wohl schon die schönen Madreporenrasen gesehen, deren Aeste alle gleichförmig wie Kleiderhaken ihre Richtung lichtwärts genommen haben: und noch mehr: Jetrachtet man die einzelnen Aeste, so sieht man. wie alle Polypengehäuse lichtwärts liegen. wiihrend an der Gegenkante der Kalk ohne Polpparien ist. An den grossen Madreporenselhimen findet man nienals Polypen an der Lntertälehe: alles streht senkrecht zum Lichte empor. Lis ist kein \%weifel, dass die Korallen dureh ihren ausgeprägten Heliotropismus die charakteristischen Gestalten dor Rifie mit hedingen.

In dieser Bezichung kommt für die Korallen wohl noch ein anderer Factor in Frage: die Kalkbildung. Muray wies mit Irvine nach. dass der kohlensaure Kalk verschiedener Secthiere ans dem schwefolsamren Kalk des Mecrwassers gehildet wird (hei Gegenwart ron kohlensaurem Ammoniak) und dass diese Lmwandlung in warmem Wasser viel leichter erfolgt als in kaltem. (O) die .. PHanzenthiere" dazn nur die Krohlensä̈ure des Stoffwechsels verwenden, oder oh das Coelom altch direct Kohlensä̈re resp. kohlensames Ammoniak ans dem Mecrwasser anfnimmt*) ist. soriel iell weiss, norh nicht hekannt. In letzterem Falle wïrde es sicle um eine thierisehe Assimilation handeln und es wäre danach leicht $z$ er er-

*) Reichlich genug vorhanden ist ja freie Kohlensäure im Meerwasser, wie die Lntersuchungen Buchanan's während der Challenger-Expedition rergeben haben. Auch 11 oppeSeyler (.. Leber die Verhreitung absorbirter (iase in Wasser des Bodensees und ihre beziehung zu den in ihm lebenden Thieren und Pthanzen." 24. Heft des Vereins fïr die Ge- 
kiären. warmu die riffbildenden Korallen an die oberen Yoneil gebunden sind. wo die rothen Strahlen des Spectrums noch nieht völlig athsurhirt sind. all rine Kour, deren untere emptindliche Grenze sehom hea 10 m 'Tiofo limeren muss.

\section{Die Farbe und Durchsichtigkeit der Oceane.}

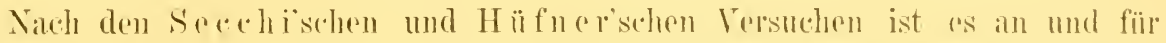

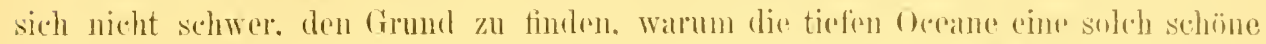
Bhane Farbe besitzen. Im allgemeinen weiss man jal, dass das Meer der Spregel

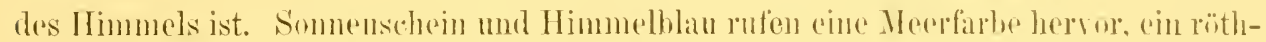

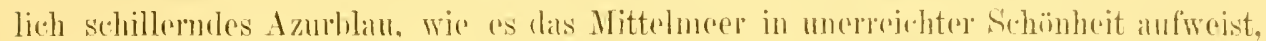
denn hier ist der Himmel ann reinsten, während in den offenen tropischen Mecren die

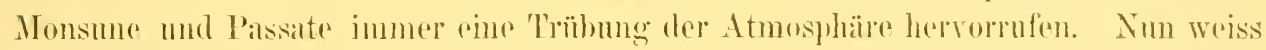

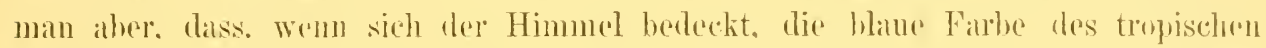
Meeres trotzdem forthesteht. Wem auch nicht so ghänzend und sehillemd. Je meh" Licht, desto mehr Glanz, desto tiofer die azurne Bläue: natürlicherweise: derm desto tiofere dringen anch die blanen und violetten Strahlen in die 'Ticfo ein. wïhrend die rothen hei gledicem Absorptionscoefficienten in den oheren Schichten zurïrkgehalten werden. Von den blanten Strahlen haben wir gesehen, dass ihr Absorptionscoefficient sehon ein sehr geringer ist: wic viol geringer ist "r "rst boi den violetten orlex ultravioletten Strahlen! So ist es leicht zu erklären. dass Fol und Sarasin ihre photographischen P'atten bei Villafranca noch in 400 in Tiefe belichtet fanden und die zoologische Station in Neapol im offenen Mere bei ('apri selbst in $550 \mathrm{~m}$ Tiefe nach einhalbstündiger Anssetzung. (Petersen).; Die Einwände gegen letatere liesultate sind nach Hïfner"s Tntersuchmmgen hinfüllig. Von flachen Meeren weiss man wohl, dass sie die Farbe des Bodens wirdergohen. Vor allem gilt dies für die Gewässer, welche nicht riel mehr als 10 m tiof sincl. (Ton Termmeinigung (les Wassers ist hier abgeschen.)

Schwarzer und graner Schlick, gelber Sind und grüner Algenboden, rothe Florillenwiesen u. s. W. gehen dem Wasser bestimmte 'Tinten. Für den offonen Ocean bildet denselben Lntergrund das dunkle Blam der Wassertiefen. ron der

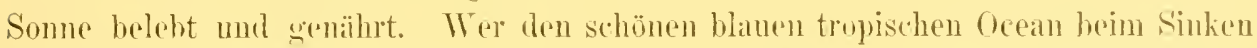
der Somne beohachtet. sieht. wie mit dem schwindonden goldenen Ball and ilie Farben des Wassers dahin schwinden. Noch ist es dinen Augenblick hell, wenn die Sonne gesunken ist, aber das Wasser ist dunkel. schwarzliau und reräth die Nacht, die schon in geringer 'Tiefe aingetreten ist und ewig in den ahyssischen Tiefen herrscht.

schichte des Bodensees und seiner [mgrobung) hat nenerdings zu Veapel folgende I aten gewonnen, die ich der Anschanlichkeit halber hior mittheilen will:

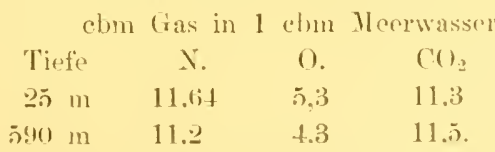

Zwar ist es wahrscheinlich. diss die Hälfte der hohlenwänre locker an Bicarbonat gobunden ist, doch bleiht anch in diesem Falle ganug iihrig.

s) s. ('hun: Die pelagische Thierwelt in griesseren Meerestiefen. S. 59. Hibliotheca zoologica Heft 11888 . 
Dass die Meere der kalten Zone nicht das satte Blau der warmen aufweisen, und sogar oft grünliche Töne zeigen, dürfte seine Erklürumg darin finden, dass die Lichtmenge hier an und fïr sich eine geringere und die Atmosphäre nahezn immer voll ron Niederschlägen ist. Ein schöner Sommertag hringt auch ein blaues Mecr. wenn auch nie den Glanz des tropischen Oceans.

Ob die Wasserwärme, das schiefere Einfallen der Sonnenstrahlen und der Salzgehalt endlich hier nicht Modificationen hervorrufen, mïssen besondere Untersuchungen hervorthun.

Fin Factor aber, dem man hishang wenig Beachtung geschenkt hat und welcher oft nicht ohne Bedentung zu sein scheint. ist der verschiedene Planktongehalt der tropischen und der kalten Mcere. Nach den liesultaten der Planktonexpedition und denen dieser Arbeit darf es ja nicht mehr zweifelhaft sein. dass die tropischen Gewässer weit ärmer an microseopischer Planktommasse sind als die kalten. Insbesondere ist es in letzteren das zeitweise Anftreten einer Lmmasse ron Diatomeen, was den warmen Meeren vollständig zu mangeln scheint. (Nicht eimmal die Phycochromaceen können hier in Frage kommen. da sie nur sehr zerstrent und an der nmmittelbaren Oberfäche leben, ausserdem aber anch den kalten Meeren zukommen.) Vor allem ist es die Durchsichtigkeit, die Reinheit der erystallenen Fluth, welche man nur in tropischen Neeren in ilrer Vollendung sicht und welche durch die Arunth an Plankton zu erklären ist.

von Drygalski sigrt in einem Aufsatz ..Zur Bestimmung der Meeresfarbe. (Petermann's Geogr. Mittheilungen 1892 S. 286) ron den Grönländischen Grwässer'n :

..Den Grundton der Meeresfarbe müssen wir, wie es sich ja anch bei den frïheren Meeresforschungeu herausgestellt hat, als ein tieferes Blau bezeichnon. dem Farhe I. der Forel'schen Scala recht gut entspricht. Wohl durch Beimengung organischer Substanzen, wie ẹs sich in einzehen Fällen dureh die gleichzeitigen Planktonfänge Dr. Ian häffen's mit Sicherheit erkemnen liess, wird diese tiefhlane Farbe in bläuliches Grïn, Grün und dann in bräunliche Töne übergeführt. Besonders die Davisstrasse war an hrümnlichen Nüancen reich n. s. w."

Ich will hier mu noch vorweg erwähnen, dass im zoologischen Institut zu Kiel Ostseefünge gezählt worden sind, die in 1 chm Wasser eimmal 4.5 Millionen ('hactoceras und ein andermal 100 Millionen lihizosolenien enthielten und dass Peck (60) noch weit grössere Mengen in der salzigen Bussard-bay in NordAmerika gefunden hat. ITeleh ein Enterschied, wenn man, wie ich jüngst im April, öfters 15 ee Diatomeenplankton in 1 cbm Ostseewasser findet. während ich in Samoa als Höchstmatass nur 1,4 ce und dazn noch C'opepodenmaterial faud. Wohl scheint es rorzukommen, dass zu gewissen Zeiten der Planktongrehalt in den Polamereren sehr niedrig ist. wie es Tanhöfon meldet. welcher in Grönland im Felnuar 0.35 ec $(27 \mathrm{~m})$ und im September 170 ce $(26 \mathrm{~m})$ fand und daraus wäre es anch zu erklären. dass Scoresby ron einer Durehsichtigkeit der See von 145 Meter hei Spitzhergen (was ührigens Kr rümmel für einen Schreibfehler hält) herichtet; das Cmgekehrte ist in den Tropen zweifellos nicht der Fall, es scheint dort ehen immer wenig Plankton vorhanden zu sein. 


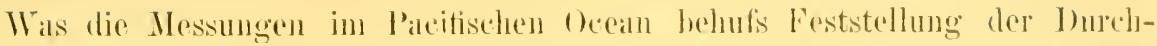
sichtigkeit betriftt. so will ich nur dio grösseren l'ntersmchungsserien erwähnen,

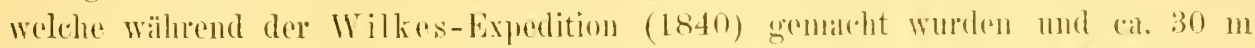

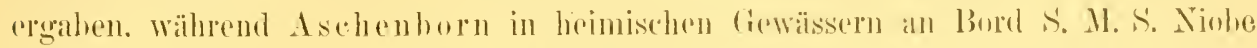
mngefïh 3 mal weniger fant. (Amulen der Hỵlungraphie 1888.) Im ïbrigen

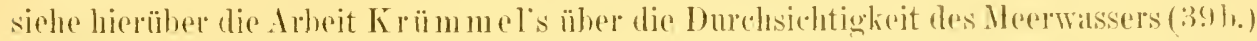

In nemester Zeit hat Professor .J. 'Thoulet in Nincy (Bericht im Promethens No. 340 April 1896) in ciner Arbeit alle Faretoren herïresichtigt. Fr hält

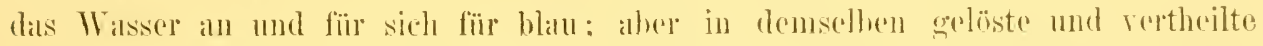

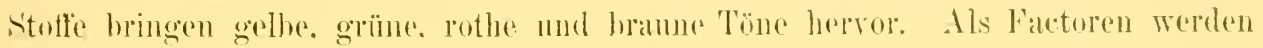
ilufgefühnt:

1. Ticfe des Wassers.

2. Farlye des ripundes.

3. Intensität des Himmelsliclites.

4. Erhebung der Sonue ïher den Horizont.

5. Temperatur und Salzgehait. Welche den Brechumgsindex des ITassers rerändern.

6. Bewegung der Oberflïche und Richtung der Wrellenbewegung in liezug auf den Beobachter.

7. Beschaffenheit. Grösse und Menge der rom Wasser in der Schwehe gehaltenen mineralisehen oder regetahilischen K̈̈rper (Algen).

8. die Gogenwart mikroskopischer Thioe und ihe bewegungen. welche zum Theil rom Lic]ite und dor Atmosphäre abhängơn.

Diese Arheit. Welche mir arst nach Niederschreilung der rorhergehenden beilen bekamnt worde. relgisst keinen der anseheinend in Frage kommenden Punktr. Aber 'Thumlet seheint die Arbeit ron Hïfner nicht bekannt gewesen z.1 sein, und ïber das Plankiton standen ihm keine Daten zu Gehote.

Fir hespricht in dirsem Simme die Trsalchen der Namen des Gellhen. des

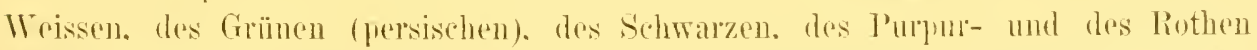
Mereses. Weleh letzteres seinen Kotallenbänken seinen Namen verdanken soll. Die

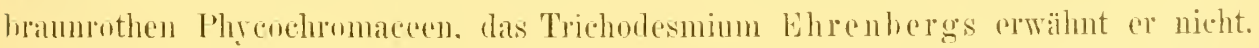
Tremn man indessen hei Botraditung dieses Heeres den fgowïhnlichen niederen Standpunlit hei Snez wählt, so kimn es einem nicht zweifellalft sein. dass aurh hier die Sumne es ist, welehe diese Anslösung anf der Netzhaut bee den Istacliten

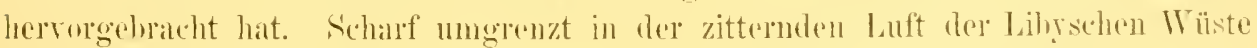
sinkt der gondrothe Somnenball und setzt den Ahendlimmel in furpume Gluth. In Osten das Sinaligehirge in losafurbigem Schimmer. dazwischen die splegelnele blane see, im Viderelanz roth schimmernd. in scinem Schatten violett: Wats resmïgen die zerstrenten gelbrothen Flaten del Algen. elic wenigen kïmmerlichen Korallenrifto der Ostküste oder gar die rerbältnissmäsigg grosse Kahl ron louthen ('opepoden.*) welche ich dasclbst find. gegen die Crossalligkeit des Wïstenlichtes.

*) Die Obertläehenfänge daselbst. Eurle Juli und Infang August. von (iiesbrecbt bearbeitet (56c.). wiesen nahezu durchweg nur starkroth getiirlite Coperpoden auf': der Sitz des Farbstofts war allerdings im l'arenehym, in den Oeltropten. Im ïbrigen erscheint es richtig. weun Simxoth ron den pelagischen Schnechen der Plaulitonexpedition verall- 
welches nur an den Polen, wenn auch nicht an Tinten. so doch im Spiel des Jichtes ühertroffen wird.

Sind es nicht dieselben Empfindungen, wenn Selenka in seinen ,.Sonnige Welten* (S. 27.2) mit den Augen des Künstlers folgende Betriulitungen anstellt:

.. Im rothen Meer und indischen Ocean fesselt vor allem der Farbenweehsel des Wassers. Bei klarer ruhiger Luft erscheint die See dnnkelveilehenhlau, an den Lntiefen grünlich, bei schwach bewölktem Himmel kornhlumen- his lichtblan. im Reflex dunkler Wolken biangran, marinehlau bis tintensehwarz. Eine leichte Brise wirft grünliche T'inten dazwisehen und im Reflexe der Strahlen des Sonnenauf- nnd Cutcrganges glüht das Wasser wie flüssiges Kupfer."

\section{Die Wachsthumschnelle der Korallen.}

Dana giebt an (3e S. 123), dass eine Mäandrina ca. 2 cm im Jahre wachse und Madreporen bis zu $7 \mathrm{~cm}$ (s. bei Dana weitere Angaben).

Nach Agassiz (26d) wurden Exemplare ron Orbicella, Manicina und Isophrllia an einem Telegraphenkabel bei Key West im Jahre 1888 gefunden, welche 3 -7 $\mathrm{cm}$ in 7 Jahren gewachsen waren.

Demnach schätzt Agassiz an den Floridariffen, dass sich ein Riff ron 13 m Mächtigkeit in 1000-1200 .Jahren gebildet haben könne.

Eigene Beobachtungen an Korallenstöcken liegen nicht ror.

Aber die Photographie ron 1880 gieht einige Anhaltspmnkte für dic Verschiebung der Riftkante. Tenn man die Karte ron 1895 betrachtet, so sieht man, dass die kleine Ausbnchtung, welche zwischen dem inneren (Bake) und äusseren Riffivorsprung liegt, sich etwas ansgefüllt hat. Es wäre dies ein Beweis für ein ziemlich ausgiehges Riffivachsthum, zugleich ein Beweis für die Richtigkeit, dass an der Leekante in Hafen die Korallen genug Nahrung finden.

\section{Temperatur und Salzgehalt.}

Es wird angegeben. dass die 'Temperatur' des Vissers nicht unter $21^{\circ}$ C. fallen darf, wenn die Korallen noch fortkommen sollen. Alle Korallenriffe liegen innerhalb der Wendekreise mit Ausnahme der Bermudas (320 ${ }^{\circ}$. Br.). welehe rom Golfstrom erwärmt sind. Dort kommen indessen Meerestemperaturen bis zu $19^{\circ}$ C. vor und eine Amplitude rom melor als $12^{\circ}$ C:

In Samoa ist die mittlere Temperatm des Meerwassers $27,5^{\circ}$ ('. mit mur sehr geringen Schwankungen.

Im neuen Segellandbuchatlas des Stillen Oceans wird als mittlere Wasserdichte fül Samoa 1027 angegeben.

gemeinernd sagt (Verh. der deutsehen zool. (iesellsch. 1895 S. 123): .. I)ir höehste andawernde Belichtung. Welche anf der Erde möglich ist. erzeugt bei langer Daner in den dem Lichte am meisten exponirten Theilen (hei Schnecken im Ifantel und im Kusammenhange damit im Bhutr) die Stimmung zur Abscheidung ron Farben. Welche den kïrzesten Wellen des Spectrums intsprechen." 


\section{Der Einfluss des Süsswassers in Samoa.}

Schon Dalna wies darauf hin, dass die samoanischen lifte durch die Sü̈sswasserzuflüsse nicht in nemenswerthem Grade hecinflusst werden. Er fïhrt unter anderen anch den wasserrejehen Falefä-Fluss an. dessen Mündung durbh din Korallen-

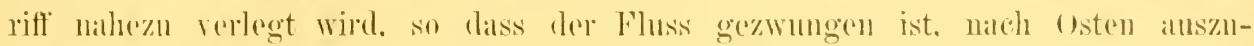

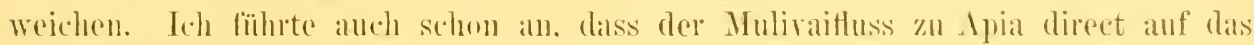
Mittehriff anstlesst. Wie anch das Flüsschen in der Solnsoln-bucht dirent auf ein Kitf ilusmündet.

Die durch die Flüsse niedergefï̈lrten Wassermengen sind zur Trockenzeit so gering. dass einc Aussiissung wegen der Gezeiten nicht stattfinden kimn. Anders ist es allerdings zur Regenzeit. da die reissenden Bergflüsse alsdann dureh Errlentheile so getrïht sind. dass die Vermureingung wohl schädlich wirken kamu. Hier scheint die lange Trockenzeit alsdimn ausgleichend zu wirken. 


\section{Eine nene Auffissumg der Entstehmng der Atolle in Hinblick auf die Darwin'sche und Murray'sche Theorie.}

Bei der Darwin'schen 'Theorie war einer der leitenden Punkte die wunderbare Form der Atolle. Tor allem wurde von 1)arwin und seinen Anhängern den in die fainge gezogenen Formen ein besonderes Gewicht beigelegt und hetont, lass die Krater meist rund und oval, nie aher eine solche oblonge ronfiguration hesässen. Ferner wird die Gösse vieler Atolle als Gegenheweis angeführt und die Häufigkeit in einem engumgrenzten Gebiet.

So sagt Dana (3b S. 124): .. Die Theorie der unterseeischen Krater arfordert, dass der Boden vollständig mit solchen bepflanzt wiire (70 in einem einzigen Archipel) und sie müssen alle ron derselben Erhebung sein. Es ist nicht hekamnt. dass so viele gleich grosse Tulkane auf einen Gebiet rorkommen. Die Andenvulkane wechseln ron 1000 his 10000 Fuss in Hohe.

Ferner griebt es Atolle ron 50 Meilen Breite mul 20-30 Meilen sind gewöhnlich.

Solch grosse Kräater" sind aber unbekamnt."

Gegen die Kahl der Krater lassen sich leicht im pacifischen Gebiet Gegenbeweise finden: wie aus der Topographie Samoats herrorgeht. bilden die Samoainseln eine ununtribrochene Reihe ron kratern: 70 werden sich hier leicht aufbringen lassen.

Betreffs der Grösse der Krater liesse sich sagen, dass der grosse Krater ron Haleakala anf Hawaici $45 \mathrm{~km}$ im Durehmesser hat, während Tliegenatoll in den Paumutu allerdings 60 Meilen lang (ca. $100 \mathrm{~km}$ ) und in den Malediven sogar eines rom 80 Meilen Länge ist.

Lines ist aller richtig, dass Kahl und Grösse vereint niroend noch heobachtet worden ist, demn die Samoakrater sind nur klein mol der Haleakala ist rereinzelt, wenn anch einige grössere krater noch auf Hawaici ihm beigesellt sind.

Jordan sagt (18): .. Die Kratertheorie ist einfach Inreh die Thatsache widerlegt. dass Atolle oft Grundrisse zeigen, wie sic Krater erfahrungsgemäss nie haben, \%. 13. fünfinal so lang als breit." 


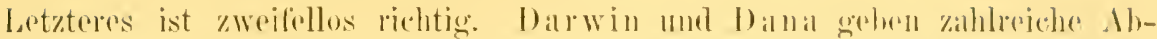
hildungen in ihren Bülehern. so das ats 3 lingen hestehende Metsehnikuflatoll

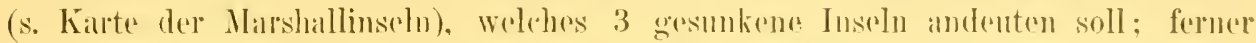

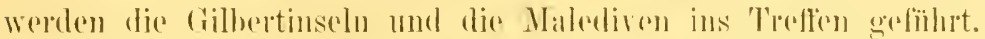

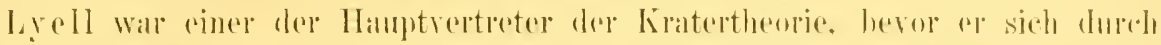

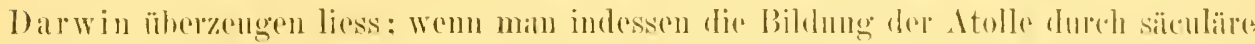

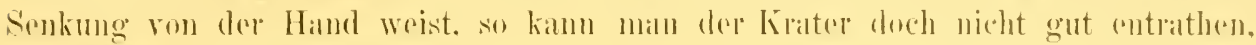

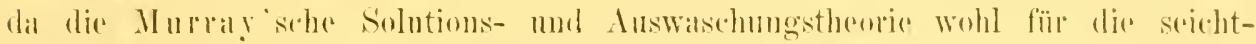

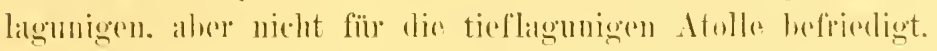

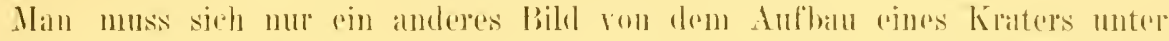

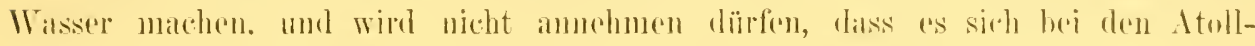
gabieten in allen Fällen un versmbene obersereisehe Kiater handelt.

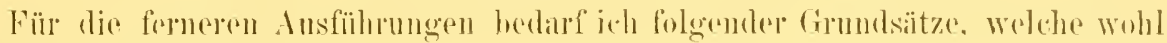
unhestritten bleiben diürten:

1. Atulle mit tiofon Lagmen sind his jetzt mur in vulkalusehem Golifet beohatehtot worklen.

2. Vulkanische 'Thätigkeit kommt anch submarin vor.

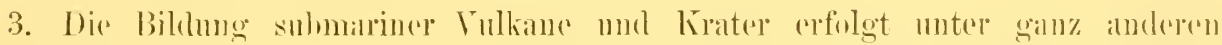
Borlingungen als in der specifiseh viel leichteren Laft.

4. Jie Atollgruppen ptlegen moist aine gewisse Richtung zu rorfolgen und die einzelnen Atolle einep Gruppe halen ihre livelutung im Ganzen in demselben Simme.

Hierhei mörhte ich im voraus an die Worte ron Agassiz erinnern (26) ... Nirgend finclen wir hessere Beispiele ron Bildung submariner bänke in Verhin-

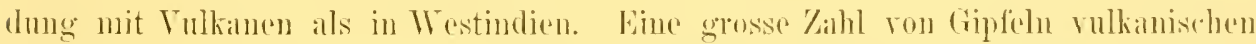
Irsprungs sind nahezu his zur Meeresobertlähe erhohen und diemen als Cimmd

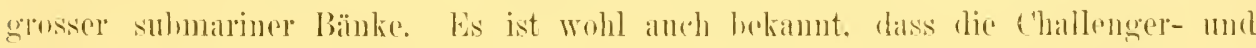
Tusealrori-Lothmogen aine Zahl submariner Erhehumgen ergeben haben. heeleckt mit Depresiten von Pteropoden- mol Gloligerinemsehlamm. altsgedehnte Bänka hildend.

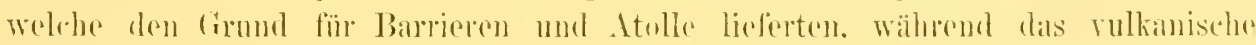
substratum rullstïndig verborgen ist."

\section{Die Configuration des Meeresbodens im Stillen Ocean.}

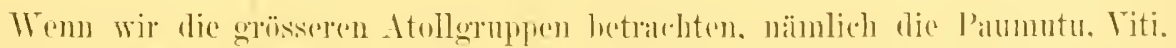
Tonga. Ellice. Ciblhert, Marshall-Lnsehn nud Calrolinen. so sohen wir. dass die cin-

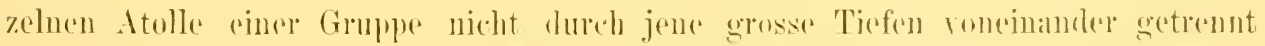

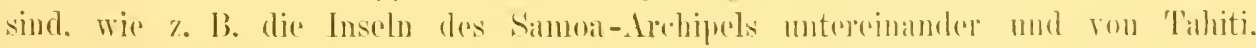

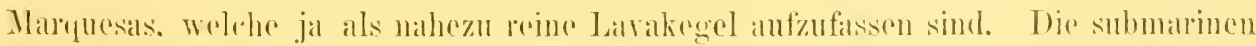

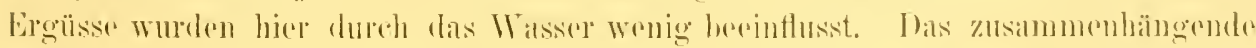

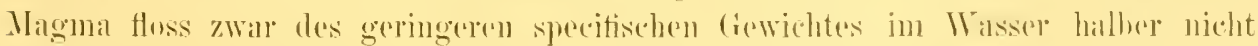
demenemiss zu Thale wie an der Luft. Fs thïrme sich anf. während es an der

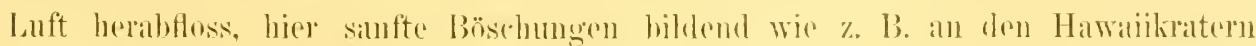
ersichtlich ist.

Anders alber. Wrem anstatt des Magmas nur vulkanische Aschen nud Simde ausgeworfen wurlen. Anfwirhelnd wurden sio llureh dio jewribig vorhereschenden

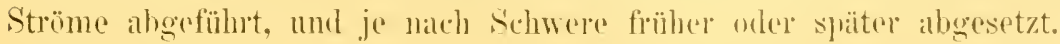


Wenn man auf der Karte die Höhenrïcken des Stillen Oceans betrachtet an der Hand del Stromkatrte des Segelhandbuchatlas Tafel 4. so fällt es anf, dass sie im allogemeinen die Richtung der Hauptströmungen einhalten. so die Paumutu-, Ellice-. Gilhert-Inseln die Passatdrift, die Cirolinen die Ost- und Westdrift.

Nun will ich natürlich damit nicht sagen, dass jene submarinen Höhenrïcken den Strömungen ihr 1)asein verdanken; die Spaltenbildung der brolkruste nnd die daran sich ehemals anschliessende rulkanische Thätigkeit kïmmert sich wenig um die Wind- und Ausgleichsströmungen der Oceane.

Auch rlie Frage, oh diese Höhenzïge als primär gebildete vulkanische Erhebungen oder als Theile eines versunkenen Continents aufzufissen sind. interessirt hiel nicht weiter. As Thatsache dürfte gelten, dass ïberall Zeichen vulkanischer Thätigkeit nachgewiesen sind. Was namentlich ans den Archipelen erhellt, wo Atolle und rulkanische Inseln zusammen vorkommen. wie in den Titi-. Tongat, Palauinselu u. s. W., nicht zu geschweigen von Samoa.

- Wenn man aber diese submarinen Höhenzüge als vorhanden betrachtet und vulkanisch thätig. so liogt es anf der Hand. dass hei tiefer Lage der Auswurfstelle die anfgewirbelten Asche- und Sandtheile dureh die Ströme weit abgetragen werden. ehe sie zur Ahlage kommen, und dass dadureh die Form dieser Erhebungen im Lauf der Jahrtausende sehr hecinflusst wurde. Jo höher aber die Rücken steigen. je mehr werden sich isolirte Kogel auszuhilden rermögen, je nach Ausdehnung und Stärke der Auswurfstellen. denn desto rischer kam das Sediment zum Absatz.

\section{Submarine Vulkane und Geyserfelder als Bildner des Unter- grundes für Atolle.}

Im vorhergehenden wurden die Grundzïge schon belenchtet. Weiter oben wurden schon Beispiele angeführt, dass submarine Aushrïche mit Asche, Sand und Lapilli leute noch vorkommen.

Es darf jia sonder '/weifel angenommen werden, dass in der tertiären und posttertiären Zeit die vulkanische 'Tlhätigkeit gerade in der Südsee sehr ausgebreitet und eroiehig gevesen ist; allmälig hat seit dieser /eit ein Frö̈schen der Thätiğkeit stattgefunden, welche hente $1 n$ noch an einzelnen Stellen und rerhälnissmässig sehwach rorhanden ist. Immerhin besitzen wir in der Sürlsee noch alle Abstufungen, von den Javargöissen in Hawaii bis zu den Warmwasserquellen und zur Solfitarenthätigkeit an den rerschiedonsten Orten.

Inshesondere fehlt es aber nicht an zahlerichen Beweisen von Auswürfen ron Asche mul Simd. Wormuter uns der Mimus-Aushruch und die Entstehung des Faleon-lstand hesonders interessiren ('laraweral. Krakatan 11. s. W.). Bui ersterem (Manúa) Hogen, trotzdem der lílater nachlier a. 100 Meter tief unter der Oberfläche befunden wurke die steine viole 100 Meter hoch in die Läfte empor; noch lohredeher ist das plützlich entstundene, ganz aus Ische zusammengesetzte Faleon

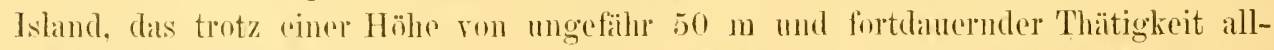
mälig wirder wegrgewaschen wirl (siehe III. 5.), ähnlich Ferdinandea im Mittelmeer.

biese isolirten lanoxysmen sind matürlich schwache Belege gegenïber solch' grossen Atollgehieten. Man muss aher duch bedenken. dass die vulkanische Tbätig- 


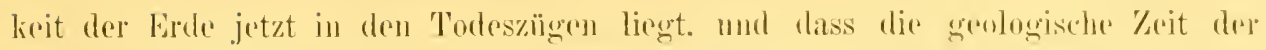
rollkommenen Ruhe nicht mehr allzuweit entfernt ist. Dir Erele altert.

Immerhin lat man aber an rinzeluen Stellen und gerate in der Sïndsere noch

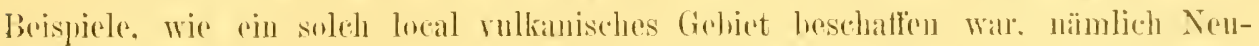

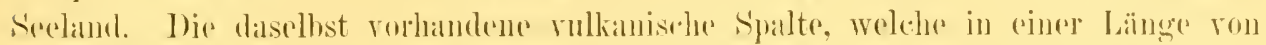

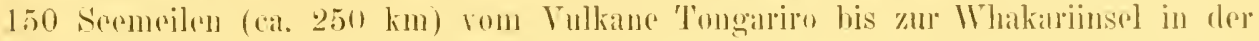

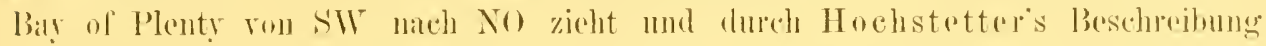

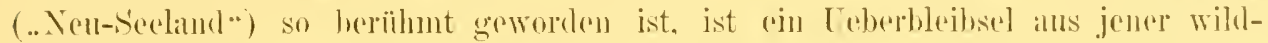
vulkanischen \%eit. Grgen 100 Stellen sind hente noch rorhanden. wo der Dampf

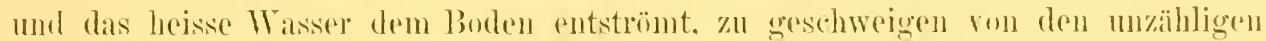

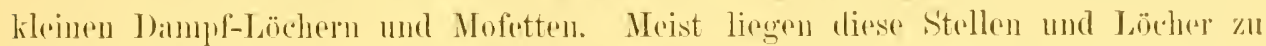
rinzelnen Gruppen vereint, wie beim Gegserfeld ron Whakarewarewar von 'Tikitere. Waiotapu, Orakeikorako. Mairakei. Tampo. Tokitano u. S. w. Der Aushrueds des 'Tarawera-Boros. dureh den im .Jalure 1886 die weltheriihnten T'erassen an hotomahana zerstöt wuden. mul die des Tongario (Ngauruhoe und Rimpehu) sind noch in frischer Erinnerung. Anf piner Tour in dieses Gobict (s. Globus April 1896 .. bin Planktonansflug in dip vulkanische Gegend Neu-Sechand s") habe ich aber anch ibberall gesehen. wie diese Stellen ringeengt worten sind und wie ansgerlehut diese Thätigkeit fröher gewesen sein muss. leh hahe anch daselhst gehört und gelesen, dass zwischen dem thätigen Krater der Whakarinsel und dem Festlancl (in der Richtung (ler Spalte) mehrere Quellen submarin beobachtet worden sind.

Man denke sich num ein solches rulkanisches Feld submarin, anf eimem Plateau. wie z. B. disjenige. welches ron Samoa nach NW läuft und die Ellice. Gilhert. Marshall nud weiterhin die Carolinen trägt. Die Lavaergiisse. welche dieses Platean gebillet haben, sind versiegt: Asche. Erden u. s. W. werden stetig in die Höhe getlagen. breiten sich im Wasser bammförmig aus. um dann nach den Seiten sich abzusetzen. Nehen den Tulkanen die zahlreichen Solfataren mon Geyser. Welche durch den Druck der ïherlagernden Wassermasse direct ron olren gespeist. eine besunders ansgielige Thätigkeit entfiltet hahen müssen.

\section{Die Meeresströmungen und Gezeitenströme als Anordner des Sediments.}

Dieser Absatz erfolgte indessen nicht so regelmässig nnd nugestiort, wie es seheinen möchte. Die Strömungen des Meeres tragen dic suspendirte Masse fort,

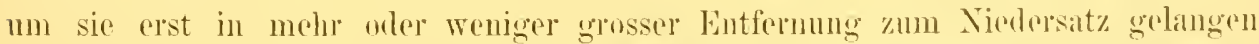
zu lassen. Aher nieht alloin rulkanisches Material wird das sein: alle pulagischen Thiere. ror allem das Pankton, das mit dem Strome treibt. wird. sobald es mit dem heissen Wasser in Berülrumg kommt, abgetödet und mischt sich dem Sechment bei. So wird es leicht erklärt. dass je nach Anordnung, Kahl und Thätigkerit sulcher Quellen die sich hildende Kraterform rine rerschiondene seju muss. dass

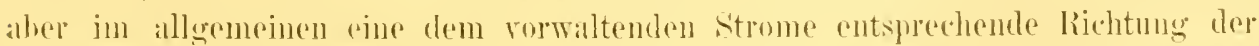
Atolle wird rorhanden sein müssen. Mördo nun dieser Strom inmer in derselben Richtung und stark sein. so mïste die Hauptaulnänfung immer in der Richtmug

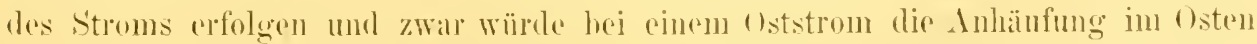
grösser sein als in Westen. Ws miste also aine Hufeisenform hei einem Atoll 
entstehen. In der That gieht es anch solche, namentlich in den Palauinseln (siehe Semper"s Karte 9 (.). wo die 3 rorhandenen Atolle eine Oeffnung heziehungsweise S'chwälhe gegen Süden zeigen, da hier der an der Nordküste Nen-Guineàs nach

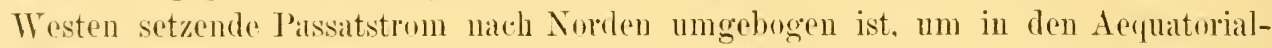
gegenstrom zu münden. Wronn dieser Nordost-Strom noch durch den Sï̈dwestmonsun unterstiitzt wirl, soll der Strom hier ïber \& Seemeilen in der Stunde laufen (ungeführ $1 \mathrm{~m}$ in der Secunde). eine gewiss nicht zu untersehätzende Kraft. Auch in den Milrshallinseln ist ein solehes Hufeisenatoll, die offene Seite drm Strom zugekehrt. Leider sind diese Atolle noch nicht genïgend rermessen. so diss die Angaben nit Torbehalt gregeben werden mïssen.*)

Fin solch stïlierer Strom erscheint für die Bildung eines Hufeisens nothwendig. da gröhere Stücke sehr rasch sinken, so dass sie durch einen schwachen Strom nicht wesentlich hecinflusst werden. Günstig rerhalten sich alher anch die feineren Bestandtheile. Thoulet hat daröber Untersuchungen angestellt (Expériences sml la Sédimentation. Annales des Mines 1891) mol gefunden, dass die Niedersetzung im Salzwasser Imgleich (viele 100 mal) rascher erfolgt als in destillirtem Trasser und dass anch die Wasserwintme die Senkung begünstigt. Crobigerinenschalen von $0.1 \mathrm{~mm}$ sanken $7 \mathrm{~mm}$ in des. Secuncle und ein Strom von $3 \mathrm{~mm}$ in der Secunde buh sie sehon vom Boden ab, während 6 mal grössere Glohigerinenschalen eines $10 \mathrm{mal}$ grösseren Stromes bedurften. Ein Iruck ron 15 Atmosphären ïhte keinen merklichen Einfluss aus. Diese Cntersuchungen sind nicht neu. S'chon Scheerer und Schulze (s. Poggendorf"s Amalen lid. 821851 und Bd. 129 1866) hithen solche Beolachtungen gemacht und kurz vor Thoulet (ler amerikanische Geologe Brewer (Memoirs of the Nat. Acad. of Sciences Vol. II 1883). Welcher nachwies. dass $3 \%$ " Mecrwasser alle Trïhungen in 30 Minuten rollständigger ahscheidet als Sünswalsser in 30 Monaten (s. Kr ïmmel 39b S. 75 ).

I)a die gewöhnliche ungeführ 9 Monate des .Jalnes andanernde Passatelift in den Atollgehieten selten aine grössere Geschwindigkeit als ${ }^{1}$, Secmeile in der Stunde (= a. 1/4 m in der Secunde) erreicht mol hier die Gezeitenströmung('n theilweise fördernd. theilweise compensirend und gar rïekstromig wirken kömuen, so ist es wohl erklärlich, dass man es hier ïhorall mit geschlossemen . Itollformen zu thun hat, und diss nul dic Richtung des Stromes in Allogemeinen in del Atoll-

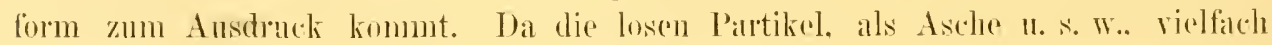

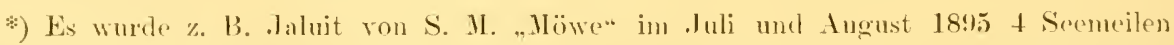
westlicher liegend gefunden, als in den karten rerzeichnet ist und in dem Burjehte des Commandanten, dam. ('apitinlientenant faber heisst es unter anderem (A. H. Juli 189mi):

. Wras die einzelnen Atolle anbelangt, so erscheint die Mlehrahl derselben in den Karten in ihrer inneren Austehnung zu kiein angegeben;"*

und ïher Wind und Wetter heisst es daselbst:

..S. M. S. Mäwe traf in den Monaten .Iuli und August vorherrschend triilses, regnerisches unhestindliges Wetter an. Der Wind. gewöhnlich siidöstlich, wehte im 1)urehschnit, tagsiber frischer, in Stärke 2 bis 4. Nachts flate der Wind meist ab) es setzten aber hä̈fig sehr harte Böen von der Stille aus ein mit Stärke ij bis 8 mel sehweren Regengüssens. Frischer Westwind mit entsprechender see tritt manchmal gan\% plöt\%lich auf: derselbe weht sich aber nach 10 bis 14 Stunden balet wieder aus und die aufgekommene See geht schnell wieder herunter." 
an nicht viel grösseress specitisches Gewicht als das 11 alssel haben, so ist es alleh erklärlich. wie die steilen Böschungen entstehen: während sie in der Luft durch

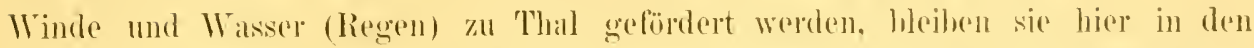

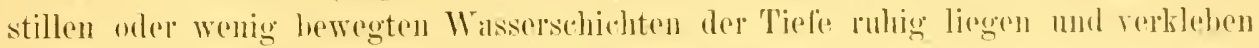
dureh mechanische und rhemische Verbindungen.

Man hat ringeworfen. dass solche submarinc Giplice ansserbalb der Atollgerebete nicht beohachtet seien: doch spricht Heilprin ron 7 solchen Erhelungen bis zu 12 Eaden nuter die Oherfläede zwischen lissabon und T'eneriftia, und ron 300 nachgewiesenen in allen ()oamen zusimmen. Mam muss nit rinem Crtheil in dieser Beziehnug ïher die Süilsee vorsichtig sein. welehe im Ganzen ja noch so ungengegend rermessen ist.

Whe ich indessen zur krörterung einiger localer Terhältnisse in der Süidsee ̈̈bregehe. möchte ich 3 Arten von Strömmugen unterschieden wissen, solche durch Ausgleich (Mecressträmungen), dureh die Anzichung (Gezeiten) mud dureh Winde (l)rilten) entstandene. Den Winddriften ist, wenn sie nicht durch perennirende Winde entstanden sind. keine grosse Tiefe zuzuweisen, wihlerend den Gezeitenströmungen. namentlich an den Küsten. grössere Wirkungen zugedacht werden müssen. leciler ist gerade darïher wenig bekamnt. wie tief die einzelnen Strömungen reichen*).

Cober die Anordnung der grossen Strömungen im pacifischen Ocoan sagt ('ïsar Puls in einel Arbeit, welche aus dem Material der Seewarte zu Hamburg hervorgegangen ist (Oberflähentemperaturen und Strömungsverhältuisse des derquatorialgüurtels des Stillen ()ceins.**) I)issertation Marburg 1895. Seite 34-36): ..Zu heiden Seiten der Kalmenzone fliessen die beiden ron den Passaten hervorgerufenen Aequatorialströme über die gallze Breite des Gecams nach Wresten. Der sïdliche Aefuatorialstrom ist der bei weitem mächtigere, sowohl wils breite als anch was feschwindigkeit hetrifte. Seme /one ist im Mittel zwischen $120 \mathrm{~S}$. Br. und 5" X. Br. Die Zone der grössten Geschwindigkeit. der stärkste Stromstrich. ist der Nordrand auf der ganzen Strecke ron den Galallagos an bis zur Nordküste von Neu-Guineal hier werden zuweilen Stromversetzungen von über 100 Seemeilen in 24 Stunden gefunden. Narh Süden 7.11 nimmt dio Geschwindigkeit zienlich rasch ab: manche Beohachtmogen scheinen daranf hinzudenten. dass ansser diesem sehr ausgeprägten, starken Stromstrich nördlich des Aequators auch sï̈llich daron. etwa in $5^{\circ} \mathrm{S}$. Br. wiolerum ain weniger gut ansgeprägter Strich grösserer Ge-

*) Fiir den mächtigen (rolfstrom liegen nenerdings Resultate in dieser Ilinsicht vor von dem Commandanten des Vermessmesclamplen's .. Blake". In den A. H. Juni 1896 heisst ('s dariber: ..Pillsbury's Leistung besteht darin. dass el -- um gentue strommessungen alusfïhren zu können - das regehrechte Ankern eines grösseren Schiffes auf́ offenem Ileere in Wassertiefen bis zu $4 \mathrm{~km}$ zucrst ausgefïhrt und sehrittweise veronllkommnet hat." Pills bury fand mitten im Strom (15 Seemeilen Abstand) an der Ohertläche 3.1 Sm. Geschwindigkeit in der Stunde und in 238 m Tiefe noch 2.2. während er in (isermeilen Abstand 2.65.m. und in der Tiefe 0.6 fand (jenseits der Strasse 1.7 und 1.45̆). Es lässt sich ermessen. dass nur verhältnissmässig wenig bei der langsamen P'issatdrift fïr die Tiefen abfillt; dass aber die grösseren Strömungen, wie erwartet. recht tief hinabreichen. ist nunmehr sichergestellt.

*) Siehe anch die Besprechung im Globus Nr. 19 dieses dahrgangs von lierhard Schott. Woselbst anch eine Strömungskarte. 
schwindigkeit auftritt, wie er mit grösserer Bestimmtheit im atlantischen Ocean ron Hoffman nachgewiesen ist. Dieser zweite Stromstrich, der etwa von $100^{\circ}$ lis $140^{\circ} \mathrm{W}$. Lg. rorhanden zu sein scheint. kommt aber nicht klar zum Ausdiuck II. S. W."

,Von etwa $140^{\circ} \mathrm{W}$. Ig. an nimmt der 'Theil der Strömung südlich rom Aequator eine etwas südlich ron West liegende Richtung (wie auch der Passat etwas nördlich rom Ost weht), wodurch ein grosser Theil des Wassers unser Gebiet rerlässt. Wrestlich von 180" hört diese Erscheinung wieder auf: das übrigbeibende Wasser sammelt sich wieder und strönt nördlich von Neu-Guinea, auf wenige Grade zusammengedrängt. wieder mit sehr grosser feschwindigkeit. um ummittelhar vor Gilolo nach Norden muzubiegen und die Wurzel des Gegenstroms zu bilden."

,Zwiselıen den beiden Passatströnungen nach Osten fliesst über die ganze Breite des oreans hin der Aequatorialgegenstrom, dessen Gesehwindigkeit hauptsächlich ron der südlichen Aequatorialströmung ablängt: ist diese stark. so ist anch der Gegenstrom stark, erreicht jedoch niemals, ausser an äussersten Westende, wo er durch den Monsun unterstiitzt wirl. dieselbe Geschwindigkeit, wie der Nordrand jener. bleibt vielmehr um mindestens $1 / 4$ dahinter zurëck."

..Uits ist gewöhnlich das Normalbild, das die Strömungen so lange inmehalten. wie es nur irgend geht; sie lissen sich nu ungerm und nach langem Kampfo mit widligen Winden zwingen. andere Bahnen einzuschlagen und keluren sofort wieder zum Normalzustand zurïck, sobald die widrigen Verhältnisse aufgehört haben. obne erst die Gunst des Windes ahzuwaten. So verdrängen die Monsune das Westende des nördlichen Aequatorialstroms nu langsam aus dem Grbict zwischren Philippinen und Marianen und nur wïhrend der drei Monate Juli bis sejetember gelingt ihnen das zumeist."

..Achnlich ergeht es dem Westende des südlichen Aequatorialstroms, del" aber wohl nur im Decemher nördlich rou Nen-Guinea und weiter östlich unter-

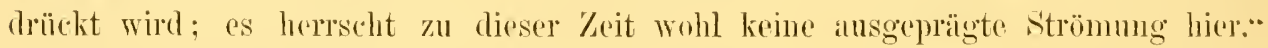

„Den härtesten Kampf aher hat der Gegenstrom zu führen. lir ist keine rom Wind hervorgerufene Strömung. wie die Aeruatorialströme. sondern cine Ausgleirhsströmung. die die grossen Wassermassen. dio die Passatelriften (besonclers die der südlichen. demn die der nördlichen können in del Hauptmasse mach Norden ahfliessen) natch Westen geführt liıben. wieder ahführen muss. So ist sie weniger rom Winde ahhängig als die I) riftströnungen: sie muss bestehen. so lange die l’assatströmungen hestelıen."

Die Atollgehiete. Welche zur Betrachtung kommen kömnen. sind die Paumutn-, die Ellicer-, (Lnion- und Phoenix-). Gilhert- und Marshallinseln. ron denen Kanten heigegeben sind. Von den übrigen Gebieten anch die Cirolinen. Pallaninsehn, während in don Viti- und Tomgainseln die Strömungen nicht ansgeprägt gुenug

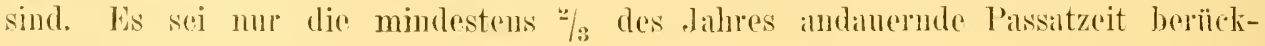
siclitiot.

In der reinen Passatdrift liegen dir nördlich rom Samoa gelegenen Ellice-, Enion-. Phoenix- und Gilhertinseln. Die Drift ist bei Puls ron Ost nach West 


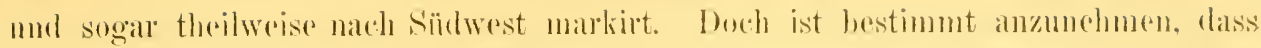
sie dem häufig ans mehr sïdöstlicher liechtung wehenden l'assat zufolge ring

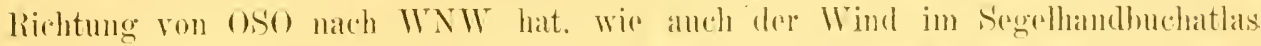

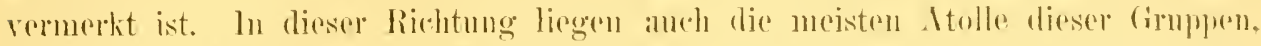

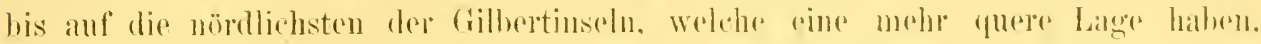

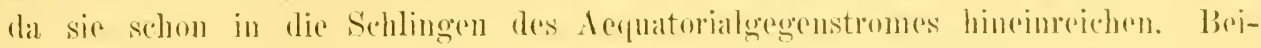
liegende Karte aus nana's Buch ist in diesem sime nit f'foilen versehen.

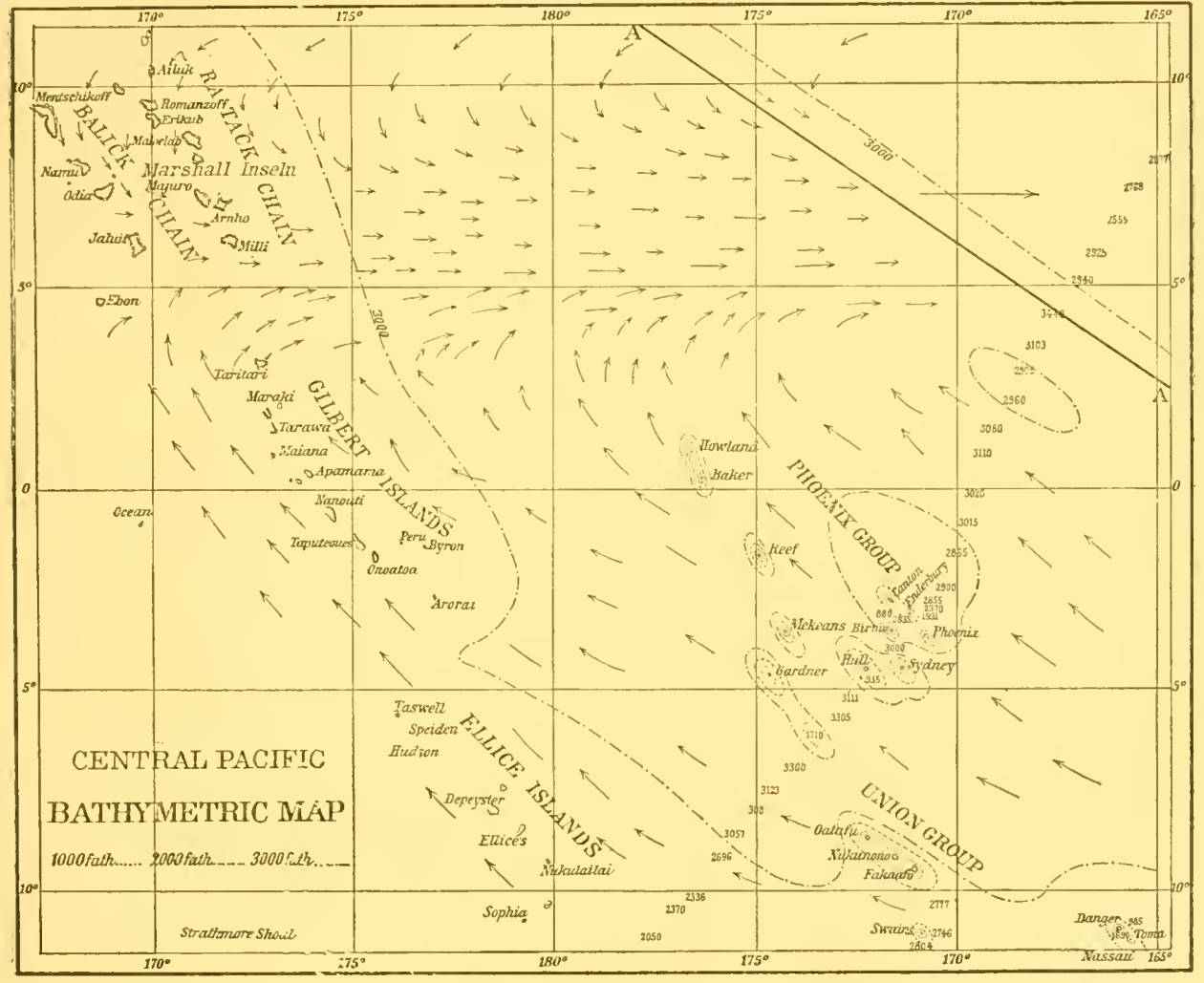

Karte aus Dana's .,Corals and Coral Islands”. welche sehr sehön die lichtung der Atolle und submarinen Bänke im Sinne dex Siidostpassatdrift zeigt (bis \%u den Marshall-Inseln hin). Inie Pfeile denten die Strömungen an.

Wichtiger sind die Panmutu und Marshallinseln. Welche von reaschiedenen Strömen heingesucht werden. Erstere ron OSO nach $\mathrm{W}_{\mathrm{X}} \mathrm{W}$ zichend. werden an

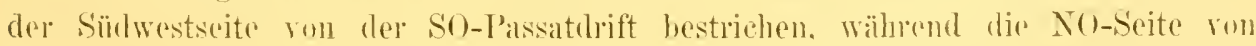
einem nahezu quer oinlaufenden Strome getroffen wird. Wreher als Kreisstrom nach Südosten abgelenkt wirl (s. Segelhandhuchatlas. T'af. 4.). Tas Kärtchen der

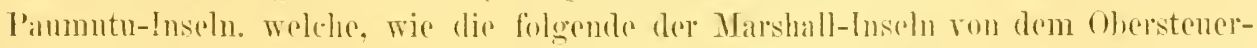
mamemaiten Hölich im hatendepent der Kaiserlichen Worft zu Kiel auf das genaneste angefortigt wurde. zeigt. dass die Atolle an der SW-Kante der Passatdrift folgen. während die nordëstlichen im Simne des quer einlanfenden Stroms liegen. (Sielıe umstehende Karte.) 
Besonders lehreich sind die Marshall-Inseln (siehe nebenstehende Karte). Die nürdlichsten liegen in der No-Passathrift. welche nach Sïden umbiegend in ca. $8^{0}$ n. Br. in den Aequatorialgegenstron eimmïndet. Die Atolle folgen den Windungen des Stromes, wie das Specialkärtehen zeigt.

Da diese Inselı im Laufe der nätchsten Jahre durch S. M. S. ,Möwe“ genau rermessen werden sollen, so darf man weitere interessante Aufschlüsse erwarten.

Die C'arolinen, welche grösstentheils im Aequatorialgegenstrom liegen. scheinen im Allgemeinen auch die Richtung dieses Stromes einzuhalten. Sie sind indessen zu wenig bekimnt, um als Anhalt dienen zu können. Eine ausgesprochene IVest-Ost-Richtung hat indessen die im selben Strome gelegene einsame PalmyraInsel. wïhrend die etwas südlicher gelegene Weihnachtsinsel eine mehr südistliche Richtung hat.

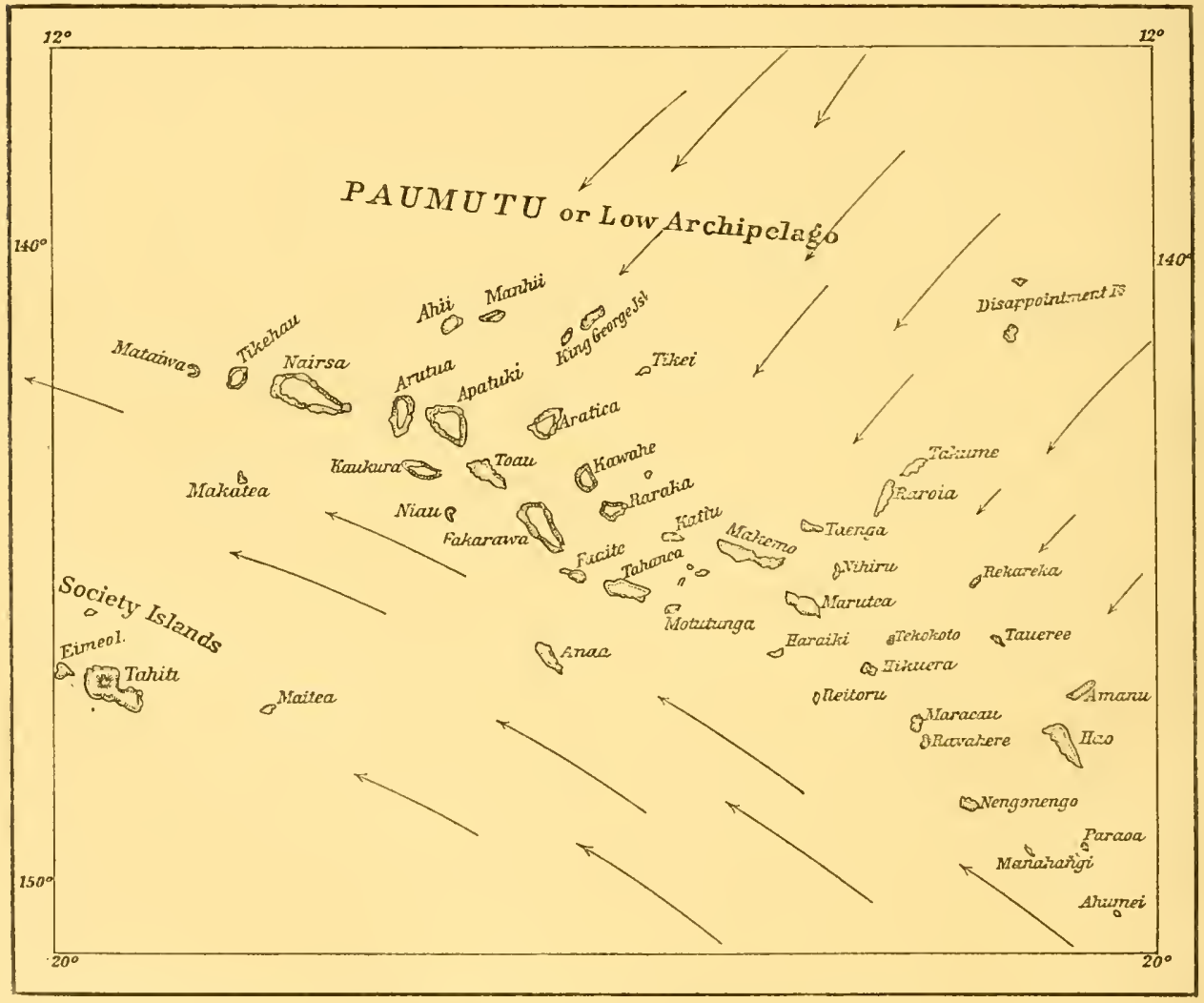

Die Pfrile deuten die Stromrichtung der Passatzeit an.

Ton den Palaninseln wurde schon gesagt, dass die 3 nördlich gelegenen Atolle nach semper alle nach Sï̈ten offene Hufeisen hilchen. Sie werden an dieser Seite ron rinem starken Strom getroffen.

Fine sülöstliche Richtung hat anch das grosse Atoll Ongtong-Java bei den Salomonsinseln. wolches in der Palssitdrift liegrt.

Leider sind allenthalben die Termessungen noch so wenig gefördert, dass genauere Ausfïhrungen noch nicht erlaubt erschemen. Ich gebe die Daten dess- 
halb nur. um die Aufinerksunkeit auf' diesen \%usammenhamg vom Atoll und Strom \%ul kenken.

lch kamm es jedoch hierhei nicht unterlassen, nochnals datrauf hinzuwerisen, dass dieser Zusammenhang nach meiner Meimung durchaus nicht üheratl vorhanden

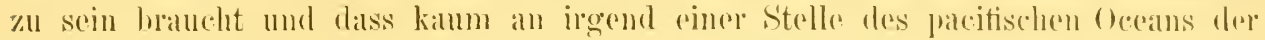
Strom jahrias jahrein in derselloen Richtung fliesst. diss fermer Winde und ror allem die Gregeiten ïherall moditicirend wirken.

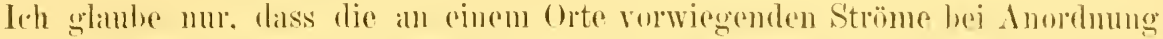
des Auswurfs submarine bruptimsstellen. wemn dies Material günstig war. den in diesem Gebiet gelegenen Itollen ihre charakteristische Gestaltung gegoben haben.

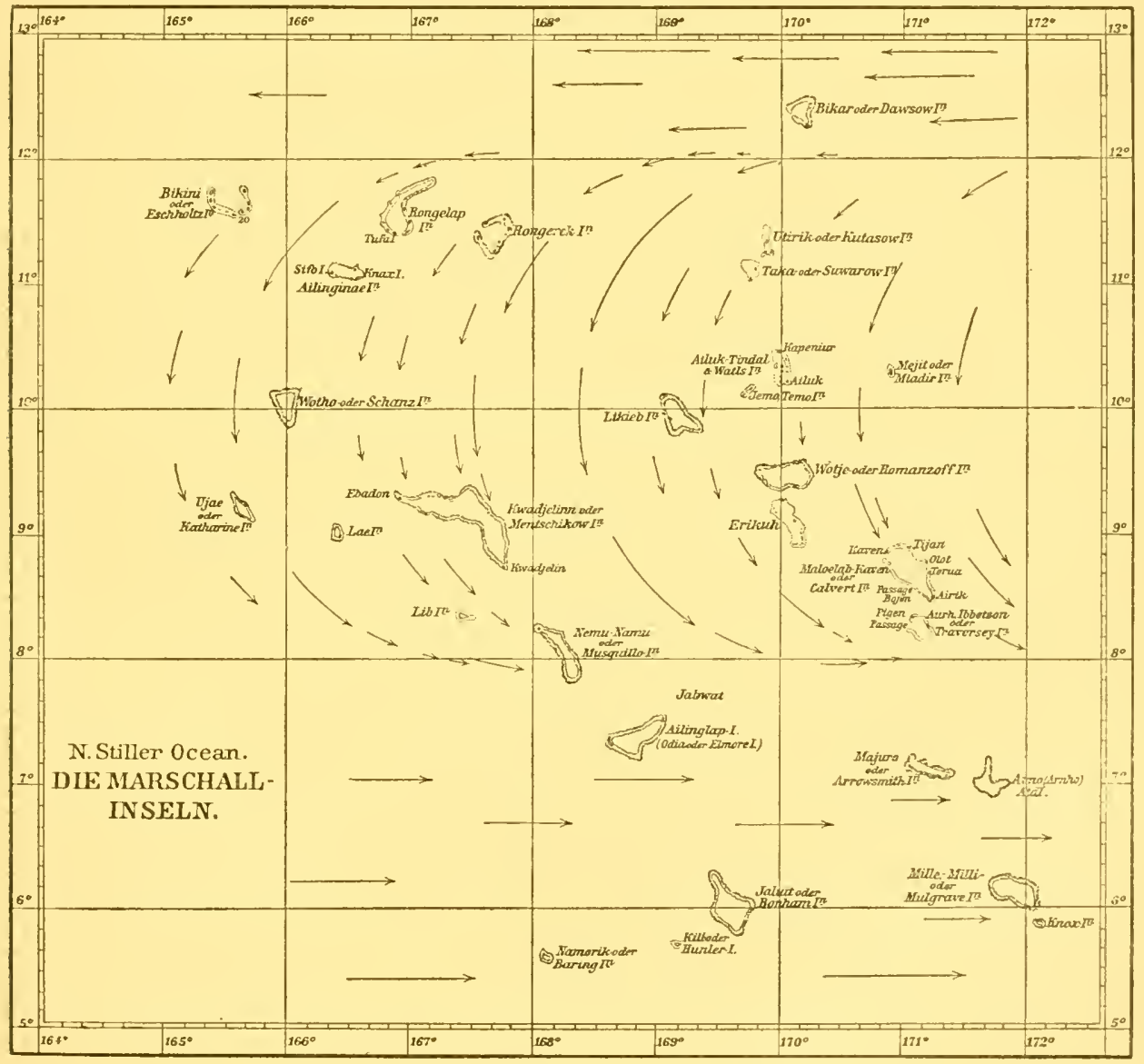

lie Pieile denten die strömung der Passatzeit an.

\section{Die Bildung der Lagune von Atollen und die Murray'sche Theorie.}

Lm die Entstehung ron Atollen auf submarinen hratern zu umgehen. hat Murray die Bildung tiefer Lagunen durch Lösung des todten Kalkes im Meerwasser zu erklären rersucht. Ich hahe schon ohen in Alschnitt II erwähnt. dass diese Ansicht rom rersehiedenen Autoren als Bourne. Irvine. Ross. Hickson. 
Sluiter. Agassiz u. s. W. nicht getheilt wurde. welche jedoch in den äbrigen J'mikten Murray beipflichteten.

Tuter andern stellte Irvine (Nature 1888, S. 461) Messungen ïber die löslichkeit des Korillenkalkes in Mecrwasser an und fand diesclbe gleich 5 his.

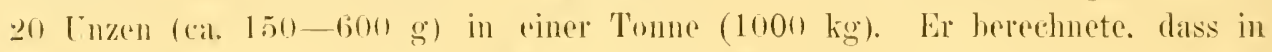

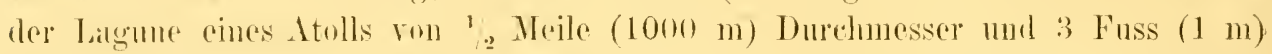

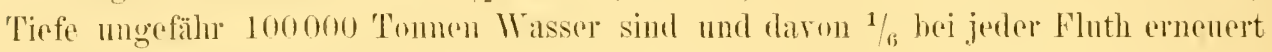
wird, woratus sich ergehen wïrde. dass jährlich nugefähr 3000 'Tomnen Kälies im Scewisser abgufühlst wïrolen.

Wemn mam nm annimmt. dass das Atoll an del Riffkante 3000 m Lmfang hat, so wärde also anf 1 m Kinte eine 'Tonne Kalk kommen. welcher ron den wachsemen Korallen des Fusses durch Trümmerhildung auf der Plattform ersetzt werlen mïsste.

Die in Betricht limmmencle Breite des Fusses zu $100 \mathrm{~m}$ gerechnet und das Wachsthmm der Korallen 211 em durchschnittlich im Jahr (siohe Abschnitt V, 7 ), wïrde dies gerale 1 ehm Kalk = eat. 6000) Kg (6 Tomnen) geben.

1)at die Zahlen niedrig gerechnet sind, so erhellt dianus. dass der Ersatz des anfgelösten Kalkes von anssen her leichthin möglich ist.

Bei grossen Atollen liegt dies freilich weit nngünstiger. da die Fläche sich rergrössert, die litfikante jedoch dieselhe bleibt. Hier fällt aber die grosse Tiefe der Lagune ins fiewicht und es wäre hier geratezu nothwenelig anzmnehmen. dass die Korallen aus derselben Tiefe aufgewachsen sind, was den Erfahrungen widerspricht.

Für die kleineren flachen Atolle, deren kagune zum Theil versandet ist, fïllt es nicht schwer. eine Erklärung zu tinclen. Die Bildumg kiann anf einer submarinen umgrenzten Erhehung stattfinden: wenn die Korallen in den Bereich der Dünung kommen, wird der leewärts liegende Theil mit Trümmern bedeckt. während nach anssen hin der Riffrand sich mittelst des Fusses an die OberHäche erhebt.

Jedes Strindriff bildet ja einen Sector eines soldhen Atolls. mur dass die Vorsimdung dort durch den Strom geregelt ist.

Man muss den Gezeiten-Strömen vor allem bei der offenhaltung der AtollLagmen eine nicht zu untersehätzende Bedentmog beilegen.

Bei den kleinen Itollen kommen sie nichit genügend zur Geltung: die Dünung wirkt von allen Sciten, wemn anch an cler Luvseite stärker: die Kufuhr ïberwiegt hier die Alfulır. je kleiner je melır.

Je grösser das Atoll ist, je mehr dreht sich das Terhältniss ins Gegentheil 1 m.

Für die grossen Atolle mit den his zu $100 \mathrm{~m}$ tiefen lalgunen, wie in Titi. Panmutu 11. s. w., kamn man der I'rïforminung vines Lntergrundes in oben besprochener Wreise nicht gut entrithen.

Fïr die offenhaltung soleher latgunen kommen aber zweifellos nehen den Cnterströmungen, wie sie Murray für die schottisehen Seren nachwies demeh Wind. Nature 1888 S. 479$)$ auch noch die Ströne in Betracht. wolche alurch die tiefen Spalten und Läeher des Rillkranzes direct in die Tiefe der Lagme dringen. Solehe Durchlöcherungen und Höhlungen. wio sie schon oben (Alosehnitt IV. 5 c) be- 


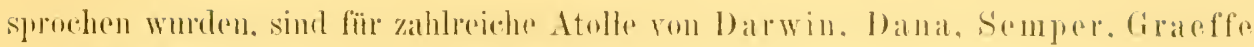

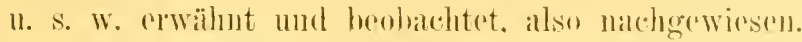

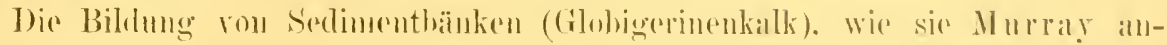

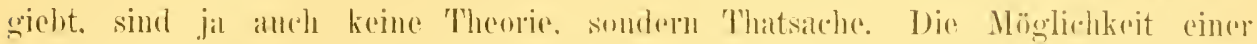

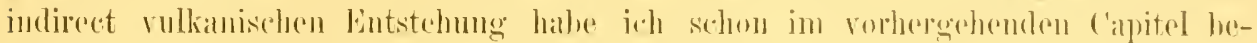

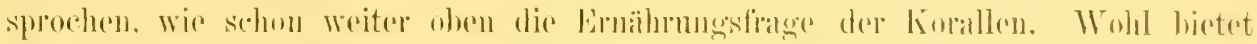

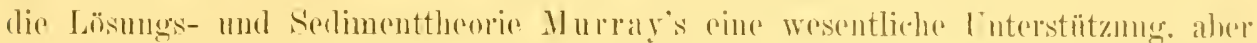

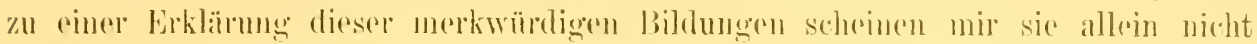
7.11

\section{Tektonik des Untergrundes.}

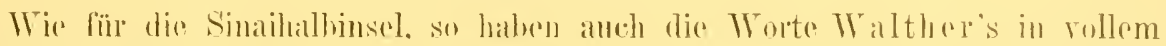

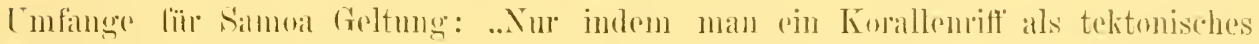

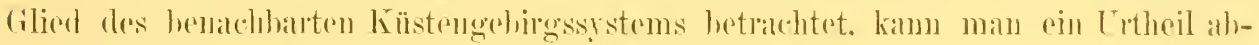

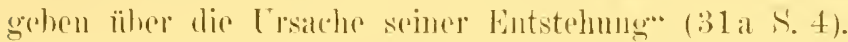

lie Grïnde für die Anwendung derselben atuf Samoa sind des längeren hei Beschreilomg der dortigen Kïste ausgeführt. Ls erïbrigt nur noch nachzuweisen, dass der Kü̈ste roreglagerte Bäule. dle zur Bildmug von Barrierenriffen fülren kïnnten. anch anderweitig rorhanden sind. In der Ostsee ist rine solche der Stoller Grund und Mittelgrund bei Kiel: ich erinnere fermer an Helgoland, das westwärts an der Stejlküste eine sulomarine Barriere besitzt. an der sanfteren ()stliüste die Sanddünc. Wäre Helgoland tropisch. so wïrole es im Wresten von einem Barrierenriff. im Osten ron cinem Strandriff begrenat sein. Zahlreiche Beispiele liessen sich beihringers.

Merkwürdig erscheint es oft, dass Tahiti ron Barrieremiflen ungeben ist. während Samoa unter denselben Bedingungen liegend, derselluen nahezu ganz entbehrt. Die Barricrenriffe kommen abes ïberall dort nur an der Strilkïste vor, wälurend der flachen Westlïste der Hauptinsel Strandriffe rorgelagert sind.

Die Challenger-Expedition lat die Tektonik des Lntergrundes im paldischen Ocean wesentlich den Foraminiferen zur Last gelegt. Es wurde gefunden, dass der kohlensaure Kalk in grösseren Tiefen rerschwand. während der Lntergrund in seichteren Tiefen reich an Kalk war.

Die Anilỵsen sind limz folgende (22):

$\begin{array}{ccc}\text { Zahl der Proben } & \text { Tiefe } & 0 \text {, Kilkgehalt des Schlammes } \\ 14 & \text { his } 500 & 86.0 \\ 24 & 1000-1500 & 70.0 \\ 42 & 1500-2000 & 69.5 \\ 68 & 2000-2500 & 46.7 \\ 65 & 2500-3000 & 17.0 \\ 8 & 3000-3500 & 0.88 \\ 2 & 3500-4060 & 0.00 \\ 1 & \text { ïher } 4000 & \text { sjuren }\end{array}$

Wie bekannt hat Murlay daraul seine Theoric der Entstehung der steilen Böschungen gefusst. Allein zugegehen. dass rlies riehtig ist. su erseheint die Bildung tiefer Lagunen auf flachen Seclimentbänken nach wie vor unerklärlich. 


\section{Die einstige Lösung der Frage. Bohrungen.}

Schon oben hathe ich angeführt. dass Murray mit weitgehendem Blicke den irischen Geologen Sollas zu veranlassen vermochte, die zur Zeit sich bietende Gelegenheit der Vermessung der in Norden ron Samoa gelegenen Ellice-Insehn zu benutzen. Die Admiralität sagte ihre Bereitwilligkeit zu, den daselbst stationirten Krenzer .,Penguin” zu diesen '/wecken zur Verfügung zu stellen, und die Royal Society hewilligte liheral die Mittel. Ich habe auch schon meinem Kweifel Ausdruck rerliehen, (b) die Resultate den krwartungen entsprechen werden, da die Cnterscheidung und Detinirung von Riffkalk und Korallenkalk zur Zeit noch Schwierigkeiten bietet. Wird schon in 10-20 m Tiefe indessen rulkanisches Stratmm angetroffen werden, so wäre dies wohl sehr fördernd für die antidarwinistischen Anschaumngen, aber noch nicht beweisend, so lange nicht ron anderen Inseln anch gleichlautende Ergehnisse vorliegen. Der vielerfahene Murray schrieb mir jüngst auf eine Anfrage hin in jenem entgegenkommenden Tone. wie er den englischen Gelehrten vielfatch in so hervorragendem Maasse zu eigen ist, ïber diese Bohrungen: ..Personally I do not expect any rery definite result from the operations, but one (an nerer tell, where and how most interesting information may be proeured."

Darwin hat rergebens gehoftt. solehe Bohrungen zu erleben. Eim Jahr vor seinem Tode, 1881. schrieb er an Alexander Agassiz wegen der kurz zuror erfolgten bekannten Veröffentlichung Murray's die rïhrenden Worte: . Wemn ich Cnrecht habe, dann ist es mm so besser. je bälder ich anf den Kopf geschlagen und rernichtet werde. Es scheint mir immer noch ein wunderbares Ding, dass keine langjährige und grosse Senkung in den Betten der grossen Oceane vorhanden gewesen sein sollte. Ich wünschte. dass ein vielfacher Millionär sich es in den Kopf setzen wollte, Bohrungen durch die pacifischen und indischen Atolle zu machen und Mark für Schliffe aus einer Tiefe ron 500 his 600 Fuss heimzubringen.*

Iuch Krümmel hat jüngst im Globus anf die Nothwendigkeit solcher Buhrungen hingewiesen.

the ich von Mnrray’s Plänen wusste. ging ich damit um. ein Gesuch an die kgl. Academie der Wissenschaften zn Berlin zu richten. Leider war es derselhen nicht möglicl. die für solche Bohrungen nothwendige Summe zu bewilligen. und su wird bngland anch hierin den Ruhm haben. dieser Frage znerst practisch und wissensehaftlich näher getreten $7 u$ sein.

\section{Kurze Zusammenfassung der gewonnenen Schlüsse an der Hand der Betrachtung der samoanischen Korallenriffe.}

1. Die Bildung der verschiedenen Formen der Korallenriffe wird erklärt dureh clie Tektonik des Inntergmoles in Bezichung zur Tektonik der Küste.

2. Her Lntergrund der Atolle wird gehildet dureh muterseeische Bergkuppen (ausgefüllte Atolle) oder submarine Kirater (tieflagunige).

3. Die Krater künnen so beschaffen sein, wie die oberirdischen; in den meisten Fällen handelte es sich indessen wahrscheinlich um submarine Geyserfelder und Vulkane, deren Sediment durch die Meeres- nud Gezeitenströmnngen angeordnet wurte. 
4. Die nerkwïrdige Form der Itolle erklïrt sich aus der Anordunng der heissen Quellen und Answurfsstellen und aus der wechsolnden Einwirkung der Ströme.

5. Dis Wachsthmm der Korallen ist der Sep zu. d. h. in der brandung mehr behindert als im stillen Wasser.

6. Tals l'lankton der Tropen ist ärmer als das der gemässigten Zone, ehenso ist im Hafen mehr Planktun als in dele offenen Sere.

7. 1)as Vordringen der liffkante gegen die See geschieht mittelst des Fusses. Tie Breite dieses Fusses ist proportional dor Stärke der anf die lifflkante stehenden seere

8. Die T'iefengrenze der Riffe wird bedingt dured den starken Holiotropismus der Anthozoen. Als die Tiefengrenze ist $\mathrm{m}$ Allgemeinen die rom $15 \mathrm{~m}$ anzuselen. In Hafen wirkt dere ahgeführte Lagrunensand modificirend.

9. Die Nahrung ist innerhalh der Korallenriffe in reichlicherem Malsse rorhanden als allsserhalb dersellien. 


\section{I)ie Rifffimuna von Samoa insbesondere in ethno- logischer Beyiehıng.}

Die Korallemifte hilden nicht allein einen Schutz lïr die Schifffahrt. sondern sind anch fïr die Sü̈lscevölker bedentsame Nahrungsquellen. Desshalb wissen die Eingeborenen deren 1 erth wohl zu sehätzen und sehenken ihnen die gehührende Aufmerksamkeit. Da die Famma der samoanisehen Riffe im wesentlichen mit der anderer liffe in der Südsee übereinstimmt (treffliche Abbildungen findet man besonders in dem grossen Werke von Saville Kont). so will ich mu einen kurzen Abriss goben. zumal da mir die Keit und die Hittel für ein eingehendes Studium dafïr mangelten. Ich glaube desshalh moly hringen zn können, wemn ich die Thierwelt mit den Augen der Samuaner betrachte. indem ich das wiedergebe, was ich dureh eine grtündliche Erkernung dor samoanischen sprache und stetigen Verkehr mit den Eingehorenen daselbst zu arfahren Gelegenheit hatte. Eine seln wesentliche Luterstützmog hatte ich dabej durch das Dictionary of the Samoan language des lier. George Pratt. Welcher 40 Jahre in Samoa ansässig war mol erst jüngst zu Sirchey verstorhen ist. (3. Auflage 1893).

\section{Riff- und Schifffahrt.}

Die Samoaner sind im Allgemeinen gute Seclente und mit dem Irasser vertrant: indessen verdiencu sie es sicher nicht als Auszeichnung. dass ihre Inseln Navigatoreninseln genannt wurden, was Bougain ville auch wohl nicht bealssiehtigte. indem er dem Arehiped nur narigatorischen Werth heihegte. I)ie einheinischen grossen taumualua. mit denen einst die Mere durehkreuzt warden, den Bug und das

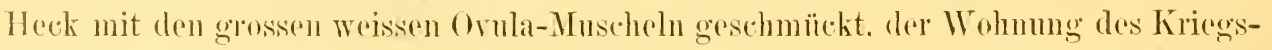
guottes Fée. des Oetopus, sicht man hente selten mehr. Im Atuakriego 1894 hatte

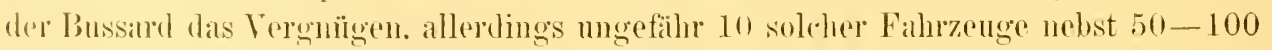
anderer im Schlepe zu laben. Nannentlich amerikanische Bonthaner lohren jetzt dic Eingeborenen Boote europäischen Stils zu hanen. wolchen sie his zu 100 in

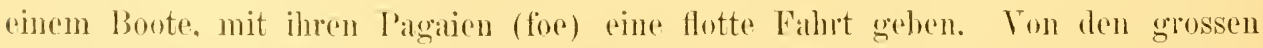
Doppelbooten, taula, die ein Deck verband, aul dem eime Hütte stand, und welehe rin grosses Mattensegel und einen Mast an Barkbord lïhnen (die Hütte war gleichfalls nach Stemerbord. der luxseite, schräg abfallend und gedeckt. während sic 


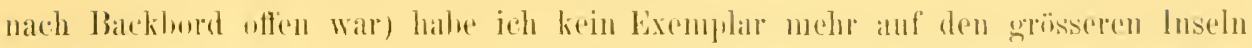

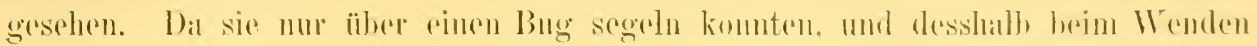

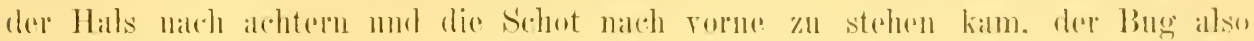

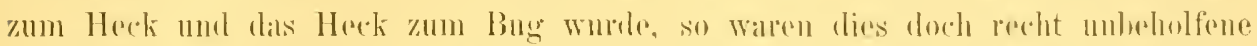

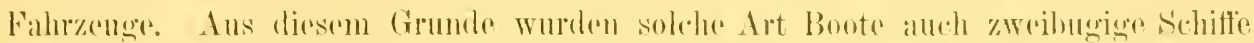

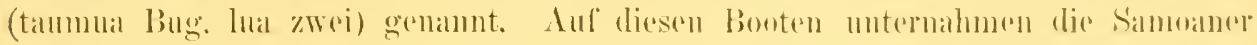

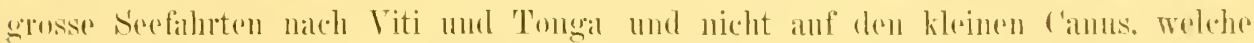
zaller ror dem Hafen rom Lamgopango gessehen hat (Reise um die Welt).

1)iese Besehrönktheit, nur ïhrer

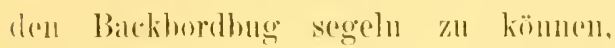

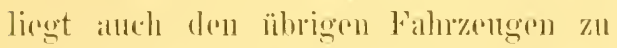
Grunde. dem Bonitofanghoot, váalalo. llem isitzigen sontill und esitzigen parnpalo. indem diese alle den Ausleger (ania) an Batckborel tragen, also falls sie segoln wollen. alueh $111 \%$ ̈̈̈ber backlwod-bug sogeln kïnmen. Wrems sire nicht riskiren wollen zul kentern. Desshall, hiess anch die Kiriegstlotte von Epolu lauama, da sie auf der Fallurt

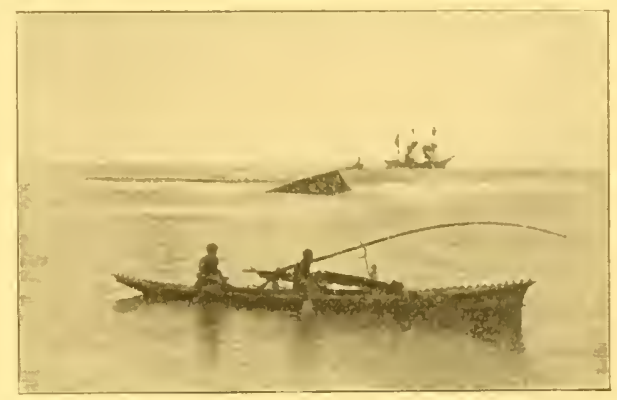

Bonitolont im Apiahafen.

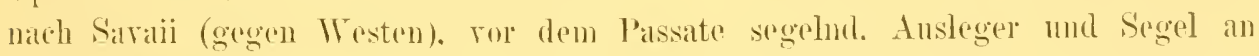
Backbord liatte.

Falls e's gilt. nul das äussere Rilt behufs Fang ron Fischen mud Secthieren zu besuchen. so wire gewöhnlich der kleine paopan oder soatau benutzt. welche sich dadurch von len indern muterscheiden. dass sie ans einem Stück Holz gefortiggt sind. Wozu häufigr der Brodfuchthaum dient. Das Riff heisst áan (anch schwinnuren). kleinere (Simmriffe) heissen wohl auch pinepine: die Lagme wird aloalo gemannt und ein Dorf. das eine lagune besitzt, wirl als tailoalo gepriesen. bie Simmaner kemnen daselbst wohl den bei Fluth anf das hand setzenden Strom

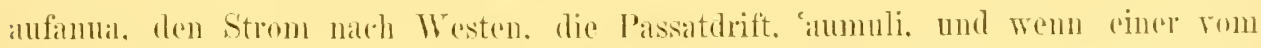

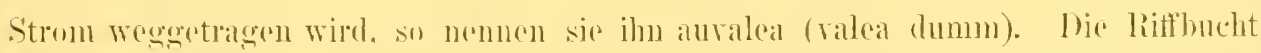

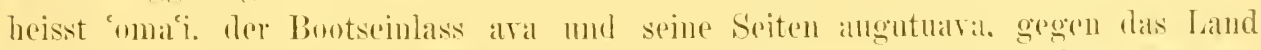

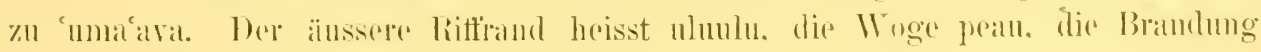

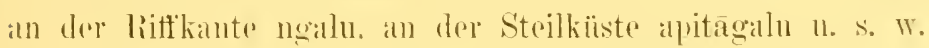

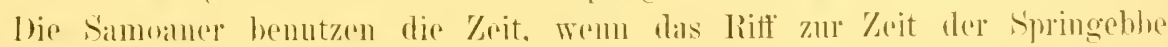

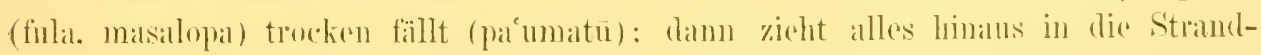

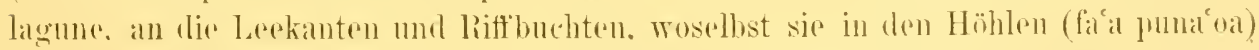

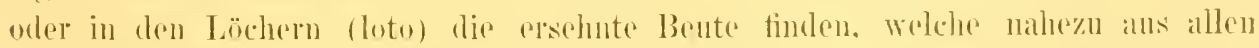
"Thielgattungen sich zusammensetzt. Ein belehtes Bild bietet dam die somst so

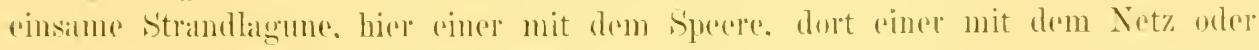
gatr mit der Hand fischend. Wolle geesalht mit dem dureh die Blïthen des

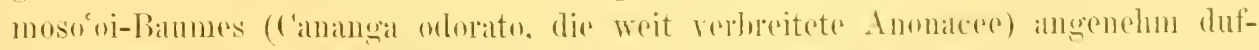
tenden foreosmussöls widerstehen sio lange der ludissen Mittigssomme. mur mit dem

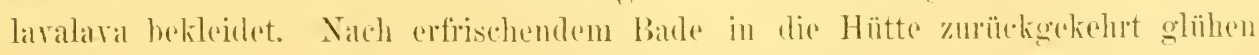
aber noch lange die Wangen wunderbau durch die lichthraune I Iant der sehlank go- 
bauten Mädkehen und anch die Samoaner bewundern dies als Schönheit und nennen es filatsamisami (sami Meer).

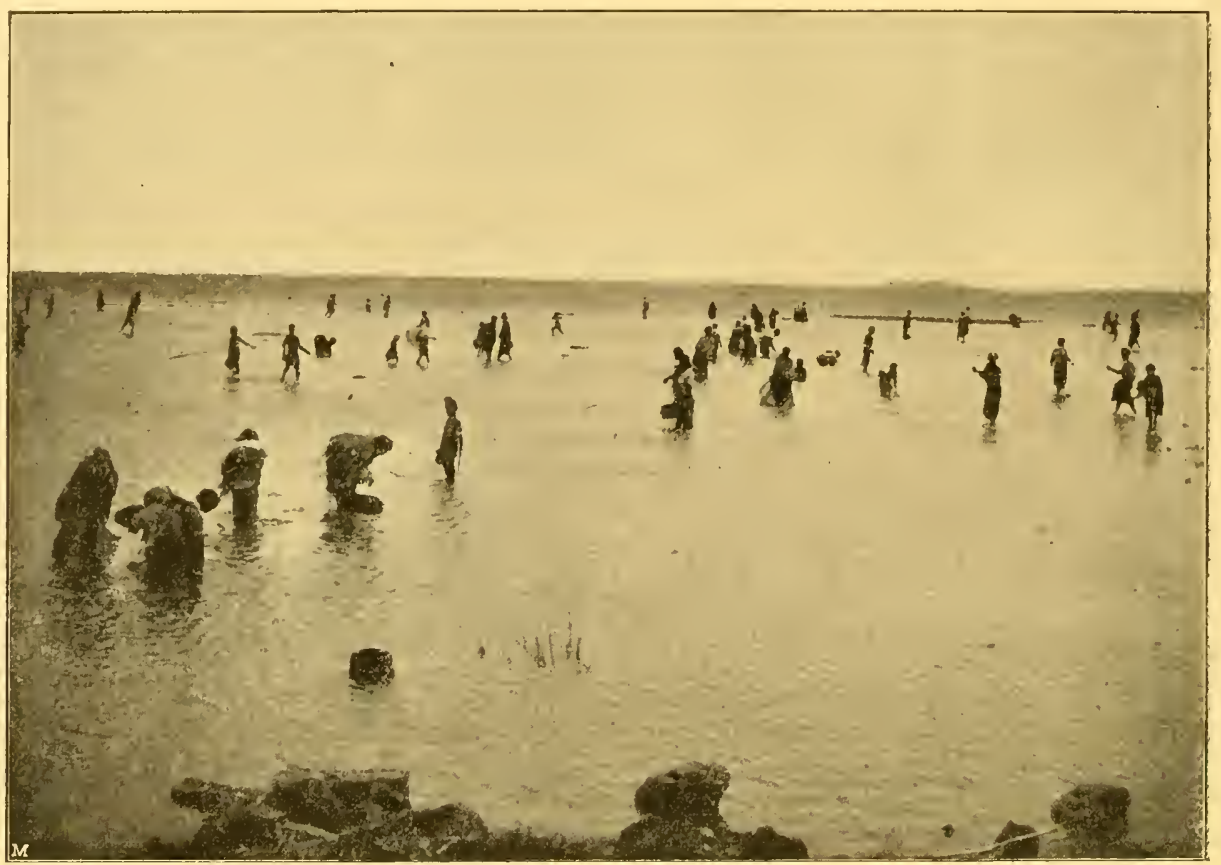

Fischende Eingeborene in der Strandlagune. Andrews phot.

\section{Die Corallen und Corallinenalgen.}

Die Madreporen sind die hervortretenden Bildner der samoanischen Riffe Namentlich sind es die grossen tellerförmigen Platten der species eytherea. picifera u. s. w., welehe an den Alhängen der Leckanten in Lnzahl anzutreften sind (s. Bild.). Eine ähnliche Schilderung macht Klunzinger von den Korallemiften des rothen Mareres (17a.). Am Riffrand selbst findet man häutig M. globiceps mit gedrungenen fingerhntförmigen Aesten und unten ans der Tiefe steigen die lohen Aeste der M. acuminata, hrstrix, plantaginea empor; hier im stillen Wasser sicht man anch die feinen Stylasterarten (granularis. rosens). welehe die Samoaner allentlalben zum Kaufe als 'immuna (rothe Korallen) anbieten. [nter den zahlreichen Arten, welche durch Dana und die Godeffroy sehe Simmlung bekannt geworten sind, will ich mur noch einige nemen: Halomitra pileus, Coeloria Forskaclana Esperi, Montipora verucosa, Pavonia lata, eactus und frondifera. Pachyseris rugosa. Leptoria phrygia, Fungia dentata. Millepora tortuosa u. s. w. Die Milleporiden nennen die Samoaner pungau, anch máan (beissender Stein), während sonst eine grössere Konalle mur pungal oder 'amu heisst. Die hreiten Madreporensehalen werden lapar, die grossen ästigen feofeo genannt.

Die Korallinenilgen spielen anf den samoanischen Riffen nicht dieselbe Rolle, die ihnen anf andern Riffen zngeschrichen wirk. 
Viel rerbreitet ist indessen einc Art Lithotamnion. Wolche die Simoaner

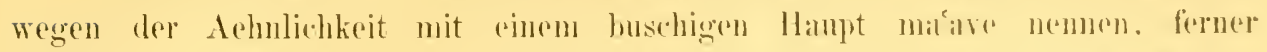

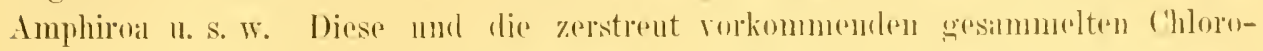
phyceen*) sind in lichenswïrdigster Wrise ron Major a. D). Rainbold in ltzehue

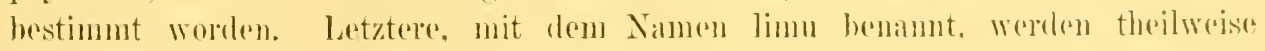

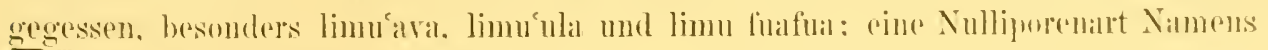
aluit wirel als Bimsstein rerwendet.

\section{Das Leben im umgebenden Meere.}

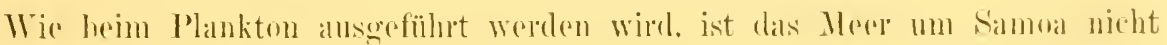

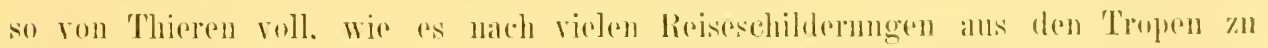

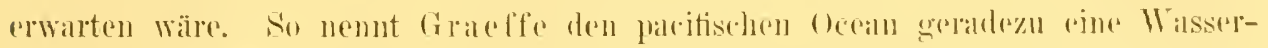
wïste. Denn wenn man von Sï̈len her den Wendekereis passirt. habren die letaten

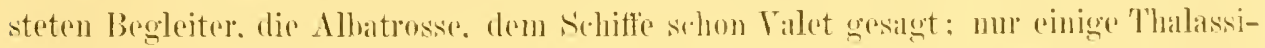
dromen und Töjpelsesechwalben (Anous stolielus) sind noch zeitweise zu sehen.

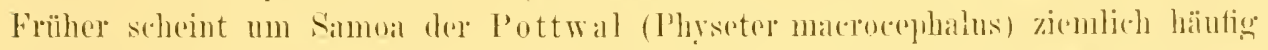
gewesen zu soin: die Zähne soines [nterkichors sind heute gesmchte Artikel unter

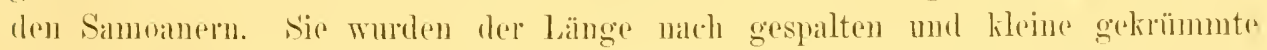

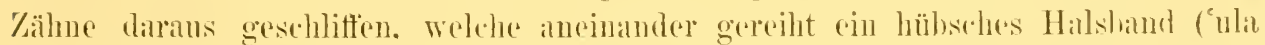
lei) geben, den Sehmmek der Dorfjungforn (lei der Walzalln. tafola der Wal). Jetat sind die Wale durch die steten Nachstellungen der Walfischjäger selten geworden: immerhin habe ich mich rinigemale von ihrem Dasein überzengen können mel S. M. S. ..Falke" sah einen jungen auf dem litfi hes Mulifanual gestrandet. der indessen ror Ankmuft rines Bootes wioder freikin.

Fast noch seltener wie die Wale scheinen dio Tolphine zus scin. denn irh habe während meines ganzen Aufenthaltes in Samoa nie einen daselhst gessehen, während sie in Nen-Seeland mul Australion nie zu fehlen pflegten. Auch die Sammaner wissen ron dem masi masi (die Heerdo heisst langai) nicht viol zu erzällen.

Neben Delphinen scheint anch eine Phocacna-drt (mumul) rorzukommen.

Wie die Zähne des ITales. so wird auch die Schale des Nantilus. des sesema, zu einem Schmuck gohraucht. dem sogenannten fuiono: es ist dies ain Stimband aus einel dopjelten Reihe ron hasehussogrossen l'lättehen. hä̈nlich perlmutterartig schimmernd, rou cinem foinen Geschmack zeugend. Dar Santilus scheint indessen selur selten in Silmoa zu srin.

Eine grössere Bedentung kommt dem Haifisch in Simmal zu. Im allgemeinen heisst er malie. und wemn sehr gross tanifa. eine dmble Art fanifani. pine helle tanifatea. Ex ist in der Lagune zu gewissen Zeiten häutig (maliealu) und wird daselhst mit dem Not\% gefangen: vorhel worken Feste gefeiert (umuto auf Tutnila), damn zicht alles hinaus anf den Fang (lopamalie). Dies berwerkstenligen sie durch Treiben und Lälommathen mit einer Kname (lutu). auch dadurch. dass sie Köder ans Netz binden (mangimanginoa). Besondere Geschenke (liva) errial-

*) Unter diesen befand sich die an Madreporenzweigen wachsende eigenthïmliche Valonia rentricosa I. Ag.. bisher nur von fiudeloupe bekannt. nit ihren tambeneigrossen grünen, durchscheinenden Thallusblisen. 
ten den glücklichen Fischer: das Fleisch wird gegessen. die Zähne zu Gperationen repwendet, wie der Konorhen des fliegenden Hundes. I)ie Gegend der Apolimastrasse ist heriedhtigt wegen ihres Reichthums an Haitischen. Als der ..Bussard*

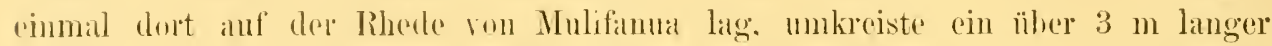
gefleckter ('alcharias heständig das Sehiff. ging anch schliesslich an die ausgehängte Angel: beim Aufleissen des Colosses brach jedoch der starke stählerme Haken. Anch im Apiahafen wurde zoitweise ein schwarzer kleiner Hai beobatehtet. welcher den Kïrle indessen nicht nahm. Hier gassirte es im Jahre 1892, dass cin Matrose

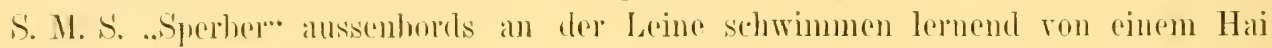
horbängt wurde. Als a desishalh alus dem Wasser genommen wurde und anf der Fallheepstreppe wohl einen Fuss ïber Wasser stand. setzte der Hai ans dem Wasser narh nud riss dem Mann einen Theil des Gesïsses ah. Woron er indessen wieder genals (der Mamn). Dieser unbestreithare Fall diüfte für diejenigen lehoreich sein, welehe immer noch hezweifoln. dass der Hai den Mensehen angreift. L'm so wnnderbarer klingt as allerdings. wem eine frïhere Expedition von Samoa herichtet. lass die Eingeborenen $n$ it den Haien $u m$ äher Bord geworfene Eingeweide von Shehlachtthieren förmlich kïmpften.

Im allgeneinen scheinen die Samoance wenig Aligst vor Haien zu haben, wenigstens in Apia. wo sie ron ihren Booten ans oft stundenlang haden. Dies geht auch alus Berichten ron Pritehard hervor. Er erzählt, dass ein Mamn im Boote hinausfuhr und die Haitische fütterte: als einer nahe kam, warf er ihm dine Schlinge äbre den Schwan\%, die indessen beim Holen brach. Ins Wasser springend, fing (x) den Tamp, dep an Fisch sass. und belegte ihn im Boot: anf diese Weise ge(angु es ihm demm anch, den Hati allmälig an Land zu bringen.

Anch ron 'Tutuila crählt Pritchald einen ähnlichen Fall. der äbrigens mit einem Biss des Haitisches in die grosse Zohe des kühnen Fängers endete; es scheint, dass allerdings diese Haie nicht sehr gross waren (wohl Mustelus).

Die Simoaner kemmen auch den Hammerhai (Sphỵma) mud nemen ihn matilitalingat. d. h. das Ange im Ohr.

Nicht selten ist der gremeine Rochen ('Thgon). fali ganame, dessen mit Widerhaken sägeartig besetzter Stachel (foto) als tödlich gilt. Er wurde von Meuchelmörderu unter die Matte der ausersehenen Opfer gelegt, sodiss diese hem Tmwenclen des Köppers den Stachel sich in den Iceib trichen. Ein Rochen mit sehr lanuher Hant (faicili) wird als Feile rermendet.

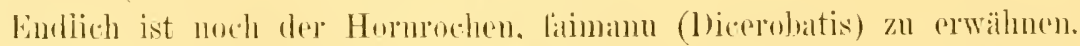

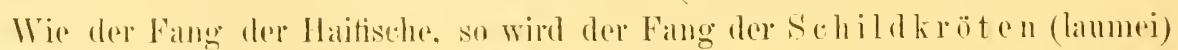

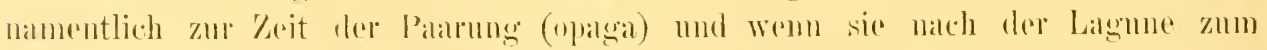

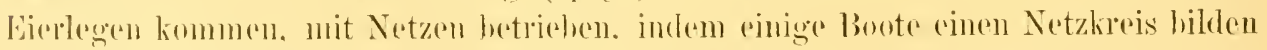

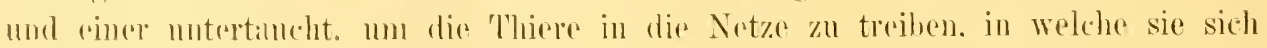

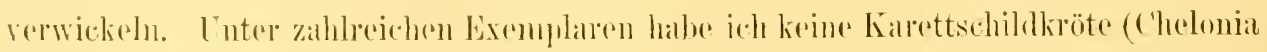
imbricatal) geschente die als rorkommenel angegeben wiol: meist handelte es sich

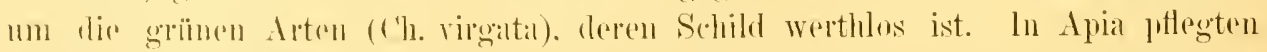

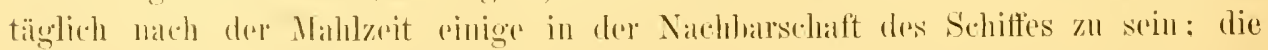

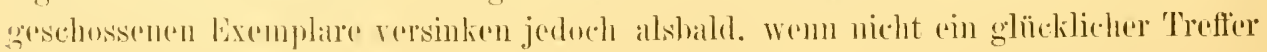

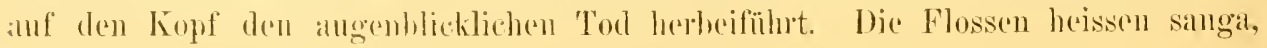




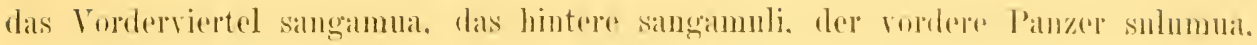
der hintere sulumuli: Volu ist rin weiterer Nime für Sehilelkrïten.

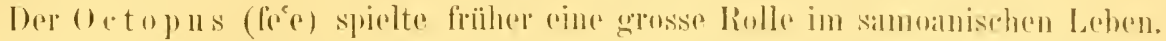

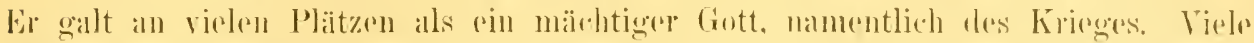

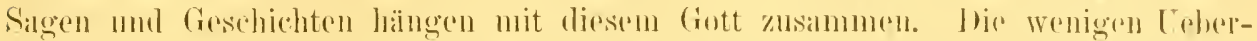

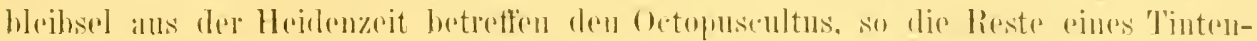

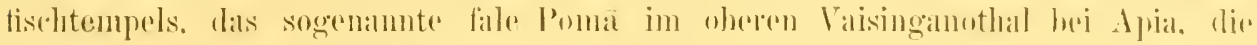

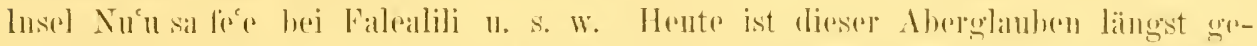

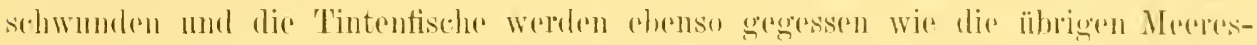

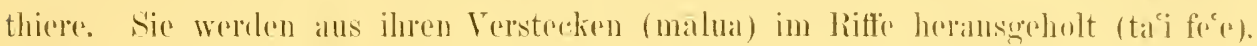

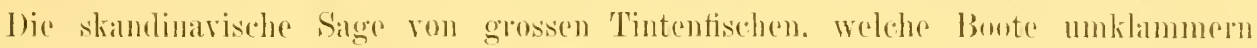
und in lie Tiefe ziehen. wird rom Wyatt Gill (Jottings from the Pacitio) aluch

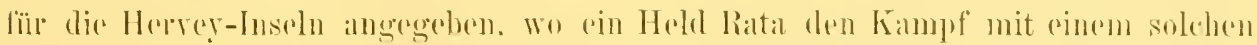

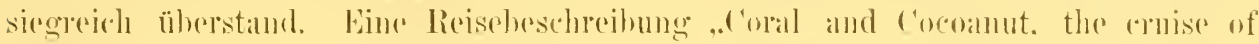

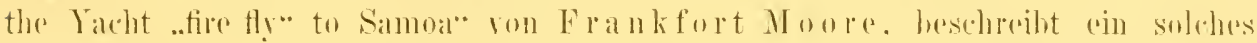
Torkommoniss anch für Apia gelogentlich des Palobofanges: dio Simoanel wissen

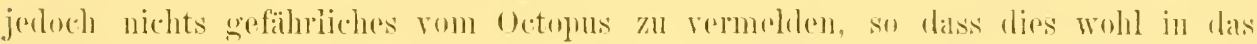

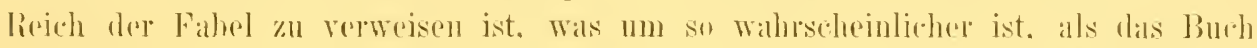

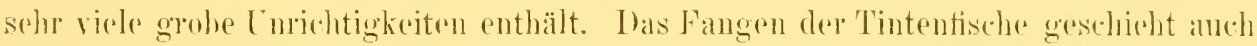

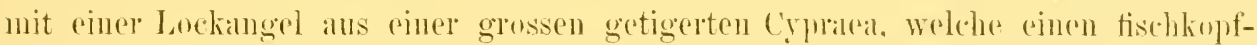
ähnlichen Stein umsehliesst. Anch werclen oft nur die Blätter des rothen ti-Strandedes (lordilyne) an einen Stein gebunden (lacei).

Es bleiben noch die secschlangen zu crwähnen. welche im Gegensatz $z u$ den Landsehlangen (ugata) giftig sind. Am hänfigsten sind die woitrulueiteten

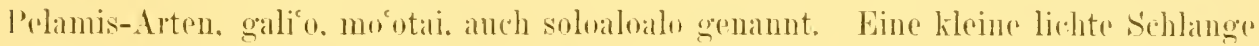
mit mugiftign Jiss heisst sulusululatoi.

Eine sedöne Simmlnng ron Seeschlangen regdanke ich der Güte des Herru l)r. Fun in Apia: die Verarbeitung stelit noch alls.

\section{Fische (ial) und Fischfang (fingota).}

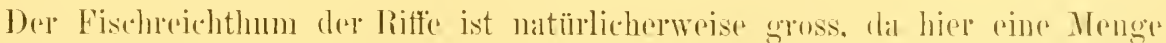
ron Nahrung sich tindet. Die Zahl der Arten wird indessen noch ëhertroffen dureh dio Mamnigfaltigkeit dor Formen und Farben. Tch labe schon in der Einleitung

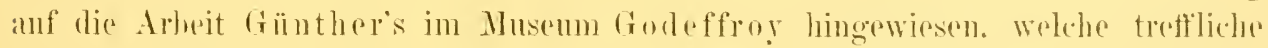

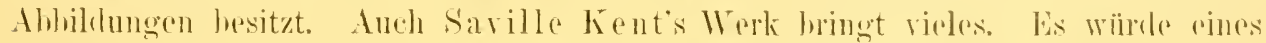
Buches allein bediirfen. um das nur wongg bekannte zusammenzutragen, Lond

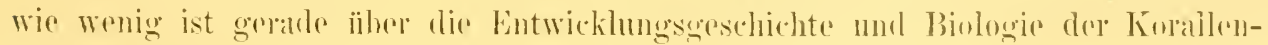
fische bekamnt!

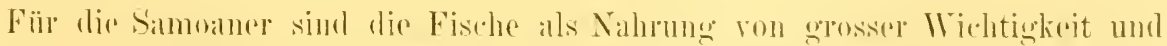

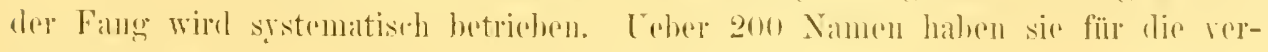
schiedencen Arten, ein \%ejchen, wio viele es hior gioht.

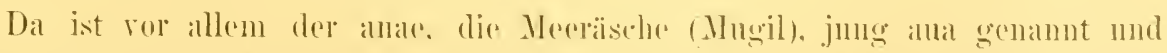
allalele. Wenn or aus Angst vor dem rerfolgenden malanli aus dem Wasser suringt.

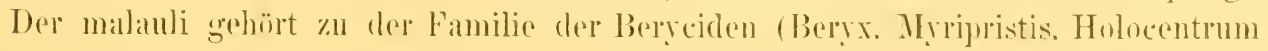


11. s. w.), von denen gegen 20 malan-Aiten unterschieden werden (laulolo, wenn in der latgune gefingen.).

Fermer der Secbarbe (Mullus) táulecia, das Emblem von Safotulafai auf Savaíi.

Am Rifte selbst die zahlreichen Symamipinnes, der bunte Chatodon ephippium (tifitifi), der goldgelhe Holacauthus u. s. w. Viel gefangen wird der gemeine Nasentisch, mue, (Naseus unicornis). Der Kofferfisch, moamoa (Ostracion), der sue ('Triodon). und tiutu (Diodon), der filoa (Pristipoma), der matácléele (Apogon).

Ferner ist bokamnt rin Häring (atnle), der fliegende Fisch (mālolo) (Exocoetus) (im fiegrensitz zum Indischen Ocean um Samoa recht selten). der grüne. aber delicate fungausi. der ngatila (Serranus). der mutu (Chilodactỵlus), der sungale (Anabas), eine kleine durchsichtige Plemronectide, ali. der Sägefisch sáolà (Pristis). der pone (Acanthurus). der Hormhecht. ise (Belone). der giftige iliü und mavan. der commensalische Fierasfer ínui. u. s. w.. u. s. w.

Alle ïbrigen Fische übertrifft jedoch an Wichtigkeit der Bonito. (Thỵmus pelamyss) atu genannt. in Thutuila ía, in der Poesie pau. Der Fang dieser wilden Raubfische ist der volnehmste Sport im samoanischen Ichen. Fin hesonderes Boot, das sáablo oder tafanga, vorne mnl alchtern gedeckt und mit grossem Ausleger, dient rliesem Zweck, da die Verfolgung und Aufsuchung der Bonitoheerden (inafor weit anfs Meer himausfïhrt. Wo die Möven über dem Wasser sich sammeln (pale), da sind ạnch die Bomitos nicht fern. da ist Nahrung. Der Fang geschieht mit dem Perlmutterfischhaken (matau), dem Flieghaken (tio). Welcher mittelst einer Locine (ifo) an einem langen. fest in dis boot eingesetzten Bambusstock geführt wild, welcher einen hölzernen Anfangstheil (tuan) hat. Durch die Fahrt des Bootes wird der Haken ïber das Wassel gezogen und der Fisch angelockt. Der erste so gefingene atu in der Saison, der guatongià, wird dem Dorfhäuptling zu Füssen gelegt. Abel nicht allein anf offener See. wo er eine Grösse von 1-2 m erreicht, kommt er vor, sondern auch in der Lagune und in den Häfen, wo or die in den Schutz der zu Anker liegenden Schiffe fliehenden kleinen Fische verfolgt und einen solchen Lärm rerursacht, als ob jemand ins Wasser gefallen wäre. Er tritt local oft in grossen Mengen auf, mom dann rasch wieder zu verschwinden, je nach Menge der Nahrung. So schreiht Wy ytt Gill (.Jottings from the Pacitic S. 157): .. Als wir im .John Williams nordöstlich ron Lord Howe Island fulıen, wïhrend der Dämmerung an einem Decembermorgen. Salhen wir das Meer roll ron kleinen Fischen, ähnlich Sprotten. Seevögel flogen darüher. nach Herzenslust sich sättigend. Kur\% daranf kamen Heerden ron Bonitos in heisser Terfolgung nachgestïryt. Mit einem halhen Dutzend Perlausternhaken ohne Köder fingen wir in wenger als einer Stunde 116 Bonito, deren gröster 'Theil eingesalzen wurde. Während des 'Tages segelten wir langsam durch eine zahllose Menge von Bonito. - Wir hïtten leicht einige 1000 ror Somnenmergang fangen können. Tährend der folgenden Nacht war das Meer erlenchtet; demn wemn die Bonito mahe an der Oberfläche durch das Wasser fuhren. wurden sie phorphorescirend - ein Anblick mvergesslich denen, die ihn einmal genossen."

Die Samoinel verwenden versehiedene Methoden zum Fing der Fische. Die einfichste Art ist das Steinhanfen machen in der Lagune (taufatu), um dadurch Fische anzulocken. Viele sind geschickt im Fang mit der Hand (lima malie), mit chem Bugen und Pleil (tamoio) und mit dem igelartigen Fischspeer (sóásóa). 


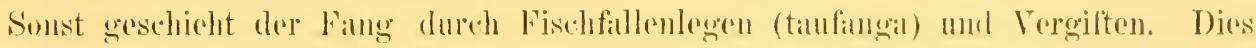

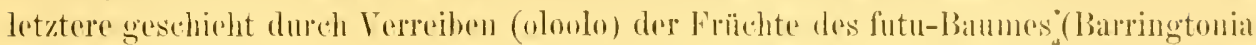

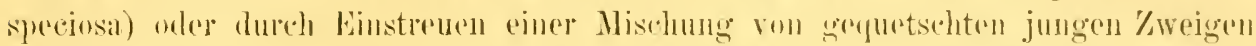

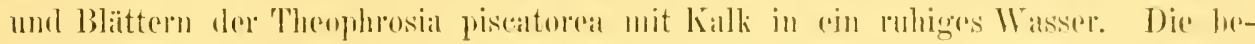
täubten Fische lasson sich alsdann greifon. Scho helieht ist alled das Fische

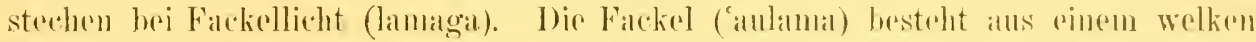
cocoswedel. Die Ausbente pflegt indessen dabei leine grosse zu sein. Sitalt des

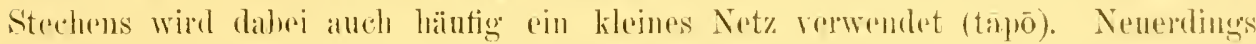

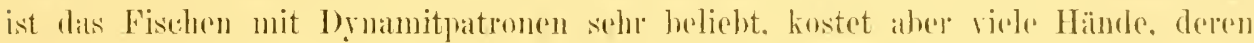
zerfotzte Theile ich oft zusammenzullicken das Vergun̈eren hatte.

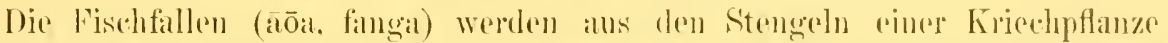

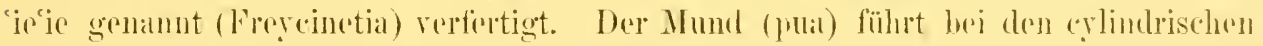
Formen dureh rinen langen Eingang (tapua) in den geräunigen Korh. Eine kleine

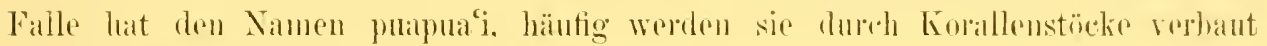
(tallamm). so dass sio kitum sichthar sind.

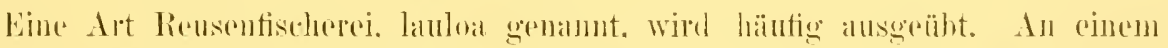
Seil werelen Coeoswedel angeflochten und damit ein grosser 'Theil der Lagune

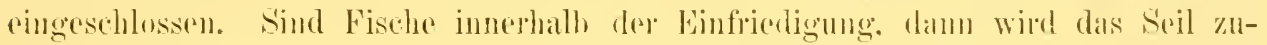
sammengeholt (fo) und die Fisele in einen Sick (tui) getriehen. Anf cincm Steinhaufon (tula) steht dahei meist ein Leiter (tantai) diesere Operation.

Ein einficher Moclus ist anche einen angen Riffeinlass cinfiach durele eine Falle zu rersehliessen (tualviaoa). Von Fischuetzen ('mpegal), welehe aus dem

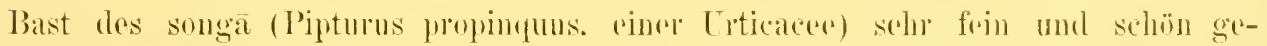

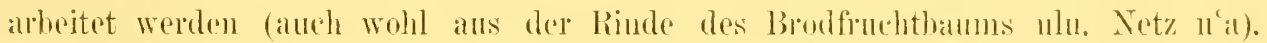
werden viele in rerschichlone. Weise gebraucht.

I) wohl häufigste ist die Art, wie der anac (Mugil) gefangen wird. Ton mehreren grossen booten, soatau, wird mittelst rines langen Notzes in der flachen

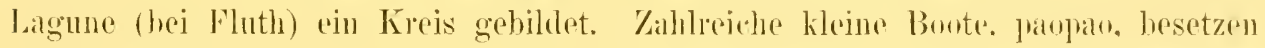
die Lücken zwischrn den grossen bonten mit dreicekigen Notzen, aine hreite Seite an den durch Treibhölzer (uto) schwimmenden Rand des grossen Netzes legenul. Der Kreis wird darauf enger gemaldit. mud einer springt ins Wasser. um die Fische zom Springen ïloer dis Netz mit rinem Stock (latauta) zu treihen. Wobei sie aufgefangen werden. Ku Flössen wird das Holz des tou (Cordia aspera) rerwendet. Ganze Dorfschaften ziehen an bestimmten 'Tagen auf Befehl dor Häuptlinge hinaus in die Latgune zum Fischfang. dem sieh keiner entziohen darf. wenn er nicht harter Strafe gewälig seill will. Lnalusgenommon (das Ausnehmen vor der Lamulumg gilt als

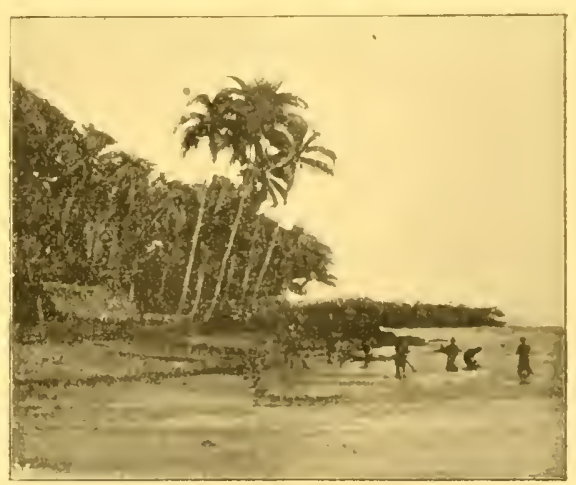

Fischende Eingeborene am Strande. ungehörig. palunatuina) werden die Fische dem Dorfhüuptlinge am launde zu Füssen gelegt, der sie austheilt. und dem der hester und grösste Fisch (tafré) zugehört. 
Besonderes Ansehen erfient sich der ga'ogáoletai, der Mann. der viele Fischmethoden weiss: mehr schöner Blicke darf sich aher der Jüngling erfreuen. der rom Fischfang heimkehnt mit ainem lantiti, die Fische wie ein titi um seinen Leih hängend. Denn die Damen essen in Samoa mindestens eben soviel und gern wie dic Männer.

Lnzählig sind dic Worte, die sich auf die Geräthschaften. auf die Fangarten. die Stadien der Fische u. s. w. bezichen. ein Studium vieler Jahre, das sich aher bei dem offenen Blick der Naturvälker für solche fü̈ sie so wichtige Diuge wohl lohnte.

\section{Fingota.}

Fingota nennen die Samoaner eigentlich alle wirhellosen Thiere. inshesonelere Medusen. Echinodermen. Mollusken. Kruster, Würmer u. s. w. Von Mesusen labe ich nur eine Aurelia im Hafen von Pangopango. allerdings wïhrend dreier besuche heständig daselbst gesehen ('alu'alu? valoca?). Oefter sah ich indessen die sesēma, die weitverhreitete violette Velolla und zwar auf offomer See und im Apiahafen. Lamane heisst eine grosse Actinie.

Besonders häufig unter den Seeigeln ist der alamea, die langstachelige Diadema. welche sich allenthalben in die Korallenblöcke einbohrt. Folanalameal heissen die Samoaner eine Manupulation der Selbsthilfe, inclem sir den eingetretenen alameaStachel durch die Saugkraft des 'Thieres wieder ausziehen lassen und so sagen sie aluch folau alamea, wemn ctwas ron selhst heilt. Hin glosser Echinus ohne Inormen hreisst palutu, zwei andere ofaofa lauago und ofafa sina, einer "ina, einer sã vaci, riner vatue, einer endlich vama, dessen Stacheln als Nadeln Verwendung finden.

Mehrere Arten Seesterne werden unter aveau zusammengefisst. Sulisuli ist ein specieller Name.

Endlich die grosse Zahl von Holothurien (und Symapten), deren Eingewride (wie das mancher Seeigel) als sea gegessen wird, hesonders das der lonm. Dic gewöhnliche Holothuric heisst funa oder fungad und wenn sie seir gross ist ulatpo: je nachdem sie schwarz, weiss oder roth ist, wird sie funafuna uli, sina orler ngatale geruamnt. Sonstige Nimen sind: amu'u 'ulutunu, loli, maisu (schwarz), matamalu, matefanau, peval II. S. w.

Sie kommen indessen nicht so zahlreich vor, dass an eine Trepangfabrikation gedacht werden könnte.

Von den Krehsen wissen die Samoaner ungeführ 30, von den Mollusken ungeführ 50 Namen anzugeben.

Am wichtigsten von ersteren ist der ưu, ler coeosnussräuber (Birgus latro). wolcher hauptsäthlich auf Manná (ein Baum voll Krebse heisst dort pei) mol anf 'lutuila vorkommt. Sein foister Schwanz heisst angani und ist natürlicherweise selu beliebt. Desshalh ist der Krebs selten. Häufiger sind die Meereskrebse, die Lysiosquilla maculital vomehmlich, und die Langusten. Am meisten gefangen wird indessen del Carcinus, pa a genannt, der eine recht ansehnliche Grösse erreicht und vortrefflich schmeckt. Neben den seltenceren Salzwassergarneelen, den ulat ai, ist aher vorzinglich oin in den Flüssen sehr verbreiteter Palatemon. der ulavili, welcher olt über $10 \mathrm{em}$ lang wird (abgesshen rom dem lingen 1. Fussparr) und in Silzwasser gekocht vortrefflich mundet. Eine Landkrabbe, (Gecareinus), welche 


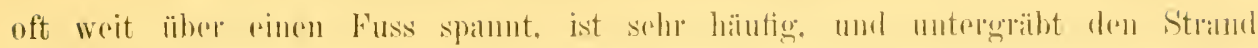

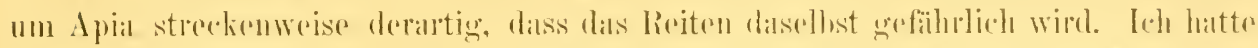

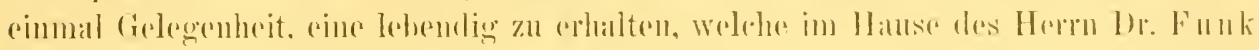

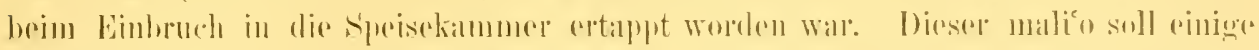

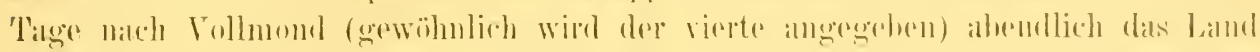

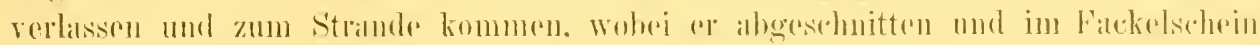

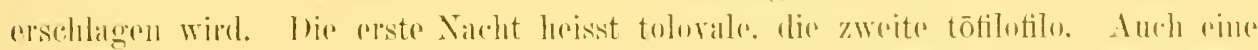

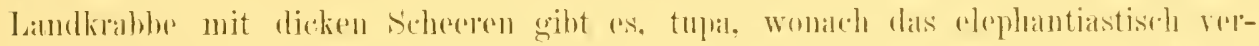

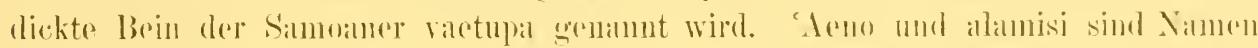

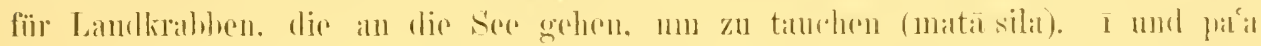

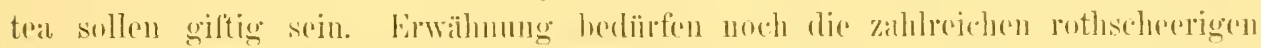

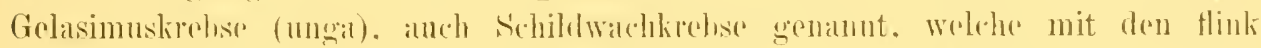
hïpfenden Periophthalmusfischen den Mangrovesumpef hinter A pia bevöliern. Forbes beschreiht sir treffiend rom liecling-itoll.

Muscheln und Schnecken (pule) sind häntign auf den libton.

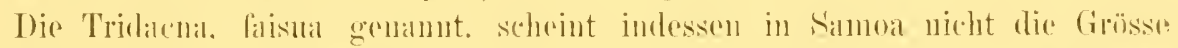

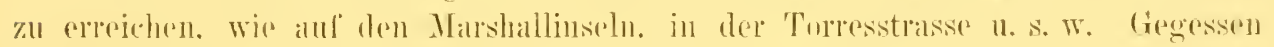

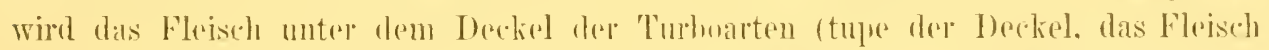

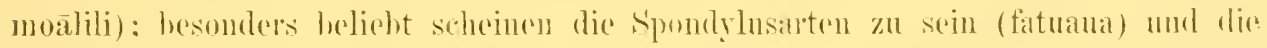

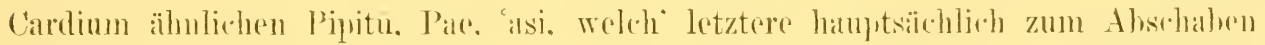
der Tutungarinde hohufs Zubereitung des bistes des Papionualubeerbaumes für die

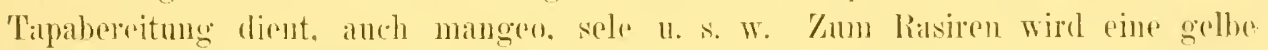
Mesodesma ähnliche Muschel rerwendet, tipi sele ava gernamnt. auch die Tollina ähnliche Pipitala. Die Pumala (Cassis comuta) diente früher als Kriegstrompetr. die Orula wrulum (Cymaea orulum), wie sehon erwïhnt. als Schmuck der Kriegsfalluzenge, da man glaubte. dass in den leeren Schalen der Geist des Kriegsugotes fere, des Oetopus. hause.

Ob die in Fiti nicht seltene Cypriea aurantinm anch in Simoa rorkommt. wie angegeben wird. habe ich nicht erfahen könuen. Auch die P'erhmuttermuschel von Tahiti, tilil. seheint recht selten zul sein.

Eine schöne malakologisehe Sammlung erhielt ich in Apiat dureh die ciöte des Herru Alesander Sehmidt, welche noeh nieht rerabeitet ist. Ieh gene daher die obongenannten Daten nit Vorbehalt wieder.

\section{Der Palolowurm.}

Wie die Zoiten des Haifischfanges und des anare, des kileinen lo im Juli u. s. w.. so hildet anch die \%eit des Palolofanges zu Beginn der Rrogenzoit. des Va i Palolo. im Octoher und Norember einen der Höhempunkte im samoanischen Leben. Wochenlang spricht alles nur divon. Wie wohl der närohste Palolo ausfallen mag, wie die fröheren waren und waun der näkdste soin wird. I)ie alten Lente und Dorfhäuptlinge springen mit ihrem liatle rin. denn das taluese, dats falsch herechnen. ist hier von grossem Shbaden, dal in wenigern Mlinuten sich dats ganze Erscheinen des Wurnes abspielt. Ith will mich nicht lïnger dahei auf-

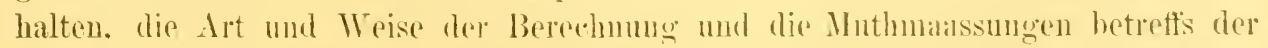
Ursachen des lirscheinens zu erörtern. da Herr l)r. Collin die bekannten Notizen 
hierüber zusammengestellt hat anlässlich der Bearbeitung des Materials. welches ich während zweier Jahresfeste sammelte. Im Jahr 1893 walr der grosse Tag der erste Norember. im Jahre 1894 am 20. desselhen Nonats in Apia, wo ich heide Feste mitzumatchen Gelegenheit hatte. Als S. MI. S. ..Bussard" am 24. Octoher 1894 nach Matantu auf Savaili kim, war daselbst der Palolofang schon 3 Tigge rorher an 21. Octoher gewesen, war also einen Monat früher als in Apia. Ich hatte Gelegenheit, die Corpora delictorum in Bananenblättern gedünstet zu sehen und anch - zu selhmecken. Anch frisch habe ich einmal diese Borstenwïrmer (Palolo- [Lysidice-] viridis Gray) rersucht und gefunden. dass sie gar nicht ühel munden. Nicht sn gut schmeckte ein langer, kleinfingerdicker Regenwurm (Oligochaete) der ans dem Sandstrande stamnt. dem die Samoaner ein Loeh in den Leih beissen, um die Geschlechtsorgane herauszudrücken. Ehensowenig schmeckten mir die daumengrossen Carabuslarren. welche die Samoaner mit Genuss lebentig verzehren.

Essen und Tanz bildet wie immer den Haupthestandtheil des Palolofestes. filleatlici, auch falepā genannt. Das Auftreten des Wrumes erfolgt am Tage. am Tage des letzten Viertels und am Tage nach demselhen: der erste Tag heisst usmoa. anch motusanga, der zweite oder grosse Tag tatelega und der dritte salefunga. Als Zeidhen des Erscheinens des Wrurmes wird auch das Auftreten eines keinen Fisches. mosi mosi. unmittelbar vorher angegeben. Zum Fange dienen verschiedene Netze: in Lefenga sah ich einen rensenartigen Korb aus dümnen cocoshlattrippen zusammengesetzt, mit dem Namen 'enu. auf Saraíi ein langes

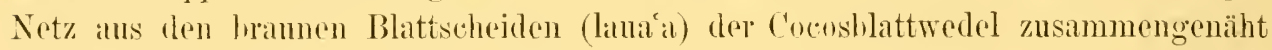
und unten mit einer kleinen Oeffnung: dies Netz heisst taepă. In civilisirten A piil werden natürlich emropaiische Notzzenge verwandt. mit Vorliebe Stücke ausser I) ienst gestellter Muskitonetze, welche üher einen racketartigen Rahmen gespannt werden. Der Ertrag ist nicht immer lohnend: doch kommt es zuweilen vor, dass solche Cnmassen gefangen werden. diass sugar samoanisehe Mägen zur Vertilgung nicht ansreichen und Schweine zngezogen werden müssen. Der Ort des Schwillmens ist nicht die flache Latgune, sundern eine Riffbucht. eine tiefe Stelle inmitten des Strimdriffes. In Apia ist dies die Lelepabucht, gegenüber der Landecke Matautu. diss Palolotief. das eine Tiele von $13 \mathrm{~m}$ anfweist.

Der Fang hietet einen eigenthïmlichen Reiz. Noch bei Nacht gegen ${ }_{12}^{1} 4$

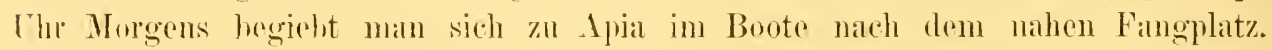
Am Himmel steht der Hallımond. am klaren Sternenhimmel, nur wenig Licht spendend. Line kühle Lanntbrise rult das Gefühl der Morgenfrische wach. Man durehquert den Hafen. stenert anf den Riffeinlass bei Matautu zu und dringt im Strandcallal in wenig Minuten his zur Landspitze vor. Von hier ist das Palolotief noch $250 \mathrm{~m}$ entfernt church die fliche Lagune getrennt. Vor 4 Lhe kommt man noch einigermaassen leieht hinüher, we'm dis Bont nicht zu sehr besetzt ist. nach 4 Chr ist e's schon mühsilm.

Tastend suchen die Bonte in der Dunkelheit ihren Weg zwischen den Korallenrasen. die hier die Lagmue theilweise füllen, his man plötzlich in tieferes Fahrwilsser gelangt. Dunkle Schatten rom früher angekommenen Booten sieht man anf Iem glatten Wasser liegen, ein Zeichen, dass man schon am Platze ist. Gegen 
5 Uhr heginnt es sich allunälig im Osten zu lichten. Schon erkennt man in der Nähe einige bekannte Gestalten, blumenbekräinzt und duftige Ketten ïber die Brust. Aber nur ein leiser Gruss tönt dem Anknmmenden entgegen. als ob man fürchtete. die Bente durch Lärm zu verscheuchen. Linzelne Personen schöpfen schon Wasser und es seheint, dass der Fang gout wird. Es wird lichter und lichter; die kurze Dämmerung heginnt. Jetzt sieht man das Wasser, und bald gewahrt man auch einzelne lange dünne Wiurmer in demselben sich sehlïngelnd forthewegen. IBald mehrt sieh mit der Helle anch die Zahl derselhen: niemand achtet mehr des Nitchbarlu; alles schöpt und fïngt, die Bente in bereitgestellte Eimer abschïttehnd. Blickt man aber anf, so gewalut man ein wunderhares Bild: ror sich das hohe grïne Land, die Schluchten noch in Dunkel gehöllt, die lichten Höhen in saftigem Grün sehillernd: muten aher an Strande die Hütten zwischen den nickenden Cocospalmen, ein endloser grüner Strand; der frische ablandige Morgenwind, roll ron Blüthendïften, rersehencht die Müde der kurzen Nacht; seewärts der weite, stille Ocean im ersten Blau des Morgenlichtes auflenchtend; unermüdlich wïlzt er seine Fluthen gegen die nahe Riffkante an. wo der weisse Gischt zusammenstï1zt, die erste See schon gefolgt von einer zweiten und dritten in unaufhörlichem Spiel; in dem stillen Wasser rings umher ein buntes Gewirl von Booten und Canoes, eine Lnzahl junger geschmiickter Mädehen und alter Treiber, emsig fischend unter Lalchen und Scherzen: da hebt sich schon die Sonne im Osten; nur noch rereinzelte Würmer durchqueren lebensmüde die Oberfliche: alles eilt dem Lande zu, um die Boote, ehe es zu heiss wird. über die nun nahezu trocken gefallene Lagune zu ziehen. Anf der stillen Wasserfläche des Palolotiefs sieht man nun die Bonitos die Nachlese halten: bald aher ist diselhst alles wieder stille wie zuror. 


\section{I)ie Centrifugirung des Plankiton.}

Es liegt nirht in meiner Absicht, die Hensen' sche Methode rerbessern oder gar schmälern zu wollen: als ich im Frühjahre 1889 nach Kiel kam, um in die Kaiserliche Marine einzutreten, rïstete man eben zur grossen Planktonfahrt. Auf mich allein angewiesen, habe ich im Lanfe der folgenden .Tahre während zahlreicher" Fahrten practisch die Methode geprüft. aber tahei stets bedauert, dass sie an den einzelnen zu grosse Anforderungen stellt, nicht allein an das Wissen, sondern anch. an die Zeit und die C'asse.

Hensen's Methode wird allen grösseren wissenschaftlichen Expeditionen als Muster zu dienen haben: sie ist die Methode der Hochsee. woselbst in grösserem Cmfang zu planktonisiren nur denjenigen rergönnt zu sein pflegt, welche sich an Bord eines für wissenschaftliche Zwecke in Dienst gestellten Schiffes befinden.

Was soll aber der einzehe Mann mathen. weleher allein an der Küüste weilt, oder an Bord eines zu Anker liegenden Sehiffes sich hefindet? Was soll der Reisende machen, der ïber eine gedrängte Zeit verfügt und sich doch gern üher den Planktongehalt eines bestimmten Meerestheils oder Süsswassersees in kurzer Zeit rergewissern möchte?

Es kamn nicht genug darauf hingewiesen werden. dass eine Uebersicht über die Resultate am Orte des Sammelus nicht allein neue Gesichtspunkte und Lüickeu enthïllt, sondern anch sehr zur Arbeit anspornt.

Jeder weiss, wie das mechanische Sammehn ohne die Kenntniss des Eireichten müde macht und wie umgekehrt übersichtliche Resultate anspornen und harte Arbeit rergessen machen.

Man hat sich lis jetzt im Allgemeinen mit wenig Planktonfängen hegnügt; muss doch rinc grosse Serie von Füngen. welche nach Hensen's Angaben verarbeitet werden soll. jedem eine gewisse Beklemmung verschaffen, dem man sie zur Terarbeitung ïbergiebt.

Wenn aber auch Hensen 's Schluss richtig erscheint, dass man aus wenig Stichprohen anf die Berölkermng eines Meerestheils Schlüsse ziehen kann, (wenigstrus zur Jilneszeit des Fanges*). so wird, es in vielen Fällen doch wichtig sein, diesen Schlüssen durch eine Reihe ron Messungen Beweiskiaft zn geben.

Hensen sagt äher einen Fang in der Sargassosee mit 2.300.000 Individuen anf 1 em (..1)ie Lebensgemeinde in der Fläcle des (Geans“. Deutsche Rerue XIX. Juni Heft S.319): "Viele in engerem und weiterem [mkreis gemachte Ziige mit demselben Netz und vertiealem Aufzug ergaben ähnliche Ifengen und ganz ähnliche Zusammensetzung der Lebensgemeinde; 
IVird man erst viele tausende von Fïngen wïhrend de verschiedenen Jahresszeiten aus rinem Mrepesahschnitt hesitzen, damn wird man erst sagen dïrforn, dass man ihn wirklich kemut.

Man wird noch mehr verlangen müssen: eine übel viele Jahre ausgedelunte Benbalehtungracit.

Solche Forschmogen seheinen aher nur möglich, wenn man die Masse tess Planktonfanges basell und genan messen kann. Sind diese Massen ühereinstimmond.

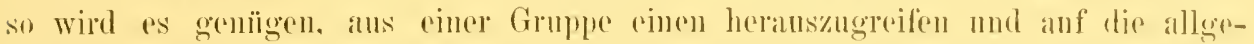
meinen (omponenten durehzuzählen. Die wissenschaftliche l ntersuchung des Matr-

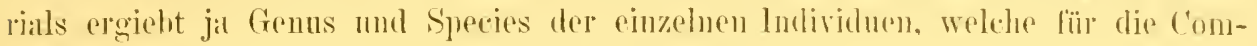
position vielfach nur ein secmntäres Interesse hositzen.

Zur Messung simd rersediedene Methoulen rorgessehlagen worden: Bestimmung durch Terdrängung. dhureh Absagen, durch Borechumeg des C'ubikinhaltes der ein-

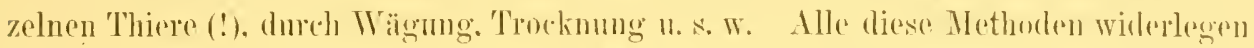
sich ron selbst; theilweise muss das Material geopfert werlen, anderntheils ist

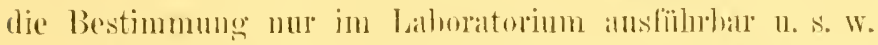

Am hesten ist noch die Bestimmmog des Rohvolumens, das Sichabsetzenlassen des Finges in Aleohol während 24 Stunden, welches Verfahron wïlurend der Planktonexpedition in Anwendung kam. Aber abgesehen daron. dass sich repschiedenes Material rerschieden schlecht absetzt, mangelt ehen oft die Zeit, namentlich beim heisen. Mas anservirte Material ergieht aber rin geringeres Volumen als das frische.

Hensen sagt darïher (52a S. 137): .. Tiele Jiatomeen verhalten sich wie Togelfedern: Peridineen mul copepolen sind ziemlich gut messhar, andere Formen des Planktons nehmen Zwischenstellnngen ein. Man sollte daher glauben. dass mit Volumenshestimmung hier ïherhanpt nichts genutzt werden könnte, indessen

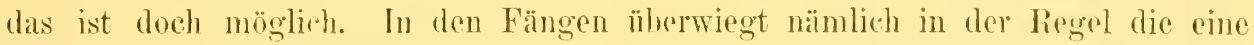
oder die andere Gruppe so sehr, diss alle anderen digegen zurïelitreten: daher sind ähnlich zusammengesetzte Fänge unter sich nach dem Volumen einigermalassen rergleichhar, aber nicht vergleichhar mit Fängen verschiedener Znsammunsetzung: und solehen aus rerschiedenen Jahreszeiten oder solehen, die mit rersehiedenem Netzzeng gemacht worden sind."

Fïr das 24 stïndige Ahsetzen des Fanges verhalten sich die Diateneen natiurlich anders wie die Copepoden: ja die Phycochromaceen pflegen sich zur Zeit der ..Blïthe" ührohaupt nicht von selhst niederzusetzen, th sie damn specifisch leichtel als das Wasser und der Alcohol sind. Bei Fang mit kileinen Netzen und auf

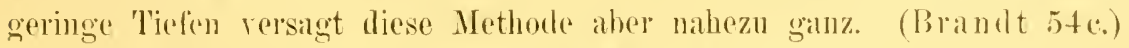

Desshalb habe ich rersucht. die Masse des Planktonfanges durch c'entrifugirung zu bestimmen, weil hierlurels grbiche Bediugumgen fïr alle ('omponenten geschatfen werden, und da ich nun äber eine 3 jührige Erfahnung darin gehiete und dir Nothode in den rerschiedensten Breiten angewandt mul als ausführbar

kein einzigar Zug ergah, entschiedene Abänderungen der Mischung. Lugischerweise ist man gezwungen. his zum Beweis des Gegentheils anzunehmen, dass die an diesen Stellen gemachten Befunde für die ganze Region Geltung luben. I)as ist ein lireis ron etwa $1000 \mathrm{~km}$ Radius oder eine (If)riläche, die der Landfliche von Ifrika nahe glejehkommt." 
befunden habe. so stehe ich nicht an. sie zu empfehlen ror allem für Küstenfänge und fü l das Studium der Planktonvertheilung in den Kolallenriffen. wo es gilt und leicht fällt, viele Fïnge zu machen und es in erster Linie interessirt. zu erfahren. wie viel Plankton rorhanden ist.

Dabei sind die Fänge wohl untereinander vergleichbar, da ein Bestandtheil immel vorhanden ist, nämlich die copepoden, woson ich noch weiter unten zu sprechen haben werde.

Dass das Material nicht durch die Centrifugirung leidet, kann ich dadurch beweisen, dass ich bei der Bearbeitung der Copepoden des Haurakigolfes in NenSeeland nahezu nur centrifugirtes Material gebraucht habe, das eine siehtbare Beschädigung nicht aufwies.

Weit abgesehen davou, dureh das näher anzngehende Verfahren die Hensensche Methode schädigen zu wollen, glauhe ich vielusehr ihr Stütze zu verleihen, indem diese leicht auszuführende und vereinfachte Modification dazn dienen möge, ihr die gebülnende Anerkennung zn rerschaffen.

\section{Die Ausführung der Fänge:}

\section{Fang und Netze.}

Wenn die Tiefe nicht bekannt ist. wird sie im Hafen erst ansgelothet. In See bej treihendem Schiff arheite man stets in Lurseite, damit die Leine nicht nuter den Kiel schmeidet. Kur Verwendung kam stets ein Apstein'sches Netz (56a) mit nngefïhr $1 /$ is gm Netzöftuung und wurden die Fänge damit im Hafen meist auf 10 m Tiefe gemacht, gelegentlich auch rom Grund aus bis $2040 \mathrm{~m}$, da in grösseren Tiefen Sehifle nicht zu ankern pflegen. Gelegenheit zum Fang hei nicht ankernclem Schiff bot sich nur selten (s. Tabelle C.).

Das Aufholen des Netzes geschah mit der Geschwindigkeit ron ungeführ 1/2 $m$ in einer Secunde.

Da ich fand, dass die Weite der Netzöffnumgen durch Vernähung des Messingringes bei den 3 in Gebrauch genommenen Netzen variirte, liess ich mir nenerdings limge aus Messinghand anfertigen, am unteren Theil behufs Festühung: des Conus umgeschlagen und durchlöchert. (S. 122 Fig. g.)

Für Studien in kleinerem Massstahe lassen sich 4 Wreiten empfehlen:

1. 100 (1m (104 mm Durchm.) dient als kleines leichttransportahles Netz. hauptsïchllich zı Süsswasserfängen;

2. ${ }^{1 / 5}$ (qm (130,3 mm Durchm.) für Küstenfänge. rornämlich in lıeimischen Gewïssern :

3. ${ }^{1} / 50$ 4m (159.6 mm I)urchm.) hauptsächlich für Kï̈stenfünge in den Tropen und S'ecfänge:

4. ${ }_{25}$ qm (225.7 mm Durchm.) für Seefänge.

Grössere Netze können ihrer Unhandlichkeit und ihres hohen Preises halber nur hei grösseren Expeditionen Terwendung finden. Das von der Planktonexpedition gewöhnlich gebrauchte Net\% von 1/1n qu Oeffunng kostet gegen $300 \mathrm{Nl}$

Als Netzzeug kam Nüllergaze Nr. 12 und Nr. 19 in Anwendung. Im Allgemeinen wird es sich empfehlen. nur die feinste, $\mathrm{Nr}$. 20, zn verwenden. Wenn 
man indessen nur anf die Menge Wrerth legt, genügt $\mathrm{Nr}$. 12 vollkommen, jat ist vorzuzichen. da damit melne gefangen wird (an Masse).

Mit der Grösse der Netzöftinng wächst naturgemäiss dic Breite und die Länge des Netzes. Das Terhältniss von Netzöfhumg zu Filtribfläche stellt sich ungefïhr wis $1: 20$.

Dil nicht alles Wasser in der Sätule tiltrirt (durch Verdrängang), muss ein geringes zu dem famgrolumen addirt werden. Bei Müllergian Nr.20 ist dies ungeführ ${ }^{2}$, , bei $\mathrm{Nr}$. $12=1 / 10$. (siehe Hensen's 'Tahellen, die übrigens schwer verständlich sind). denn der Durchmesser der Löcher von Nr. 20 ist $=0.05 \mathrm{~mm}$, der vou Nr. 12 aber $=0,1 \mathrm{~mm}$.

Es ergieht sich daraus, dass man mit Nr. 12 auf diejenigen Thierformen nicht rechnen dirf, welche kleiner als $0,1 \mathrm{~mm}$ sind. Dal solch kineine Individuen

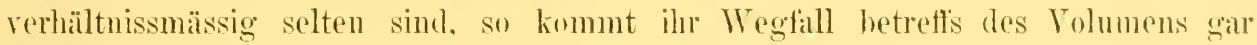
nicht in Betracht. Aber anch wenn sie mässig reichlich vertecten wären. würde ihr Volumen doch nicht gegen das der copepoden in Concurenz treten, nicht einmal gegen das zweite Zehntel. das bei Nr. 20 verloren geht. Aus diesem Gruncle crhält man für C'entrifugirzwecke weit richtigere Resultate mit $\mathrm{Nr}$. 12 als mit Nr. 20. Auf allo Fälle thut man aber gut, bei quantitativen Fängen mit Nr. 12 sich wenigstens etwas pualitatives Material mit $\mathrm{Nr}, 20$ zu sichern.

Da ich mit beiden Netzen Fänge gemacht hahe. hahe ich keinen Ausfall zu beklagen. Die Zahlen aus Neu-Seeland. wo sich in den Fängen sehr zahlreiche Diatomeen. Globigerinen. Tintimen u. s. w. befinden, zeigen ja anch. dass man mit Nr. 12 genïgende Resultate in hiologiseher Hinsicht gaünstigenfalls erhält. Die Fänge mit Nr. 19 dienen als controle. Bei dem kleinen Volumen der Hafenfünge lohnt es sich kaum, einen Filtrationscoefficienten in Rechnung zu bringen. zumal da die Methode nicht ideales leistet. Die Fehlermöglichkeiten lassen sich indessen noch nirht klar ïbersehen.

\section{Besichtigung und Filtrirung des Fanges.}

Ist das Netz aus 10 m Tiefe senkrecht anfgeholt, wird es noch einigemale (je nach Diatomeenreichthum) in das Wasser bis zum conischen Aufsatz eingelassen und dann rasch alus dem Wrasser geholt, damit möglichst alles in den kimer gespült wird.

Der Fang wird dann in ein Glas ahgelassen. der Hahn wieder geschlossen. das Netzzeug des Filtriremers mit einer Spritze ron aussen ahgespritzt. und danu der Inhalt dem ersten Ahlass hinzugefügt.

Bei Betrachtung des Fanges erkennt das geübte Auge leicht, ob es sich um .gute. Fänge oder num Beschmutzmug handelt. Ist man zweilolhalt. so ist das schou ein gä̈nstiges Zeichen: dis Microscop hringt leicht Aufsehluss darrühel. Bei ankernden schiffe muss man stets am Bug die Fänge machen, dimnit man nichts ron den nach achtern treibenden Abgüssen mit fä̈ngt. Yor allem muss die \%eit des Ascheheissens rermieden werden. Wem sich ein starker Gezeitenstrom geltend machte. wio z. B. in Auckland. so wurle die Zeit des Hochwassers nder Niedrigwassers gewihlt und zwar, ehe das Schiff zu schwojen begann. Wreil sich damn das Wassep am Bug am reinsten erwies. Ist Wind und Strom enteregengesetzt. so diss der (H)erflïchenschmutz nach rorne treibt. so wird man die Fänge hesser am Heck ausfïhren. 
Hier muss die persönliche Erfahrung z.n Hülfe kommen, die freilich nur der besitzt. welcher lange zur See fährt. Jeder macht seine ïblen krfahrungen und auch beim Planktonfangen wird man nur durch Schaden klug. Diese Cebelstände rermeidet man, wenn man rom Boote ans Fïnge macht. Man thut alsdann gut. dieselben erst am Lande zu filtriren und centrifugiren, namentlich bei schlechtem Wretter: alsdann ist es freilich oft unmöglich, ïherhaupt Fänge zu machen.

Hat man den Fang für hranchbar befunden und grössere Thiere (Medusen. Amphipoden ete.) mittclst einer Spritze oder eines Hebers entfernt (was bei den kleinen Netzöffnungen nicht oft nothwendig zu sein pflegt), so wird der Fang dureh einen kleinen limer filtrirt. wozu man kurzweg den am Apstein sehen qualitatiren Fangnet\% angeschranbten rerwenden kamm (S. 122 Fig. f.). Freilich kömnen dabei noch einige kleinere Formen verloren gehen, welche gerettet waren. Bei ,exacten" biologischen Fängen wird man desshalb gut thun, direct aus dem Gefäss in ein kleineres Messglas den Fang hinein zu centrifugiren. wozı man nur einige besondere Einrichtungen brancht und was zugleich eine ziemliche Zeitcrsparniss wäre.

Die untere Oeffhung des kurzen Filtrir-Cylinders muss durch ein Läppchen ron mindestens derselben Netzzengnummer algeschlossen werden. aus der das zum Fang verwendete Netz besteht. Am besten nimmt man dazn immer Nr, 20. Das Läppchen wird dureh einen Kklommring festgehalten.

Nalch mehrfachem Ausspïlen des Glases wird das Läppehen abgenommen. auf der Cylinderwand ansgebreitet und mit Daumen und Zeigefinger der linken Hand festgehalten. Nit der rechten Hand schibt man mittelst eines feinen schmalen Spatels die Planktonmasse vom Läppehen ab und ïberträgt sie direct in die C'entrifugirmessglïser. Dies kamn su genan gemacht werden. dass anf dem Läppehen katum ein Exemplar zurückbleibt. woron ich mich durch das Microscop des öfteren überzengt habe.

\section{Die Messgläser und die Centrifugen.}

Für Hafenfünge und 1/75 em Netz kam ich in Nen-Seeland und Samoa immer mit Röhrchen aus. welche nu $5 \mathrm{~mm}$ Lichtenweite und $115 \mathrm{~mm}$ Länge besitssen (S. 122 Fig. a). Sie sind auf 2 ec im Ganzen graduirt und tragen die ' ${ }_{10}$ Theilstriche $5 \mathrm{~mm}$ von einander entfernt, so dass man sehr genau ahlesen kann. Fïr heimische Verhältnisse und $m$ anch für das $1 / 50$ Netz eingerichtet zu sein, habe ich indessen solche von $7 \mathrm{~mm}$ lichtenweite nnd $115 \mathrm{~mm}$ länge anfertigen lassen, wo die $1 / 10$ 'Theilstriche nur at, $3 \mathrm{~mm}$ ron einander entfernt sind. Sie genügen für diese Zwecke indessen vollauf. Sie passen genan in die 1 cm weiten Messinghüllsen der ..Reisecentrifuge" hinein. Natürlicherweise sind einige grössere Messgläser für ğrössere Fänge (namentlich in den kalten Meeren wïhrend der Diatomeenzeit) nothwendig (zu 3,5, 10-20 (c). für welche einige weitere Messinghülsen zum Anhängen vorhanden sind, (Bei dem dranssen angewandten Apparat waren nur ungefïhr $20 \mathrm{~mm}$ dicke Hülsen rorhanden.) Angewandt wurde ein ('entrifugirapparat. welcher dis Princip) der Kugel-Kreissel-centrifuge (nach Prof. Gä r to erWrien und Franz Hugershoff-Leipzig) und der Latutensehlïger"schen sich horizontal stellenden und zurückfallenden Röhrchen rerlindet. Acht Röhrchen 
von $20 \mathrm{~mm}$ Inurehmessel sit\%en um die Welle, welehe mittelst rinel 2 m lingen starken Schmm zweinnal hintereinameler abgezogen wirel, wodureh jerlesmal der Apparat auf die Datuer ea. 2 Minnten von selhst länft. Die liöhrehen sind ron

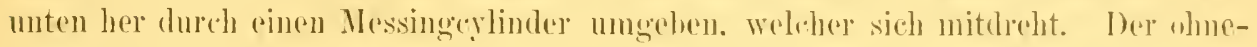
dies nicht lejehte Apparat musste in einem festen Kasten angehracht werden. son-

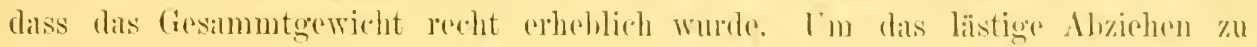

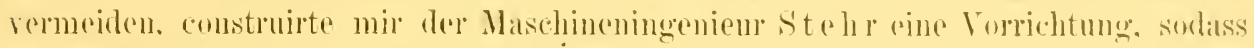

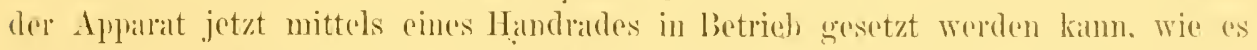

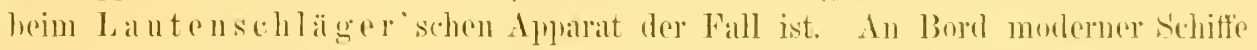
bailt es leicht, don betried durch einen kleinen kilectromotor zu erwirken. wodurch diss Arbeiten sehr erleichtert wird. In Allgemeinen möchte ich rathen. dem

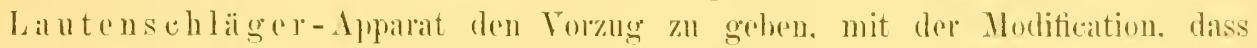
statt \%weiel Hülsen minclestens acht in der ('ontrifugirseheibe sitzen, welehe mindestens $120 \mathrm{~mm}$ lang und $20 \mathrm{~mm}$ Lichtenwoite hahen.

Auch dieser Aplarat kimn natürlich nicht ïberall hin seiner immerhin nivdet

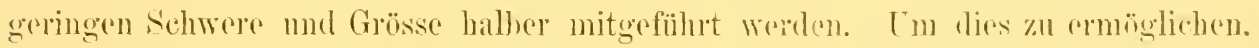
habe ieh mir einen Apparat eonstruirt. weleher auth dem kïhnsten beresteiger. falls es erwïnseht ist. ̈̈berall hin folgen und ohne die Hülfe eincs andern bedient werken kann. Er ist mit einem Microscop mud pinem Zähitisch nebst allem Znhehör zur Messung in einem Kasten zusammen untergehraleht. Welcher nur 35 zu $3 ! \mathrm{cm}$ hoch ond breit ist und eine Dicke ron $17 \mathrm{~cm}$ hesitzt. In ein wasserdichtes Futteral eingeschlossen, in welchen ein kleines Süisswasserplanktometz mebst Leine untergehracht werken kamn. wegt dieser Kasten alles in allem nicht ganz 15 kg. eiue gewöhnliche Trä̈gerlast. Das Futteral trägt Riemen, so dass alles hecpuem auf dem Rïcken transportirt welelen kann.

Der Centrifugirapparat solbst, welehen ich zur Enterseheidung ..Reisecentrifuge" nenne. wiogt nicht ganz $3 \mathrm{~kg}$ (s. mmstehend).

Er wird dureh Abziehen einer Schnur ähnlich der Kreisselcentrifuge in Bewegung versetzt. muss jedech wïhrend des Ahlanfens in der Hand helalten werden. da der leichte Ban kamm erlaubt, ilm irgendwo festzuschrauben. Der Fuss ist ans Holz, der lahmen aus einem gehogenen kräftigen Bandeisen, welches durch bisenrippen verstärlit ist. Aus der Abhilklung erhellt die Form. Neun Messinghülsen (e) ron $10 \mathrm{~mm}$ Lichtenweite und $115 \mathrm{~mm}$ Länge sind mittelst je 2 Haken an einer Tragscheihe (d) eingehängt. Eine gieichgrosse Scheihe (b B) befindet sich datrüber. welche hehnfs kin- und Anshängen der Hülsen anf- und ahgesehohen worden kann. und einen abuehmhalen Deckel, die ('entrifugirscheile (a) trïgt. unter der dic beim Centrifugiren wagerecht stehenden Hölsen gerorogen sind. I)ie

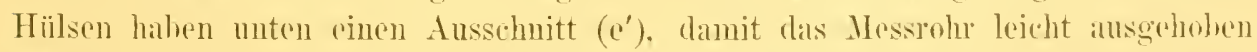
werden kam und anch oine Cehersicht über den Fortschritt des c'entrifugirens emöglicht ist. ohne dass die Hülse ansgehängt zu werden hrancht. Der Apliuat ist in der Werkstatt ron ('. Z wiekert in Kiel angefertight und kostet 45 Mark dasellust.

Boi grösseren Fïngen ron Diatomeen (thaetocelas) muss man die Messgliser so weit nehmen. dass die centrifugiete Misse nicht riol mehr als dreimal so hoch wie breit ist. da sonst die Resnltate zu umgleich werelen und die Fünge sich schlecht ahsetzen. 
Aus den angegebenen Messungen lässt sich leicht berechnen, wie gross ungefähr die Mengen ausfallen bei den verschiedenen Netzöffnungen. Darauf wird man hei Anwendung rerschiedener Netze zu achten haben.

Die Messgläser füllte ich ror dem Cebertragen mit $30-40 \%$ Alcohol; ist de! Fang reich, so muss man entsprechend viel zuror ahgiessen.

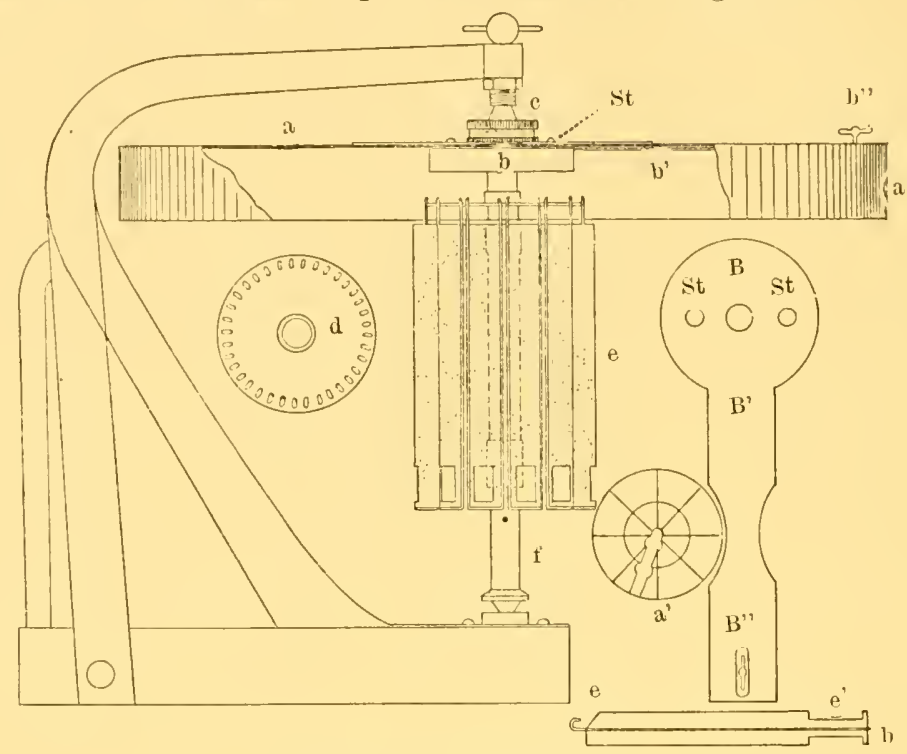

Reise-Centrifuge.

at abnehmbare Centrifngirscheibe. Hie seite gegen den Beschauer ist behnfs Einblick durchbrochen.

a' diesellse verkleinert von ohen gesehen.

b b" l, stiitzscheibe für die Centrifugirscheibe mit Kianpe zmm Festlegen (b" B") und 2 stiften (St) zum Einlassen.

B B' B" dieselbe von oben gesehen, isolirt.

c schrabe zum Festselirauben der Centrifugirsehejhe anf die Stützscheibe.

d Tragscheihe mit Löcherm zum Einhingen der Messinghiilsen (e).

e Messinghülsen znm Einsetzen der Messö̈hrchen mit Ansschnitt (e') behufs Ansheben der (i]ïser.

f muterer Theil der Welle zum Aufwinden der Abziehschnur mit Loch.

\section{Das Centrifugiren.}

Das Idealste ist, dass man einen Fang so lange centrifugirt, bis sich das Volumen nicht mehr setzt. Bei den kleinen, mahezu reinen Copepodenfängen Simoas wall das nach zweimaligem Abziehen schon erroicht. Auch waren die Fänge in Neu-Secland nicht so gross und diatomeenreich. dass ein längeres Centrifugiren nothwendig geworden wäre. 3000 Umdrehungen in einer Minnte lassen sich mit den Lautensehlägor'schen Apparat ereichen; die Kreisselentrifuge leistet disselhe: allein anch 2000 sind ausreichend.

Wie schon erwïhnt, läuft die Kreisseleentrifuge nahezu 2 Minuten. wovon jedoch nur die erste in Betracht kommt. Zweimaliges Ahzichen würde also zweiminutenlauger Lmolehung mit der Hand gleichkommen.

Wem die Fänge besonders reich an Diatomeen (wie z. B. die Chaletocerasfïnge in der Aprilzeit im Kieler Hafen) sind, so genïgen 2 Minuten nicht. Inshesondere die Chatowerasionmen setzen sich ihrer zahlheichen Borsten halber nur schr schwer zusammen. Weite Messgläser sind hierfür unerlässlich. Hier muss Eiffihrung mithelfers. (Siehe Tortrag auf der Naturforscher-Vers. Frankfurt 1896.) 


\section{Verrechnung.}

Hensen hat alles anf 1 am Meeresoherflitehe berectunet, indem ar den lir-

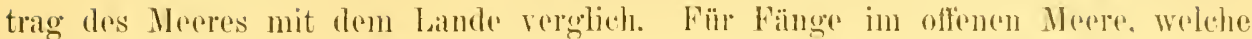
grössere Tiefen als $200 \mathrm{~m}$ durchifischen, ist dies sicher sehr zwerkimässig.

Für Küstenfü̈nge möehte jeh jedoch dies in Alorede stellen. Dals Land ist

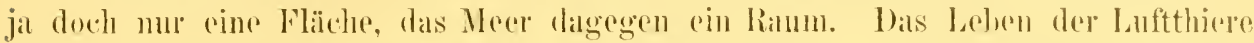

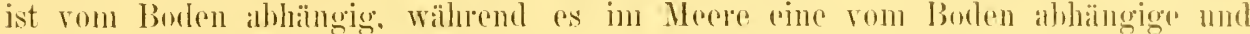

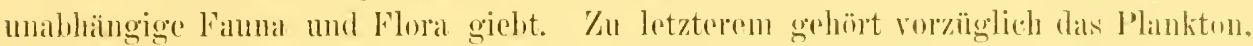
wenn aluch der Lïnfluss der Küste auf die Masse üherall hervortritt. Wollte man alles anf 1 ym Neceresoberflaiche berechne'n, so wäle as mindestens nothwendig. dass alle Fänge rom Boden aufwärts gemacht wïrden. Alle übrigen Fänge hätten nur relativen ofler gall keinen Wrerth. An der Küiste. Wo Plankton iiberall bis zum Boden vorhanden ist. würde man aber desshlalb. wenn man immer rom Boden ans fischt, sehr ungleiche Resultate erhalten, die muter sich arst nad lomrechnung rerglichen werden könnten.

Desshalb habe ich für die Küstenfïnge (resp. alle Fünge bis zu 200 m) die Berechnung anf 1 chm als Einheit durclugefïhrt.

lieselbe ist einfich:

die Kilhl der Fünge (n) $=1$

die centrifugirte Menge $(c)=0.2$ a:

die Tiefe des Fanges $(\mathrm{t})=10 \mathrm{~m}$

und die Oeffinungstläche $1 / 5$ ism (o) $=7.5$ gessetzt.

heisst die Formel $\frac{\because .0}{\mathrm{n} . \mathrm{t}} \quad\left(\frac{0.2 \cdot 75}{1.10}=1.5 \mathrm{cc}\right)$

Bei der Notirung wurden folgende Formehn angewandt:

$1 \times 10 \mathrm{~m}=0.2$ ec $\| 1$ (bm $(10 \mathrm{~m})=1.5 \mathrm{a}$.

Bei allen Ausrechnungen geschah dies bis zur zweiten Decimale, welche nur approximativ Geltung hat, aber für spätere Berechnungen wichtig ist.

Anders rerhillt es sich freilieh. wenn man Fïnge alus grösseren Tiefen. z. B. $1000 \mathrm{~m}$ und noch tiefer. macht. sei es in der See oder in den tiefen Fiorden einer Küiste. lintweder muss man sie hetrachten, als ob sie aus 200 m Tiefe gemacht wären. wenn man sie zum Vergleich ziehen will. oder man muss sie anf $1 \square \mathrm{m}$ berechnen und solche Fünge nur unter sich rergleichen. Was entschiedem als das richtigere erseheint.

\section{Die Zählung.}

Dureh die Einführung der Zä̈hlung der Planktonorganismen in rinem quantitatiren Fang hat Hensen seiner Methende das hestimmte Gepräge verliehen.

Er sagt dariuber (52 a.):

..Für die numerisehen Bestimmungen des Inhilts der Fünge sind eine Reihe ron Zählungen arforderlich. Von den zilhleeichsten rolkommenden formen zïhlt man nur eine kleine Qunote des ganzen Fanges, ron den weniger reichlichen Furmen cine entsprechend grössere Qunte und ron den seltenen Formen, insofern sie zugleich ron erheblicher Grösse sind. ziilhlt man womöglich de'n ganzen Fang durch." 
Die Zählung wird in diesem Sinne sehr genau durchgeführt und hedarf bej den grossen Oceanfïngen natürlicherweise einer grossen Zeit.

Bei den Küstenfïngen, wo es sich meist immcr um ein geringeres Volumen handelt. wenn man hier wie gewöhnlich mit einem kleinen Netz ( $1 / 75 \mathrm{qm})$ und aluf greringe 'Tiefen (ll) 111 ) arheitet, wofül marn entsprechend mehr Fänge machen kinn. verhält sich dies anders. Entweder greift man hier einen Fang zur rählung heraus oder man wirft mehrere gleichsinnige zusammen, nachdem maln sie einzeln zuror centrifugirt hat und zählt eine Probe davou durch.

Da die absolute Masse eines einzigen solchen Planktonfanges ( ${ }_{15}$, $4 \mathrm{~m}$ und $10 \mathrm{~m}$ ) gewöhnlich nicht viel mehr oxler weniger als 0.2 ce ergiebt, so erhellt daraus schon zur Genüge die grössere Einfachheit. In den Tropen pflegt sogar diese Zahl kaum erracht zu werden.

Bei der Zählmng dieser kleineren Fänge rerwendete ich weder Hensen's grosses Zählmicroscop) noch seine Stempelpipotten (wenigstens nur eine zu 0.2 ec behufs ('ontrolle). Nicht als ob ich dieselben durch bessere Materialien oder eine bessere Methode ersetzen liönnte - die Grïnle sind pecuniärer Natur. Denn eine

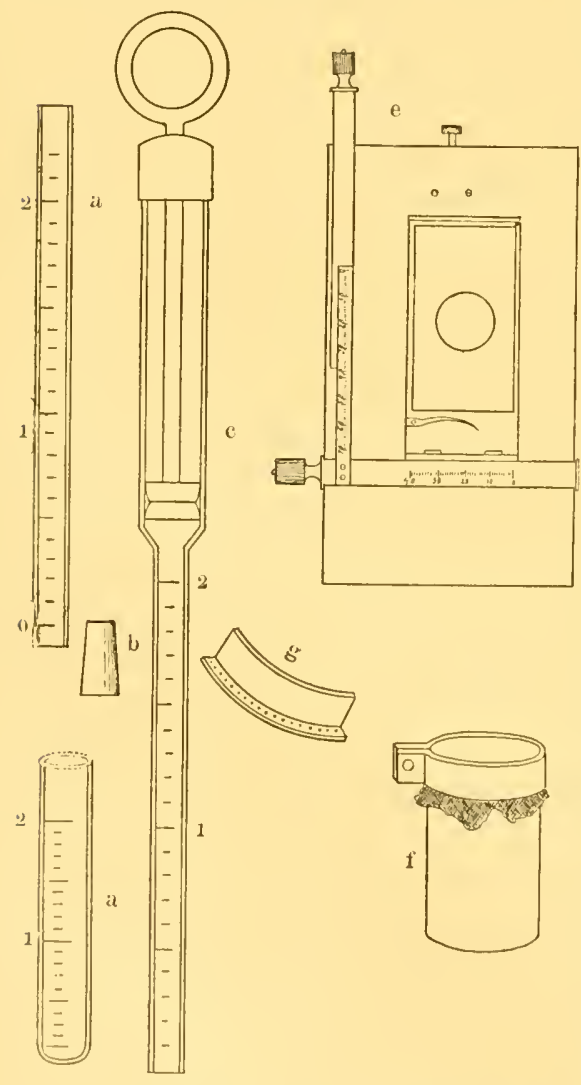
Pipette linstet 18 M., und da man eine Serie davon besitzen muss, so belaufen sich die Anschaffingskosten recht hoch. Dazu kommt. dass der Tramsport des umfingreichen und schweren Microseops und der leicht zerlreehlichen, difficilen l’ipetten fïr den lieisenden mit leichtem Gepäck wegfüllt. wem er ïberhaupt beahsichtigt, Zählapparate mitzunehmen.

Als Vähltisch hemutzte ich einen Apparat, wie iln Zwickert in Kiel ersonnen lat, und welcher an die gewöhnlichen Microseope mit rierkanten Objecttischen angeschraubt werken kimn (S. 122 Fig. e). Fr trägt cine Glasplitte $45: 75 \mathrm{~mm}$, welehe in $1 / 2 \mathrm{~mm}$ Längsstriche eingetheilt ist. Diese Platte kann im Allgemenen 4 'Tropfen Wassel tragen. wemn sie durch Aleohol nnd Acther fettfrei gemacht ist. Gut thut man, die Fläche rost mit einer dïmnen Glycerinschicht zu ïlerzichen. um das rasche Verdunsten zu rerhïten. An Bord, wenn das Schiff nicht ruligg liegt, empfichlt sich die Anwendung der Glyceringelatine, $\left.{ }^{*}\right)$ die auch zum Einschlnss von Prijparaten in diesem Simme dienlich ist. (Abschluss mit C'anadabalsam.)

Die Manipulation stellt sich bei einem gewöhnlichen Fang ohne ïbermässigen Diatouncenreichthum folgendermalissen diur:

*) Wasser $42 \mathrm{ce}$. (ilycerin 38 ec. (ielatine $7 \mathrm{~g}$. C'arbolsäture 1 g. heiss durch Glaswolle filtriren. 
Lis wird eine $1 / 2-1 \%$ Planktonanfschwemmming dargestellt, alsu $1 / 2-1$ cec centrifugirten Materials auf 100 ( Wasser. Die Aufsedhwemmmer geschient in einem langen Glaseylinder ohne Sehnamze zum Ahgiessen, damit heim Alusehluss mit der Hand währemel des Durchschüttelus nirhts verloren gedit.

Ist der Fang gut durehgeschüttelt. so rntnimmt man mit einer Spritze aus

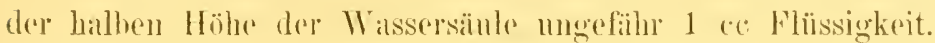

Die Spritze ist folgendermatssen heschaffen: Eine gewölnliche filasspritze läuft muten in cin kurzes gewöhuliches (ilasrohl bon al. 7 mm 1)urehmesser alls. so dass man eincen engen Gummischlanch ülerzichen kamn. Dureh den Gummischlamch mit der Suritze verhmelen wird rin heiderseits offones Glasmessiohr rom $115 \mathrm{~mm}$ Länge und $5 \mathrm{~mm}$ Lichtenweite. das in ${ }_{10}^{10}$ ec eingetheilt ist und zwal so, dass dev Nullpunkt nicht an der unteren Oethumg selbst. somderm einige mm dariibler liegt. (S. 122 Fig. a.)

Ist die Probe ron ungelähle I ec ans dem Mischungscylincler entnommen, wird das mutere Ende raseh durch pinen genau eimpassenden Gummistopfen (b) rerschlossen und his zum Nullpunkt eingetriehen.

Es wird nun abgelesen. wie viel Mischungswasser entnommen ist und notirt.

Das Messohr wird alstam ron de] Spritze algenommen. centrifigirt, wieder an die spritze gebateht, der Gummistopfen vorsichtig entfernt und durch einen Drnck auf den Spritzenstempel die unten angesammelte Plankton-Prohe anf die Zïhlplatte entleert. Was meist in 2 Tropfen rreicht ist.

Beim Wiederansetzen des Messmolures an die Spritze muss man darauf achteu. dass man den Gummischlanch nicht weiter und nicht weniger überzieht, als der Gummistopfen unten eingeschohen ist. Dadurch wird verhütet. dass im ersteren Falle hem Abnehmen des Stopfens otwas wegspritzt, oder im letzteren cine Lultblase anfsteigt. was ein neues f'entrifugiren nöthig macht. Was auf dem Gummistupfen liegt. wird durch einen Spatel ahgetragen.

Einfacher gestaltet sich das Terfahren. wenn das Messrohr an die Spritze angeschmolzen ist $(e)$. Nur ist eine Centrifugimug dann nmmöghich. I)amm muss man den lnhalt sich niedersetzen lassen mol so lange anf die Zählplatte ahtropfen. resp. ron nenem zählen. his in den 4 Tropfen nichts mehr cnthalten ist. Was meistens beim dritten male schon der Fall zu sein pflegt. Natïrlich muss mall dariuf achten. dass die Spritzenstempel gut sehliessen: die gewöhnlichen, aus zwei Ledermünzen hestehenden (eine nach oben. die andere nato unten geschlagen). thun ihren I)ienst wortrefflich.

Wem anch diese Methode mit dor grossen Genanghiejt der Stempelpipetten nicht wetteiferm soll. so liefort sie duch recht hrauchbare Resultate. wie mir mehrere controllzählungen gereight hiben.

Da man die bejderseits ntfenen Messröhrehen anch zum ('entrifugiren der Fangmassen äberhampt rerwenden kamm. so beträgt dir gamze Ansegalne hierfür den Betrag für eine Glaspritze und ringe dun rothen fommischlamelss.

Da die nun zu zählende Planktonporbe den hundertsten Throl ungefähr des Gesammtfanges heträgt.*) su kïmnen also mathematisch mu die Individnen jedes-

*) Die Simmafänge ergeben, dass in 0.1 ecentrifugirter l'lanktonmasse ungeführ 1000 Individuen sind. Dies kann natïrlich sehr schwanken. meist ist es mehr. 
mal auf der Platte sein, von denen wenigstens 100 im Fange rorhanden sind. Zählt mann desshalb einige 100 Individuen durch und erhält $1 \%$ in der Zählung, so ist dies für eine Uebersicht genügend.

In Allgemeinen können bei dieser Zählung nur Thiere resp. Pflanzen Berücksichtigung finden. welche in diesem Yerhältnisse zum minclesten vorhanden sind und ich glaube, dlass dies für die Kenntniss der Zusammensetzung des Küstenplanktons meist vollkommen genügt.

Nicht genügen wird dies freilich der Biologie und wissenschaftlichen Thiergeographie. Die meisten Zoologen hetonen ja, dass der wissenschaftlichen Verarbeitung der Fänge der Vorrang gebuihrt. lis scheint mir desshalh genügend. zwcimal 1 ee einer $1 \%$ Planktommischung genau durchzuzählen und die Componenten dieser Probe festznstellen. was in 1-2 Stunden hei einiger Lebung erledigt ist. wenn kein Diatomeenfang vorliegt. Yom übrigen Planktonfang wird alsdamn niach Abfiltrirung durch das Netzeimerchen möglichst viel auf dem Zühltisch durchgesehen und alles hei der Zühlprohe nicht Beohachtete sorgfältig notirt. Aus der Zahl der dabei beobachteten seltenen Individuen kann man daun ihre relative Häufigkeit abschätzen, die, wenn sie oder die Zählung richtig ist, unter $1{ }^{0}$ bleihen muss.

Natürlicherweise künnen während einer solch` kurzen Zeit nicht alle genera nud species gezählt werden. zumal wenn sie für die Wissenschaft neu sind. In der Hauptsache kummt es ja in rielen Fïllen daranf an. die Hanptcomponenten zu erfaluren und die häufigeren mbekannten Individuen durch eine kurze Zeichnung im Gedä̈htniss festzuhalten. Specielleren ökologischen und biogenetischen Studien bleiben natürlich eigene Modificationen vorhehalten.

Die Gruppen. die in Betracht kommen. sind hauptsächlich folgende:

1. Gruppe. Crustaceenliarven Nauplius

$$
\text { loea }
$$

2. Gruppe. Copeporlen

junge unbestimmte

alte

Oithona

Corycacus .

Harpacticiden

etc.

3. Gruppe. Ostracoden

Halocrpriden

4. Gruppe. Cladoceren

5. Grippe. Termes

Eradne

Podon

etc.

Sagitten

liotatorien .

6. Gruppe. Tunicaten

Appendicularien 
7. Gruppe. Protozoën

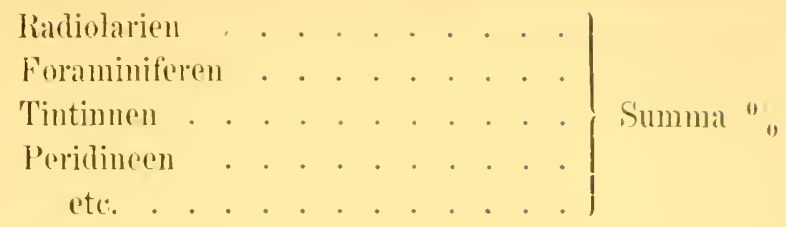

․ Gruppe. Metazoën

Diatomeen

Coscinodiscus

Chatoceris

Rhizosolenien

Phycochromaceen

9. Gruppe. Crsteu

Larven

Eier .

10. Cruppe. Macroseopisches: Medusen. Hyperiden, Schizopoden, Anmeliden ete.

Irie die eentrifuginte Menge, so wirl am Schluss auch die Gesammtsumme auf 1 ( ) hm herechnet.

Ieh gliuhe, dass ein solches Verfahren völig genügt. um Aufsehłuss ïloe die Vertheihng und die Composition des Planktons an den reaschiculenen ()rten zu gewinnen.

Denn was nützt an und für sich dic exacteste Zühlung im mathematischen simue, wem das Medium ein schwankendes ist: Hensen hetont selhst an den rerschiedensten Stellen seiner Arbeiten, dass er auch das Klein-P'lankiton nicht für mathematisch genau vertheilt hält: ich hahe mich in tausenden von Fällen iübelzeugt. dass dies nicht der Fall ist. und niemandem ist es noch eingefallen. dies zu behampten. Wenn ich aher an einer Stelle zehn Fänge hinter einander mache. und bei allen sehwankt die Menge. wenn anch nur mm ein geringes in der Zusammensetzung und im Volumen. wie es die Tahellen zur Genüge zeigen. Was nützt dann die minutiöseste Zähhnng eines cinzelnen Fanges, woun alle andern rerschieden sein kïmnen:

Wenn ich aher für ein freicres Arbeiten in dieser Beziehumg fürderhin das Wort eroreife. so thue ich es ausdrücklich nicht in der Absicht. mu mich zu denen zn gesellen. welche geradezu Schmähumgen auf die Männer gehäuft hiben, die in unermïdlicher Arbeit und Aufopferung das Material gezählt. gesichtet und verabeitet haben, welches während der viermonatlichen Oceanfahrt des .. National* im Jahre 1889 gesammelt worden ist. ein Material. für diss noch vieler Jahre Arbeit nothwendig sem wird, his es als abgeschlossenes Ganzes rorliegt. Es ist ja anch nicht immer im Toraus abzusehen, was bei der genauen Zählung für den Specialisten abfällt. Es scheint mil sicher, dass die accuraten Resultate der Planktonexpedition namentlich für die kommenden Genorationen ron nicht ahzusehendem Werthe sein werden: durch eine solche Arheit wall es allein möglich. die Ansführbarkeit der Methode klarzulegen und die gewonnenen Resultate vermögen zweifellos anderen Forschungen die Wege zu chnen. und weitere Arbeiten leichter zu gestalten. Aller Anfang ist schwer. Soi die wissenschaftliche Wolt doch wenigstens damit zufrieden, dass diese Arheiten wirklich ausgeführt worden sind: es nimmt ja niemand die Verpflichtung damit auf sich. sie nachzumachen. 


\section{IX. 'Zur Planktonvertheilung im Pacifischen Ocean.}

\section{Die Resultate der Fänge in Samoa.}

In Tabelle $A$ sind die einzelnen Fänge nachgewiesen. Es wurden im Ganzen 212 einzelne Netzzïge in Samoal ausgeführt. welche ergaben, dass durchschnittlich 0,42 ce Plankton in $1 \mathrm{chm}$ Wasser hier rorhanden war. Das Maximum war 1,4 ce im Juni zu Apia (Nr: 36), das Minimum 0.04 zul Leone im Octoher. Hierbei muss aber bemerkt werden, dass die unter 0.1 ec bleibenden Mengen meist anf Plätzen gewonnen wurden, welche keine Häfen, sondern Rheden zu nennen sind. wo also der orean direct einwirkt. als MInlifanna und Leone (Nr. 51. 56. 59), und dass die grossen Mengen wesentlich durch Sagitten verursacht sind.

Da aber an einer Stelle gewöhnlich mehrere Netzzüge hintereinander, oder an cinem Orte an verschiedenen Stellen zur selhen Zeit solche gemacht wurden. so ergeben sich in der That eigentlich nur 37 Fangserien an rerschiedenen Plätzen und zu rerschiedenen Zeiten, also 37 Durchschnittsfiunge. Diese vertheilen sich auf folgende Orte:

\begin{tabular}{lr} 
Apia & 13 \\
Saluafita & 7 \\
Pango-pango & 5 \\
Vailele & 4 \\
Fangaloa & 2 \\
Nulifunua & 2 \\
Fallealili & 1 \\
Safita & 1 \\
Leone & 1 \\
Falefã & 1 \\
\hline
\end{tabular}

Von diesen Fangserion hat ebenfalls Nr. 36 den höchsten Durchschnitt mit 1,0 ec wie $\mathrm{Nr} .56$ (Leone) den niedrigsten mit 0,08 ee.

Dic höchsten Fänge wurden im Mai und Juni erreicht, also beim Beginn der Passatzeit. Da jednch December, Jamnar, Fehruar und März ausfallen, so kann eine Angabe üher das Schwanken des Planktons in Samoa nur von relativer Bedeutung sein. 
Fïr die nahe bei rinander golegenen und ungelaihr dieselhen Verhältnisse darbietenden Plätze Apia und Saluafita ergiebt sich lolgendes:

\begin{tabular}{|c|c|c|c|}
\hline Mai & 1).49 & “c & $(\mathrm{Nr}, 35,75,76,7(i)$. \\
\hline Imni & 0,78 &.. & $(\mathrm{Nr}, 36.77,78)$. \\
\hline Juli & 11,53 & .. & ( $\mathrm{Nr} .37,38,39,43)$. \\
\hline August & 0.33 &, & (Nr. 47, 48, 50, 5丷.) \\
\hline September & 0.52 & .. & $(\mathrm{Nl} .53)$. \\
\hline actober & 0.3 & ". & (Nr. 58, 60.) \\
\hline Noramber & 0.69 & & $(\mathrm{Nr}, 1$ u. 2.) \\
\hline
\end{tabular}

Merkwürdig ist, dass die bejden Fünge zu Apia an 5. Juni $189+$ ( $\mathrm{Nr} .36$ ) und an selhen Tage des Jahres 1895 ( Nr. 77) mit 1,0 ee und 0.75 a in ihren Jahrö̈ngen die höehsten sind. Bei dem leider lïckenhalten Material will ich daran keine weiteren sehlüsse knüjfen. Lis geht nur dalaus lervor. dass Schwankungen im P'lamktongehalt auch hior rorzukommen scheinen, dass sio indessen gemäss dem geringen Wechsel in der 'Temperatur der Jahreszeiten rerhältnissmässig geringe sind.

Wie aus Nr. 39. 42 (a-c). 43 hervorgeht, so killu es rorliommen, dass

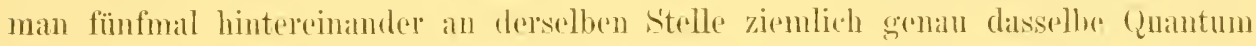
fïngt. Es kann aher auch rorkommen. dass man aus gloicher 'Tiefe beim ersten

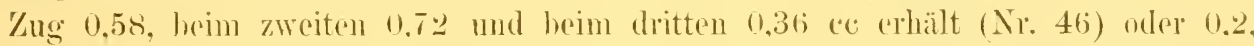
0.09 und 11.3 (Nl: 45). Ans diesem Grunde ist es mit den Stufenfängen ïbre bestellt.

Es ist eine längst gewürdigte Thatsache, dass die lorizontale Terhreitung der pelagischen Thiere wechselt, namentlich die der grösscren, als Meduscn. Tunivaten II. S. W.

Um über das Microplankton einigen Aufschloss zu erhalten. hahe ich in 13 Fangserien einige Finge auf 10 m und einge ans grösserer Tiefe zur selhen Zeit und an selber stulle gemalt:

F'ür den grösseren leichthm unterhalb $10 \mathrm{~m}$ sprachen 9 und zwar:

Fangserie Oberflitche bis zII $10 \mathrm{~m}$

49

50

52

$5+$

55

56

57

73

74

45

46

53

58
$0,32 \mathrm{ce}$

0.29 ..

$0.22 \quad$.

0,23 .,

$0.07 \quad$..

0.07 ..

0.22 ..

$0,5 \quad$-.

$0.31 \quad$..

Oberfläche bis zu (siche Kilammer):

$$
\begin{array}{llll}
0.43 & \cdots & (16-19 \mathrm{~m}) \\
0.37 & . . & (19-20 \mathrm{~m}) \\
0.45 & . . & (14.5 \mathrm{~m}) \\
0.25 & . . & (35 \mathrm{~m}) \\
0.1 & . . & (35 \mathrm{~m}) \\
0.08 & . . & (33 \mathrm{~m}) \\
0.34 & . . & (35 \mathrm{~m}) \\
0.81 & . . & (20-30 \mathrm{~m}) \\
0.55 & . . & (20 \mathrm{~m})
\end{array}
$$

Dis Umgekehrte eroahen 4:

Im Allgemeinen wïrda dies dafiil sprechen, diss in Simoa unterhalh der 10 m-Grenze (wohl bis zu 20 m) hei Tage mehr Micmplankton vorhanden ist als 
oberhalb dieser Grenze: da ich aber die Stufenfünge zur Studirung der horizontalen Verbreitung röllig unzureichend halte. so rermeide ich es. irgend welche festen Schlïsse zu ziehen. Dies erhellt auch aus folgenden Beispiclen:

$\begin{aligned} \text { Fang } 44 . & \text { f) } 1 \times 20 \mathrm{~m}=0.18 \ldots \\ & \text { i) } 1 \times 25 \mathrm{~m}=0.08 \ldots \\ . \quad 45 . & \text { b) } 1 \times 40 \mathrm{~m}=0.05 . . \\ & \text { d) } 1 \times 10 \mathrm{~m}=0.05 . . \\ . \quad 53 . & \text { b) } 1 \times 17 \mathrm{~m}=0.07 . . \\ & \text { d) } 1 \times 10 \mathrm{~m}=0.09 . .\end{aligned}$

Wenn anch die Masse nicht absolut in diesen Fällen maassgebend ist, so erhellt doch ans der schwankenden Planktonmenge bei mehreren gleich tiefen Zügen an einer Stelle (ohne besondere Beimischungen), dass ein Schluss ans einer einzigen Reihe ron Stufenfïngen ein sehr trïgerischer sein kann.

Wenn man Studien über horizontale Verbreitung machen will. wird man Schliessnetzfänge unbedingt fordern müssen, wie sie Birge in neuerer Zeit in Lake Mendota in kieinerem Maassstahe mit Erfolg ausgeführt hat (56 c. S. 81.).

Besonderer birwïhnung bedarf aher hierfür auch ein sehr einfaches Verfahren. welches Peck (61) angewandt hat, nämlich mittelst eines Pumpenschlauches Wasser ans bestimmten Tiefen zu heben. Cutersuchungen in dieser Richtung sind namentlich an Bord grösserer Schiffe leicht ansführtar. Anch während der Fahrt katnn man auf diese Weise wenigstens qualitatives Material sich erwerben, wie meine Fïnge ans dem rothen Veere beweisen (58e.).

Fin Zengniss für die gleichmässige Vertheilung in einem Hafen ist Nr. 50, wo in Saluafata an 10 rerschiedenen Stellen ziemlich gleiche Mengen gefumlen wurden, die nur zwischen 0,3 und 0.47 ec schwankten.

Versuche wurden anch einmal angestellt. of im Innern des 2 Seemeilen langen Pango-pango-Hafens an 3 rerschiedenen Plätzen ron innen nach aussen rerschiedene Vengen und zwar am weitesten innen am meisten rorhanden wäre. Anch hier war das Resultat negativ. Leider komnten die Cntersuchungen nicht his zum Ausgange der Bucht fortgesetzt werden (Nr. 74).

Endlich wurde dalranf gealehtet. ob nicht bei Niedrigwasser zu Apia mehr Plankton vorhanden wïre, als beim folgenden Hochwasser. Die darauf abzielenden Fünge entschiedlen dies zu Gunsten des Niedrigwassers, was bei der grösseren Armuth des Neeres ja nicht $\mathrm{zn}$ rerwundern wïre. Leider konnte anch hier nicht genïgend Material gesimmeit werden, um dies sicher zu stellen.

Die Daten sind folgende:

\begin{tabular}{|c|c|c|}
\hline Nr. Fang & Ehbe (Niedrigwasser) & Fluth (Hochwasser) \\
\hline 42 & 0.35 ec & $0.24 \kappa$ \\
\hline 44 & $0.41,$. & $0,26 \quad$. \\
\hline 76 & $0.47 \ldots$ & 0,27, \\
\hline $\left.\begin{array}{c}77 \\
78\end{array}\right\}$ & $0.75 \quad .$. & 0.6 \\
\hline
\end{tabular}

Die Fünge sind wïhrend zwei direct auf einander folgender Gezeiten gemalelit (s. Tabelle.). 


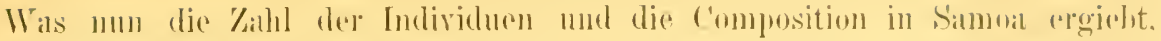

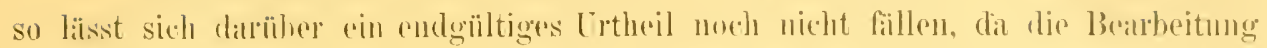

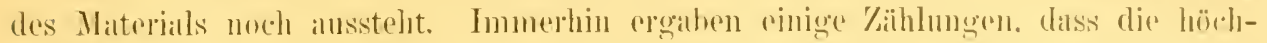
sten Malisse im .Juni nud Juli alleh am meisten Individuen haben, während die kleinstru anch writ an Kahl zuriïckstehen. \%. B.:

$\begin{array}{ccc}\text { Ni. } & \text { (1) } & \text { rilhl } \\ 36 & 1.0 & 150010 \\ 38 & 0.67 & 170100 \\ 77 & 0.75 & 13500 \\ 39 & 0.4 & 2100 \\ 44 & 0.26 & 1100 \\ 51 & 0.11 & 1650\end{array}$

lı der Happtsalehe bestehem alle Fänge in Samoa ans C'opepoden und Gstracoden nud namentlich hei den grossen Matssen treten stets auch Sigitten wenigstens dureh ihs Volumen in den Vordergrund. Glohigerinen und Molluskenlarven vou

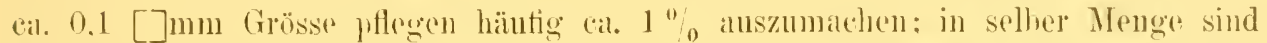
Diatomecen gewöhnlich rorhanden und wohl anch Radiolarien. Nerkwürdigerweise sind Lalren von Kónallen. Echinodermen, Medusen u. s. w. recht selten in den quantitativen Fïngen: nul die nie fohlenden Nauplins- und sonstigen Crustaceenlarven treten hier stets in Erscheinung. sowic die Appendicularien.

Enter den Copepoden sind die kleinen Oithonaformen hesonders zahlreich und gemein: danehen vorwiegend C'alamus, Paracalanus, Acartia und corycaeus.

Bei den Ostracoden scheint es sich ledighich um das noch unhekannte $1 \mathrm{~mm}$ grosse Weibehen der merkwärdigen Euconchnecia Nüller's zu landeln. Alles Specielle hleiht späiteren Veröffentlichnngen rorhehalten.

\section{Die Resultate der Fänge in Neu-Seeland und Neusüdwales.}

Lis wurden im Ganzen hier 117 einzelne Fänge ansgeführt, welche in Tabelle D) nïher hezeichnet sind und durchschnittlich 1,84 ae Panktom auf 1 chm Wissel ergahen. Das Maximum wall hiee 8.5 ec $\left(\mathrm{Nl}^{\circ} 31 \mathrm{~h}\right)$ im Hafen ron sydney. das

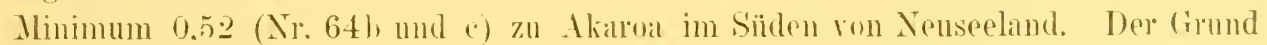
fïr diesen kleinen Fang ist anch hier die Nühe der offenen See. indem der Fang im Hafenausgang hej Hochwasser stattfand.

1)er Ialfen ron Sirdney (Port .Jackson) ist daselbst hekannt Wegen seines Reichthums an Peridincen. Noctiluken. Tintinnen, Diatomeen n. s. W.: er ist ron:

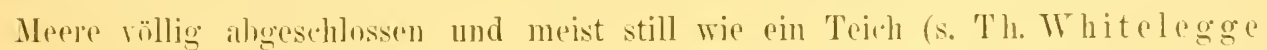
.On the recent diseoluuration of the waters of Tort .Tackison" Records of thr Australian Museun. Vol. I. Nr. 9. ()et. 1891).

Finen 'Theil des Planktons ron Aucklamel (N.\%.) hahe ieh selhst an Ort une? Stelle bearleitet (59). I h hatte daselbst so eine Lebung dureh die häutigen Luter-

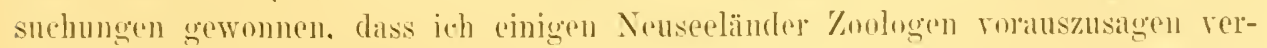
mochte. wirviel und was ungefiiln ieh fangen wïrde. sie waren sehr rerwundert. als ich ihnen die rontrifugirte Masse und alshald die compronenten unter dem Mjeroseop nachwies (Fang $\mathrm{Nr}$.61a). Dil jeh $110 \mathrm{l}^{\circ}$ dic \%eiten ron December his April in diesen Gegenden zuhrachte. so rermag ich matürlich nicht anzugehen. we 
der Planktongehalt in diesen Gewïssem weehselt. Lis steht zu erwarten. diss zu gewissen \%eiten noch Weit grössere Massen an Diatomenen for allem an ('hactuceras, Coscinoriscus mol Rhizosolenien werden beobahtet werden. als sie z. B. Fang 14 , 20 und 23 dirbieten. Anhänfungen ron Glenoulinimu sind im Port Jackson im Mär\% 1891 in solcher Auselehmug beobalchtet worden. diss das Wrasser blutroth geföilst wall.

Ich sellust fand zul selhen \%eit daselhst grosso Anhäufungen ron Diatomeen (in Fang Nr. 33 Asteriouella).

Fin weiterer Luterschied von Samoal ist der Reichthum dieser Gerwisser an

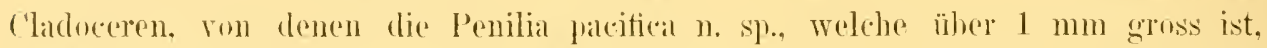
im März im Hamlakigolf in solchen Massen auftrat, dass rinmal $38 \%$ im Fang 22 (= ca. 8000 in 1 chm gez:̈̈lt wurden.

\section{Vergleichung der Resultate unter sich und mit anderen.}

Wenn man die Tabellen A und $\mathrm{D}$ auch mur flüchtig durchschant, so muss doch auffallen, dass in ersterer die anf 1 chm berechneten Planktommengen unter 1. in letaterer darïher sind. mit geringen erwähnten Ausnahmen. Aus den zahlreichen Füngen ergieht sich, dass dies kein Zufall. sundern ein bestehendes Factum zu sein scheint. wie demn auch die Gesammthurehschnitte 0.42 ce and 1.84 ee nichts an Dentlichkeit zu wänschen ïbrig lassen (s. anch die folgonde Vehersicht).

Dass die tropischen Gestade ärmer an Plinktom sind. zeigen auch die 11 Fïnge ron Viti (s.Tabelle B) mit demselben Durchschnitt 0,42 ec, wie die 212 Fänge Simoas.

In derselben 'Tabelle ist noch ein Fang von Aden (Nr. 79), welcher wohl etwas 70 hoch ansgefallen ist $(1,0 \mathrm{ce})$. da die Rhede roll Sand ist mud dis Wassere lemgenuäss verunreinigt war.

Ohwohl ich bee der. Heimkehr überzengt war. lass dies an anderen tropischen Plätzen sich ähnlich verhalten müsste, erwartete ich doch in einem stillen Bimnenmeer, wie es der Hafen von Suez im Rothen Meere ist, cine Ansnalme. Wie arstaunte ich. als ich daselost von vier Netzzügen den Durchsehnitt 0.46 ee auf 1 chm Wasser erhielt. Ich hin weit entfernt damit sagen zu wollen, dass diese Xenge immer hier vorhanden wäre: aber dies giebt doch zu denken!

Billd wall ich wieller in Kiel.

Von relgleichenden Fïngen in ler Ostsee seien erwähnt:

19. December 18951 chm $(10 \mathrm{ml})=4.4$ ce (Peridineen)

\begin{tabular}{|c|c|c|c|c|c|c|c|}
\hline .. & .. & , & .. & ." & $=3.65$ & .. & .. \\
\hline .. & .. & .. & .. & . & 2,9 & .* & . \\
\hline .. & .. & .. & . & .. & 4.4 &. & .. \\
\hline .. &.. & .. & .. & .. & +.9 & .. & .. \\
\hline 14. & April & 1896 & ., & ., & $=6.6$ & .. & (c'latetoceras) \\
\hline. & .. & .. & .. & .. & $=11.0$ & .. & .. \\
\hline 15. & .. & .. & .. & $(20 \mathrm{~m})$ & $=18.0$ & .. & .. \\
\hline 29 . &., & ., & .. & $(10 \mathrm{~m})$ & $=6.0$ & .. & .. \\
\hline 22. & Miai & .. & .. &.. & 3.25 &. & .. rerschwunden) \\
\hline 28. & .. & .. & .. & .. & 1.4 & .. & (Rotitorien) \\
\hline .. & .. & .. &. & .. & 2.2 & ., & .. \\
\hline
\end{tabular}




\section{Ue b e r s i c h t}

̈̈ber die Mengen der P'anktonfünge ron Samoa-Viti und Neuseceland-Tensïdwalrs.

\begin{tabular}{|c|c|c|c|c|}
\hline \multirow{2}{*}{$\begin{array}{l}\text { C'entrifugirte. } \\
\text { anf' I cbm Wasser } \\
\text { berechuete Mengen } \\
\text { in ec }\end{array}$} & \multicolumn{2}{|c|}{ Einzelne Finge } & \multicolumn{2}{|c|}{$\begin{array}{l}\text { 1)urchselanitte der Fung- } \\
\text { serien }\end{array}$} \\
\hline & $\begin{array}{l}\text { Smmou- Titi } \\
(212)(11)\end{array}$ & $\begin{array}{l}\text { Neusecland- } \\
\text { Teusürlwales }\end{array}$ & $\begin{array}{l}\text { Sunoa - Yiti } \\
\text { (37) }\end{array}$ & $\begin{array}{l}\text { Neuserland- } \\
\text { Neusiillwaldss }\end{array}$ \\
\hline $0.01-01$ & 10 & - & 2 & $=$ \\
\hline $0.1(0.2)$ & 28 & & 3 & - \\
\hline $0.2(0.3)$ & 35 & - & 8 & - \\
\hline 0.3 & 45 & - & 7 & - \\
\hline 0.1 & 28 & - & 6 & - \\
\hline 0.5 & 25 & 6 & 6 & 2 \\
\hline 0.6 & 23 & 2 & 3 & - \\
\hline 0.7 & 19 & 4 & 2 & 1 \\
\hline 0.8 & $\dot{j}$ & 1 & - & 一 \\
\hline 0.9 & 3 & 5 & 1 & $\ddot{2}$ \\
\hline 1.0 & 2 & (i) & 1 & 20 \\
\hline 2.0 & - & 27 & -- & 7 \\
\hline 3.0 & $\cdots$ & 7 & - & 2 \\
\hline 4.0 & - & 2 & - & 1 \\
\hline 5.0 & - & 1 & - & 1 \\
\hline 15.0 & - & $\cdots$ & - & 1 \\
\hline 7.0 & $\cdots$ & - & - & - \\
\hline $8.0(--9.0)$ & - & 1 & - & $\ldots$ \\
\hline Summe der Fänge & 223 & 117 & 39 & 37 \\
\hline $\begin{array}{l}\text { fresammtdurchschnitt der } \\
\text { Jiengen. . . . . . . }\end{array}$ & $0.42 \mathrm{ce}$ & $1.8+\mathrm{ce}$ & ebenso & - \\
\hline
\end{tabular}

\section{Die Copepoden als constanter Component aller verticalen Planktonfänge.}

Es ist trot\% mamnigfacher Betomungen immer noch nicht gentigend durchgedrungen. dass as einen componenten im Plankton gielot. woldere nie fehlt. die copepoden. Seit ich auf Schiffen lehe. habe ich niemals weder einen yulntitativen noch einen qualitativen Fang gemacht. in welehem diese Vertreter anch mu spärlich gewesen wilren (alugesehen von den Fïngen in Fahrt. Wenn das Xetz nur über die bewegte See legt. Wobei die Ansheute immer gering zu sein ptlent). Haeckel

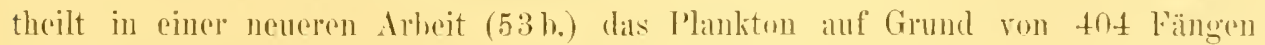
des Srldiffecapitäns .J. Hendorfe in Bremen win in

I. Monotones Plankton - mindestens ${ }^{9}{ }_{10}$ des ganzen Volumen ist aurs Massen ainer einzigen Furm oder Formengrupe gecbildet. 
II. Prävalentes Plankton - mindestens die Hïlfte des ganzen Volumen ist aus

Massen einer einzigen Form oder Formengruppe gebildet.

III. Polymiktes P'lankton - keine Form erreicht die Hälfte.

IV. Pantomiktes Plankton - aus sehr zahlreichen, versehiedenen Arten, Familien und Classen äusserst bunt zusammengesetzt.

Diese Fintheilung ist zweifellos practisch. Ehenso gut könnte man aber die Planktomfünge danach eintheilen. wie viel \% Copepoden sie enthalten, und wieviel an Zahl. roransgesetzt. dass die Fänge rertical gemacht sind.

Haeckel sagt ferner nämlich:

„.Das monotone Plankton ist uniform. wenn nur cine Species, pluriform. wenn mehrere Species die Nasse zusammensetzen. Cuter den 152 monotonen Planktonfü̈ngen finden sich 57 Fïlle von Copepolen (36 uniform und 21 pluriform): 34 C'rustaceen (verschiedener Ordnungen): 21 Radiolarien (meist pluriforme Polycyttarien; 9 Oscillaturien (meist miform Trichodesmium) u. s. w."

Hacekel fand unter 57 monotonen copepoden-Füngen 36 uniforme. also solche, in denen eine einzige Species ${ }^{9}{ }_{10}$ aller Componenten ansmachte. Dies weist daranf hin. wic Hendorff diese Fïnge gemacht hat: wenn cr cine Yerfärbung des Wassers sah, so fischte er mit dem Oberflïchennetz durch, um möglichst viel daron 7.11 erbeuten; dies wirl anch dadurch reranschanlicht, dass nem uniforme Eänge ron Oscillatoren darunter sind, welche bekanntlich meist an der Oherfläche schwimmen (siche atuch Challenger-Notizen ron der Arafura-See, Capitel 6.).

Da ich in Neu-Seeland und Australien. im Pacifischen und Rothen Meer und in der Ostsee (hies ror allem in ler Danziger Bucht in Sommer 1892) diese grossen. Anhäufungen gesehen habe. so ist mir ein monotones Phycochromacenfing nichts wunderbares. Er ist ein Schaustïck für eine Sammlnng. aher dient doch weniger für Compositionsheweise. Dass das Wasser ron Oseillatorien anch durchsetzt sein kann, ist matrirlich; so fund ich jetzt. da ich diese Zeilen niedersehreibe (Ende Mai). das Wasser der Ostsee ron den dänischen Insehn bis Rügen voll ron diesen Bündeln. so dass es leicht bräunlich aussalt. Die Copepoden waren aber doch an Volumen vorhersehend. Die Fänge, welehe ich in Sanoal gemateht habe, sind annähernd monotone Copeporlenfänge: darmuter ist aber kein einziger uniformer. Ich schreibe Hacekel's grosse Zahl an uniformen copepodenfüngen (36) der horizontalen Fangart zu, und da Hacekel die Fänge nicht selbst gemacht hat, so hahen seine Angaben natïrlicherweise nur relativen Werth. Im ührigen ist die in Anssicht gestellte grössere Vuröflentlichung alıuwarten. Ieh will hier nur noch hiszufügen, dass ich unter meinen Fängen noch keinen uniformen copepodenfang gesehen habe: bei einem Verticalfang von mindestens $10 \mathrm{~m}$ halte ich einen soldhen für nahezu ausgeschlossem.

Dalss die Copepoden uhirputär sind. beweisen die rerschiedenen Angallen solcher Forscher. welche sich specialistisch mit Coprepoden befisst haben; Haeckel steht freilich anch hier im Wilerspruche (53a Seite 51). wem er atuch ihre Bedentung anerkennt:

.. Intessen gilt allch fïr aliese widhtigste Gruppe der Planktonthiere dilsselbe, wie fïr alle anderen. dass ihr Auftreten sehr ungleichmässig und von vielen Bedingungen : allängig ist." 


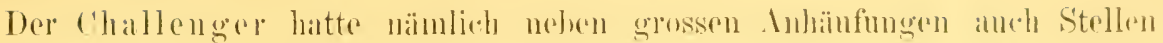
gefunden. wo keine copeporm in Fang gewesen sein sollen. Brady gieht im Reisebericht folgende Scizze (lieport S. 8+3):

.. Die copepoden sind malezu universal in ihrel Vertheihung und schliessent

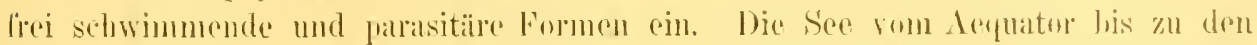
Polen lieferte gerosse Mengen von ihmen. so dass sie oft mit weissen Bändern viole Meilen writ gefärbt ist. Aher die Esscheinung diesel kleinen C'reaturen an der ()herfläche unterlient Bedingungen. deren Natur im Ganzen kitum rerständlich ist."

Man sieht, Brady spricht hauptsä̈chlich rou der Oherfläche.

Dahl silgt (57 h. 28.2$)$ :

.. Die Copepoden sind zur Futscheidung der oben angeregten Fragen wegen ihrer weiten Verhreitung zweifollos die wichtigsten Organismen. Von der oherfläehe des Oceaus his in die grössten Tiefen linal). rom Pol his zum dequator. aul' hoher See. an der Küste. ja auch im Brack- und sïsswasser. üburall findet man c'opepoden und zwar in Folge ihrer geringen Grösse so zahlreiteh. dass man hilum irgendwo ein Netz auswerten kann, ohne einige Thiere dieser Orelnung zu hekommen." Allerdings darf man nicht glauben, dass man an einem orte immer" dieselhen Arten und noch dazu in gleicher Neuge findet. Ich kamn in dieser Beziehmo nicht genuy anf Giesbrecht's Worte verweisen (58b. S. 768). die a. in seinem grossen copepoden-Wrerke gehraucht:

.. Aher anch unter den letztgenannten Meeresabschnitten ist höchstens die irtenarme Ostsce erschöpfend auf ihre pelagischen copepoden untersucht; die ïhrigen Species-Terzeichnisse sind unrollständig nnd selbst jahrelanges und durch alle Jahreszeiten fortgesetztes Durchsuchen des Auftriebes eines Meereszipfels rerbüret noch nicht die Kenntmiss aller dort rorkommenden Arten. wie ich dem in dem seit 1882 durchischten Golf von Neapel noch bis in die letzten Zeiten immer wioler seither ibersehene Arten antraf."

Algesehen ron den grossen Diatomeen- und Peridineenfüngen der kälteren Meere, welche ja nur zu gewissen Jahreszeiten erzielt werden, bilden die Copepoden nahezu immer an Tolumen den grössten componenten, jedoch nicht an Zadhl. llies ist bei der Kleinheit dor Diatomeen $\mathrm{u}$. $\mathrm{s}$. w. hegreiflich. deren INenge die Irocentzahl der C'upepoden herahdrückt. ITemn man 500000 Individuen in einem Fang zählt. wovon 10\%/. copepoden sind, so macht dies 50000. Anderseits ergicbt ein Fang mit 5000 Indiriduen und $90 \%$ Copepoden $\$ 500$ ron diesen.

Dies erhellt aus einigen Beispielen von Neu-Seeland und Sanoa, die ich hier folgen lasse:

Nr. des Fanges und Ort.

Nensecland 20

21

.. 23

.. 25

.. 61

.. 62

.63

. .66

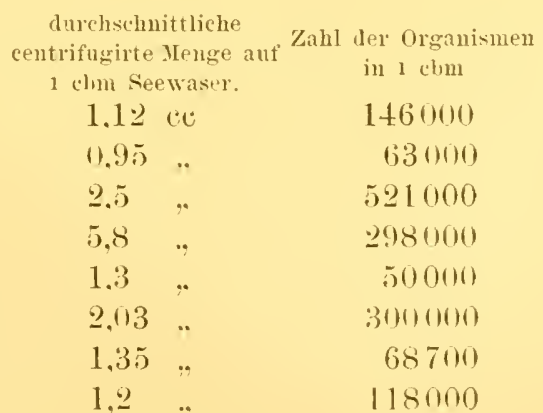

davon Copepoden
(ohne Nauplius)

$12+00$

7000

88575

83500

37250

15000

18550

55400 in ${ }^{\circ} 0$

8.5

11

17

28

75

5

27

47 


\begin{tabular}{|c|c|c|c|c|c|c|c|}
\hline \multicolumn{2}{|c|}{$\begin{array}{l}\text { Nr. des Fanges } \\
\text { unil ort. }\end{array}$} & \multicolumn{2}{|c|}{$\begin{array}{l}\text { durchschnittliche } \\
\text { centrifugirte Henge auf } \\
1 \text { chm Seew asser. }\end{array}$} & \multirow{2}{*}{$\begin{array}{l}\text { Zahl der organismen } \\
\text { in } 1 \text { clom } \\
17000\end{array}$} & \multirow{2}{*}{$\begin{array}{c}\text { davon Copepoilen } \\
\text { (unit Nanplins) } \\
14100\end{array}$} & \multirow{2}{*}{\multicolumn{2}{|c|}{$\begin{array}{l}\text { in } \% \\
83\end{array}$}} \\
\hline Samoa & 38 & 0,68 & $\mathrm{ec}$ & & & & \\
\hline .. & 39 & 0,4 &.. & 2000 & 1400 & & 70 \\
\hline .. & 40 & 0.56 & .. & $5-6000$ & $\pm 500-5000$ & a. & 90 \\
\hline .. & 42 & 0,3 & .. & 2000 & 1500 & & 74 \\
\hline .. & 43 & 0.5 & .. & 7500 & 6200 & & 83 \\
\hline .. & 44 & 0.41 & .. & 4800 & 3360 & & 70 \\
\hline .. & 46 & 0.48 & .. & 5000 & 4500 & & 90 \\
\hline .. & 57 & 0.37 & .. & 5400 & 4700 & & 87 \\
\hline. & 77 & 0,75 & , & 13500 & 10800 & & 80 \\
\hline
\end{tabular}

Also nicht so sehr die Kathl der Copepoden ist einem Wechsel unterworfen. als vielmehr die del übrigen 'omponenten. Wemn man einen Meerestheil nicht über viele Jahre hinweg stetig untersucht hat, so wird man in jedem Falle ïber diese so lange im ungewissen sein, his man eben das Microscop zu Hülfe genommen hat.

Freilich weehseln sogar die Zahl der einzelnen Copepodenarten in ihrem Verhältniss, so in Neu-Seeland hauptsächlich Enterpe acutifrons, Oithona, Temora u. S. W., in Samoa Oithona. Acartia und die Calaniden. Ja Ostraeoden und cladoceren treten hald lier. bald dort als Erö̈nzung hinzu, die Zahl mehr oder weniger heeinflussend. Hiel fehlt es noch an zusammenhängenden biologischen Studien. um diese V'roültnisse ïberschauen zu können.

Aus den obigen Zahlen geht anch hervor, wie viel Raum fïr die ührigen Componenten hei den copepodenreichen Fängen Neuseelauds ührig bleibt. Die meisten der Coprepoden sind kaum 1/2 mm lang, hänfig noch indessen $1 \mathrm{~mm}$. während grössere schon seltener sind. Ton den kleineren darf man ungefülır 1000 auf 0,1 ce rechnen: doch ist dies natïrlich grossem Techsel unterworfen, wenn man hedenkt. dass der grösste bis jetzt beohachtete ropepode Heterochata Grimaldii Rich. $10.2 \mathrm{~mm}$ lang ist, allerdings ein Tnienm.

Das Schwanken der einzelnen Planktoncomponenten sogar in der engeren Classe tiel mir schon während des Sommers 1892 anf, als ich an Bord des Vermessungsschiffes. S. M. S. ..Nantilus”, Gelegenheit hatte, die Danziger Bucht eingehend liennen zu lerneu. Ich hielt damals im VTestpreussischen Fischereiverein zи Danzig eincu Vortrag über die Ergebnisse dieser Studien. wobei ich unter anderem folgendes ansfülnrte:

.. Tenn man von den übrigen Theilen des Plankton sagen kann, dass sie nur an gewissen Stellen und zu gewissen Zeiten auftreten, so kann man von den foprepoden sagen, dass sie ïberall und immer vorhanden sind. Sie werden oft rinige Millimeter gross und sind ihrer sehmellenden Bewegung halber leicht zu sehen. Lis ist bekimnt, dass viele Fische sich hamptsächlich von diesen Kurebsen nähren und ich branche nur an den Hering zu erimneru, nm die grosse Wichtigkeit dieser Thiere als Fischmalumg im Meer zu betonen. Wemn eine Ordnmo ziemlich gleichmässig rertheilt ist, so ist es sicher die der Copepoden. Zuweilen treten sie jedoch anch in solchen Mengen anf. dass sie meilenweit die Oberfä̈che des Meeres roth färben. Dies machen sich die Heringsfischer zu Nutze, dem sie wissen, dass die ..Rothïsung“" reichen Ertrag für ilne Netze bringt. Aber auch 


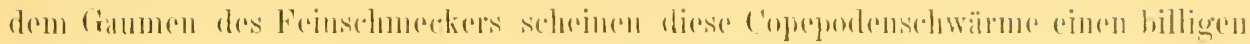

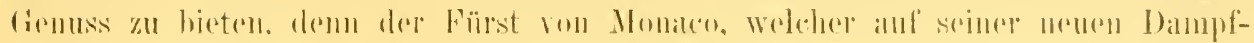

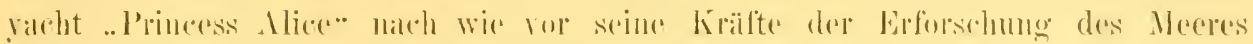

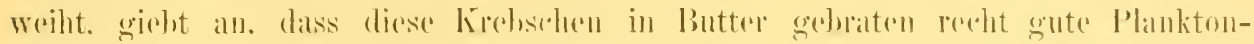

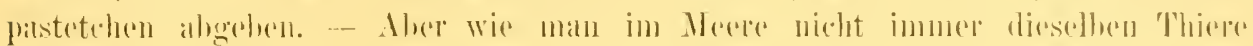

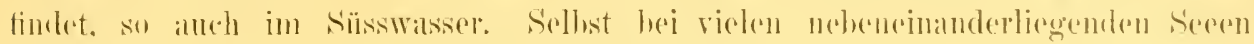

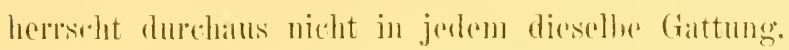

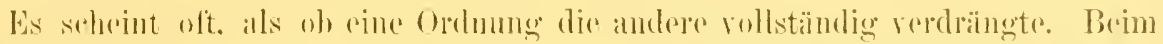

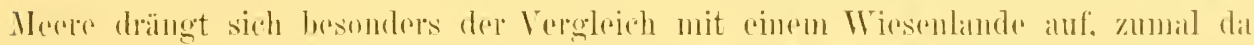

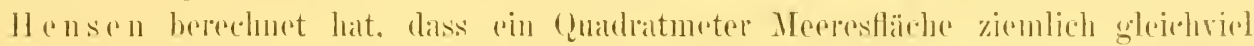
urganische Substanz liofort wie rin Quadratmoter ('ulturlame (150-180 g'). Wrum man nämlich das More mit drem Micoseon durelowandert, so findet man diesolben Bilder. als uh man dureh ein grosses Wiesenland dahin schritte, und dasselhe zu

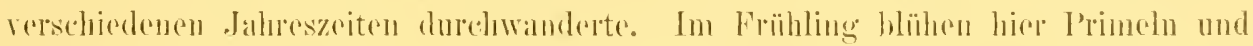

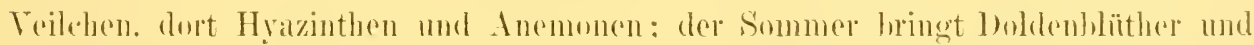

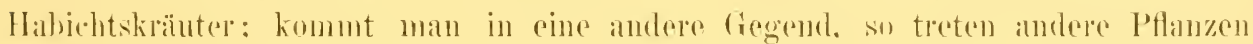
auf mod die alten rersehwinden. Ein Bestandtheil in diesem Wiesemplankton findet sich aher äberall und zwar der für die brob̈hrung des lindviehes wichtigste. das Grats. Das Gras des Meeres aber. das nirgends fehlt. sind die copepoden und der Hering ist das Rindrioh, das sich auf diesen Wridephätzen tummelt."

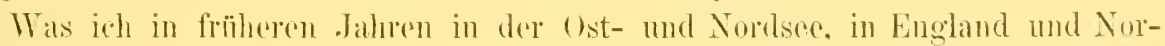
wegen allenthalleen gefunden. hahe irh in der südsee bestätigen können. und wenn ivh atueh weiss. dass diese bifahrungen noreh lange nicht genïgen. su stehe ich doch nicht an, diese Anschaumgen als meine frei gewonnene Teberzeugung kund-

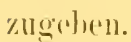

\section{Kü'sten- und Seefänge.}

Wie das (Mikro) Planktun der twopisthen Zonen quantitativ geringer ist als das der gemässigten und kalten Zone. so ist das l'lankton der offenen See geringer als das der Külste.

Lm hier vergleichende Zahlen zur Hand zu hahen. muss man jeden Fang auf 1 cbm Wasser berechnen. Schon in der Einleitung zu Capitel VIll babe ich erwïhnt. dass dies bei den Secfüngen häehstens bis zn 200 m Tiefo geschehen killn. weil sonst die Zahlen viel zu nienlrig ansfalleu.

Nach den neueren Messungen darf ja 200 m als die Gromze angersehen werden. his zu welcher das Plankton in nenuenswerther Menge rorhanden ist. ja vielleicht ist für die Cubikmeterherechnung eine weit geringere Tiefo als Grenze anzunehmen.

Branelt sagt ïher die Sehliessnetzfïnge der Planktonexpedition (5+e): .. Fin wichtiges Ergehniss besteht zunächst darin. dass im Athantischen orean eine dichtere Beväkerung nur in den oberflächlichen Sohichten ron $0-200 \mathrm{~m}$ sich findet. I)iese Thatsalche drülekt sich sehon in des von Sehö̈tt reröffentlichten Tabelle der Volumina aus (s. 55. Tahelle 10). Sümmbliche 29 Schliessnetzä̈nge enthielten so geringe Mengen rou Drganismen. dass eine zurerlässige Volumbestimmung durch Absetzenlassen nicht mehr möglich war. Das Volumen hetrug stets weniger als 0.5 cem. 
wïhrend der kleinste rergleichbare Vertiralfang ron $200-0 \mathrm{~m}$ in dem gamzen untersuchten Gebiet 1.5 cem Masse enthielt. Die Region rom 200-400 m 'Tiefe ist schon erheblich ärmer als die daribluer befindliche Wasserschicht. Inter $400 \mathrm{~m}$ aber herscht ausgesprochene Armuth im Veroleich zu den olerflächlichen s'chichten."

Dass C'hun bei Neapel ..sowohl an dere obertläche wie in allen Theilen his zu $1400 \mathrm{~m}$ ein reiches pelagisches Thierleben" fand. führt lis landt anf die Ausnahmestellung des Mittelländischen Meeres anderen Meeren gegenüber zurïck. da. wie bekamnt, dis Mittelmeer sich in seinen Tiefenwärmen anders rerhält.

Die späteren Schliessuctzfünge ('hun s bei den canarischen Inseln scheinen indessen ähnliche Ergehnisse wie die Plantonexpedition zu lage gefördert zu haben. Auch haben Grobben und r. 11 arenzeller im Nittelmer niederere Resultate als Chun erhalten.

Agassiz berichtet ïher folgende Ergebnisse seiner Studien in dem westindischen Gehiet (26f, S. 8): ..Ich dachte, ich kömnte keinen besseren Platz finden, um endgültig die verticale Verbreitung des pelagischen Lebens festzustellen. als bei Havand. wo tiefes Wasser (bis 900 Faden) nahe am Land ist und ein grosser Necresstrom, der Golfstrom, fliesst, weleher bekamnt ist für den Reichthmm an pelagischem Leben. das er mit sich trägt. Wir fischten in 100. 150, 250 und 300 Faden und an der Oberflüche oder nahe darunter und ich fand nichts, was meine alten Ansichten ändern kömnte. welche ich in den l'reliminary Reports der ..Albatross"-Expedition von 1891 itusgesprochen habe. In keiner Tiefe erhielt ich mit dem Tamnernetz irgend eine Species, welche nicht auch zu irgend einer Zeit an der Oberfä̈che gefunden worden wäre. Selhst in 100 Faten $(185 \mathrm{~m})$ Thefe war der Betrag an pelagischem Leben viel weniger als in dem Bereich von der Oherflïche bis zu jener Tiefe. In 150 Faden war noch weniger und in 250 und 300 Faden enthielt der geschlossene Theil des Tamnemetzes nichts."

(Cund Seite 9. Tongue of the Oeean, zwischen den Korallenriffen der Great Bahama Bank):

.Wir fischten $u m 9$ h $30^{\prime}$ a. m. in der Tiefe ron 100 bis 110 Faden ungefähr 20 Minuten lang: das Netz schloss sich rortrefflich. Nur cin Copepode wurde von dieser Tiefe anfgebracht. während in dem offenen Theil des Netzes mehrere Exemplare von Eucope, viele Diphyesglocken, zahloeiche Copepolen, Alciope, Schizopoden, Larven ron Brachiuren. Macruren. Doliolum, Appendicularien, Gasteropodenlatren und Collozoum waren,"

Ein weiterer Fimg daselbst in 300 Faden erbrachte ungefähr dasselbe Resultat. chenso wie zilhlreiche älnulich ansgeführte Fänge an anderen Plätzen.

Ich will nur noch erwähnen, dass Muray auch 100 Faden als untere Grenze angiebt.

Nach diesen Ausfïhrungen dïrfte as wohl gestattet sein, Fänge von $200 \mathrm{~m}$ Tiedo als Vergleichsfïnge bei der $1 \mathrm{dbm}$ Berechmmg herbeizuzichen.

Anerkamntermatassen lat jede Küste ihre eigenen Vertreter, welche der Hochsee fehlen und umgekehrt. Sogar bei den kieinsten Inschn ist dies der Fall. wie es die Planktonexperlition fïl Ascensiom U. s. w. find.

Hensen berichtet ron Bermula (Vortrag in der Gesellschaft dentscher Naturforscher und Aerzte 1893): ... Auf Bermudal lagen wir in Gezeitenstrom nur 


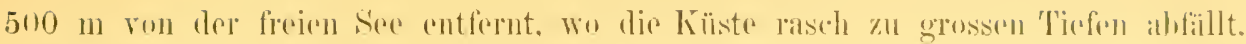

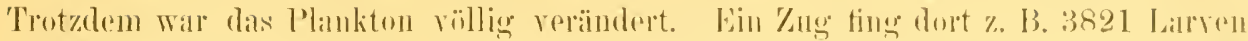

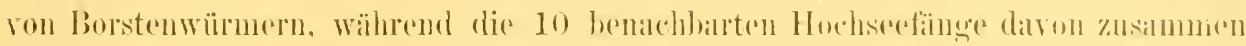

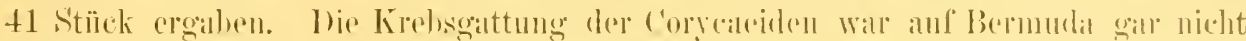

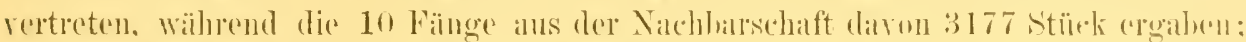

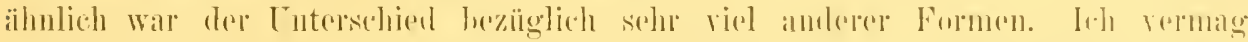

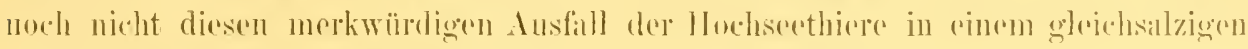
murl gleichwarmen Küstenwasser theoretisch zu hergrimlen."

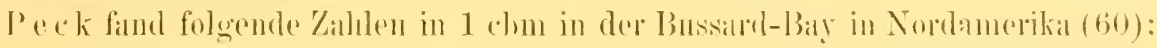
Ditum :
Inuenhafen:
Alssermhafon:

13. September 1894

150) Million(')

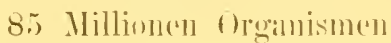

$2+$.

1128

13

27.

700

21

wobei es sich hetrefts der grossen Zahlen un Exuriacha. Chactoceras und Mnlosiral hanchelte.

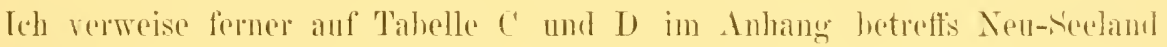
und Australien.

Währenel in 117 Fängen in den Häfen durehsehnittlielı 1.84 ec gerfunden wurcle, brachten 11 Secfïnge nur durchschnittlich 0.29 ec.

Leider wall ieh nie so glïcklich. in dem Veere mm Samoa Seefünge matehen za können. Nur ein einziger 100 m-Fang nahe den Tongainseln stelit nir hice zit Gicbote.

Aber ich habe bei Besprechung der Resultate der Samoafünge sehon crwähnt (s. d.), dass in den vier Fällen hei Ehbe dentlich mehr gefunden wurde als bei Fluth.

Ferner zeigt atuch 'Tabelle A rerschiedene Fänge (z. 13. Nr. 51 u. 56). deren Planktonmassen aussergewöhnlich niedrige sime (meist unter 0,1 ). Haran sind offenhale die Fangplätze sehuld. denn Mulifunnil umel Leone sind oftene Rherlen.

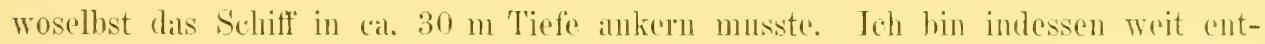
fernt. diese als beweiskräftig zu erklären und muss es späteren Lntersuchungen üherlassen. diese Beweise zn schaffen.*)

Jeh glaube abere doch dureh die Befunde in Neu-Seeland und Austrialien und denen der I'lanktonexpedition zn dem Schluss berechtigt zu sein, dass die Simoalinseln sich analog rerhalten.

Für die Korallenriffe erscheint dies ron Wiehtigkeit.

Murray sagt nämlich $(21$ a $)$ :

..Schleppnetzexperimente zeigten inmer viel weniger frelagisehes teden in den Lagunen als am äusseren Riffrinde. Die Lagune wird weniger günstig lïr das Wachsthum aller der massireren corallenarten. Wemn clas äussere Riff die (herfläche erreicht und den freien Eirsitz des Vissers ahschneidet."

*) Qualitative Planktonfänge, deren ich um samoa mehrere machen kunnte, vermeide ich absichtlich anzufiihıen. da trotz grosser Lebung. deren Häekel sich rühmen kann. Täuschungen hier zu leicht mäglich sind. In ïhrigen sprechen sie fïr die Armuth der offenen See. 
Lis wäre sehr zu wünschen. dass quantitative Netzzïge auch innerhalh der Atolllagunen gemarht wïrden, und Vergleichsfïnge in der umgebenden See. damit die Insichten ïher die Ernährung der Corallenrifle durch Thierströme aus der Trelt geschatit wiilelen.

Sehon weiter oben habe ich die Gründe dargelegt. warum dies nicht sein kamm, hei der besprechung der Fusshildung (IV. 5 a u. b.) und hei Besprechung der Mecresströmungen als Nahrungsyuelle ( $\mathrm{T}, 3)$.

Im nächstron Cappitel werde ich darzuthun rersuchen, dass der tropisch-pacifische Ocean recht arm ist und ans allen Vutersuchungen und Schlüssen muss man annehmen. dass die relatir arme Küstenfuuna sowohl im Riffgebiet als auch an andern tropischen Küsten immer noch reicher ist als der offene Ocean.

\section{Die Armuth des tropischen pacifischen Oceans.}

Es wäre eigentlich ïberflïssig. bei diesem Thema noch länger zu rerweilen. In Capitel 3 ist es schon genügend hetont (ebenso Abschnitt V7I. ('al). 3), wie rerhältnissmässig arm dieser Meerestheil ist.

Ich will jedoch noch einige Daten gehen und ror allem einigen andern Beobachtern das Wort verleihen, um darzuthun. dass diese Beobachtung nicht vereinzelt ist.

Am 31. August 1893 hatte der Postampfer ..Karlstuhe* Syuner verlassen, um die Ablösungsmannschaft der deutschen Kriegsschiffe nach Apia zu bringen. Es ging mitten in die Sürdsee hinein. von deren Wunder uns Furster und ('hamisso berichtet. und die man nun wirklich selhst zu Gesicht bekommen sollte. Auch ich glauhte immer noch fest an die alten Thalitionen und hotite auf eine rerche Ausbente. Kahlrejehe 'T'̈̈mmler hatten das Schifi' in die See hinaus begleitet. darunter eine wohl ïher $3 \mathrm{~m}$ lange orea-Art. wolche weit äher einen Meter hoch in die luft sprang. um sich daun auf den Rücken in das Wasser fallen zu lassen. so dass der Gischt his zum hohen Bug des Sehittes heraufspritzte. Kahlreiche Albatrosse folgten hestïndig dem Schitt. Seeschwalhen und Sturmvögel, und Nachts war ein herriches Meerlenchten im Schranhenwasser sichtbar. lis liess sich gint all.

Am 2. September zeigten sich zahtreiche Silpen an der oberflärhe von 5 his $10 \mathrm{~cm}$ Läinge.

Am 3. September waren die Albatrosse rereinzelt: einige fliegende Fische (Exocoetus) zeigten sich und abends glitzerte die Bugwelle prächtig.

An 4. September waren die Ahatrosse verschwunden. $25^{0} \mathrm{~s}$. Br. waren erreicht. Mittags whrde indessen noch ein einziger ron Gansgrösse schwimmend gesehen. Lis zeigten sich Anhäufungen ron l'hycochromaceen, welche stollenweise das Wisser gelly fürbten. Einge fliegendr Fische.

Am 5. September Wendekreis mel 180. Längengrall passirt. Gegend der Vitiinseln. Mässig viel fliegende Fische. ron denen einel von gegen 40 em Iänge zweimal den Schiffishug hei 14 Meilen Fahrt krenzte. ohne die Flossen zu hewegen.

Auch am folgenden 'Tage wurden noch einige bunte grosse und viele kleine gesehen. 


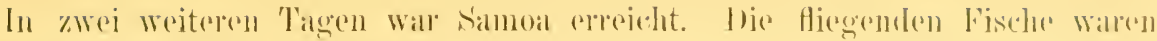

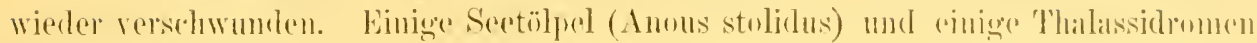
war alles, was sich noch zoigte.

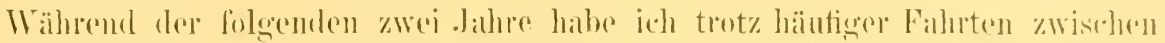

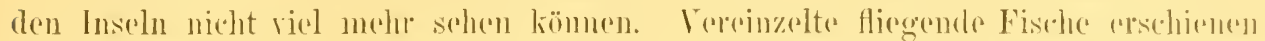

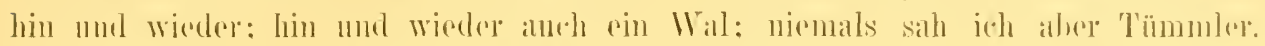
Trot\% stmudenlangen täglichen Sitzens an Schiffshng komnte ich in drm durch-

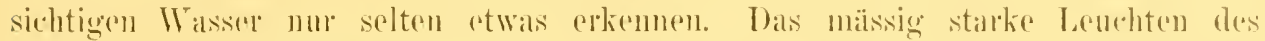

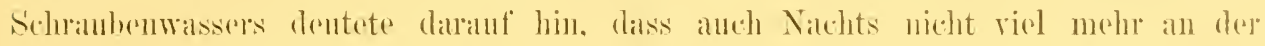

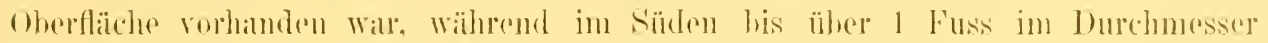

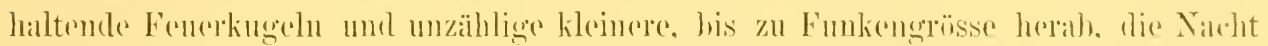
verherlichten. Wie irh sehon ohen erwähnte, waren die Mrelusen in Hafen rons Pingor-Pango mul anigemale die Velellen die einzigen grösseren Planktonthiere. welche ich mm Samoa im Wasser sah.

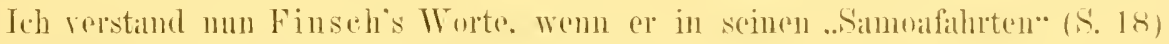
ïher die lieise ron Sydney nath Nen-Guincal sagt:

..Im ährigen verliof die Reise whne besondere Zufülle in gerwhuter Ein-

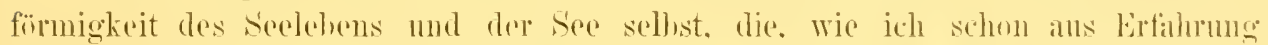
wusste, in diesen Breiten weng bietet nul je näher dem Acquator. immer ärmer wirel. Vergehens späht man mach Walthieren und ist schom zufrieden. wenn gelegentlich eine Schar lustiger Delphine das Schiff cine Zeit lang umspielen oder fliegente Fische ihr Element rerlissen, mu nach kurzer laftreise wieder in dasselbe rinzutaluchen."

Wenn Balboa, als er den ,stillen* Ocean zum ersten Mal erblickte. Zoologe geweson wäle. so müsste man seinem Scharfblick Bewunderung zollen. Er wusste nicht, wie reeht er hatte.

Freilich ist dies nicht die Ansicht einer Expedition, welche diese Breiten nur zweimal durehfihren hat. Thre grossartigen Leistungen in der 'Tiefsee-lisforschung hahen natürlich reranlasst, class man auch ihren Oherflächenstudien cine

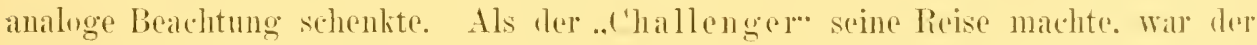
Glauhen an den allgemeinen lieichthum der tropischen Gewässer noch so tief wurzehnd, dass es umuöglich war, an der Hand qualitativer Netzaïgor zu einel andern Ansieht zu kommen. Jeder weiss, dass bej Alschätzen sellost der Geïhteste grossen Täuschungen unterworfen ist. Dru Anfschluss dariulnel liomnte allein eine yuantitative Methode bringen.

Da die Anschaunngen der .. C'hallenger-Lxpedition"* leitend wurden für alle weiteren Forschungen. so habe ich mir die Mühe genomnen, alles lerauszusuchen. was ïber I'lankton in palcitischen Oeean gesagt ist (s. Narritive of the Vuyage Tol. I. 2. 'Theil).

Die Daten begimen mit Sydney (Aufenthalt 6. April bis s. . Imi 187t). Seite 462 .

..Die lamplpinasse wall häutig im Gehranch hehufs l)redsehen und Netztischen im Sydneybafen mod die Schleppuetze wurlen bäufig gehraucht. Anneliden- unct

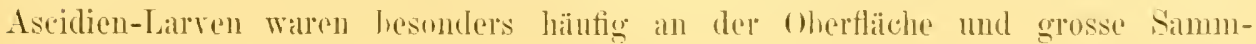


lungen ron Invertehrates wurden rom Boden aufgehracht." (Alles ïber Plankton rom Hafent).

\section{Seite 46\%. (Fahrt ron Srdney nach Wellington-Neu-Secland.)}

..Die Oherflächennetze waren beständig im Gebranch und die Naturforscher gehranchten medurfach die Boote. um das Oberflächenleben zu heobachten. Pulvinulina micheliniana war zahlreicher als früher hemerkt worden; am meisten daron wurden gefangen. wenn das Netz in 80 Faden Tiefe sehwebte. Beim grösseren Theil der Exemplare hüllte die hräunlichgelbe Sareode die Schale ein und in zwei Fïllen wurde beobathtet. dass dieselbe in blasenähnlichen Ausdehnungen ansseworfen wurde, scheinhar zum Zweck einer Flosshildnng. ähnlich wie das später bei Hastigerina heohachtet wurde. Coccosphären waren hesonders häufig an der Oherfläche. Kleine. ganz durchsichtige Massen von Sulze wurden häutig an der ()herfläche gefangen u. s. w."

Seite 47 t. (Oestliche Küste ron Neu-Seeland, ca. $35^{0} \mathrm{~s}$. Br.)

..Am Ahend war rin schönes Schanspiel ron phosphorescirendem Licht an der Oberfläche, verursacht durch Pyrosoma, als das Schiff mehrere Bänke (banks) derselben piassirte."

Seite 485. (Tongal.)

„Eine grosse Foraminifere (Orbitolites) ist sehr gemein auf den Riffen."

Seite 521 leisst es (Ort zwischen Api und Raine Island in den Nenen Hebriden): „Die (Oberfläche nnd Lnteroherfliche war voll (teeming) von Leben: alle gewöhnlichen tropischen Formen wurden hier in grossem Eeherfluss gefunden. Die Liste der erbenteten Thiere war beinahe identisch mit der des tropischen Atlantic, obwohl heträchtliche Cnterschiede bemerkt wurden in der relativen Menge der Species."

Seite 544-545: „D)ie Oberflächennetze in der Arafura-See (zwisehen NenGuinea und Australien) lieferten grosse Mengen ron I)iatomaceen (Diatoms). häutig gefüllt nit ciner gell, scheinenden Masse, und erinnerten an die Diatomaceenfünge während der Fahrt im Antarlitisehen Ocean. In der Nïhe der Arrou-Inseln waren Oscillatorien (Trichodesmimm) schr zahlreich. welehe an ringen Plätzen tiefroth oder gelblichhramn fürbten. Die Trichodesmiumbündel waren gewöhnlich zu grossen Haufen oder Linien zusammengedäuft. Diese Algen schienen nur an der OberHäche zu sein, da mit Netzen, welche einige Faden unter der Oberfläche liefen. sehn wenig gefangen wurde. Zwischen (ap York und Arrou wurde nicht eine einzige pelagische Foraminifere in den Netzen gefangen und anch im Boden wurde keine gefunden. Das Wisser wall grünlich gefärht: aber als das Schiff sich den Arrou-Inseln nählerte. wurde das Meer wieder han und einige wenige der wirklich pelagischen und oceanischen Organismen wurden wieder in den Schleppnetzen hemerlit. Da das Wasser der Arafura-See ein niederes specifisches Gewieht hat, su ist es sehr wahrscheinlich, dass einer oder mehrere grosse Flüsse in dasselbe von Nen-Gunea hineinfliessen; die Fanna der Oberfläche und des Grundes ist desshalb mehr die einer grossen Bay, als die des Oceans."

Seite 606-607: Während des Pissirens der ('elehes-See wall'gewöhnlich ruhiges Wetter und wälurend des Lothens wurden Bonte ausgesetzt, um den Naturforschern zu ermöglichen. Studien zu machen. Nehrere Arten von Oscillatorien 


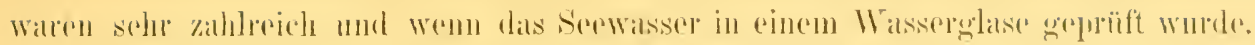

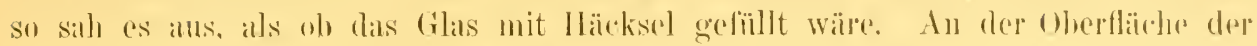

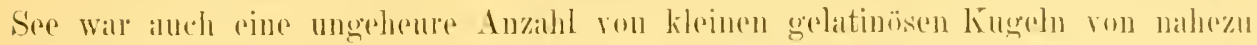

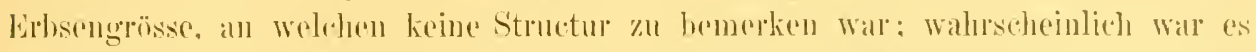

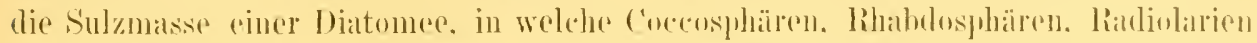
mnd die Fäden ron Triehodesmium rerwickelt waren. Lie Schlepplnetze. ringeholt. waren mit riner dicken Substanz wie mit rines Art Leim gefüllt, verursaleht dureh diese urelatinösen Kugeln. Wemn die Netze aul und nieder geholt wurlen, son enthielten sie eine viol grössere Versehierlenheit von Organismen und weniger von der Sulmuasse und weniger (Dscillatorien. so dass diese sehe wahrsebeinlich an dir numittelhare oherflïche gebunden waren. Globigerinen. P'ulvulinen. (trhuliusn und Pullenien waren solı Zahbreich in den tieferen Zü̈gens."

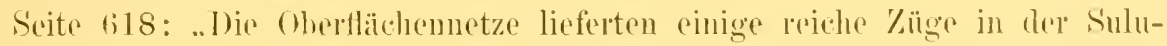
See: die Amphipoden waren besonders zahleredeh."

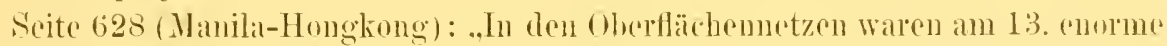
Mengen von Foraniniferen und Radiolarien: ller reichste Fang wurde crlatten. als das Netz hundert Faden himuntergelassen wurde."

Seite 638: ..Dis Wasser zu Hongkong war prïelitig phosphorescirend, während des ganzen dufenthaltes des Schiffes. Noctiluea miliaris, verschiedene species ron C'eratium und Jiatomeen waren immer in grossen Kalnlen rorhanden und dameben copepoden. Cirripedienlarven. Anmelidenlarren. Hỵdromedusen. Appendiculatien und Diphyes."

Seite 67s: ..Der Boden war blaner Schlick, welcher bei Zusatz ron schwacher Säure nicht aufbrauste und kejne Kalkschalen enthicht (2550 Faden). obgleich pelagische Mollusken und Foraminiferen reichlich an der Oherflïche grefungex wurden."

Endlich die Roise ron den deutsehen Schutzgebieten nach Japan (S. 738): .Die Oberfäehenfauna und Florat war durchaus besonders reich und abundirend. In der Gegend des Gegenäquatorialstromes zwischen dem Aequator und den C'arolinen wurden pelagische Foraminiferen nud Mollusken in grossen Mengen in den Oberflächennetzen gefangen, alle frïheren Beobachtungen übertreffend, - Die pelagischen Foraminiferen scheineu in grossen Bänken zu treihen: an einem Tagor kïmnen ungeheure Mengen ron Pulvinulinen gefangen werclen, während am nü̈chsten Tige P'ullenia sehr zahlreich ist und Pulvinulina nillezu ganz fehlt. J)io schwerer beschalten Indiriduen wuden gewöhnlich 100-150 Faden unter der Oherfläche gofangen. \%wischen 10 und $20^{0}$ Nordhreite waren Oscillatorien sehn zallhlrejch an der Oherfläche. und loiatomeen, besonders cine grosse cylindrische Etmodiscus. waren zahlreicher weit rom Lande ah, als in dem trupischen Itlantic. Die Liste der (Oherflïchenthiere in Note-book ist beinahe dieselbe. als clie Seite 216 und 217 gegebene. aher die relative Mehrheit von Radiolarien und Diatomeen ist hesonders bemerkenswerth."

Demgegenüher heisst es (S. 758) während der lieise ron Japan nach Hawaíi

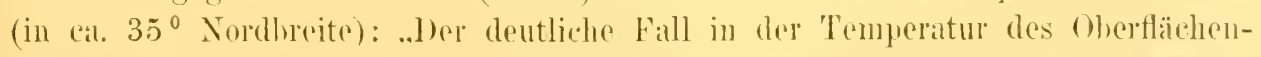
Wassers am 21. Juni (Station 240) wurde schon orwïhnt: zul selben Zeit wurde ein Wrehsel in der Oberfäebenfanna bemerkt. Das schiff passirte an jenem Tage 
rothe und weisse Flecke im Wasser. Die rothe Farbe wurde rerursalcht durch mngehemre Zahlen ron ('opepoden (Calanns propinqums brady) und Hyperiden, nud der Inhalt der Schleppnetze glich sehr dem. welcher in kalten Wasser sürdlich ron den Kerguclen und rrozet-Insehn erbentet wurde." — ..Der grosse tropische Etmodiscos lex. Procystis. Pulvinulina menardii. einige von den tropischen Formen der Cilohigerinen nut von anderen pelagischen Foraminiferen. die dem wärmeren Trasser der Oceane rigenthïmlich sind, fehlten. Andererseits waren hier ungehene Zahlen von kleinen Diatomeen und won Lepas fascicularis nnd seinen Larren."

Seite 776 (Reise von Hawaii nach Tahiti im troplisehen Gebiet): ..Die Schleppnetzfünge waren sehr ergobnissereh wïhrend der Fahrt. inden der lieichthmm an Jeben in den ïynatorialen und gegenäynatorialen Strönnmgen und sowohl die Kalıl der Sprecies als der Individnen bemerkt wurde."

Als der .. Challenger" anf Valparaiso hielt und the tropische Kone rerlassen hatte. heisst es Seite S04: ..Es wurlen viele Oherflïehenthiere in den Sehleppnetzen an jedem 'Tag gefangen, alher die Zahl der Formen war viel geringer als in den tropischen Grewissern."

Scite 833: ..Es wurde zwischen Juan Fernandez und Talparaiso hemerkt. dass das Wasser rou einer griunlichen Farbe wurde. als man sich dem continent näherte. in starkem Gegensatz zu der hlauen Farbe. welche seit dem Verlassen ron Japan rorgewaltet hatte. 1)a war ein entsprechender Wechsel in dem allgemeinen Character der Oherflädhenthiere: Diatons, Infusorien und Hydromedusen wurden sehr zahlreich. währent die pelagischen Foraniniferen rerschwanden."

Man sieht. wie spärlich die Notizen gerade üher Sychey und (N. Y.) Wellington sind: anch das Material an Plankton scheint nur zum kleinen Theil rerarbeitet worden zu sein. denn von Sydney sind in Challenger Report nur gegen 15 Copepoden heschrieben, nnd von Nen-Seeland - nicht ein einziger. Während eines viormonatlichen Anfenthaltes in Haurakignlf der Nordinsel vermochte ich 9 Copepoden und + clatuceren als neu fïr Nen-Seeland zu beschreiben (s. 59). Da die weitere Bearheitmo des Materials noch nicht abgeschlossen ist. so hoffe ich noch mehrere nene Vertueter hinzufügen zu können.

Wie ans den Angahen des ..Challenger" herrorgeht, triftt man die Ausdrücke, änsserst reich. sohr reich (abundant, excedingly rich n. s. w.), allenthalhen seln bäufig.

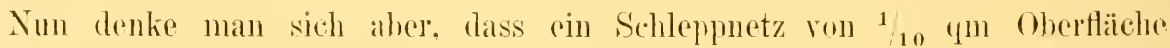

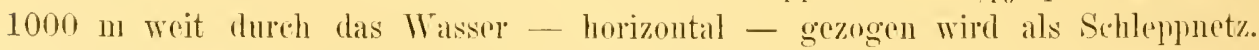
Teh nehme nach meinen Kü̈stemmessungen an, dass auf 1 chm Hoehseewasser 0.2 a Mice-plankton kommt (centrifugirt), was gheich dem Gewieht ron 0.2 g。 - mindestens - ist. Dies gähe 20 ac auf $1000 \mathrm{~m}$ (= 100 dom), als Rohvolumen das Doppelte, also nugefïhr to ce. gewiss eine recht erkleckliche Masse micrescopischer Wrosen. Ungerechnet sind dabei die makroscopischen Thiere.

Nun hahen wir sugar einen Anlaalt dafür. dass diese Schätzung das Richtige ziemlich nahe treften dïrfte.

bohufs Bestimnung des Kalkgehaltes des Planktons. um der Bildung suhmaniner Sedimenthänke näher zu treten. Wurden in tropischen Pacitic einmal 4 volumetrische Bestimmungen vom .. ('hallenger" horizontal ausgeführt. Mau schleppte 


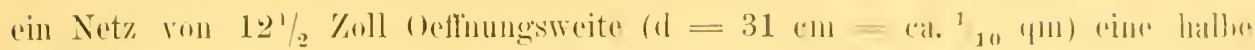

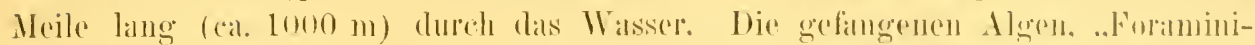

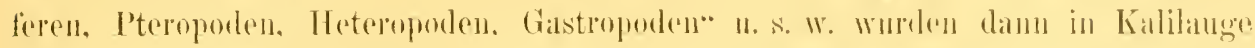
gekocht. der Rest gerasehen und gewogen. I)as liesultat ron + Fängen wall als

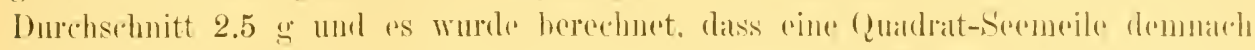

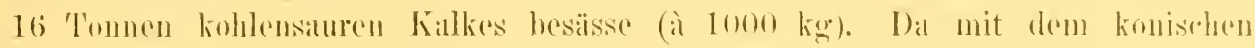

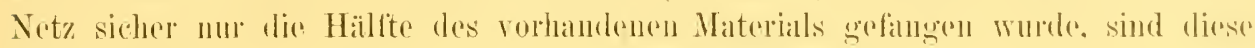
Kahlen doppelt zu nehmen: also

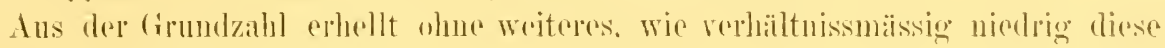
schermball ungehoure /allal ist.

Mit Einrechnung der makroscopischen Thiere wälen also in diesenen und in 20 ee centrifigirten Planktons $(=20$ s) 5 g Kalk. Wals leicht möglich ist.

Da jecloch keine näheren Angahen üher die richtige Kasammensetzung der

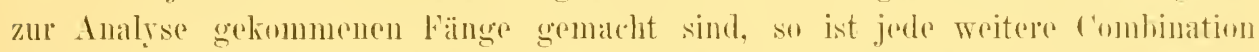

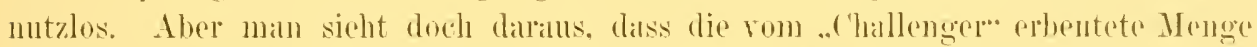
mit diesen Resultaten ungefüh ähereinstimnt, dass alber kriueswegs der lieichthum cin so sehr glosser gewesen sein kam. wonigstens in diesen 4 Fällen.

Für die Armuth des tropisehen Pacific sprechen noch unter anderen die Berichte folgender Forscher:

Semper sagt in seinem Buch .die Palaumselu" (S. 19 11. 20):

Als wir an 1. und 2. März in jenen südöstlichen Strom hineingeriethen mud einige Thernometermessungen mir die hohe Heereswälme ron $22{ }^{0}$ R. am elsten Tage. später sogar $23^{\circ}$ R. ergahen, nahm ich voller Erwartung moin Netz zur Hand. Denu ich dachte mich wieder in eine ähnliche warme Strömung versetzt, wie sie am Cap der

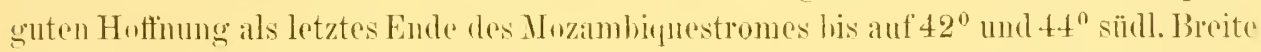
heruntergeht und welche mir anf meines liojse nach singalpore eine leberfülle der sehönsten pelagischen Thiere ins Netz lieferte. Drei Tage lang fuhren wir danals in rinem so dichten Schwarme der polossalen Fonerzalpfen (Prosoma gigantemm). dass selbst hrin Wasserschüpfon mit Vimern häutig die fast 1 Fuss langen Thiere gefingen wurden. und des Nakhts lenchteten alle diese Mrriaden ron Wesen. dio den ocean lis zum Horizonte zu bedereken schienen in so zauberhaftem Lichte. dass ich mit cinziger Ausnahme einer wunderbaren octobersturmnacht nördlieh ron Helgoland nie etwas äluliches gesehen zu hahen glaubte. Leidel wurde meine Erwartung gänzlich getäuscht. 'Thotz der tiofhlanen reinen Farbe des

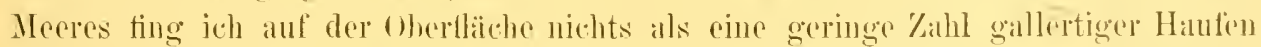
ron eimzelligen Algen. Wie sie mil so oft schon in den l'ropen das Fischen mit dem feinen Netz rerleidet hatten: mul anch bei Windstill('n his zu 60 s0 Fuss T'iefe niedergedassene und durch die starken, ancls hior wirkenden Strömungen in senkrediter Stellung erhaltene Notz hrachte mir keine Aushente."

Studer sacgt ïher das oherflächenlehen im sïdliehen Stillen Ocean S. 279 des Garzelleroiselorichtes:

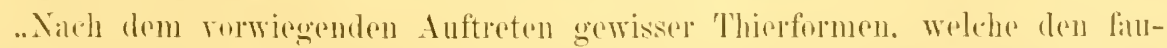

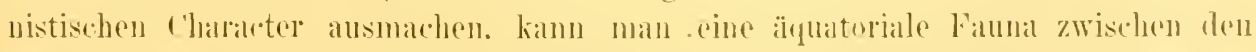
Wrendekreisen mit constant hoher Wissertemperatur unterscheiden. I)iese ist. wiu

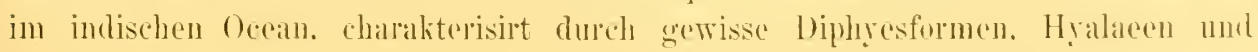


C'leoduren, das massenhafte Auftreten ron Emphansia, gewisse Hyperidenformen. oxycephalus, Phronima, die kleinen Fischarten Lepotocephalus und Scopelus und eine gewisse Armuth rom Copepoden.

Dic sïdliche Zone. sich jenseits des 30. Breitegrades mehr charakterisirend. zeichnet sich aus durch das zum Theil massenhafte Auftreten ron Salpen. das Auftreten dler Sigritten. Zilhlreiche Copepoden und eigene Gattungen von Hỵeriden. Eigenthümlich erscheint auch das 'Znsammentreten gewisser Arten in Gruppen, so dass man an einer Stelle rorwiegend Sagitten. an einer andern Salpen. bestimmte Hyperiden oder C'opepoden findet, während unter den Wondekreisen die Formen gleichmässig gemischt rorkommen."

Bezeichend ist auch der Befund Gieshrecht's bei der Verarbeitumg der Copepoden des Alhatross (1891 Westkïste ron Central-Amerika):

.Die Expedition des ..Albatross" zeigt indessen, dass unsere Kenntniss jene. Fauna noch sehe lückenhaft war: dem ohwohl seine Fänge quantitativ dürftig und arm an Individnen waren. so lieferten sie doch unter 48 Species nicht weniger als 10 neue."

Besonders bezeichnend sind jedoch die Angahen Graeffe's, welcher während häufiger Segrelfahrten in der Lmgebung Samoas diese Gewässer gründlich kennen lernte (12 a. S. 1163):

... Auffallend ist in diesen liegionen das gänzhehe Fehlen pelagischer Secthiere. während man glanben sollte, dass diese grossen, ruhigen Lagmnenseen und auch das mmgehende Neer wegen der vielen Riffe der wahe Tummelplatz dieser Thiere sein mïssten. Quallen habe ich während meiner ganzen Seereise überhanpt lieine geschen. olenso keine Syphomophoren. und die einzigen Seethiere mit pelagiseher Lebenswcise, die in das bei juler günstigen Gelegenheit ausgeworfene Schleppuetz gelangten, waren Pyrosomen, einige Pteropoden nud Heteropoden in kleinen unansehnliehen Arten und kleme Rippenyuallen. Nicht eimmal die hlane Velella, die i.h an andern Stellen der Sü̈lsee gefunden, schmückt und heleht einigermassen die nuermessliche Tisserwüste. Tebrigens soll das Neer an der Linie bei den Kingsmillinseln reich an solchen Thieren sein und dann war auch möglicherweise jetzt nicht die günstige .Jahreszeit für dieselhen."

Ich selhst habe Telellen im Gamzen dreimal gesehen. eimmal an der Südhïste Cpolus und zweimal im Apiahafen (Juli-September). Die Schwärme waren indessen nicht gross: es waren wohl nicht viel mohr als einige 100 Exemplare.

Quallen scheinen nux in stillen Hafenwasser ron Pango-Pango gut zu gedeihen. wo ich eine Aurelia-Art bej jedem Besuche wahrmahm. Anch im Hafen ron Sura in Viti war aine solche Art vorlanden.

Vor cleg Bucht von Pango-Pango fing ich eimmal in ungeführ 20 m Tiefe zahlerehe kleine Salpen von Erbsengrösse.

Meinc liesultate aus dem pacifischen Ocean simcl. ohwohl es eigentlich nur Kö̈stenfünģe sind. mit den atlantischen Fängen dep l'...nktonexpedition, soweit abschätzhar, ïhereinstimmend. Hensen sagt (52b. ś.

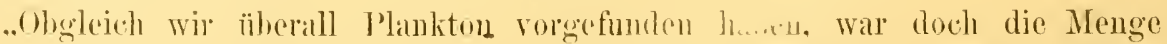
derselhen unter und nahe den 'Tropen relatir gering, nämlieh im Mittel achtmal geringer, als im Norden bis zu den Nonfundiandbänken himnter. Terler rinzehe dieser 
Finge wird weit ïbre hundert versehiedene Formen enthalten, aber die Armuth all Masse ist doch aine aldfallend herventretende. gesicherte 'Thatsache."

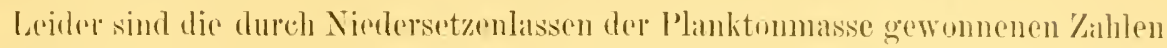
zum Vorgleich für mich wenig bauchbar. Nur mit Vorbehalt gehe ich desshall die auf 1 dom reducirten Messzahlen der 200 m-Fänge der Panktonexpedition, inclom ich ammehme. dass sich das hohvolumen in diesem Fille $\mathrm{mm}^{2} / \mathrm{s}$ durch centrifugiren veringert (selbe Arbojt Hensens s. 249):

$\begin{array}{cc}\text { Rohwolumen } & \text { reducirt auf } \\ \text { auf } 1 \square \mathrm{m} \text { Oberfläche }(200 \mathrm{~m}) & 1 \mathrm{~cm} \text { (contrifugin) }\end{array}$

im Norden bis Nenfundlandhank

Neu-Fumdland his Bormudats

Sillogasomerle

I)ureh Nordïlunatorial-(ruinea und Süid-

Aequiturialstrom his Ascension

In Südäquatorialstrom, Aseension his Parà

Nordiilynatorial-Gninea: Südäquatorialstrom:

P'alri his Salloassomeel

Nord ron den Azoren bis zum Canal

\begin{tabular}{|c|c|c|}
\hline 160 & $\approx c$ & $(1,48$ \\
\hline 40 &.. & 0.13 \\
\hline 35 & . & 0.12 \\
\hline 130 & .. & 0.39 \\
\hline 60 & .. & 0,18 \\
\hline 93 & ., & 0.28 \\
\hline 83 & .. & 0.65 \\
\hline
\end{tabular}

Obwohl diese Zahlen nur relativ sind, stimmen sie doch mit den Resultaten meiner allerdings wenigen (11) Seefänge ron Australien ïherein, welehe zwischen 0.2 und 10.49 schwanken, durchschnittlich 0,26 ec ansmachen.

Es seheint demmah. dass der offene Ocean der Tropen allenthalben um ein deutliches ärmer ist. als der der gemässigten Zonen. und dass im offenen Oeean ïherhaupt allenthalben eine gerwisse Armuth vorherseht.

Wiehtiger sind in dieser Beziehmng dio Zählungen, die indessen ron der Planktonexpedition noch nicht rorliegen.

Der einzige Seefang. welchen ich nahe dem Wentekreis im offenen Parifischen Ocean durch die Güto des Capitäns zur See Flichtenhöfer machen komnte (ein zweiter misslang). rerhält sich folgendermalssen:

()rt: $26^{0}$ sïdl. Br. bei den Tongainseln (offener Ocean),

\%eit: Alemels of Ihr.

Datum: Infang December 1893,

Tirfe: $100 \mathrm{~m}$,

Netz: $1 / 75 \square$ पul, Zeug Nr. 19.

macruscopische Thiere: 1 kleine erbsengrosse Meduse,

Menge (2 mal centrifugirt) $=0.2 \mathrm{cc}$,

auf $1 \mathrm{chm}$ Serwasser berechnet $=0.15$ ec (ohme Fehlervergïtung),

Zahl der organismen in 1 chm Meerwasser 25.50 (2 Zählungen).

Lngeführe Zusammensetzung:

ropepoden $54 \%$ (davon ${ }^{1 / 3}$ Namplius). Tintimen $\tilde{o}^{0}$

Appendicntarien 7 .. (a). $2 \mathrm{~mm}$ lang) Peridinium 3 ..

Rhizosolenien 11 .. (ca.) Caratium 2 ..

Coscinodiscus :3 .. Globigerinen 1 ..

Radiolarien 6 .. Iystun etc. 5 .. 
Dieser einzelne Fang schliesst sich den oben gegebenen Zahlen ziemlich an; ohwohl er der dem 30. Breitengrale nahegelegenen Fangstelle halher nicht für einen reinen Tropenfing gelten kinn, ist er loch recht niedrig.

Als ein einzelner Fang entbehrt er batürlich jeder Beweiskraft, spricht aber zu unsern Gunsten. Sicheren Aufsehluss kömnen hier alleh nur systematisehe Messungen hringen. die wohl in nicht allzufermer Zeit ron irgend ainer Seite ansgeführt werlen diürten.

Was sind die Gründe für die grössere Armutlı der tropischen Gewässer an Microplankton?

Die Amuth an Diatomeen ist gewiss ain guter Fingerzeig. da inshesondere die copepolen anf diese angewiesen sind, wie ich des öfteren zu beohachten Gelegenheit hatte.

\section{Wrarm aher die Armuth an Diatomeen?}

Hensen's Grïnde scheinen mir dies nicht zu erklären (52l). Eine zweifellose Thatsache besteht, dass an der Küste mehr Microplankton vorhanden ist, als in offenen Ocean, vor allem in den gemässigten Zonen. Die relitive Küstenarmuth der grossen Oceane ist sicher ein Factor: Ob hier die producirende Küiste der gemässigten und kalten Zone einen Gegensatz bildet zur consumirenden Korallenküste der Tropen, ist vorerst nicht alozusehen. Die Frage muss eine offene bleiben.

\section{Gross- und Kleinplankton. Haeckel und Hensen.}

Lis ist eine leider zu bekannte 'Thatsache, dass Hacekel als ein seharfer Gegner der Planktonexpedition anfgetreten ist und dadureh dieser Expedition und deren Arheiten sehr geschalet hat. Wenn es auch sehr wahrscheinlich ist. dalss sich die Ansichten dereinst klären werden. so ist es doch zur Keit schlinm genugs. dass die planktonischen Entersuchungen durch solehe Angriffe erschwert und hintangehalten werden.

Es scheint nir indessen erklärlich, wio ein solcher Streit entstehen konnte: es scheint mir auch möglich einen gewissen Verglejeh herbejzuführen, soweit sich die Meinnngen nur nicht an Worte binden und das grosse Ganze ins Auge fitssen.

Aus practischen mud theoretischen Grönden ist es aber mothwendig. das Wort "Plankton" zu zerlegen und nicht kurzweg ron ..Plankton" zu sprechen. sonder"n ron Gross- und Kleinplankton, ron macroseopischem, mit dem Ange lejeht sichtharen Macroplankton med microsenpischem, Microplankton.

Hire kilnn man ohne Bedenken den Satz aufstellen: Das Maceoplankton scheint seh* ungleichmässig vertheilt zu sein, wïhrend dis Micropla nkton ïberall in einer bestimnten Menge rorhanden ist, welche mu innerhall, gewisser rerhailtnissmässig geringer Gren\%(n) schwanlit.

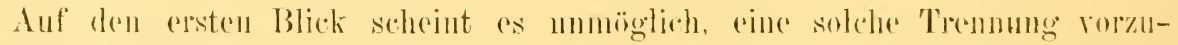
nehmen, da die Grenze sich theoretisch sehe schwer ziohen lässt: in ler Praxis vollführt sich jedoch dies selor leicht, wie sirh schon aus dem Capitel ïher die Copepoden ergioht, indem diese Kruster anen stetigen componenten billen. In der That ergaben sich nur äusserst selten Schwierigkeiten in dieser Bezichung: 


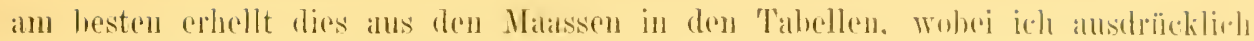

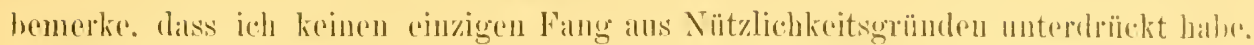

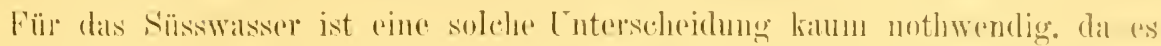

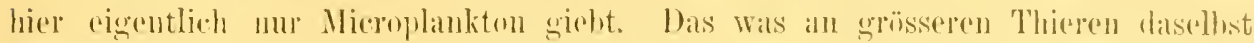

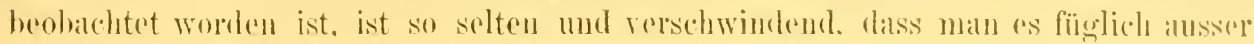
Aeht lasson kimm.

Fül das salzwassele löst sich die Flage chenso leicht, wemn man die gerossen

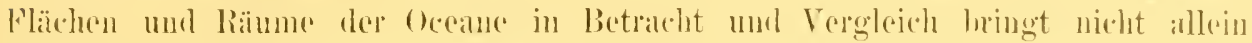

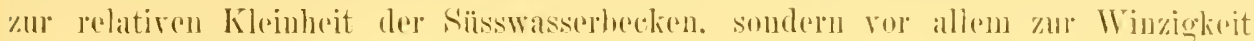

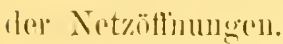

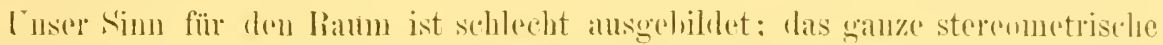
Henken des Inuchsehuittsmenschen ondet bei dinem hahlen hiter.

Wie oft habe ich gehört, wem ich jemanden einen Fang mit einem Notz.

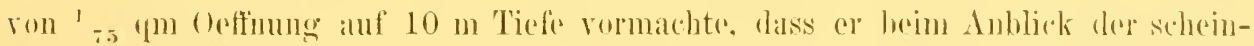
bat grossen Memge im Glase ansrief: . Wieviel muss man daron schlucken. wenn ma!l crsïuft!’”

Kommt bej einen guten samoanischen Fing von 5000 Individuen in 1 ehm Anch nur ein einziges anf rin Glas Wasser! Freilich kam es bei den biatomeen-

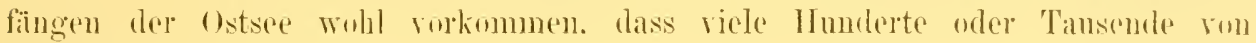
\%ollen darinnem sind!

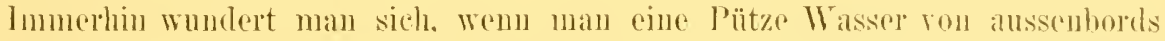
holt mul selur wenig oder nichts darinuen sieht und ist geneigt. diraus den sidnlus' zu ziehen. dass hier das Plankton sehr arm ist. Fährt man aher eine Strecke weit und sieht alle $10 \mathrm{~m}$ ungrefïhr eine Qualle (eine relatir recht grosse Anbäufung). so wirl in das 'Tagehuch geschrieben: .. Tiel Plankton*. Aehnlich rerhält es sich. wem man lei aurh nur leicht bewegter See mit lem Sehlepunct\% fischt und wemn man bald daraul hei glatter Oberfläche cinen Schwarm antriflt, vichleicht hesser gresagt eine Auhäufung

Wreden solehe Notizen zu chomologischen Kwecken ausgehentet. so möchte ich sic mit der Untersuchumg eines Arztes rergheichen, der eine Krankheit num ans dem Anhlick des Patienten diagnosticirt, ans don Anzeichen dor Hant. die inneren Oreane aber nicht untersucht.

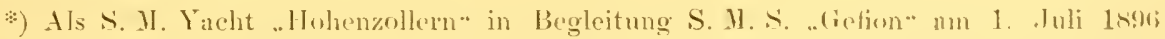

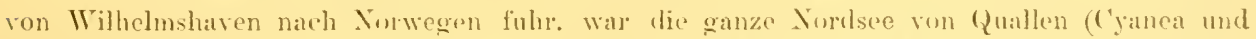
Auclia) sozusagen voll. D) zirmlich vieł see war. ersehien eine Ibschätzung unnitz. An

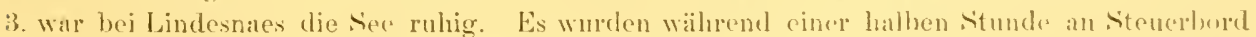

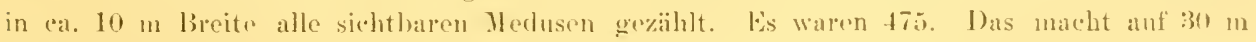
aine Qualle uder auf ("a. 300 yul cine cinzige.

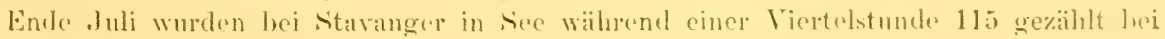

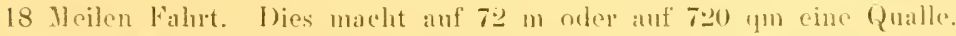

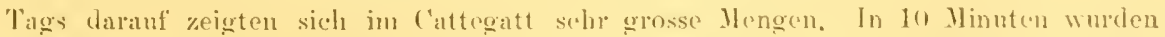
gezählt 5:50 Quallen (meist Aurelia). Was alle 8 m oler auf ca. 80 pm eine ergielut. Xieht mitgerechnet ist hierbei cine Anhäufung. welehe ungefahe 10 m im Gevert hatte und seluätzungsweise 100200 Stïck aufgewiesen haben malg. Solche Anhänfungen wurden im Laufe des 'Tages mehreremals gesichtet. mul mïssen dem Wind und Strum zugewiesen werden. 
Was man rom fihrenden Schiffe aus an Plankton sieht. ist im Allgemeinen nur Macroplankton. Bei glattem Wasser kinn man wohl anch fliegende Pontelliden und schwimmende Sagitten sehen: ich hahe sie oft den geübten Blicken der Seelente gezeigt, sie sind aber meist erst nach langem Beobachten und dann noch unsicher erkannt worden.

Ander's verhält es sich freilich, wenn einzehe Componenten des Microplanktons hei glatter See schwarmbildend auftreten, wie die Copepoden, Peridineen, Phycochromaceen, Protococeen u. s. w. lis handelt sich hier offenbar um das Schwärmen soleher Organismen unter jeweilig günstigen Bedingungen und der Ausdruck ..Schwarm" ist desshalb sehr bezeichnend für diese localen Anhäufungen. Aus diesem Grunde hefinden sie sich in dieser Zeit, wenn es das Wetter gestattet. an der Oherfläche. treiben jedoch hald ah und vertheilen sich wieder. Wenm man desshall) inmitten eines solchen Schwarmes einen verticalen Fing macht. so wird man sich wundern, dass man nicht wesentlich mehr erhält als an einer schwarmfreien benachbarten Stelle. rorausgesetzt, dass man nicht einen Phycochromaceenkuchen mitnimmt. Dies wäre genau so, als ob man eine Qualle mitfinge und diese bei der Menge des Microplanktons in Anrechnung brïichte.

Es zeigt sich eben hierbei, dass die horizontale Verbreitung sehr wechseln kann, die rerticale jedoch mur in engen Grenzen, und in gewissem Grade ist der Streit zwischen Haeckel und Hensen doch nur der um die Fangart, ol die horizontale oder die verticale die richtigere ist.

Die Verticalfünge sind aber die Sonden, mittelst derer man üher den Gehalt der Wassermassen an Microplankton immer Aufschluss erhält. unbekümmert um horizontale Verschiebungen. Desshalb sind sie für Messungen allein brauchbar.

Dariu und in der ungleichmässigen Vertheilung des Macroplanktons gipfelt der Widerstreit.

Haeckel sagt (53a S. 57): ,.Die Zusammensetzung des Plankton aus rerschiedenen Organismen ist sowohl in qualitativer als in quantitativer Beriehung sehr ungleichmässig und ebenso ist die Vertheilung desselhen im Ocean nilch Ort und Zeit sehr ungleich."

In gewissem Sinne hat Haeckel vollständig Recht, ror allem für das Nacroplankton. Aher auch fïr das Mieroplankton haben wir gesehen, dass mit den Jahreszeiten die Mengen wechseln, dass in den Tropen viel weniger ist, als in den kälteren Meeren, dass die Composition sehwankt, ja sogar, dass man an einer Stelle, wenn man mehrere Züge hintereinander macht, durchaus nicht immer genan dieselbe Nonge fängt; - aber alles dies doch in gewissen Grenzen.

Wir wissen rom jedem Landstriche oder besser vielleicht Walde, dass er eine bestimmte entomologische Fanna repräsentirt. Anch hier kömnte man sagen, diss die Insecten ziemlich gleichmïssig vertheilt sind, denn ïberall, wo Vegetation ist, wird man bei genauem Durchsuchen anch eine gewisse Menge finden. Die Locustenschwärme, die Nonnenraupen, Maikäfer u. s. w. bringen anch hier zeitweise Modificationen hervor, die aber doch das ganze faunistische Bild nicht umändern. Der Grundstock an Insecten bleilot anch hier nach wie ror.

Freilich ist das Wasser ein gatnz anderes Medium als Luft, Pflanze und Erde. Desshalb kum der Vergleich nur ein einseitiger sein. 


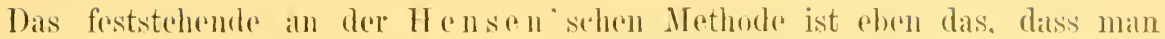

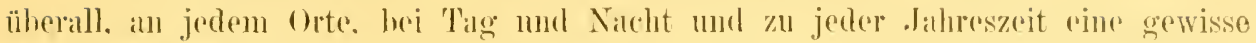
Menge ron Microplankton erhält. welche wälnend ainer hestimmten Zait als nahezu gleichmässig an clem Orte rertheilt zu erachiten ist.

Die Methode ist ehen nur für das Micpoplankton hranchbar: für das Macroplanktom ist sic unzuroichend. Desshalh balte ielo es für nicht richlig. wemn Hensen solches hei seinen Fängen in Anrechnung bringt; grössere Thiere sind für kleine Netze nur als aceidentell verrechenhall.

Dies erhellt aus folgenclen Betrachtungen:

Angenommen, dass nur 1000 Copeporden in 1 cbm Wissel sind (eine für Samoa sogar sehr geringe Menge), so würde somit nu 1 ('opepode auf I liter (chdm) Wisser kommen. Ein Netz mit 1/10n $\square$ m Oeffunngsfläche wïrle somit gerade 100 ropepoden hei einem 10 m-Kug' hringen. Man hat also hier selhst mit dem kloinsten Netze immer die Sicherheit. etwas zu fangen (s. Tahellen).

Anders bei einer Qualle. Nehmen wir den Cubikinhalt eines grösseren Copepoden zu 1 chmm, den (iner grösseren Qualle zu 1 cbdn (1 Liter) an. so wïrde, ähnliche Vertheilung volausgesetzt. auf 1000 cbm eine solehe (Qualle kommen (1 cbdum mal 1 Million: ehenso wie 1 cbmm mal 1 Million gleich 1 liter).

Man müsste also mit einem Netz von $10 \square \mathrm{m}$ Oefinmngsfläche auf $100 \mathrm{~m}$ fangen. um eine einzige zu erbenten oder mit einem solchen ron $100 \square \mathrm{m}$ auf $10 \mathrm{~m}$. Dies nur als Beispiel.

lis tritt eben hier ein gewisses Gesetz des Raumbedïrfuisses in Kraft, d. h. jedes Iebewesen muss einen gewissen Raum zur Yerfügung haben, um sich entwickeln. ernähren und fortpflanzen zn können.

Treten zu grosse Anhäufungen auf. so ist der Intergang eines Theils die unausbleibliche Folge, his das Gleichgewieht wieder einigermassen hergestellt ist.

Ob diese ïbrigens mechanischen und physikalischen Grïnden oder einem gewissen Schwärmestalium in der Fortpflanzung ine Dasein rerdanken, ist noch rine offene Frage (s. auch Heliotropismus).

Abgeschen von solchen Massenanhäufungen. wie ich sie des öfteren z. B. im rothen Meere und in der Ostsec gesehem habe. wo sich thatsächlich Individium an Individium drängt (auch Semper herichtet von einer ähnlichen Pyrosomenanhäufung im Mozambique-Strom). sieht man indessen selten. wenn üherhaupt. an der Oherfläche mehr Medusen als auf $10 \mathrm{~m}$ im Geriert $(100 \square \mathrm{m})$. ja meist uur auf $100 \mathrm{~m} \mathrm{im} \mathrm{Geviert} \mathrm{(10000} \square \mathrm{m}$ ) eine grössere. Dies elscheint bei rasch fahrendem Schiffe schon viel (siche auch die Zählungen der Planktonexpedition in der Reiseheschreibung).

Da sich indessen diese Art Thiere bei Tag in Tiefen ron ca. $50 \mathrm{~m}$ anfzuhilten pflegen (ich erwähnte sehon die diesbezüglichen Angahen Walther's und Kückenthal's ron Spitzhergen). so sind Angahen üher Wahrnehmung solcher Schwäme an der Oberfläche doch recht wenig hranchbar, da man ehen nie weiss, was unter der Oherflache ist. Da ist wieder der Raum. der zu sehaffen macht. Wohl fällt hier gesehenes in die Wagoschale, aber nicht remisstes. Das Iehen der Oceane spielt sich nicht an der Oberflüehe ah, sondern unter derselben. Was wissen wir aber üher die Vertheilung in der Tiefe? Die Hensenschen Analysen 
sind nur ein Anfang mit dem Mieroplankton. Teher das Grossplankton wissen wir noch so gut wie nichts.

Eine Eigensehaft vieler Grossplanktonthere verleiht aher doch einen gewissen Aufschluss ïher ihre Verhreitung, das Phosphoresciren nämlich. Ich habe mich während der Fahrt meist abendlich daron überzengt, wieviel Leuchten im Schraulenwasser oder am Bug rorhanden war und habe mich darïber gewundert, wieviel kopfgrosse fourige Kugeln nchen den unzähligen kleinen und kleinsten, namentlich in den neusechändischen Gewässern allabendlich erschienen, nbwohl ann Tage nichts zu sehen war. (T'm Samoa war diese Erscheinung stets weit geringer.)

Leider habe ich es unterlassen, gerade darüber bestimmte Angaben zu notiren und kamn jetat dies nu für spätere Forsehmugen empfehlen. Immerhin war ein grösseres Aufhlitzen auf $100 \square$ m für gewöhnlich das Höchste.

Ein Glaube aber hat sich dabei in mir befestigt, dass nämlich das Macroplankton auch im Allgemeinen viel ansgebreiteter ist, als es anf chen ersten Blick scheinen mag, nur muss man sich die Räume für dasselbe weit grösser vorstellen. Wie im April in der Ostsee die knopfgrossen Amelien die tieferen Schichten anfiillen. mit dem Fortschritt des Sommers zu tellergrossen Gebilden anwachsend zur Oberflïche ziehen, 1 m mit dem Winter wieder zu rerschwinden. so kam man auch für andere Thiere an andern Plätzen Zeiten des grösseren Anftretens feststellen.

Hacckel. welcher während seiner zahlreichen Besuche fremder Gestade der Entwicklungsgeschichte vor allem der Medusen und Siphonophoren seine Aufmerksimkeit schenkte, bemerkte natïrlich diesen Wechsel in der composition: es ist ja anch wahrscheinlich, dass hier ganz andere Factoren in Frage kommen, welche Hackiel andentet. Fis fehlt eben dem Matcroplankiton ein soleh peremnirender Component. wie die Copepoden es für das Microplanliton sind. Wenu nun auch Hacckel auf Grund dieser Thatsachen und seiner langjährigen krfahrumg auf dieser seiner Ansicht, wie nicht anders zu erwarten. hestehen bleibt, so wird er doch zugehen müssen, dass bewohnte mit wirklich mbewohnten Stellen in den Oceanen sehr wahrscheinlich nirgend abwediseln, und dass der tropische Ocean ïrmer an Mieroplankton ist. durchsehnittlieh wenigstens, als der der gemïssigten und kalten Zonen. Machte ja sellost Muray, wemn ich mich nicht täusche, in allerletzter Zeit gewisse Zngeständnisse in einem Vortrage in der Royal Society zul London, in dem er ungefïhr folgendes ansführte:

Das P'ankton der Tropen ist ämer an Masse. aber reicher an Arten. Während in den kilten Meeren es sich ungekehrt rerhält.

Die puantitativen Planktonfänge (nicht allein der Fang selhst, sondern anch (lie Terarbeitung) haben ja ihres systematischen, mathematischen Gepräges halher etwas ermüdendes: sie erfordern viel Keit und Ausdaner. Umsomehr sollte mam anerkemen. diss Hensen es anf sich genommen hat. eine solche Expedition durchzuführen. Allenthalben rïhren sich allmälig die Hände. Wird man aber erst eimmal das Micopolankton genatuer kennen gelernt haben, damm wird man mit grösserem Erlolge auch dem Gross-Plankton zu Leibe rïcken kömmen — wenn die dazu erforderlichen Mittel werden beschafft werden kömen. Diese specielle Forschung gehört der Zukunft: sie bilket eine der müherollsten, aber anch der dankbarsten Aufgaben der marinen Biologie. 


\section{Tiabellen mul Literaturver\%eichniss.}

\section{Tabellen.}

nic Messzahlen sind die reinen Ergehnisse der Netzäge ohne jegliche Fehlerherechnung.

Tabelle A. C'entrifugirte Küstenlianktonfänge aus Simoal.

\begin{tabular}{|c|c|c|c|c|c|c|c|}
\hline 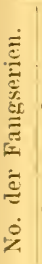 & $\begin{array}{l}\text { Ort. } \\
\text { Fangstelle und } \\
\text { Tiefe derselhen. } \\
\text { Fandr } \\
\text { rom kedhitfe } \\
\text { oder rom Boote. }\end{array}$ & $\begin{array}{l}\text { Datum. } \\
\text { Zeit des Fanges } \\
\text { bei libho oder } \\
\text { Fluth und } \\
\text { nichstes lloch- } \\
\text { oder } \\
\text { Niedrigwasser. }\end{array}$ & $\begin{array}{l}\text { Zahl und Tiefe des } \\
\text { Finge } 1.10 \text { mi, } \\
\text { richtige l'lankton- } \\
\text { menge des Fanges } \\
2 \text { mal centrifugirt } \\
\text { in ce cubikcenti- } \\
\text { meter. }\end{array}$ & $\begin{array}{c}\text { Planktommenge } \\
\text { anf } 1 \text { cbm Meer- } \\
\text { wasser } \\
\text { mugerechnet. } \\
\text { Die zanl in Klam- } \\
\text { mern bedentet die } \\
\text { Tiefe des Jetzzuges. }\end{array}$ & $\begin{array}{l}\text { Durell- } \\
\text { schuitt } \\
\text { ler } \\
\text { Fang- } \\
\text { serie } \\
\text { (auf } \\
1 \text { chm). }\end{array}$ & $\begin{array}{l}\text { Zahl } \\
\text { der } \\
\text { Indivi- } \\
\text { duen im } \\
\text { Fang- } \\
\text { serien- } \\
\text { durch- } \\
\text { schnitt. }\end{array}$ & 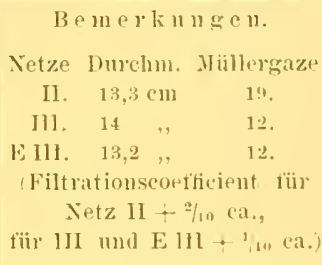 \\
\hline 1. & $\begin{array}{l}\text { Ijia. } \\
\text { Sordkïste von } \\
\text { Epolu, mitten } \\
\text { im Hafen. } \\
\text { Tief'e cia. } 13 \mathrm{~m} . \\
\text { sehiffishg. }\end{array}$ & 9. Normint. 1×93. & $2.10 \mathrm{~m}-0.15 \mathrm{ce}$ & I (1)m $10 \mathrm{~m})=11,49 \mathrm{ce}$ & 0,49 ce & - & III. \\
\hline 2. & $\begin{array}{c}\text { Apia. } \\
\text { Schiffshng. }\end{array}$ & 11. Normint. 1893. & $2.10 \mathrm{~mL}-0,3 \mathrm{cc}$ & $1 \mathrm{ebm}(10 \mathrm{~m})=0,9 \mathrm{ce}$ & $0,9 \mathrm{ec}$ & - & III. \\
\hline 35. & $\begin{array}{l}\text { Saluafida. } \\
\text { Nordküste rom } \\
\text { Cpolu, 10 sm. } \\
\text { östlich von } \\
\text { Apia, mitten im } \\
\text { llafen. } \\
\text { Tiefe } 15 \mathrm{~m} . \\
\text { selhiffsbug. }\end{array}$ & $\begin{array}{l}\text { 25. Mai Is94 } \\
\text { 9h a. m. } \\
\text { hej Fluth. } \\
\text { nichstes Hocll- } \\
\text { wasser } \\
\text { (a. 10 ha. m. }\end{array}$ & 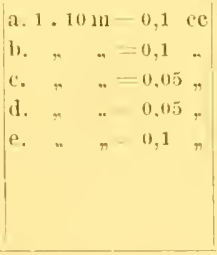 & 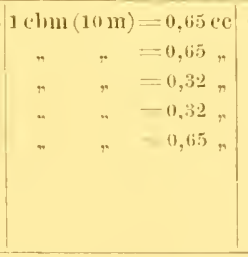 & $0,52 \mathrm{ce}$ & - & $\begin{array}{l}\text { III. } \\
\text { Sagitten erschweren das Aly- } \\
\text { lesen, in c mul if fehlen sie } \\
\text { nahezu. Viel Copepoden } \\
\text { (Oithona). }\end{array}$ \\
\hline 36. & $\begin{array}{l}\text { Apia. } \\
\text { Am Ostriff hei } \\
\text { Matantu an ser- } \\
\text { schiedenen } \\
\text { Stellen. } \\
\text { Tiefe } 10-14 \mathrm{~m} . \\
\text { Im Boot. }\end{array}$ & 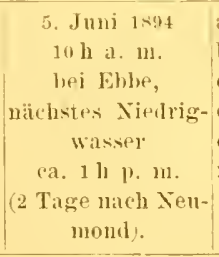 & 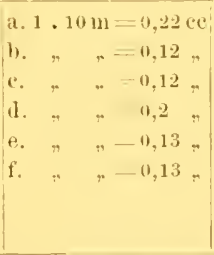 & 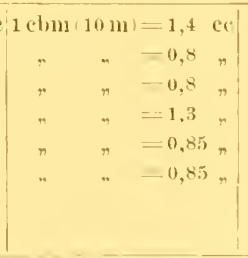 & $1,0 \mathrm{ce}$ & $\begin{array}{l}15,000 \\
\text { woron } \\
95 n_{10} \\
\text { Cope- } \\
\text { poden. }\end{array}$ & 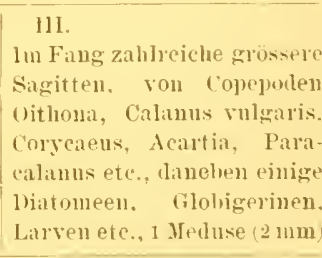 \\
\hline $3 i$. & $\begin{array}{l}\text { Apia. } \\
\text { Hafenmitte. } \\
\text { sichiftslmer. }\end{array}$ & \begin{tabular}{|} 
5. Juli 1ng4 \\
10 h a. m. \\
bei Ebhe, \\
nachstes Niedrig- \\
wasser \\
3 h 1. m.
\end{tabular} & 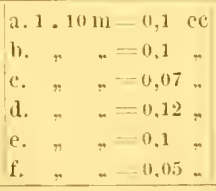 & 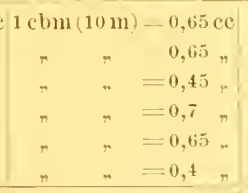 & $0.58 \mathrm{ce}$ & $\begin{array}{l}(8000 ?) \\
90 \% \\
\text { Cope- } \\
\text { poden } \\
\text { (Oitho- } \\
\text { nai) }\end{array}$ & $\begin{array}{l}\text { Ill. } \\
\text { Vereinzelt Diatomeen, Glo- } \\
\text { higerinen, Ceratim, Apjen- } \\
\text { dicularien, Acarinen, Sa- } \\
\text { gitten. }\end{array}$ \\
\hline 38. & $\begin{array}{l}\text { Saluafata. } \\
\text { yitten im } \\
\text { Haten. } \\
\text { Tiefe ca. } 1.5 \mathrm{~m} . \\
\text { Schifrolug. }\end{array}$ & 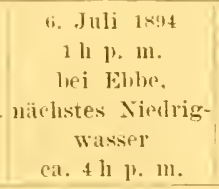 & 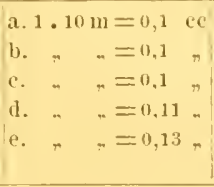 & $\begin{aligned} 1 \mathrm{cl} m(10 \mathrm{~m}) & =0,65 \mathrm{cc} \\
r \quad & =0,65 \mathrm{~m} \\
r & =0,65 \mathrm{~m} \\
r \quad & =0,7 \\
r & =0,75\end{aligned}$ & 0,6 is ec & $\begin{array}{l}17,000 \\
83 \% \\
\text { Cope- } \\
\text { poden. }\end{array}$ & 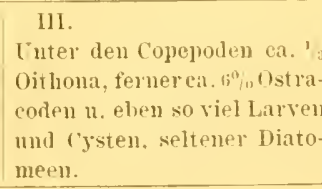 \\
\hline
\end{tabular}




\begin{tabular}{|c|c|c|c|c|c|c|c|}
\hline 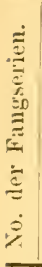 & $\begin{array}{c}\text { Ort. } \\
\text { Fangstelle und } \\
\text { Tiete derselben. } \\
\text { Fang } \\
\text { vom schiffe } \\
\text { oder vom Boote. }\end{array}$ & \begin{tabular}{|} 
Datnm. \\
Zeit des Fanges \\
bei Ebue oder \\
Fluth und \\
nichstes Hoch- \\
oder \\
Niedrigwasser.
\end{tabular} & $\begin{array}{c}\text { Zahl uud Tiefe der } \\
\text { Fänge ( } 1.10 \mathrm{~m} \text { ), } \\
\text { richtige Plankton- } \\
\text { menge des Fanges } \\
2 \text { mal centrifugirt } \\
\text { in ce (Cubikcenti- } \\
\text { meter.) }\end{array}$ & $\begin{array}{l}\text { Planktommenge } \\
\text { auf 1 chm Meer- } \\
\text { wasser } \\
\text { nmgerechnet. } \\
\text { Ine Zahl in Klam- } \\
\text { mern berleutet ile } \\
\text { Tiefe des Netzzuges. }\end{array}$ & $\begin{array}{l}\text { Durch- } \\
\text { schuitt } \\
\text { der } \\
\text { Faug- } \\
\text { serie } \\
\text { (anf } \\
1 \text { clom). }\end{array}$ & 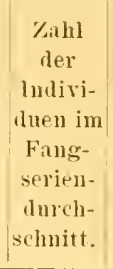 & 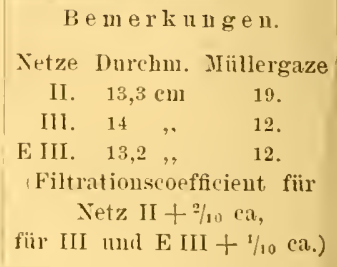 \\
\hline 39. & $\begin{array}{l}\text { Apia. } \\
\text { In der Ansfant } \\
\text { zwischen den } \\
\text { Riffen. } \\
\text { Yom Sichiftsbug. } \\
\text { Tiete ca. } 20 \mathrm{~m} \text {. }\end{array}$ & $\begin{array}{l}\text { 8. Juli } 1894 \\
2 \text { h } \mathrm{j} . \mathrm{m} . \\
\text { hei Ebhe, } \\
\text { uätchstes Niedrig- } \\
\text { wasser } \\
51 / 2 \text { lı p. m. }\end{array}$ & 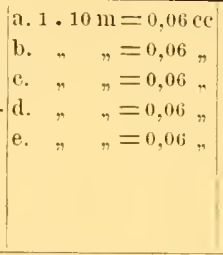 & $\begin{aligned} 1 \mathrm{cbm}(10 \mathrm{~m}) & =0,4 \mathrm{cc} \\
" \quad & =0,4 \\
" \quad & =0,4 \\
" \quad & =0,4 \\
" \quad & =0,4,\end{aligned}$ & $0,4 \mathrm{cec}$ & $\begin{array}{l}2100 \\
700 ! \\
\text { (10) }\end{array}$ & $\begin{array}{l}\text { III. } \\
\text { Von (opepod. hauptsächlich } \\
\text { Oithona, vereinzelt Cory- } \\
\text { caeus, Harpacticiden, viele } \\
\text { Calaniden; danehen ca. } 15 \% \\
\text { Ostracoden, vereinzelt Dia- } \\
\text { tomeen, Globigerinen, Lar- } \\
\text { ven ete. }\end{array}$ \\
\hline 40. & $\begin{array}{c}\text { Vailele. } \\
5 \text { Sin. östlich } \\
\text { von Apia, in der } \\
\text { Einfahrt } \\
\text { zwischen den } \\
\text { Riffen. } \\
\text { Tiefe ca. 16 m. }\end{array}$ & $\begin{array}{l}\text { 11. Juli } 1894 \\
9 \text { h a. m. } \\
1 \text { stumde nach } \\
\text { Niedrigwasser. }\end{array}$ & 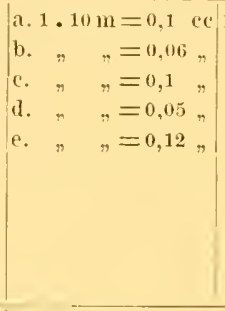 & 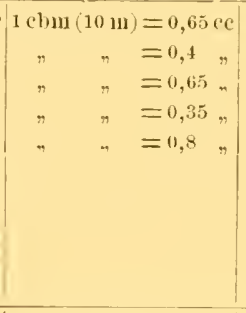 & $0,57 \mathrm{ce}$ & $\begin{array}{c}5-6000 \\
96 \% \\
\text { Cop. }\end{array}$ & $\begin{array}{l}\text { IlI. } \\
\text { Con Copepoden: } \\
75 \% \text { Calaniden, } \\
17 \% \text { Oithona, } \\
2 \% \text { Harpacticiden, } \\
\text { ausserdem: } \\
4 \% \text { Sagitten. } \\
2 \% \text { Eier, } \\
1 \% \text { Globigerinen nnd } \\
\text { Radiolarien. }\end{array}$ \\
\hline 41. & $\begin{array}{l}\text { Vailele. } \\
\text { Ebenso. }\end{array}$ & \begin{tabular}{|} 
19. Juli 1894 \\
10 h a. m. \\
bei Elhbe, \\
nächstes Niedrig- \\
wasser \\
ca. 2 h p. m.
\end{tabular} & 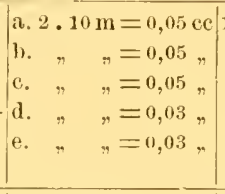 & $\mid \begin{aligned} 1 \mathrm{cbm}(10 \mathrm{~m}) & =0,17 \mathrm{ce} \\
" \quad r & =0,17 \\
" \quad & =0,17 \\
" \quad & =0,1 \\
r & =0,1\end{aligned}$ & $0,1+c c$ & - & $\begin{array}{l}\text { III. } \\
\text { Wind O.N.O.-O.z.N. } \\
\text { Meist Copepoden. daneben } \\
\text { ziemlich viel Eier. }\end{array}$ \\
\hline 42. & $\begin{array}{l}\text { Vailele. } \\
\text { Ebenso. }\end{array}$ & $\begin{array}{c}\text { Fang f-k } \\
51 / 2 \mathrm{~h} \mathrm{p.} \mathrm{m.} \\
\text { bei Fluth, } \\
\text { Hächstes Niedrig- } \\
\text { wasser } \\
4 \mathrm{~h} \mathrm{p.} \mathrm{m.}\end{array}$ & 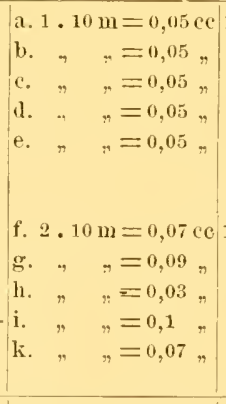 & $\mid \begin{aligned} 1 \mathrm{cbm}(10 \mathrm{~m}) & =0.23 \mathrm{cc} \\
" \quad & =0,3 \quad " \\
" & =0,1 \\
" \quad & =0,33 . \\
& =0,23,\end{aligned}$ & $0,35 \mathrm{ce}$ & - & $\begin{array}{l}\text { III. } \\
\text { In } 0,3 \text { ce ca. } 2000 \text { Individuen. } \\
\text { wovon } 74 \% \text { Copepoden, } \\
\quad 8 \% \text { Ostracoden, } \\
1 \% \text { Globigerinen, } \\
\text { Appendicularien, Cysten, } \\
\text { Larven etc. } \\
\text { III. } \\
\text { Hehrere Larven vou Deca- } \\
\text { poden. }\end{array}$ \\
\hline 43. & \begin{tabular}{|c|} 
Saluafuta. \\
Mitten im \\
Hafen. \\
Vom Schitfsbug. \\
Tiefe ca. $16 \mathrm{~m}$.
\end{tabular} & $\begin{array}{l}\text { 26. Jnli } 1 \times 94 \\
\text { 1h p. ill. } \\
\text { bei Fluth, } \\
\text { nüichstes Hoch- } \\
\text { wasser } \\
\text { ca. } 3 \text { h p. 11. }\end{array}$ & 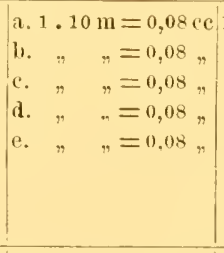 & $\begin{aligned} 1 \operatorname{cbm}(10 \mathrm{~m}) & =0,5 \mathrm{cc} \\
" \quad & =0,5 \\
" \quad & =0,5 \\
" \quad & =0,5 \\
" \quad & =0,5 .\end{aligned}$ & $0,5 \mathrm{cc}$ & $\begin{array}{l}7500 \\
83 \% \\
\text { Cop. }\end{array}$ & $\begin{array}{l}\text { III. } \\
\text { Ostracoden } \\
\text { Diatomeen } \\
\text { Larven und Cysten } 10 \%, \\
\text { Radiolarien mud } \\
\quad \text { Globigerinen } \\
\text { Im ganzen Fang ca. } 10 \text { Sa- } \\
\text { gitten. }\end{array}$ \\
\hline \multirow[t]{2}{*}{44} & \multirow{2}{*}{ 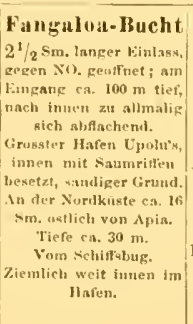 } & $\begin{array}{c}\text { 27. Juli } 1894 . \\
\text { Fang a-e bei } \\
\text { Fluth } 10 \text { h a. m, } \\
\text { uächstes Hoch- } \\
\text { wasser } 2 \text { h } \text { r. m. }\end{array}$ & 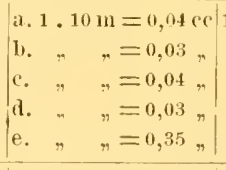 & $\left|\begin{array}{rl}1 \mathrm{cbm}(10 \mathrm{~m}) & =0,3 \mathrm{ce} \\
" \quad & =0,22, \\
" \quad & =0,3 . \\
" \quad " & =0,22, \\
" \quad & =0,25 .\end{array}\right|$ & $0,26 \mathrm{ec}$ & $\left|\begin{array}{c}74 \% \\
\text { cop. } 1100 \\
\end{array}\right|$ & \begin{tabular}{lr}
\multicolumn{1}{c}{ II. } \\
Ostracoden & $18 \%$ \\
Appendicularien & $3 \%$ \\
Diatomeen & $1,5 \%$ \\
Globigerimes n. Larven $1,5 \%$
\end{tabular} \\
\hline & & $\begin{array}{l}\text { Finge } \mathrm{t}-\mathrm{i} \text { hei } \\
\text { Ehbe } 3^{2 / 2} \mathrm{l} \text { p. m. } \\
\text { nächstes Niedrig- } \\
\text { wasser } \\
\text { sh p. m. }\end{array}$ & 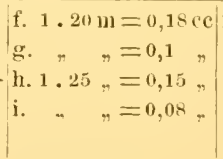 & $\begin{aligned} 1 \mathrm{chm}(20 \mathrm{~m}) & =0,65 \mathrm{ce} \\
" \quad & =0,35, \\
" \quad(25 \mathrm{~m}) & =0,43, \\
" \quad & =0,23,\end{aligned}$ & $0,+1$ ee & $\begin{array}{l}4800 \\
66^{\circ} \% \\
(0) \%\end{array}$ & $\begin{array}{l}\text { II. } \\
\text { Ostracoden } \\
\text { Alpendicularien } \quad 9 \% \\
\text { Alobigerinen u. Larven } 6 \%\end{array}$ \\
\hline
\end{tabular}




\begin{tabular}{|c|c|c|c|c|c|c|c|}
\hline 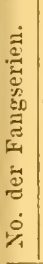 & $\begin{array}{l}\text { Ort. } \\
\text { Finnstelle mul } \\
\text { Tiete derselben. } \\
\text { Fang } \\
\text { rom Schifle } \\
\text { orler rom Boote. }\end{array}$ & $\begin{array}{c}\text { Datum. } \\
\text { Zeit des Fanges } \\
\text { boi Ehlue oder } \\
\text { Fluth und } \\
\text { nidchstes thoch- } \\
\text { oder } \\
\text { Niedrigwasser. }\end{array}$ & $\begin{array}{c}\text { Zahl mul Tiefe der } \\
\text { Fäne (1.10 m), } \\
\text { riehtige L'ankton- } \\
\text { menge des Funges } \\
2 \text { mal centritugint } \\
\text { in ce (cubik'enti- } \\
\text { meter). }\end{array}$ & 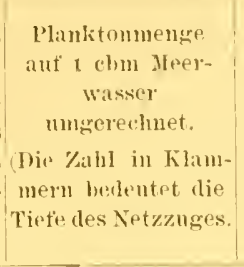 & $\begin{array}{l}\text { 1)urch- } \\
\text { schuitt } \\
\text { der } \\
\text { Fing- } \\
\text { serien } \\
\text { (ant' } \\
1 \text { chun). }\end{array}$ & $\begin{array}{l}\text { Zald } \\
\text { der } \\
\text { ludivi- } \\
\text { duen im } \\
\text { Fang- } \\
\text { serien- } \\
\text { dureh- } \\
\text { selonitt. }\end{array}$ & 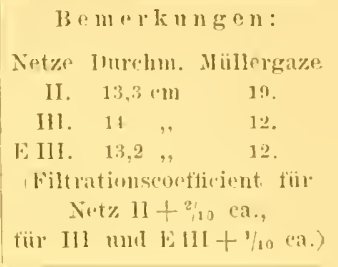 \\
\hline 45. & 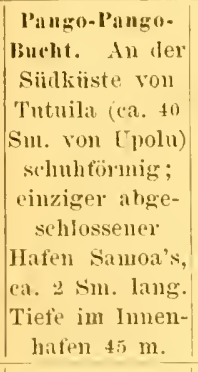 & $\begin{array}{l}\text { 29. Juli } 1894 \\
1 \mathrm{~h} \mathrm{p.} \mathrm{m.} \\
\text { bei Fluth, } \\
\text { Hächstes Hoch- } \\
\text { wasser } \\
\text { ca. } 4 \mathrm{~h} \mathrm{p.} \mathrm{m.}\end{array}$ & 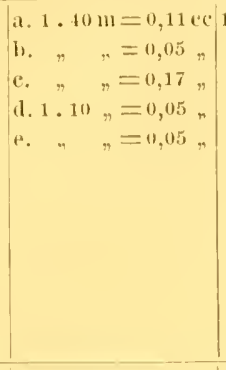 & $\begin{aligned} 1 \mathrm{cmm}(40 \mathrm{~m}) & =0,2 \mathrm{ce} \\
" \quad & =0,09, \\
" \quad(10 \mathrm{~m}) & =0,3 \quad=0,36 " \\
" \quad & =0,36 "\end{aligned}$ & 0,26 ec & $\begin{array}{l}4400 \\
75 \% \\
\text { (Cop). }\end{array}$ & 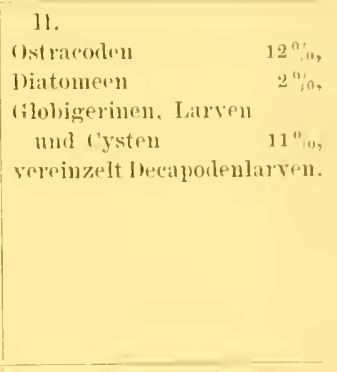 \\
\hline 46. & $\begin{array}{l}\text { Pango-Pango. } \\
\text { Derselbe Platz. }\end{array}$ & $\begin{array}{l}\text { 30. Juli } 1894 \\
\text { 4h p. m. } \\
\text { bei Fluth, } \\
\text { näehstes Hoch- } \\
\text { wasser } \\
5 \text { h y. m. }\end{array}$ & 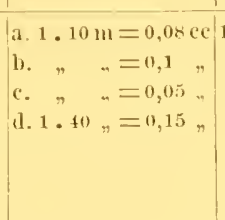 & $\begin{aligned} 1 \operatorname{cbm}(10 \mathrm{~m}) & =0,58 \mathrm{ce} \\
" \quad & =0,72 \\
" \quad(40 \mathrm{~m}) & =0,36,27\end{aligned}$ & 0,4 ec & $\begin{array}{l}5000 \\
93^{11} \% \\
\text { Cop). }\end{array}$ & $\begin{array}{l}\text { II. } \\
\text { Ceratien } 3 \% \text {, } \\
\text { ausserdem Ostracoden, Eier, } \\
\text { Hyneriden, Coscinodiseus } \\
\text { etc. }\end{array}$ \\
\hline 47. & $\begin{array}{c}\text { Apia. } \\
\text { Alte Stelle } \\
\text { mittenimHafen. } \\
\text { Tiefe ca. } 13 \mathrm{~m} .\end{array}$ & $\begin{array}{l}\text { 8. Angust } 1894 \\
4 \text { h p. m. } \\
\text { bei Eb\}e, } \\
\text { näiclistes Nierlrig- } \\
\text { wasser } \\
\text { th p. m. }\end{array}$ & 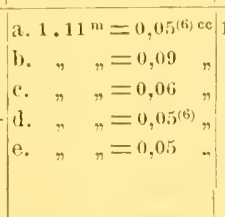 & $\mid \begin{aligned} 1 \operatorname{cbm}(11 \mathrm{~m}) & =0,36 \mathrm{ce} \\
" \quad " & =0,59 " \\
" \quad " & =0,39 \\
" \quad & =0,36 " \\
" & =0,33 "\end{aligned}$ & 0,41 ee & - & 1I. \\
\hline 48. & $\begin{array}{l}\text { Saluafata. } \\
\text { Tiefe } 19 \mathrm{~m} . \\
\text { Bug. } \\
\text { Mitten im } \\
\text { Hafen. }\end{array}$ & $\begin{array}{l}\text { 12. Angust } 1 \text { ing4 } \\
\text { th } 30^{\circ} \text { p. m. } \\
\text { bei Ebbe, } \\
{ }_{1 / 2} \text { Stmude nach } \\
\text { Hochwasser. }\end{array}$ & $\begin{array}{l}\text { a. } 1.17 \mathrm{~m}=0,03 \mathrm{ce} \\
\text { b. " } "=0,05 n \\
\text { e. " }=0,05 " \\
\text { i. " " }=0,06, " \\
\text { e. " " }=0,05 "\end{array}$ & 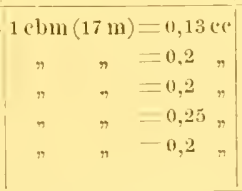 & 0,2 ce & - & II. \\
\hline 49. & \begin{tabular}{|} 
Falefa. \\
3 Su. östlich \\
ron Saluafata. \\
Offene Rhede. \\
Nur im Westen \\
Riff, im Osten \\
Steilküste. \\
Tiefe ca. $20 \mathrm{~m}$, \\
a mud b \\
am Bug, \\
c, d und e \\
an Heck.
\end{tabular} & $\begin{array}{l}\text { 13. August } 1894 \\
3 \text { h p. m. } \\
\text { bei Fluth, } \\
1 \text { Stmonde vor } \\
\text { Hochwasser. }\end{array}$ & 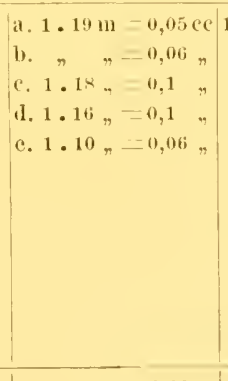 & $\mid \begin{array}{cc}1 \mathrm{ebm}(19 \mathrm{~m})=0,19 \mathrm{ce} \\
" \quad(1 \times \mathrm{m})=0,23 \\
" \quad(16 \mathrm{~m})=0,45 \\
" \quad(10 \mathrm{~m})=0,43\end{array}$ & $0,34 \mathrm{ce}$ & - & $\begin{array}{l}\text { II. } \\
\text { In den Fingen Schmutz } \\
\text { durch Asche. In das Innere } \\
\text { dor Bucht mïnlet ein cal. } \\
5 \text { m lneiter Fluss. Im Fange } \\
\text { meist copepoden, Ostra- } \\
\text { roden, vereinzelt Radio- } \\
\text { larien, Irotocysten, Dia- } \\
\text { tomeen. }\end{array}$ \\
\hline 50. & \begin{tabular}{|c|} 
Saluafinta. \\
\& Fänge \\
im Boote an \\
den ver- \\
schieifensten \\
Stellen des \\
lfafens. \\
i mo k \\
$(9$ und 10) \\
vom Schiff aus. \\
Tiffe 20-25 m.
\end{tabular} & $\begin{array}{l}\text { 17. Angnst } 1894 \\
\text { (Vollmond) } \\
10 \mathrm{~h} \mathrm{a.} \mathrm{m.} \\
\text { bei Ebbe, } \\
\text { nächstes Niedrig- } \\
\text { wasser } \\
12 \mathrm{~h} \mathrm{a.m.}\end{array}$ & 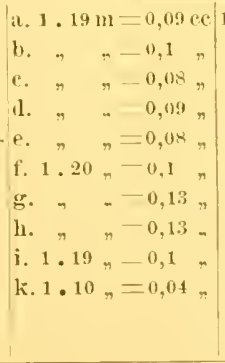 & 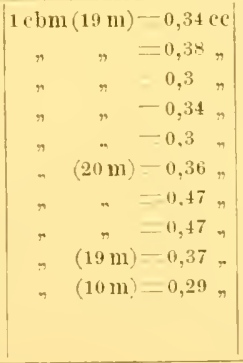 & $\mid$\begin{tabular}{c|c}
0,36 ce \\
$\mid$
\end{tabular} & $\begin{array}{l}\text { ca. } 7000 \\
\text { ca. } 60 \% 10 \\
\text { ('op. }\end{array}$ & $\begin{array}{l}\text { II. } \\
30 \% \text { ostracoden, seltener } \\
\text { Sagitten, flobigerinen, Iso- } \\
\text { polenlarven und zienlich } \\
\text { vinc Decapodenlarven. }\end{array}$ \\
\hline
\end{tabular}


Dr. Angrustin Krämer.

\begin{tabular}{|c|c|c|c|c|c|c|c|}
\hline 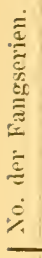 & $\begin{array}{c}\text { (ont. } \\
\text { Fangstelle und } \\
\text { Tiefe derselben. } \\
\text { Fang } \\
\text { vom sichiffr } \\
\text { oder vom Boote. }\end{array}$ & $\begin{array}{l}\text { Datum. } \\
\text { Zeit des Fanges } \\
\text { bei Elbe odes } \\
\text { Fluth und } \\
\text { nachstes Hoch- } \\
\text { orler } \\
\text { Xierlrigwasser. }\end{array}$ & $\begin{array}{l}\text { ZahI und Tiefe der } \\
\text { Fänge }(1.10 \mathrm{~m}), \\
\text { richtige Plankton- } \\
\text { menge des Fanges } \\
2 \text { maI centrifugint } \\
\text { in ec (Cubikcenti- } \\
\text { meter). }\end{array}$ & $\begin{array}{c}\text { Planktommenge } \\
\text { auf I chm Meer- } \\
\text { wisser } \\
\text { mngerechnet. } \\
\text { Die ZahI in Klan- } \\
\text { mern berlentet die } \\
\text { Tiefe dles Nutzzuges. }\end{array}$ & $\begin{array}{l}\text { Durch- } \\
\text { sehnitt } \\
\text { der } \\
\text { Fang- } \\
\text { serie } \\
\text { (anf } \\
1 \text { clim). }\end{array}$ & $\begin{array}{l}\text { Zahl } \\
\text { der } \\
\text { Lndivi- } \\
\text { duen im } \\
\text { Fang- } \\
\text { serien- } \\
\text { durch- } \\
\text { schuitt. }\end{array}$ & 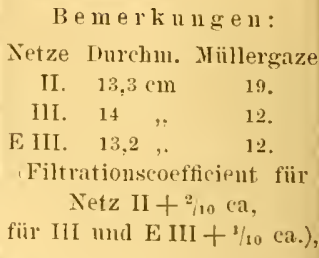 \\
\hline 51. & 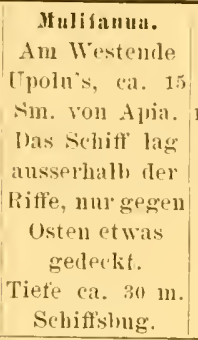 & $\begin{array}{l}\text { 2x. August } 1894 \\
\text { th 1. m. } \\
\text { bej Ebbe, } \\
\text { nïchstes Nierlrig- } \\
\text { wasiser } \\
\text { ca. } 8 \text { h f. m. }\end{array}$ & 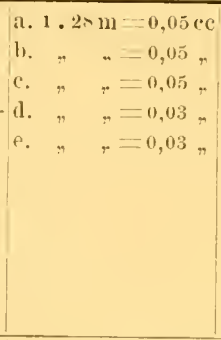 & $\begin{aligned} 1 \text { cbur }(28 \mathrm{~m}) & =0,13 \mathrm{cc} \\
" \quad " & =0,13 . \\
" \quad " & =0,13 . \\
" \quad " & =0,08 . \\
" \quad " & =0,08 \%\end{aligned}$ & 0,11 ce & $\begin{array}{l}1650 \\
70 \% \\
\text { Cop. }\end{array}$ & $\begin{array}{l}\text { II. } \\
\text { Diatomeen, Ceratien, Ostra- } \\
\text { coden, Sagitten, Appendi- } \\
\text { cularien, Cysten, Hlobige- } \\
\text { rinen etc. }\end{array}$ \\
\hline 52. & $\begin{array}{l}\text { Apia. } \\
\text { In der Einfahnt } \\
\text { zwischen den } \\
\text { Hitfen. Im } \\
\text { Boote an } 5 \text { ver- } \\
\text { schierlenen } \\
\text { Stellen. } \\
\text { Tiefe ca. 16 m. }\end{array}$ & $\begin{array}{l}\text { 31. Anerust 1894 } \\
\text { (Neumond) } \\
\text { 5h l. wh. } \\
\text { 1 Stunle vor } \\
\text { Hochwasser. }\end{array}$ & 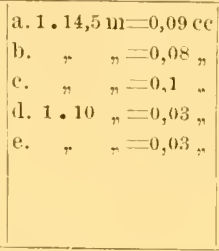 & $\begin{aligned} 1 \mathrm{cbm}(14,5 \mathrm{~m}) & =0,45 \mathrm{ce} \\
" \quad " & =0,4 \quad, \\
. \quad " & =0,5, \\
1 \mathrm{cbm}(10 \mathrm{~m}) & =0,22, \\
" \quad & =0,22 .\end{aligned}$ & $0,36 \mathrm{ce}$ & - & II. \\
\hline 53. & \begin{tabular}{|} 
Saluafata. \\
Hafenmitte. \\
Schiffshug. \\
Tiefe ca. 201 11.
\end{tabular} & $\begin{array}{l}\text { 2. September } 1: 94 \\
11 \text { h a. m. hei } \\
\text { Ehbe, naichstes } \\
\text { Niedrigwasser } \\
2 \text { h p. u. }\end{array}$ & 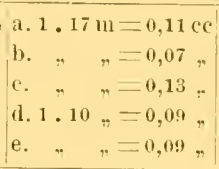 & 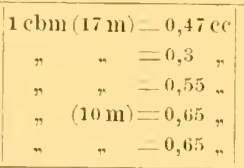 & 0,52 ce & - & II. \\
\hline
\end{tabular}

\section{Fafealili.}

Suitlkiiste rou

Upolu.

Ansienrliede.

Sichiflisbung.

Tiefe ca. $40 \mathrm{ml}$.

(Am Jieck nur

$13 \mathrm{mj}$. Strom

anf landig.

Safata.

9. Sim. Westlich

von Falealili.

offenes lreiter

Einlass.

Fangstelle

inmen zwistheu

den Rifien.

Tiefe ca. $40 \mathrm{~m}$.

56. Leour. Offeme

Rherle. Süd-

küstev. Tutuila.

Tiete ca. $35 \mathrm{~m}$.

sichiftsslong.

57. Pingo-Pango.

Tutuilis.

Innenhaten.

Tiefe ca. $40 \mathrm{~m}$

15. Octoher $1894 \mid$ a. $1.35 \mathrm{~m}=0,2$ ec $1 \mathrm{cbun}(35 \mathrm{~m})=0,37 \mathrm{cc}|0,24 \mathrm{cc}|-$

(Tag mach Voll- b. , $n=0,1, n$, $, \quad 0,19$, mond )

$4 \mathrm{~h} 1$. 111 .

bei Fluth,

c. $, \quad,=0,1 \ldots, \ldots=0,19$,

|d. $1 \cdot 10 \mathrm{~m}=0,03$,

$(10 \mathrm{~m})=0.2$

latchstes Hoch-

$$
\text { wasser }
$$

$7 \mathrm{~h} \mathrm{p}$ l. $\mathrm{m}$.

16. October $1 \times 94$

$3 \mathrm{~h} \mathrm{j} . \mathrm{ml}$.

leei Fhuth,

nïchstes Hoch-

wassey

7 h $40^{\circ}$ 1. 111.

$$
\text { |ค. " }, 0,04, \text {, }, \quad n=0,26 \% \text { | }
$$

III.

III.

17. Uetoler $1 \times 94$ a. $1.33 \mathrm{~m}=0,05 \mathrm{ce} 1 \mathrm{cbm}(33 \mathrm{~m})=0,1 \mathrm{ce} \quad 0,0 \mathrm{ccc}$

9 h a. 11 .

b. $, \quad,=0,02 \ldots, \quad, \quad=0,04$,

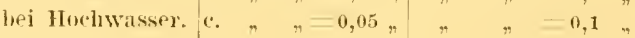

d. $1 \cdot 10 \ldots=0,01, \ldots \quad$, (10 m) $=0,07$,

e. $" \quad,=0,01, \quad, \quad n=0,07 \%$

19. Octoher 1894 a. 1 . $35 \mathrm{~m}=0,5$ ce 1 chm $(35 \mathrm{~m})=0,93 \mathrm{ce} \mid 0,37$ ce

10 h a. $111 . \quad$ b. $, \quad n=0,26, \quad, \quad n=0,52, \quad$ ( 0,28 ('e

liei Hochwasser. $\because, \quad, \quad,=0,12, \quad, \quad, \quad=0,22, \quad$ ohne a)

d. , $,-0,15, \quad, \quad,=0,28$,

e. $3 \cdot 10_{n-0,1, n},(10 \mathrm{mi})-0,22 \ldots$
I11.

Fang a mit Sigitten gemessen, b, c, d mul e ohne ¿lieselben. Sagitten gross bis zu $2 \mathrm{~cm}$ Iaug.

Ostracoden $8 \%$,

Appendicularien $4 \%$, (ilobigerinen, Cysten etc. 


\begin{tabular}{|c|c|c|c|c|c|c|c|}
\hline 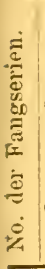 & $\begin{array}{c}\text { Ort. } \\
\text { Fangstelle und } \\
\text { Tiefe derselben. } \\
\text { Fang } \\
\text { vom sehille } \\
\text { oller rom Boole. }\end{array}$ & $\begin{array}{l}\text { Datum. } \\
\text { Zeit des finges } \\
\text { bei Ehbe oder } \\
\text { Fluth mol } \\
\text { nïldstes Hoch- } \\
\text { oder } \\
\text { Niedrigwasser. }\end{array}$ & $\begin{array}{l}\text { Zalhl und Tiefe der } \\
\text { Finge (1.10 m), } \\
\text { richtige Plinliton- } \\
\text { menge des langes } \\
2 \text { mal rentritugirt } \\
\text { in ce (rubikcenti- } \\
\text { metrr). }\end{array}$ & 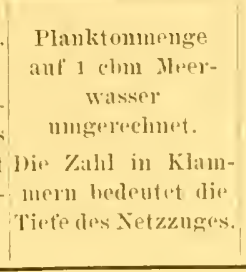 & $\begin{array}{l}\text { burch- } \\
\text { schunit } \\
\text { derl } \\
\text { fians- } \\
\text { serie } \\
\text { (anf } \\
\text { (a)m). }\end{array}$ & $\begin{array}{l}\text { Zalhl } \\
\text { der } \\
\text { lmbivi- } \\
\text { duen int } \\
\text { Fang- } \\
\text { serien- } \\
\text { durch- } \\
\text { schuitt. }\end{array}$ & 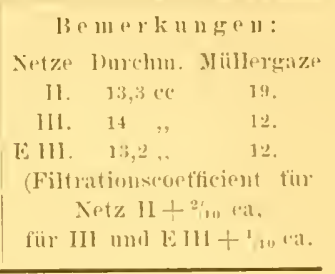 \\
\hline 58. & $\begin{array}{l}\text { Saluafita. } \\
\text { Hatemmitte. } \\
\text { Schiftshmg. } \\
\text { Tiefe ea. } 15 \mathrm{~m} \text {. }\end{array}$ & 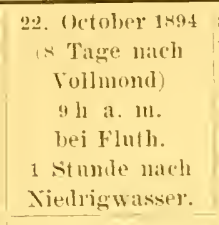 & 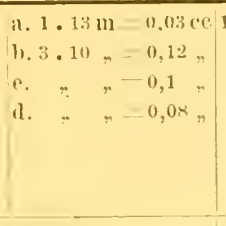 & 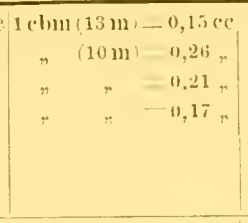 & $0,21 \quad 0$ & - & $\begin{array}{l}\text { l'alolo in silvaii. } \\
\text { III. }\end{array}$ \\
\hline 59. & $\begin{array}{l}\text { Mulifanua. } \\
\text { Tiefe ca. } 40 \mathrm{~m} \text {. } \\
\text { schiftshng. }\end{array}$ & 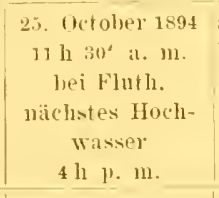 & $\begin{array}{l}\text { a. } 3.20 \mathrm{~m}-0,04 \mathrm{ce} \\
\text { b. }, \quad n-10.04,\end{array}$ & $\begin{array}{c}1 \mathrm{chm}(20 \mathrm{~m})=11,12 \mathrm{ce} \\
. \quad \%=0,12,\end{array}$ & 1,12 ce & - & $1 I I$. \\
\hline 60. & $\begin{array}{l}\text { Apia. } \\
\text { Alte Stelle. } \\
\text { schiffsbug. } \\
\text { Tiefe ca. } 15 \mathrm{~m} .\end{array}$ & $\begin{array}{l}\text { 29. October } 1894 \\
\text { (Tatg nach Nen- } \\
\text { mond) } \\
\text { soh a. m. } \\
\text { bei Ehbe. } \\
\text { nächstes Niedrig- } \\
\text { wassey } \\
\text { s h p. m. }\end{array}$ & $\begin{array}{l}\text { a. } 3 \cdot 10 \mathrm{~m}=0,14 \mathrm{ce} \\
\text { b. } . \quad . \quad=0,18, \\
\therefore \quad . \quad=0,18,\end{array}$ & $\begin{aligned} 1 \operatorname{chm}(10 \mathrm{~m}) & =0,33 \mathrm{cc} \\
. \quad & =0.4 \\
* & -0,4\end{aligned}$ & 11,38 ec & - & 111. \\
\hline 73. & $\begin{array}{l}\text { Pango-Pango. } \\
\text { Immenhafen. } \\
\text { Tiefe ca. } 35 \mathrm{~m} . \\
\text { Schitfsbmg. }\end{array}$ & \begin{tabular}{|} 
29. April 1895 \\
$1 \mathrm{~h} \mathrm{~T} . \mathrm{m}$. \\
hei Elhe. \\
naichstes Niedrig- \\
wasser \\
$4 \mathrm{~h}$ p. m.
\end{tabular} & 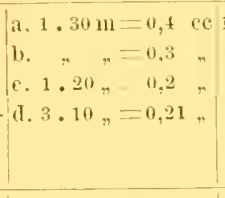 & $\begin{aligned} 1 \mathrm{chm}(30 \mathrm{~m}) & =0,97 \mathrm{ce} \\
" \quad " \quad & =0,73, \\
" \quad(20 \mathrm{~m}) & =0,73, \\
" \quad(10 \mathrm{~m}) & =0,5,\end{aligned}$ & 0,66 ec & - & III. \\
\hline 74. & \begin{tabular}{|} 
Pango-Pango. \\
An 3 verschie- \\
denen Stellen \\
im immersten \\
Hafen. \\
Im Boot.
\end{tabular} & \begin{tabular}{|} 
29. April 1895 \\
$2 \mathrm{~h} \mathrm{p}$ p. m. \\
bei Ebhe, \\
naichstes Niedrig- \\
wasser \\
$4 \mathrm{~h} \mathrm{p} . \mathrm{m}$.
\end{tabular} & $\begin{array}{l}\text { a. } 2.30 \mathrm{~m}=0,1 \mathrm{ce} \\
\text { b. . " }=0,1, \\
\text { e. } 2.20 "=0,3 .\end{array}$ & $\begin{aligned} 1 \mathrm{ehm}(10 \mathrm{~m}) & =0,31 \mathrm{ec} \\
" \quad(20 \mathrm{~m}) & =0.31 \mathrm{~m} \\
& =0,55\end{aligned}$ & $0,39 \mathrm{ec}$ & - & 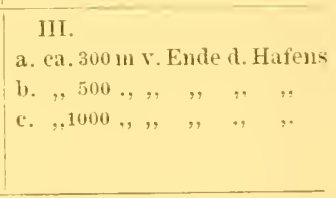 \\
\hline 75. & \begin{tabular}{|} 
Apia. \\
In der Einfahrt \\
zwischen den \\
Riffen. \\
Tipfe $13 \mathrm{~m}$.
\end{tabular} & \begin{tabular}{|} 
16. Mai 1695 \\
$10 \mathrm{~h}$ a. 11. \\
bei Fluth, \\
nächstes Hoch- \\
wasser \\
$12 \mathrm{~h} \mathrm{p.} \mathrm{m.}$
\end{tabular} & $\begin{array}{l}\text { a. } 3.10 \mathrm{~m}=0,28 \mathrm{cc} \\
\text { b. } \quad . \quad=0,2 \mathrm{~s} \\
\text { e. }, \quad=0,3 \quad\end{array}$ & $\left|\begin{array}{rl}1 \mathrm{cbm}(10 \mathrm{~m}) & =0,68 \mathrm{ce} \\
" \quad & =0,68 \% \\
" & "=0,73 \%\end{array}\right|$ & 0,7 се & - & $\begin{array}{l}\text { III. } \\
\text { Viele grosse Copeporlen und } \\
\text { Sagitten. }\end{array}$ \\
\hline \multirow[t]{2}{*}{76.} & \multirow[t]{2}{*}{$\begin{array}{l}\text { Apia. } \\
\text { schiffsbug. } \\
\text { Hafemmitte. }\end{array}$} & $\begin{array}{l}\text { 29. Mai } 1895 \\
\text { a und b } 10 \text { h a.m. } \\
\text { bei Hochwasser. }\end{array}$ & $\begin{array}{l}\text { a. } 3 \cdot 10 \mathrm{~m}=0,1 \mathrm{ec}^{\prime} \\
\text { b. } 2 \cdot 10_{r}=0,08\end{array}$ & $\mid \begin{array}{c}1 \mathrm{cbm}(10 \mathrm{~m})-0,25 \mathrm{cc} \\
", \quad-0,3 n\end{array}$ & $0,27 \mathrm{ec}$ & - & \multirow[t]{2}{*}{111.} \\
\hline & & $\begin{array}{c}\text { e mud d } 4 \text { h p. m. } \\
\text { bei Niedrig- } \\
\text { wasser. }\end{array}$ & $\begin{array}{l}\text { c. } 3.10 \mathrm{~m}=0,21 \mathrm{ce} \\
\text { i. . } . \quad,=0,18 \text {, }\end{array}$ & $\begin{aligned} 1 \operatorname{cbm}(101 \mathrm{1n}) & =0,5 \quad, \\
" \quad & =0,45 \%\end{aligned}$ & $0,47 \mathrm{ec}$ & - & \\
\hline 77. & $\begin{array}{c}\text { Apia. } \\
\text { Im Boot. } \\
\text { An der Einfalnt. }\end{array}$ & \begin{tabular}{|c|} 
5. Juni 1895 \\
$10 \mathrm{~h} \mathrm{a} . \mathrm{m}$. \\
hei Niedrig- \\
Wasser.
\end{tabular} & $\begin{array}{l}\text { a. } 3.10 \mathrm{~m}-0,32 \mathrm{ec} \\
\text { h. }, \quad-0,3 \quad \text { \% } \\
\text { e. } 4.10_{-}=0,4 \quad \text {. }\end{array}$ & 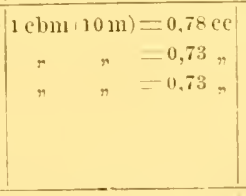 & 0,75 ce & $\begin{array}{l}13500 \\
80 \% \\
\text { Cop. }\end{array}$ & $\begin{array}{l}\text { III. } \\
\text { Leber die Hilfte der Cope- } \\
\text { loden macht Githona ans. } \\
\text { Sonst (ilobigerinen, Anpen- } \\
\text { dicularitn. Radiolarien. } \\
\text { Diatomeen etc. }\end{array}$ \\
\hline 78. & $\begin{array}{l}\text { Apia. } \\
\text { Ebenso. }\end{array}$ & $\begin{array}{c}\text { 5. Juni } 1 \times 95 \\
\text { th P. m. } \\
\text { bei Hochwasser. }\end{array}$ & a. $3.10 \mathrm{~m}=0,25 \mathrm{ec}$ & $1 \mathrm{cbm}(10 \mathrm{~m})=0,6 \mathrm{ce}$ & $0,6 \mathrm{ce}$ & - & III. \\
\hline
\end{tabular}


Tabelle B. Centrifugirte Nichtsamoanische Küstenplanktonfänge aus den Tropen.

\begin{tabular}{|c|c|c|c|c|c|}
\hline 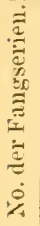 & $\begin{array}{l}\text { Ort, } \\
\text { Fangstelle und Tiefe } \\
\text { derselben. } \\
\text { Fang vom Schifle oder } \\
\text { vom Boote. }\end{array}$ & $\begin{array}{l}\text { Datum, } \\
\text { Tageszeit. }\end{array}$ & $\begin{array}{l}\text { Zahl und Tiefe der } \\
\text { Fänge, } \\
\text { richtige Plankton- } \\
\text { menge zweinal } \\
\text { centrifugirt. }\end{array}$ & $\begin{array}{l}\text { Planktomnenge } \\
\text { auf } 1 \text { cbm } \\
\text { Seewasser nm- } \\
\text { gerechnet. }\end{array}$ & Bemerkunge $u$. \\
\hline 71. & \begin{tabular}{|} 
Suva. \\
Titi-lnseln. Der Innen- \\
hafen, woselbst die \\
Fïnge gemacht wurden, \\
ist durch Korallemiffe \\
ganz vom Meer ab- \\
geschlossen. Schiffsbug. \\
Tiefe ca. $14 \mathrm{~m}$.
\end{tabular} & 19. April 1895. & $\begin{array}{l}\text { a. } 3.10 \mathrm{~m}=0,2 \mathrm{ce} \\
\text { b. } ",=0,2 n\end{array}$ & $\begin{array}{c}1 \operatorname{clnm}(10 \mathrm{~m})=0,5 \mathrm{ce} \\
" \quad=0,5 \quad "\end{array}$ & Durchschnitt 0,5 ce. \\
\hline 72. & Suva. & $\begin{array}{l}\text { 21. April } 1 \times 95 \\
7 \text { h a. m. }\end{array}$ & $\left|\begin{array}{l}\text { a. } 3 \cdot 10 \mathrm{~m}=0,14 \mathrm{cc} \\
\text { b. } 1.10 "=0,07 n \\
\text { c. } ",=0,03 n\end{array}\right|$ & 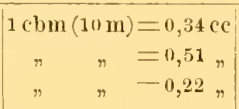 & $\begin{array}{l}\text { Durchschnitt } 0,35 \mathrm{cc} \text {. } \\
\text { Aus b ein grosser Sagitte ent- } \\
\text { fernt. }\end{array}$ \\
\hline 79. & \begin{tabular}{|} 
Aten. \\
Arabien. Anf der Rhente. \\
Tiefe ca. $10 \mathrm{~m}$.
\end{tabular} & $\begin{array}{l}\text { 29. Juli } 1895 \\
11 \text { h a. m. }\end{array}$ & $\begin{array}{l}\text { a. } 3 \cdot 8 \mathrm{~m}=0,3 \text { ce } \\
\text { b. } 2 \cdot 8 n=0,25 n\end{array}$ & $\begin{array}{c}1 \cdot \operatorname{chm}(8 \mathrm{~m})=0,9 \mathrm{ce} \\
" \quad "=1,1 \%\end{array}$ & Tiel sand im Wasser. \\
\hline \multirow[t]{2}{*}{ 80. } & \multirow{2}{*}{$\begin{array}{c}\text { Suez. } \\
\text { Im rothen Meere. } \\
\text { Tiefe ca. } 11 \mathrm{~m} \text {. }\end{array}$} & \multirow[t]{2}{*}{ 2. August 1895.} & \multirow[t]{2}{*}{$4.8 \mathrm{~m}=0,2 \mathrm{ce}$} & \multirow[t]{2}{*}{$1 \mathrm{cbm}(8 \mathrm{~m})=0,46 \mathrm{cc}$} & \\
\hline & & & & & $\begin{array}{l}\text { Insgesammt: } \\
20 \text { Fänge mit durchschmittlich } \\
0,57 \mathrm{ce} \text {. }\end{array}$ \\
\hline
\end{tabular}

Tabelle C. Scefänge.

\begin{tabular}{|c|c|c|c|c|c|}
\hline 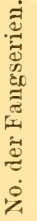 & $\begin{array}{l}\text { Ort, } \\
\text { Fangstelle und Tiefe } \\
\text { derselben. } \\
\text { Fang vom Schiffe. }\end{array}$ & $\begin{array}{l}\text { Datum, } \\
\text { Tageszeit. }\end{array}$ & $\begin{array}{c}\text { Zahl und Tiefe der } \\
\text { Fänge, } \\
\text { richtige PIankton- } \\
\text { menge zweimal } \\
\text { centrifugirt. }\end{array}$ & $\begin{array}{l}\text { Planktonmenge } \\
\text { anf } 1 \mathrm{cbm} \\
\text { Seewasser mm- } \\
\text { gerechnet. }\end{array}$ & Bemerkungen. \\
\hline 29 & $\begin{array}{c}\text { Bay of Plenty. } \\
\text { Am Ostkap der Nord- } \\
\text { insel von Neu-Seeland. } \\
\text { Tiefe ca. } 200 \mathrm{~m} \text {. }\end{array}$ & 16. Мärz 1894. & $\begin{array}{l}\text { a. } 1 \cdot 40 \mathrm{~m}-0,15 \mathrm{cc} \\
\text { b. } 1 \cdot 10,=0,05 \% \\
\text { c. " " }=0,05 "\end{array}$ & $\left|\begin{array}{rl}1 \mathrm{cbm}(40 \mathrm{~m}) & =0,24 \mathrm{ce} \\
" \quad(10 \mathrm{~m}) & =0,32 \\
" \quad & =0,32 "\end{array}\right|$ & \\
\hline \multirow[t]{2}{*}{30.} & $\begin{array}{l}\text { Castle Point. } \\
\text { ca. } 60 \mathrm{Sm} \text {. ab von der } \\
\text { Nordinsel ron N. Z. }\end{array}$ & 17. März 1894. & $\begin{array}{l}\text { a. } 1 \cdot 20 \mathrm{~m}=0,15 \mathrm{cc} \\
\text { b. } " n=0,1 \quad " \quad n=0,35 " \\
\text { c. } 1 \cdot 100 \mathrm{~m}=0\end{array}$ & $\begin{aligned} 1 \mathrm{cbm}(20 \mathrm{~m}) & =0,49 \mathrm{cc} \\
" \quad & =0,32 " \\
"(100 \mathrm{~m}) & =0,24 "\end{aligned}$ & \\
\hline & $\begin{array}{l}\text { Blenheim. } \\
\text { Cookstrasse. Nell- } \\
\text { Seeland. }\end{array}$ & 14. Fehruar 1895. & $1.30 \mathrm{~m}=0,05 \mathrm{ce}$ & $1 \mathrm{cbm}(30 \mathrm{~m})-0,1 \mathrm{co}$ & \\
\hline \multirow[t]{2}{*}{69.} & \multirow[t]{2}{*}{$\begin{array}{l}\text { Sydney. } \\
\text { ca. } 15 \mathrm{Sm} . \mathrm{ab} \text {. }\end{array}$} & \multirow[t]{2}{*}{$\begin{array}{l}\text { 4. April } 1895 \\
4 \mathrm{~h} \mathrm{p.} \mathrm{m.}\end{array}$} & \multirow{2}{*}{ 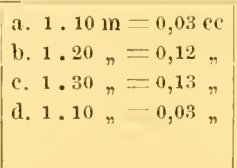 } & \multirow{2}{*}{$\mid \begin{array}{r}1 \text { cbm }(10 \mathrm{ml}) \quad 0,2 \mathrm{cc} \\
" \quad(20 \mathrm{~m})=0,44, \\
" \quad(30 \mathrm{~m})=0,32, \\
" \quad(10 \mathrm{~m})-0,2,\end{array}$} & \\
\hline & & & & & $\begin{array}{l}\text { Insgesammt: } \\
11 \text { Fänge mit durehsehnittlich } \\
0,29 \text { ce. }\end{array}$ \\
\hline
\end{tabular}


Tabelle D. Centrifugirte Küstenplanktonfänge aus Neu-Secland (N. \%o) und NenSüidwales (N.S. II.)

\begin{tabular}{|c|c|c|c|c|c|}
\hline 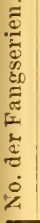 & $\begin{array}{c}\text { Ort, } \\
\text { Fangstelle und Tiefe } \\
\text { derselben. } \\
\text { Fang vom Schilf oder } \\
\text { Boote. }\end{array}$ & $\begin{array}{l}\text { Diatum, } \\
\text { Zuit des Fanges. }\end{array}$ & $\mid \begin{array}{c}\text { Zalll mol Tiefe der } \\
\text { Fünge, } \\
\text { riehtige Plankton- } \\
\text { menge des Fanges } \\
\text { zweimal } \\
\text { rentrifugirt. }\end{array}$ & $\begin{array}{l}\text { Planktomnenge } \\
\text { anf } 1 \text { cbu } \\
\text { Seewasser um- } \\
\text { gerechnet. }\end{array}$ & 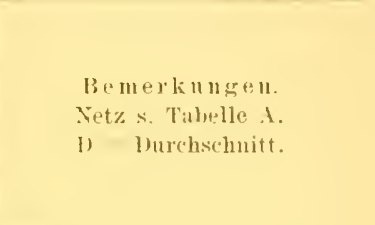 \\
\hline .3 & $\begin{array}{c}\text { Auckland } \mathrm{x} . \% . \\
\text { Norlinsel. } \\
\text { Waitemata-Inmenlafen. } \\
\text { Tiefe cea } 14 \text { m. } \\
\text { Schiftsong. }\end{array}$ & $\begin{array}{l}\text { 10. Januar } 1 \text { s94 } \\
9 \text { h } 30^{\prime} \text { a. in } \\
\text { bei llochwasser. }\end{array}$ & $3.111 \mathrm{~m}=0,25 \mathrm{ec}$ & $1 \mathrm{chm}(10 \mathrm{~m})-0,5 \mathrm{sec}$ & $\begin{array}{l}\text { Xetz No. 111. } \\
\text { ('opepoilen, l)iatomeen, Latren, } \\
\text { (ilobigerinen. } \\
\text { 1) - } 11,55 \text { ce. }\end{array}$ \\
\hline 4. & $\begin{array}{c}\text { Ancklaud N. Z. } \\
\text { Waitemata-1laten. } \\
\text { Ebenso. }\end{array}$ & $\begin{array}{l}\text { 12. Januar } 1 \text { sit } \\
11 \text { h } 30 \text { f a. m1 } \\
\text { bei } 11 \text { ochwasser. }\end{array}$ & $2.10 \mathrm{111}=$ ? & & $\begin{array}{l}\text { Windstälie } 7 . \\
\text { Der Fung war so schmutzicr, dass } \\
\text { eine Jlessung nicht möglich war. }\end{array}$ \\
\hline 5. & Aucklaud. & 13. .Іапиау 1894. & $3.10 \mathrm{~m}=1, \pm \mathrm{ce}$ & $|1 \mathrm{cbm}(10 \mathrm{~m})=3.0 \mathrm{ec}|$ & Windstirke $7 . \quad \mathrm{D}-3,11 \mathrm{ce}$. \\
\hline 6. & Auckland. & 14. Januar 1894. & $3.10 \mathrm{~m}=0.5 \mathrm{ec}$ & $1 \mathrm{cbu}(10 \mathrm{~m})=1,1 \mathrm{co} \mid$ & Wind $3-4 . \quad 1)=1,1 \mathrm{cc}$ \\
\hline 7. & Auckland. & 15. Januar $1 \times 94$. & $3.111 \mathrm{~m}=0,5 \mathrm{ec}$ & $\mid 1(\mathrm{l}) \mathrm{m}(1 \mathrm{l}(\mathrm{m})=1,1 \cdot \mathrm{e} \mid$ & D $1,1 \mathrm{ee.}$ \\
\hline 8. & Anckland. & 17. Januar 1×94. & Wegen viel Sulumut & atz nicht gemessen. | & Viel Wint. \\
\hline 9.) & Ancklaud. & 19. Januar Is94. & $3.10 \mathrm{~m}=0,35 \cdot \mathrm{c} \quad \mathrm{i}$ & $1 \mathrm{chm}(\mathrm{I} 0 \mathrm{~m})=0,75 \mathrm{ce}$ & Ruhig. 1) $=0,75$ ce. \\
\hline 10.) & lucklaud. & 20. Januar $1 \times 94$. & $3.10 \mathrm{~m}=11,6 \mathrm{ce}$ & $1 \mathrm{cbm}(10 \mathrm{~m})=1,3 \mathrm{ec}$ & $\mathrm{D}=1,3$ ie. \\
\hline 11. & Auckland. & $\begin{array}{l}\text { 31. . Tannar } 1894 \\
\text { bei Hochwasser }\end{array}$ & $3.10 \mathrm{~m}=1,1 \mathrm{ce}$ & $1 \mathrm{cbm}(10 \mathrm{~m})=2,4 \mathrm{ee}$ & $D=-2,+4 c$ \\
\hline 12. & Auckland. & $\begin{array}{c}\text { Dasselbe Dat. } \\
\text { bei Niedrigwasser. }\end{array}$ & $3.10 \mathrm{~m}=0,9 \mathrm{ce}$ & $1 \mathrm{cbm}(10 \mathrm{mi})=2,0 \mathrm{ce}$ & $1)=2,0$ ce. \\
\hline 13. & $\begin{array}{c}\text { Auckland. } \\
\text { Andere Aukerstelle. } \\
\text { Tiefe ca. } 20 \mathrm{~m} \text {. }\end{array}$ & 6. Februar 1894. & $\left|\begin{array}{l}\text { a. } 1.10 \mathrm{~m}=0,4 \text { ce } \\
\text { b. }, ", \quad,=0,4 \quad, \\
\text { e. } 2.10 \mathrm{~m}=0,+ \text { ce }\end{array}\right|$ & $\mid \begin{array}{c}1 \operatorname{clmm}(10 \mathrm{~m})=2,6 \mathrm{ce} \\
, \quad, \quad=2,6, ", \\
., \quad, \quad=2,6, "\end{array}$ & $\mathrm{D}=2,6$ ce. \\
\hline 14. & $\begin{array}{c}\text { Hauraki Golf } \mathrm{X} . \mathrm{Z} . \\
\text { Aussenhafen } \\
\text { von Anckland. } \\
\text { In der Tofino-Bay. } \\
\text { Tiefe ca. } 10 \mathrm{~m} \text {. } \\
\text { Sehiffsbug. }\end{array}$ & 27. Februar 1894 & 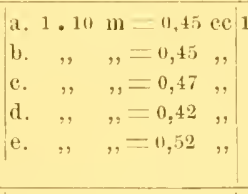 & 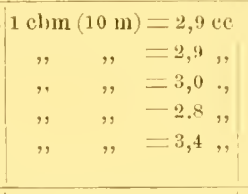 & $\begin{array}{l}1 \text { chn }-3,0 \text { ce }=\text { ca. } 500000 \\
\text { Individuen. } \\
\text { Alpendicularien, Radiolarien, } \\
\text { Diatomeen, Copepoden, liota- } \\
\text { torien, Evadue, Podon, Penilia. }\end{array}$ \\
\hline 15. & $\begin{array}{l}\text { Tofiuo-Bay. } \\
\text { Selber Platz. }\end{array}$ & $\begin{array}{l}\text { 28. Fehruar } 1894 \\
\text { a. } 9 \mathrm{~h} \text { a. m bei Fluth, } \\
\text { b. } 4 \mathrm{~h} \text { \%. } \mathrm{m} \text { bei Ehbe. }\end{array}$ & $\left|\begin{array}{l}\text { a. } 3 \cdot 10 \mathrm{~m}=0,6 \mathrm{ce} \\
\text { b. } 3 \cdot 10 \mathrm{~m}=0,9 \mathrm{ce}\end{array}\right|$ & $\begin{array}{c}1 \mathrm{cbm}(10 \mathrm{~m})=1,3 \mathrm{cc} \\
, \quad, \quad=2,0, ",\end{array}$ & $\mathrm{D}-1,65 \mathrm{ce}$ \\
\hline 16. & Tofluo-Bay. & 1. März 1894. & $3.10 \mathrm{~m}=0,6 \mathrm{cc}$ & $|1 \mathrm{cbm}(10 \mathrm{~m})=1,3 \mathrm{ce}|$ & $11 \ldots 1,3 \mathrm{ec}$. \\
\hline 17. & Iueklaul. & 5. März 1894. & $3.10 \mathrm{~m}=0,5 \mathrm{ce}$ & $1 \mathrm{com}(10 \mathrm{~m})=1,1 \mathrm{cc}$ & $11 \quad 1,1 \mathrm{ce}$ \\
\hline 18. & $\begin{array}{l}\text { Hauraki-fiolf X. Z. } \\
\text { Bei der Insel Motuhu- } \\
\text { rakia. Tiefe ca. } 40 \mathrm{~m} \text {. }\end{array}$ & 6. März 1894 & $3.10 \mathrm{~m}=0, \pi \mathrm{ce}$ & $1 \mathrm{ebln}(10 \mathrm{~m})=1,5 \mathrm{cc}$ & $\mathrm{D}-1,5 \mathrm{ce}$ \\
\hline 19. & Selber Platz. & Selbes Datum. & $3.30 \mathrm{~m}=1,6 \mathrm{cc}$ & $1 \mathrm{ebm}(30 \mathrm{~m})-1,15 \mathrm{ce}$ & $\begin{array}{l}\text { Einige Polypomedusen vor dem } \\
\text { Centritugiren entfernt. } \\
\text { D-1,15 ce. }\end{array}$ \\
\hline 20. & , & ," & $3.25 \mathrm{~m}-1,3 \mathrm{ce}$ & $1 \mathrm{clom}(25 \mathrm{~m})=1,12 \mathrm{ce}$ & $\begin{array}{l}\text { Ehenso. } \\
1 \text { cbm = } 1,12 \text { ce }=146,000 \text { Ind. } \\
7 \% \text { Copepoden. } \\
87 \% \text { Diatomeen. }\end{array}$ \\
\hline 21. &, & 7. März 1894. & $3.30 \mathrm{~m}-1,3 \mathrm{ec}$ & $1 \mathrm{cbm}(30 \mathrm{~m})-0,95 \mathrm{cc} \mid$ & $\begin{array}{l}1 \text { cbu }=0,95 \text { ce }=6300 n \text { 1nd. } \\
11^{n !}: \text { Copepoden. } \\
80 \% \text { biatomeen. }\end{array}$ \\
\hline 22. & \begin{tabular}{|c} 
Ilauraki-(iolf. \\
Mitten zwischen Tiri- \\
Tiri und Loromaudel. \\
Tiete 50-100 m.
\end{tabular} & 7. März 1894. & $2.10 \mathrm{~m}=0,5 \mathrm{cc}$ & $1 \mathrm{cbm}(10 \mathrm{~m})=1,6 \mathrm{ce}$ & 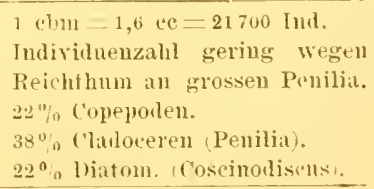 \\
\hline
\end{tabular}




\begin{tabular}{|c|c|c|c|c|c|}
\hline 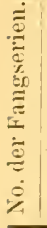 & $\begin{array}{l}\text { Ort, } \\
\text { Fangstelle mul Tiefe } \\
\text { derselben. } \\
\text { Fang vom Schiffe orler } \\
\text { vom Boote. }\end{array}$ & $\begin{array}{l}\text { Datum, } \\
\text { Zeit des Fanges. }\end{array}$ & $\begin{array}{l}\text { Zahl mu Tiefe der } \\
\text { Fänge, } \\
\text { richtige Plankton- } \\
\text { menge zweinal } \\
\text { centrifurirt. }\end{array}$ & $\begin{array}{l}\text { Planktommenge } \\
\text { auf' } 1 \mathrm{chm} \\
\text { Seewasser mu- } \\
\text { gerechuet. }\end{array}$ & $\begin{array}{l}\text { Bemerkugen. } \\
\text { Netz s. Tabelle A. } \\
\text { 1) = Inrchschnitt. }\end{array}$ \\
\hline 23.1 & $\begin{array}{l}\text { Tofino-Bay. } \\
\text { lin Haurali-(rolt, N. Z. }\end{array}$ & 8. Ḧ̈rz 1894. & $\begin{array}{l}\text { a. } 1.15 \mathrm{~m}=0,5 \mathrm{ce} \\
\text { b. }, "=0,5, \\
\text { c. }, "=0, \$,\end{array}$ & $\begin{array}{rl}1(\operatorname{chm}(15 \mathrm{~m}) & =2,0 \mathrm{ce} \\
" \quad " & 2,0 \% \\
. \quad & =3,4 "\end{array}$ & 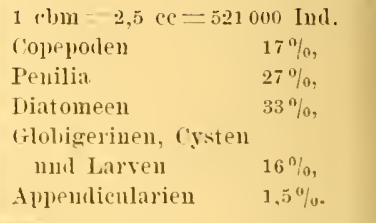 \\
\hline 24. & Tofino-Bay. & 9. März 1894. & $\begin{array}{l}\text { a. } 1.15 \mathrm{~m}=0,3 \quad \text { ce } \\
\text { b. } ", \quad "=0,3 \quad . \\
\text { c. } ", \quad "-0,45 \quad "\end{array}$ & $\begin{aligned} 1 \mathrm{cbm}(15 \mathrm{ml}) & =1,3 \mathrm{cc} \\
" \quad " & =1,3 \mathrm{n} \\
" & =2.0 "\end{aligned}$ & $\mathrm{D}=1.5 \mathrm{ec}$ \\
\hline 25. & Aucklund. & 14. Yärz 1894. & $1.10 \mathrm{~m}=0,9 \mathrm{cc}$ & $1(\mathrm{cl}) \mathrm{m}(10 \mathrm{nI})=5, \mathrm{xcc}$ & $\begin{array}{l}1 \text { clm }=5,8 \text { cc }=298000 \text { Ind. } \\
\text { Colepolen } 28 \% \\
\text { Iiatomeen } 50 \% \\
\text { Cladoceren } 2,5 \%\end{array}$ \\
\hline 26. & Iucklaud. & 15. Мäız 1894. & $1.10 \mathrm{ml}=0.7 \mathrm{ce}$ & $1 \mathrm{cbm}(10 \mathrm{~m})=4,5 \mathrm{ce}$ & $\mathrm{D}=4,5 \mathrm{ce}$ \\
\hline 27. & $\begin{array}{l}\text { IIauraki-fiolf. } \\
\text { Bei ller Insel llotn- } \\
\text { hurakia. } \\
\text { Tiefe ca. } 40 \mathrm{~m} \text {. }\end{array}$ & 15. Мä1'z 1894. & $1.40 \mathrm{~m}=0, \mathrm{ncc}$ & $1 \mathrm{ebm}(40 \mathrm{~m})=1,3 \mathrm{ec}$ & $1)=1,3 \mathrm{ce}$ \\
\hline 31. & $\begin{array}{c}\text { Port Jackson, N.S. W. } \\
\text { Hafen ron Sylney. } \\
\text { lumen in Farn-cove. } \\
\text { Schiffsbug. }\end{array}$ & Anfang April 1894. & $\left|\begin{array}{l}\text { a. } 1,10 \mathrm{~m}=0,6 \text { ce } \\
\text { b. }, \quad,=1,3 \mathrm{cc}\end{array}\right|$ & $\begin{array}{c}1 \mathrm{cbm}(10 \mathrm{~m})=4,0 \mathrm{ce} \\
" \quad=8,5 \%\end{array}$ & $1)=6,2$ (ce. \\
\hline \multirow{2}{*}{32.} & \multirow{2}{*}{$\begin{array}{l}\text { Jervis-Lay. } \\
70 \text { sur. siidlich von Port } \\
\text { Jackson. Grosse Bucht. } \\
\text { Schiftsbur. } \\
\text { Tiefe ca. } 20 \text { m. }\end{array}$} & $\begin{array}{l}\text { 24. April } 1894 . \\
\text { a, b, c sülliche } \\
\text { Anlierstelle, }\end{array}$ & 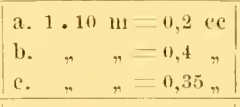 & $\left|\begin{array}{r}1 \mathrm{clom}(10 \mathrm{~m})=1,3(\mathrm{ce} \\
" \quad+2,6 \mathrm{n} \\
", \quad=2,3 n\end{array}\right|$ & $\mathrm{D}=2,1 \mathrm{c} \cdot \mathrm{c}$ \\
\hline & & $\begin{array}{l}\text { d, e. f nörlliche } \\
\text { Ankerstelle, } \\
\text { ca. } 5 \text { sn. entfernt. }\end{array}$ & $\begin{array}{l}\text { d. } 1.10 \mathrm{~m}=0,25 \mathrm{cc} \\
\text { e. } \quad, \quad \Rightarrow=0,2 \quad " \\
\text { t. } \quad,=0,1 \quad \%\end{array}$ & 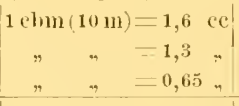 & $\mathrm{D}-1,2 \mathrm{ec}$. \\
\hline . & $\begin{array}{c}\text { Port-Jacksom. } \\
\text { Querab vom Farm-Cove, } \\
\text { mitten in strom. } \\
\text { N. S. W. }\end{array}$ & $\begin{array}{l}\text { 1. Hai 18nt. } \\
\text { Vormittags. }\end{array}$ & 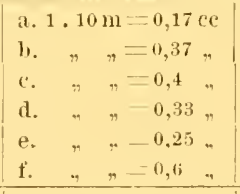 & 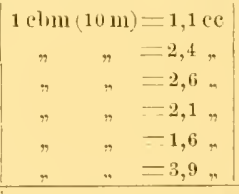 & $\begin{array}{l}\text { Netz No. IlI. } \\
\text { Nahezu die Halfte der Finge ist } \\
\text { bedingt durch eine liatomee } \\
\text { (Asterionella). } \\
\text { D-2,3 ce. }\end{array}$ \\
\hline 61. & $\begin{array}{l}\text { Anekland, N. Z. } \\
\text { Waitemata. }\end{array}$ & $\begin{array}{l}\text { 12. Hecember } 1894 \\
1 \mathrm{~h} \mathrm{pr} \text {.m. } \\
\text { Niedrigwasser. }\end{array}$ & $\begin{array}{l}\text { a. } 1 \text {. } 10 \mathrm{~m}=0,21 \mathrm{ce} \\
\text { b. } \quad " \quad n=0,2 \quad " \\
\text { c. }, \quad "=0,2 \quad "\end{array}$ & $\begin{aligned} 1 \mathrm{chm}(10 \mathrm{~m}) & =1,36 \mathrm{ce} \\
" \quad & =1,3 \ldots \\
" \quad & =1,3 .\end{aligned}$ & 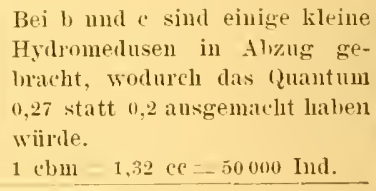 \\
\hline 6la & $\begin{array}{c}\text { Auckland, X.Z. } \\
\text { Northshore von der } \\
\text { Holzpier des ('alliope- } \\
\text { Docks. }\end{array}$ & Mitte Januar 1895. & $1.10 \mathrm{~m}=0,2 \mathrm{cc}$ & $1 \operatorname{com}(10 \mathrm{~m})=1,3 \mathrm{cc}$ & $\begin{array}{l}\text { Demonstrationszug für einige } \\
\text { Zoologen Nen-Seelands mit un- } \\
\text { gefilner Voraussage des Quan- } \\
\text { tums mud der Bestanltheile des } \\
\text { Fanges. } \\
1)=1,3 \mathrm{ce} \text {. }\end{array}$ \\
\hline 62. & $\begin{array}{l}\text { Auckland, N. Z. } \\
\text { Auf' deu Strou. }\end{array}$ & $\begin{array}{l}\text { 12. Fehruar } 1895 \\
9 \text { h a. m. } \\
\text { hei Hochwasser. }\end{array}$ & 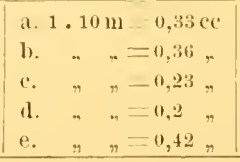 & 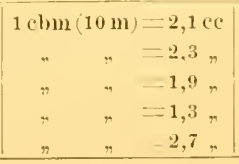 & $\begin{array}{l}1 \mathrm{chm}=2,06 \mathrm{ec}=300000 \text { Ind. } \\
90 \% \text { Diatomeen. } \\
4-5 \% \text { Copepoden. }\end{array}$ \\
\hline
\end{tabular}




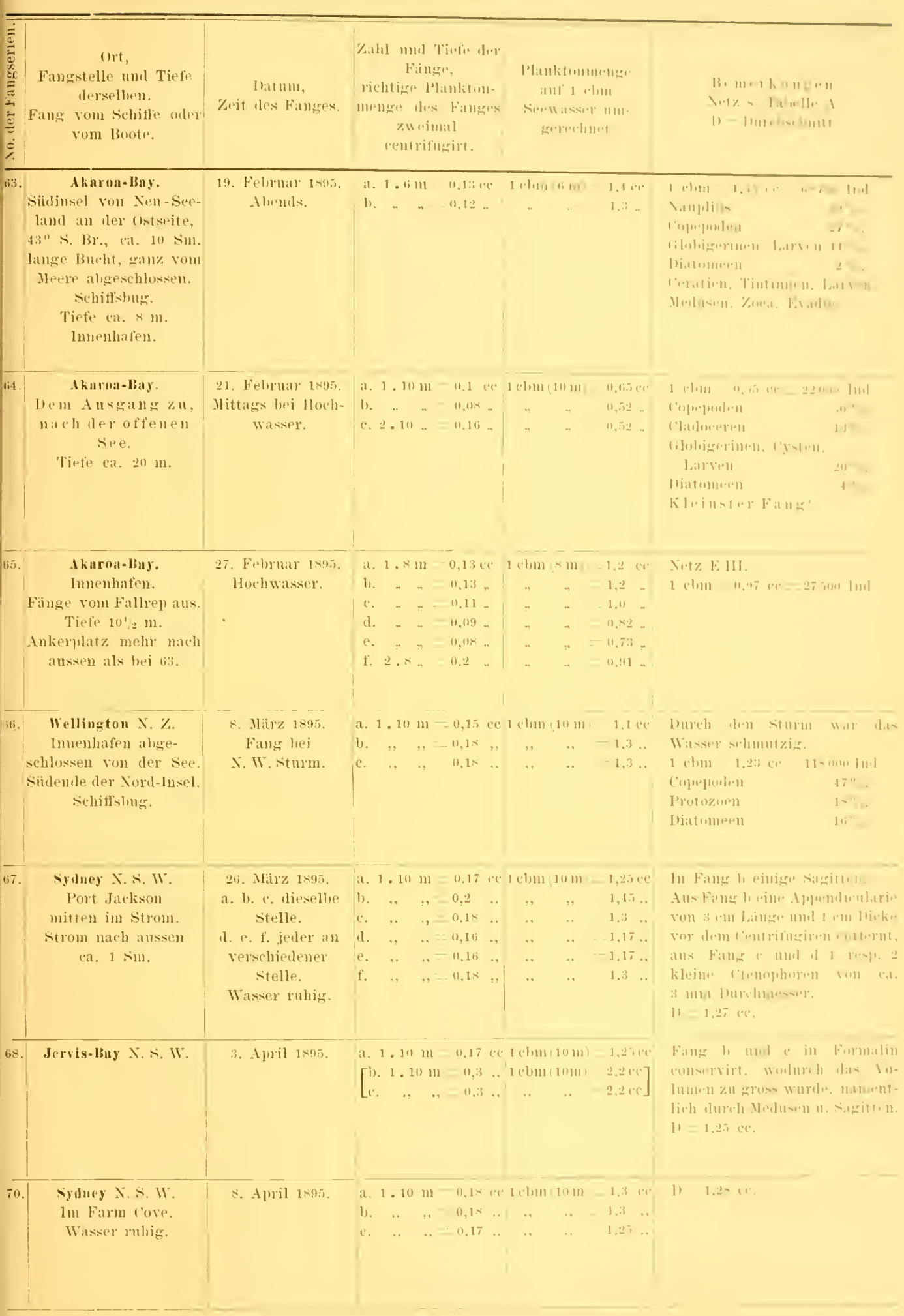


Tabelle E. Centrifugirte Süsswasserplanktonfänge aus Neu-Seeland.

\begin{tabular}{|c|c|c|c|c|c|}
\hline 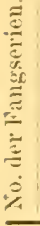 & $\begin{array}{c}\text { Ort, } \\
\text { Tiefe der Fangstelle. }\end{array}$ & 1)atmm. & $\begin{array}{l}\text { Zahl uml Ticfe der } \\
\text { Fänge, } \\
\text { richtige Plankton- } \\
\text { nenge. }\end{array}$ & $\begin{array}{l}\text { Auf I ebm } \\
\text { siisswasser lum- } \\
\text { gerechnete } \\
\text { Planktonmenge. }\end{array}$ & Bemerknngen. \\
\hline & \multirow{4}{*}{$\begin{array}{l}\text { Tahapuna-Ser. } \\
62 \text { m tiefer Kratersee, } \\
\text { in Meereshöhe gelegen } \\
\text { und kanm } 1 / 2 \text { kn vom } \\
\text { Meere getrennt, welehes } \\
\text { nur } 20 \text { m tief ist. } \\
\text { (Tofino-Bay.) } \\
\text { 1 Stmnde nördlich ron } \\
\text { Auckland. }\end{array}$} & Januar 1894. & $1.50 \mathrm{~m}=0,25 \mathrm{cc}$ & $1 \mathrm{clomn}(50 \mathrm{~m})=0,3 \mathrm{tec}$ & Netz No. II. 13,3 ec Jurehm. \\
\hline 2. & & Mitte März 1594. & $\begin{array}{l}\text { a. } 1.25 \mathrm{~m}=0.12 \mathrm{cc} \\
\text { b. } ., \quad . \quad=0,12, .\end{array}$ & $\left|\begin{array}{rl}1 \mathrm{chm}(25 \mathrm{~m}) & =0,35 \mathrm{cc} \\
., \quad . \quad & =0,35 \mathrm{cc}\end{array}\right|$ & \\
\hline 3. & & Mitte März 1894. & c. $1.50 \mathrm{~m}=0,25 \mathrm{cc}$ & $1 \mathrm{chm}(50 \mathrm{~m})=0,36 \mathrm{cc}$ & \\
\hline 4. & & Mitte März 1894. & d. $1.50 \mathrm{~m}-0,2$ ce & $1 \mathrm{cbun}(50 \mathrm{~m})=0,29 \mathrm{cc}$ & \\
\hline$\diamond$ & \begin{tabular}{|c|} 
Rotorua-see. \\
Nordinsel. \\
$10-25 \mathrm{~m}$ tief, \\
$7-8 \mathrm{~km}$ breit.
\end{tabular} & $\begin{array}{l}\text { l)ecember } 1894 . \\
\text { a. in östlich. Theil, } \\
\text { b. "westlich. " } \\
\text { c. " } " ~\end{array}$ & $\left\{\begin{array}{l}\text { a. } 1.10 \mathrm{~m}-0,05 \mathrm{cc} \\
\text { b. } 1,20 \mathrm{~m}=0,95,, \\
\text { c. }, ",=0,9, "\end{array}\right.$ & $\mid \begin{array}{r}1 \mathrm{cbm}(10 \mathrm{~m})=4,7 \mathrm{cc} \\
, \quad(20 \mathrm{~m})=3,4,, \\
,, \quad=3,25,,\end{array}$ & $\begin{array}{l}\text { Die nahezu } 10 \text { mal grössere } \\
\text { Mlenge den andern Seen gegen- } \\
\text { ibler ist hier mm so merkwir- } \\
\text { diger, als in den See die Ab- } \\
\text { wässer zahlreicher Geyser, } \\
\text { Schwefel- und Alaunquellen etc. } \\
\text { minden. }\end{array}$ \\
\hline 10. & \begin{tabular}{|} 
Taupo-see. \\
lin Herzen der Noril- \\
insel. \\
$25 \mathrm{~km}$ lang und iiber \\
$150 \mathrm{~m}$ tief.
\end{tabular} & $\begin{array}{l}\text { Januar } 1895 . \\
\text { An } 3 \text { verschiedenen. } \\
\text { nahe bei einander } \\
\text { gelegenen stellen. }\end{array}$ & $\mid \begin{array}{l}\text { a. } 1 \cdot 24 \mathrm{~m}=0,15 \mathrm{cc} \\
\text { b. } 1 \cdot 30 \mathrm{~m}=0,15, \\
\text { c. } 1 \cdot 30 \mathrm{~m}=0,1, "\end{array}$ & $\mid \begin{array}{r}1 \mathrm{cbm}(24 \mathrm{ju})=0,45 \mathrm{cc} \\
, \quad(30 \mathrm{~m})=0,36,, \\
, \quad, \quad=0,24,\end{array}$ & \\
\hline 12. & Takapuna-See. & Februar 1895. & $\begin{array}{l}\text { a. } 1.50 \mathrm{~m}=0,38 \mathrm{cc} \\
\text { b. }, ",=0,3,, \\
\text { c. }, ",=0,32,,\end{array}$ & $\mid \begin{array}{r}1 \mathrm{cbm}(50 \mathrm{~m})-0.55 \mathrm{ce} \\
,, \quad, \quad=0,43 ., \\
, ", \quad\end{array}$ & \\
\hline
\end{tabular}

\section{Berücksichtigte Literatur.}

(Die nit * bezeichneten Arbeiten sind nur ans Berichten bekannt; specielleres siche in den einzelnen Capiteln.)

\section{a. Korallenriffe, Geologie, Ocennographie etc.}

*1. Ehrenberg. a) Abhandl. der Berl. Acad. đ. W. 1831 ,Die Korallenthiere des rothen Ileeres.

b) Abhandl: der Berl. Acad. d. W. 1832 „Ueber die Natur und Bildung der Korallenriffe des rothen Ileeres".

2. Ch. Darwin. On the structure and distribution of coral reefs. (1842.) 3. Aufl. 1890. Ward, lock and Co.. London.

3. Dana. a) Report on Zoophytes of the Wilkes exploring expedition. Vol. VII. 1846.

b) Geological Ricport " $, \quad, \quad, \quad, \quad, 1849$.

c) Corals and Coral Islands. (1872.) 3. Antl. 1890.

d) Characteristies of Volcanoes with contribution of facts and principles of the Hawaiian Islands. 1890. New-York, Dodd, Mead \& Co.

* 4. Couthouy. Remarks on coral formation. Bost. Journ. Nat. Hist.

*5. Jukes. Narrative of the Toyage of H. M. S. "Fly“. 1847.

* 6. R. J. Nelson. Quart. Journ. Geolog. Soc. of London Vol. IX. 1853. "On the geology of the Biallamas and on Coral formations generally."

7. Weinland. Württ. naturw. Jahreshefte. XY'I. Bd. 1860. „Ueber Inselbildung durch Korallen und Mangrovebiische."

8. E. Ransonnet. lieise von Kairo nach Tor zu den Kiorallenbänken des rothen Mecres. Vorhandl. der k. k. zowl. bot. Gesellsch. Bd. Xlll. 1863. 


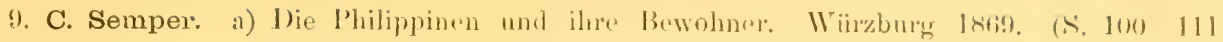

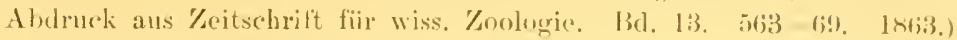

b) Die Palau-Inseln. 1873.

(c) Die natiirlichen Existenzbedingungen dro 'l'hicre. 1880).

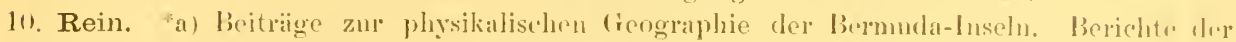
Senkenberg'sehen Naturl. (iesellseh, $186 !) 70$ P. 1 in.

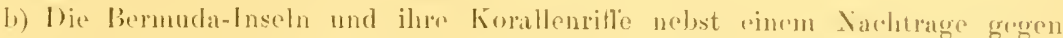
die Darwin'sche Sunkungstheorie. V'erhandhung. des 1. deutsch. (irographentages 1881 . \$. $29-41$.

11. Pourtalès. "Der Mreresboden des finllistrom's und del atlantischen Kiisten." l'etermann's gengr. Mitth. 1870.

12. Graeffe. a) . Reisen nach verschiedenen Insceln der Südsee.. Aushand 18tit. ..llanua Eruption."

b) .. Ricisen in der siidsee." Ausland 1 rici8.

c) Topographie der Schifferinseln. Journ. Mus. Gudefioy Hoft 1.

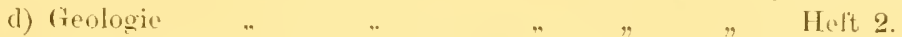

13. Balausa et Chambreyon. Bull. de la Soce (ióngr. Vol. V. 1873.

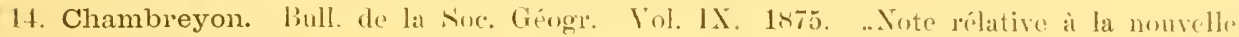
C'aléclonie."

15. E. Haeckel. Arabische liorallen. 18īi.

16. Rathbun. Brazilian ('urals and t'oral Reefs. Americ. Saturalist. Vol. XIII. 1879.

17. Klumzinger. a) Eine zoologische Excursion auf ein Korallenrift' des rothen Ileeress. Verhandl. der k. k. zool. bot. Gesellsch. 1870.

b) Dis 17 achsthum der Korallen insbesondere ihre Vermelirung durch $\mathrm{Ab}$ leger und ïber Wachsthumsstïrnngen. Wïrtt. natur. Jahreshefte 1880.

18. Jordan. .. Die Thenrieen iiber lie Entstehung der Korallenriffe." lBiolog. Centralblatt. 2. Band.

1\%. C. E. Meinicke. Die Inseln des Stillen (lecans. 1875.

20. K. Möbius. Beiträge zur Iteresfanna d(x Insel Mauritius und der Seychellen. 18si).

2l. John Murray. a) .On the structure and Origin of coral Reefs and Islands". Proc. of the Roy. Soce of Elinl,. Tol. X $1878-80$.

b) Coral Formations. Nature 1888. Vol. XXXYII. S. $414-15$.

2. - and Irvine. On coral reefs and other carlonnate of line formations in modern Seas. Proc of the Roy. sioe of Erinb. Tol. XVII. 1889.

23. - and A. Renard. Nomenclature. urigin and distribntion of Jeep Sea deposits. Proe. of the lioy. Stoe. of Edinb. Vol. XII. 1884.

24. H. B. Guppy. a) Notes on the characters and mode of formation of the coral reafs of the Silomon Islands. l'roc. of the Roy. Soc of Eitinb. Vol. XIII. 1itrij 86.

b) The Salomon Islands. their geology etc. 1887.

c) Coral formations. Tature März 188s. S. 462 11. 404. Vol. XXXVJ.

d) .Preliminary Note on Keeling Atoll*. Nature .Jan. 1889.

25. Studer, a) Verhandl. des 2. dentsel. Geograph.-Tages 18x2. S. 2325.

b) La formation coralienne dans les océans au point de rue géolngifue.

(c) l'ber Korallenriffe. 9. Iahresbericht der geogr. (res. Burn. 1888- - 9. S. 141).

„5d. P. Hoffmann. Wahrnehmungen an einigen Korallenriften dre siidsee. Verhandl. der fiesellschatt fïir Erdkunde. Bd. 1X. 188:.

26. A. Agassiz. a) The Tortugas and Florida Reefs. Jlem. of Amerie. Acad. Yol. NI. 1482.

b) Three cruises of the Blake. Boston 1886. Iände.

c) The coral Reefs of the Hawaiianislands. I3ull. of Itus. of. Comip. zool. Harvard. Vul. XVll. 188\%.

d) On the rate of growth of corals. Bull. of M[us. of. Comp. Zool. Harvard. Vol. XI. 1890. 
e) Cieneral sketch of the eruise of the ... Albatross" Fubr. til May 1891. Bull. of Mus. of ('mmp. Zoul. Harrard. Vol. XXIII. 18!2.

f) A reronnaisseance of the Bahamas and the elevated Reefs of cinba. Bull, of Mlus, of Cimp. Koul. Harrard. Vul. XXVT. 1894.

g) A visit to the Bermudas in March 18:4. Bull. of Mus. of. ('omp. Zool. Harvard. Vol. XXYI, 1896. No, 2.

27. A. Geikie. *a) Presidential Adress before the Royal Society of Eilinburgh. Proced. Vol. V'tlJ. 18x:3.

*b) Nilture 18x:3.

e) Text book of (ieology :3. Aufl. 189:3. p. 485492.

28. H. O. Forbes. A naturalist's wanderings in the eastem Archipelago. 1885. (Dentsche Vebersetzung.)

*29. O. Fintsch. Ein Besuch anf Diego Garcia in Indischen Ocean. Deutseh. gengr. B]ätter. Bremen 1887.

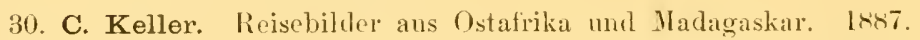

31. J. Walther. a) Die Korallemiffe der Sinaihalbinsel. 188x. Abhandl. der Math. plyys. kön. Sächs. Fesellsch.

b) Die Adamsbrücke und die Korallenrifie der Palkstrasse. Pertermann's gengr. Mitt. 1891. Ergänzmgsband XXII.

32. Wharton. a) ('oral Formations. Nature Febr. 1888 S. 391395.

*b) Masámarlu Isłand. Nature Ścpt. 1888.

33. Bourne. a) Coral Formations. Niture März 1888. \$. 114.

b) The atoll of Diego Garcia and the Coral formations of the Indian Ocean. Nature 1888. p. $546-550$.

34. Irvine. Coral Formations. Nature 1888. pp. 461, 509. 605.

35. Ross. Coral Formations. Nature März 1888. pp. 461 . 58t.

*36. Hickson. Themies of Coral Reefs and Atolls. Atless. Brit. Assoe. f. Adr of Seience 1n8r.

37. R. v. Lendenfeld. a) Leber Bourne's 1)iego (iareia liffbeschreibung. Natumiss. Rindschan. $188 x$.

b) Bemerkungen zu Inrays Theorie iiber den Bau der Korallenrifte. (ลäa 1890.

38. Sues. Das Antlitz (ler Erde. 1888.

39. v. Boguslawski und Krümmel, a) Handbueh der (lceanographie. 188x.

b) Krümmel, Bunerkungen iiber die Durchsichtigkeit des Meerwassers. Annalen der Hydrographice 1889.

40. C. Ph. Sluiter. Einiges äber die Entstehung der Korallenrifte in der Jara-See und Branntweinsbai und äber nene Corallenbildung leei Krakatau. Tatuntkund. Tijdsch. Nederl. Indie. 188?.

41. A. Heilprin. a) The Bermuda lslands a contribution to ete. with an examination of the structure of ('oral Reefs. Philat. Ts8?.

b) The corals and corral lieefs of the Western Waters of the Gulf of Mexico. Proc. Acal. Nat. Sce. Philadelphia. 1890.

42. R. Langenbeck. I) Theorieen iiber die Entstehmng der koralleninsehn und korallenriffe. Leipzig 1890.

43. Th. Fuchs. Ieber rinige Punkte in der physischen (ieographie des Meeres. Verhamll. der k. k. geologischen lieichisanstalt. 14x:2. (No.2)

44. Hüfner. leber die Farbe des Wassers. Archiv für Inat. nul Phys. 1891.

45. M. J. J. Lister. Totes on the Geolugy of the Tonga Islands. Quart. Journ. (ienlog. Sic. 1891 .

46. Jukes Browne and Harrison. The geology of Barbadoes. Quart. Journ. Cieolog. Sioe. 18.91.

47. Sollas and Cole. The origin of eertain marbles: asuggestion. Proe. Roy. Dublin Soe. 1891.

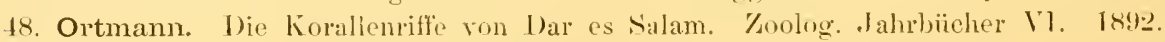

49. Saville Kent. The Great Barrier Reef of Australia, its produets and potentialities. Lonton 1893. 


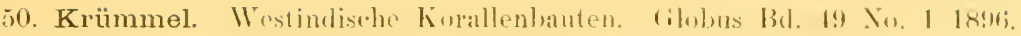

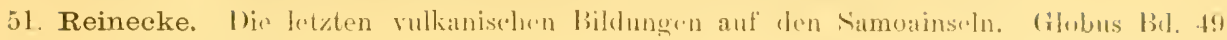
No. 17 18iti.

b. Ieluer Planktou. (nibleres heri Hensen und Ilacekel).

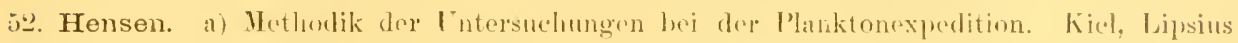
und Tischer. 18its.

b) Einge Ergebnisse ele l'anktonexperdition fler Humboldt-Stiltung. Sitzungs-

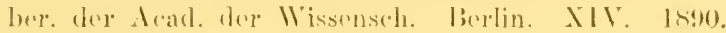

53. Haeckel. a) Pankitonstudien. Jena 18:40.

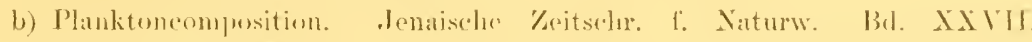
N. H. XX. 1r.

j4. K. Brandt. a) Ilacelols Insichten iiler die P'unlitonexpedition. Schrilt des naturw. Vereins tiir Sichles.-Holst. Bal. VIII. Helt 2.

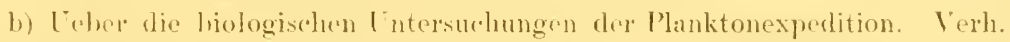
dex lieschlseh. I. Erelliunde. I)ece 1889.

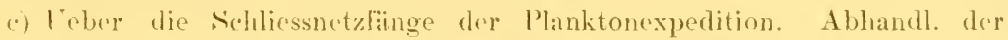
Velrinig. dentsch. Naturf. und Acrzte in libbeck 1895.

iv. Schütt. Inalytischo Planktonstudien. Kiel 18!2.2. (L. 11. T.)

5fi. Apstein. a) Das Plankton dos Süisswassers und seine puantitatior Bestimmung. Solnilt (ler naturw. Vir. f. šchll.-Holst. B(l. IX. Heft 2. 1892.

b) Quantitation Planktonstudion in Süsswasser. Bioleg. C'entralbl. Ba. XII. No. 16; 11. 17. 18 . 2 .

(:) Das Sïsswasserplanktun. 1696 ( ( . u. T.).

57. Dahl. a) llie horizontale und rertikale Verbreitung der l'opepoden im ()cean. Terh. dor doutsch. zool. liesellsch. 1894.

b) Die Verhortung freischwimmender Thiere im Ocean. Schr. des natur. Ver. l. S.hl.-Holst. Bil. X. 1895. \$̇. 28190.

5s. Giesbrecht. „1) Die pelagischen Copreoten. (Albatross 1891.) Bull. of the Wus. of ('omp. Zoology at Harve Cull. Tol. XXV. No. 12.

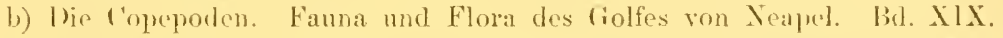

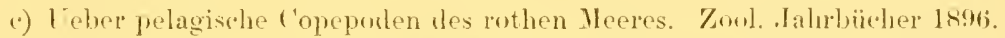

i!) Krämer. (In the most frequent pelagis: Copepodes and cladoceres of the Hauraki Gulf. Trans. of the New Kealand Inst. Vol. XXIII. 189t.

60. Aurivillius. Planktonundersokninger: Animalisk Plankton. Bihang til K. Sir. Vet.Acad. Handl. Hid. 201\%. 1894.

6il. Peck. The sources of marine fund. Bull. of the U. S. Fish. 'omm. for 18:15 S. 351 bis 368.

\section{Preisliste der Planktonmaterialien bei Ad. Zwickert, Optische Anstalt, Dänischestrasse 25, Kiel.}

1. Ein Planktonnetz (naclo Apstein) mit grossem Filtrator und extra Messingring (1/; $\square$ m) mit (raze No. 12 . . . . . . . . . . . . . . ca.

Ein Planktonnct\% (nach Apstein) mit grossem Filtrator und extra IIessingring ( $1 / \%,[\mathrm{~m})$ mit tiaze No. 20

2. Ein kleiner Filtrireiner mit Klemmring. .

3. Ein yn Seiden- (Mïller) ( Iaze No. 20

4: II. Hf.

4. Reisecentrilige.

․ Zähltisch (nach Zwickert) nebst zwei Zäilslplatton (u.s $11 . T^{1} \cdot 0$ mun) . . .

i. Eine Sitempelpipette nach Hensen (19.2 ec)

7. Ein Maasscylinder (100 (ec) .

8. \%wci Npritzenpipetten $\left(\frac{1}{3.0} \frac{1}{2} \cdot 10\right)$

4. Zehn Stïck C'entrifugimessgläser (à oo l't.).

10. Vejpackungsschachtel fïr (iläser, P’ipetten u. s. w. . . . . . . . . . .

11. Ein Kasten für C'entrifuge. S'chaclitel II. s. w. 


\title{
A n h a n g:
}

\section{Bemerkmugen über den essbaren l'alolowmrm, Lysidice riridis (Gray).}

\author{
Von Ant. Collin in Berlin.
}

Einer fremdlichen Aufforderung des Herru Marinestabsaryt Dr. A. Krämer gern entsprechend. will ich im Anschluss an die vorstehende Arbeit einige zusammenfassende Bemerkungen üher einen eigenthümlichen bewohner der Korallenriffe. den essharen Palolowurm des pacifischen Oceans gehen: ohwohl diese Notizen Neues kaum bieten werden, dürften sie doch vielleicht manchen Tnteressenten finden und Reisende, welche den Vorzug haben. jene gesegneten Gegenden hesuchen zu kümnen. vielleicht zu weiteren, eingehenderen Forschungen üher diese biolugiseh so ausserordentlich merkwïrdige, aber noch in vielfacher Hinsicht unklare Erseheinung anregens.

\section{Lysidice riridis (Gray) 1847: Ialolowurm.}

Wichtigste Titteratur:

1847. Palola viridis (nicht Palolo). - Gray. An Account of Palolo, al Sea Worm eaten in the Navigator Islands. By the Rer. J. B. Stair, with a Description by .J. E. Grily ete. - Proce. Kool. Soc. London XY. p. 17-18. Auch in: Ann. Mag. Nilt. Hist. XIX, p. 409 lis 410 (18+7). \%. Th. abgedruckt in: Encrelop. Britamn. $8^{\text {th }}$ edit. Tol. XI, 1). 297 (1856).

1858. . . . - Macdonald. .. D. ()n the external Anatomy and Natural History of the Genus of Ammelida nimed Palolo by the Samoans and Tongmese, and Mbalolo by the Fijians. - Trans. Limn. Soc. London XXI1, pt. III, Nr. XVT. p. 237-23\%, pl. XI.I.

1862. " ". - Seemann. B. Titi : An Aceomt of a Gorermment Mission to than Vitian or Fijian Fslands in the years 1860-61. Gimbridge $8^{\circ}$, p. 59-63: 4 'Textfig.

1863. " "- Hood, T. H. Notes of a Cruise in H. M. S. "Fawn" ili the Western Pacific in the Year 1862. - Ediuburgh, $8^{0}, 268$ pp., $1863 ;$ p. $126-128$ (Pulolo von Samoa.)

1865. Lysidice palolo- Quatrofages, A. de. Histoire naturelle des Anmelés marins

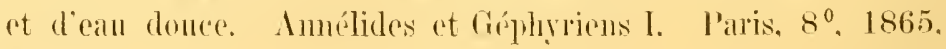
1. 379 . 


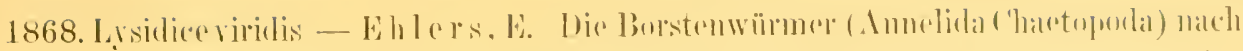

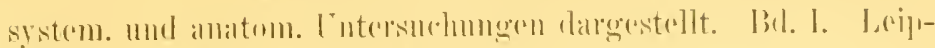
zig 1864-1868. p. :367. Ammertumg. Tal. XVI. Fig. 17-18.

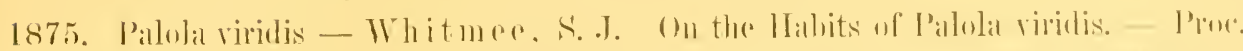

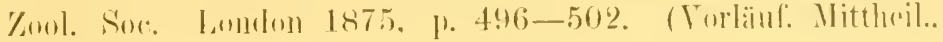
iliti.. 1. 158).

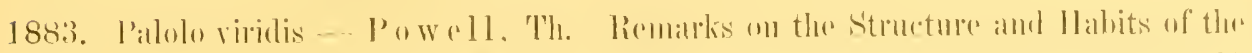

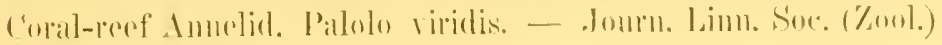
XYT. ए. 39:3 396.

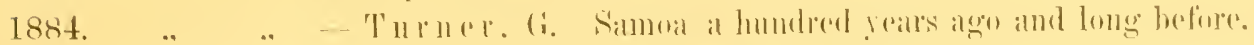
London. $8^{0}$. 1884. p. 2060 - 207.

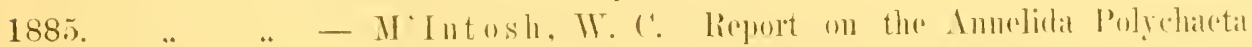
collected by H. M. S. Challeneger during the years 187:3 - 76. -

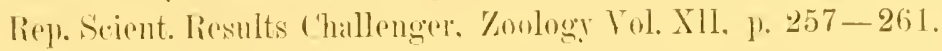

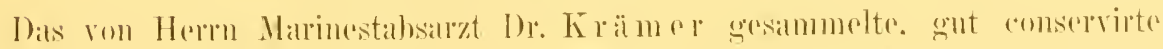

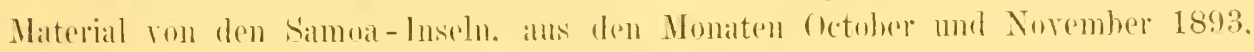

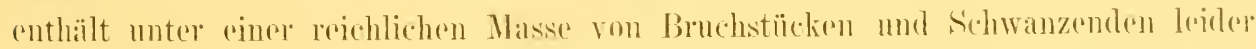
lieinen einzigen Konf. Das ist nieht mohr reromnderlich, scitulem man weiss, dass

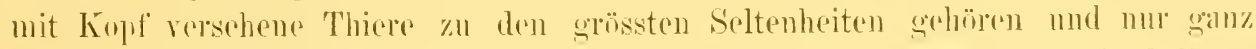
zufällig an die Oberfläche kommens sogal nur zweimal ist hishop ein Konf diesm

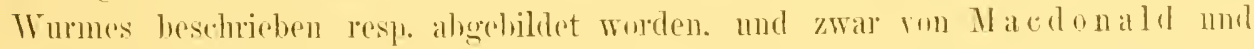
Sermann: Mabei scheint es in dem letzteren Falle überhampt zweifelhaft. oh

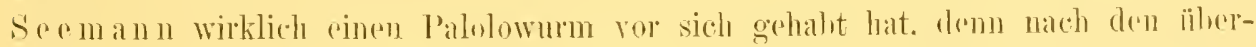
cinstimmenden Barichten vieler Beohachter errejchen sehom allein dic Bruchstücke

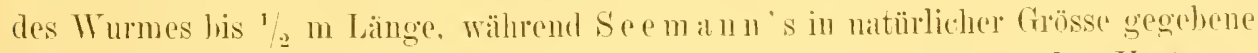
Abhildung des ganzan Thieres nur 9 am misst: anch vicle ron l)r. K lä me gesammelte Broldestïcke und solche der berliner Zoulog. Sammlung und des hiesigen Koolog. Instituts emeribhen eine viel hedentendere Länge. Sollost wem man dio amsserordentliche Verschiedenheit dor Kärperlänge ciner und derselhen Clactopodenspecies in Betrateht zieht, urscheinen dic ubigen Grössenuntersehiede doch retwas zu bedentend. mol es dürfte sich in diesem Seemann sehen Falle alson cutweder

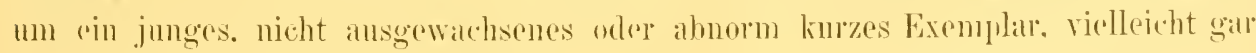
mIn rine ganz andere Art handeln.

bin Bruchstäk einer Eunicide aus der Grube selon Simmlung, jetzt im

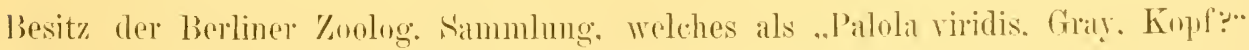
hezeichnet wall, gehört üherhampt nicht der Gattung Jụsidice an.

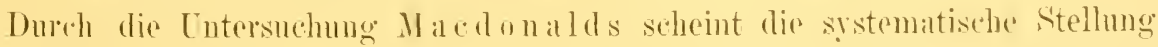
des Palolowurmes. als in die Gattung Ly sidice gehörigg. garnïgend klargestellt. wemn anch nähere Cntersuchungen. namentlich des Kopfes, hörlust wünschenswerth sind: daher muss der ron Gia ge geschaffene Gattungsnamo Palolal anfgegethen werden.

Del von Macdonald ahgebildete Kopf (Fig. 1) reigt die für Lysidice characteristischen 3 Fühler ınd den Kieferapparat. Die darauf folgenden etwa 20 Segmente waren beträchtlich schmäler, als die Segmente der reifen Bruch- 
stïcke, auch waren auf den ersten Segmenten die typischen dunklen Rückenflecke sehr undeutlich und kaum sichtbar.

Die Brnchstücke, wie sie an der Oberfläche des Meeres gefangen werlen, hahen eine Jïnge bis $50 \mathrm{~cm}$ und gewöhnlich eine Breite von 2-3 mm, welche nach Pow ell auch ${ }^{1 / 4}$ inch (ca. $=6,3 \mathrm{~mm}$ ) erreichen kanu (Fig. 2). Die Parapodien tragen keine Kiemen, aber je einen dorsalen nud ventralen Cirrus und Borstenbïndel mit zweierlei Borsten: lange fein zugespitzte, welche, wie M'Intosh gegenüber Macd ou ald richtig bemerkt, nicht um ihre Längsachse gedreht sind, und zusammengesetrte Borsten, deren Endtheil zwei kleine Zähne trägt. Von jeder dieser beiden Borstenarten finden wir $2-3$ in jedem Parapodium, in den vorderen Segmenten hinter tem Kopf sind sie jelloch nach Macdouald etwas zablreicher. Auf jedem Segment liegt in der Medianlinie des Rückens ein dunkler Fleck, auf welchem nach Ehlers die Ausführungsgïnge eines Drüsensystems münden. Diese dunklen Flecke sind durch eine über den ganzen Rüicken laufenle helle längslinie verbunden. Am letzten Schwanzsegment funden sich zwei kïrzere dorsale und zwei lange ventrale Cirren; einer dieser längeren Cirren war bei einem Lxemplar von Dr. Kr ä mer in 2 Theile zerspalten, so dass es den Anschein hatte, als ob 3 lange Analcirren vorhanden wären.

Die Farbe des Palolowumes ist sehr verschieden, und zwar sind die Veibchen im Leben schmutzig - indigofarbig oler dunkelgrün, die Mäunchen lagegen hellbraun his ockerfarbig oler weiss. In Alcohol sind die Weibchen meist schmutziggraugrïn, bisweilen anch vollständig weiss (Exemplare der Berliner Zoolog. Sammlung), die Männchen röthlichbranu. Die grünen Fier, mit welchen die weiblichen Bruchstïcke prall gefüllt sind, haben einen Durchmesser von $0,21 \mathrm{~mm}$.

Die Terbreitung des Palolo ist nach unserer jetzigen Kenntniss anf einige Inselgruppen des pacifischen Oceans beschränkt und zwar auf die Samoa-, Fidschi-, T'onga-und Gilbert-Inseln. Ob es sich bei der von Seemann ebenfulls als Fundort angegebenen Gruppe der Neuen Hebriden wirklich um Pilolo handelt, scheint fraglich, dem einige Borstenwürmer, welche angeblich dort gegessen werden, stellten sich bei der Untersuchung nach M'Intosh als Phyllodociden heraus. In der Berliner Sammlung finden sich ferner einige von Putze gekanfte Exemplare, angeblich von Neu-Britannien.

Der Palolowurm ist rin Bewohner der Korallenriffe und steigt nur zweinal im Jahre in den Momaten Oetober und Norember zur Ahlage der Gesthlechtsproducte an die O)herfläche. Er erseheint nu an gowissen Theilen der Inseln. aln der Seite der Lagmue, mahe dem äusseren Riff. Nach der Mittheihumg von Stair (hee Gray) treten die Wrürmer am liande der Ritte besonders dal anf. wo viel S'ïsswassere allsströmt. dech ist das nateh der beobachtung von Dr. Krä̈mor

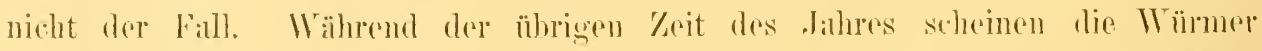
in den tieforem Regionem der Korallenriffer zu lebend. doch sind sie dort mit Ausnalume rines Falles noch nicht in ihren Schlupfwinkeln beohachtet oder dort gofangen worlen: Whitmes fand nämlich oin bemplar in den Spalten dines ahgestorbenen Korallenblokes. weleher von einer Stelle nahe dor Kö̈ste entunmmen War, an wolcher der Palnlo erscheinen sollte. 


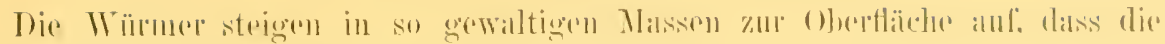

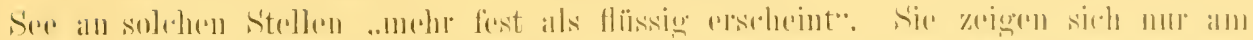

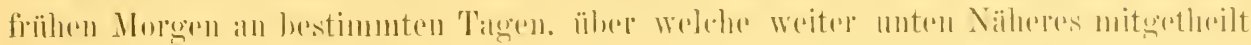

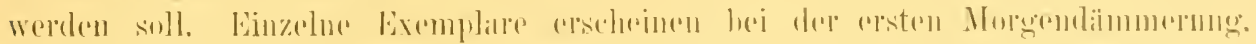

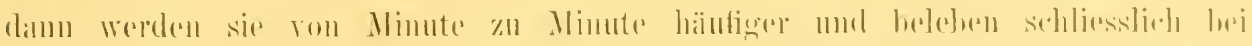

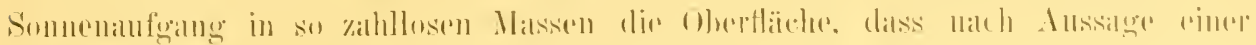

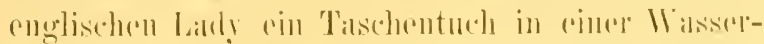
ticlie ront $t$ inches $(=10.16$ eme 1uter der Masse

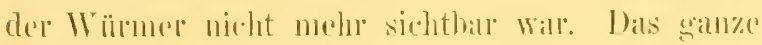

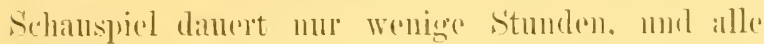

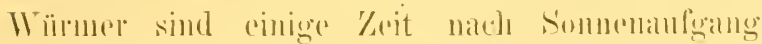
rollstiandig versehwumblen. lmunter sind es nur

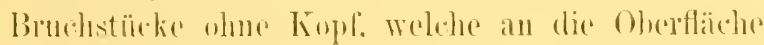

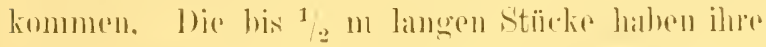

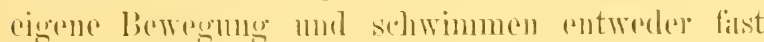

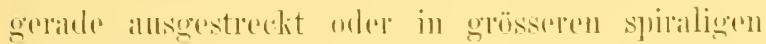

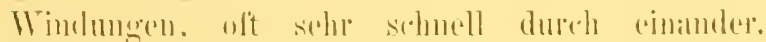

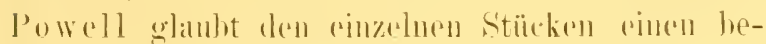
somleren Gesichtssimn zuschureiben zul müssen, da sic den Fingköblen geschickt auszuwejehen suchen.

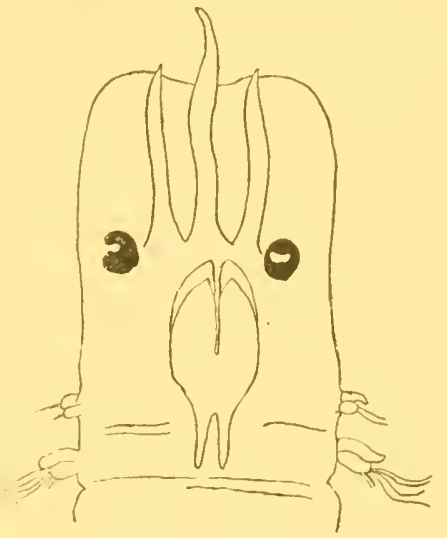

1

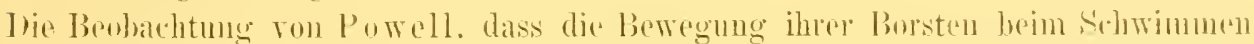

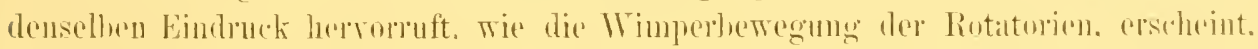

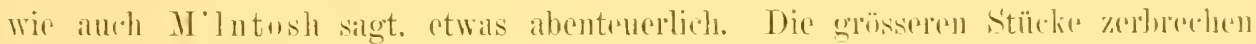

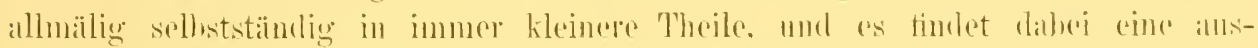

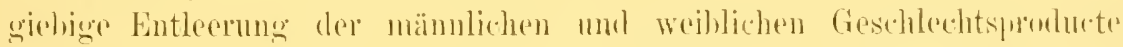

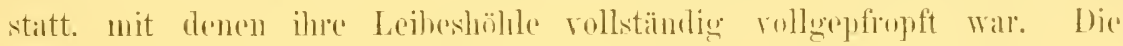
Theilung der stülele setzt sirh inmer weritor fort. bis schliesslich num

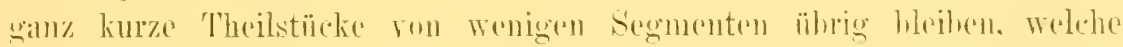

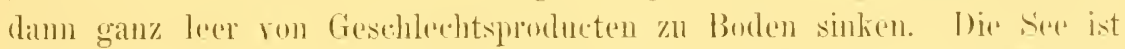

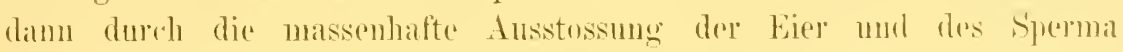

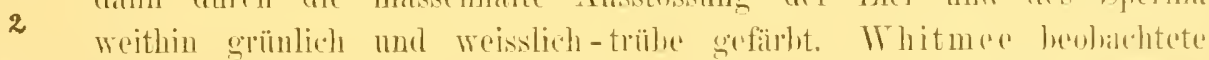

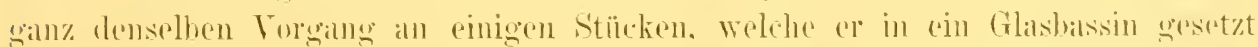

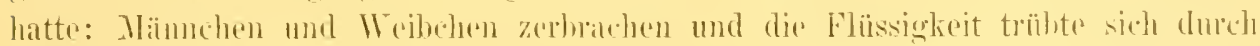

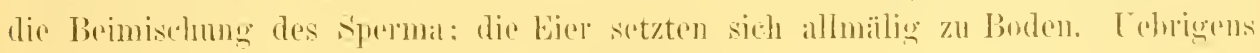
entwickelten sie sich in Apuarium nicht weiter.

lis scheint zweifellos, dass die 'Thiere allein zum \%wecke ler Ablagerumg der Geschlechtsproducte und zur Befruchtung der bier an lie Oberfläche lionmen. Dieser Process wirl dureh die leichte Zerlnechlichkeit natürlich Jegünstigt und beschlemigt. Dass die Theilstïcke, deren innere Organisation zum Theil atrophischen Character trägt und welche in der Bildung ron cieschlechtsproulucten gänzlich anfgegangen zu sein scheinen und ihren Endzweck damit erreicht haben, etwa nach ihrem Uutersinken wieder zu nenen 'Thieren anwachsen sollten, scheint gïnzlich ausgeschlossen, vielmebr werden sie sïmmtliclı zu Grunde gehen. Hicrgegen wïrle auch Powells Beobachtung nicht sprechen, welcher grössere Bruchstricke, ohne weiter zu zerplatzen, durch "Ei- und Samenleiter" (vielleicht die 
Segmentalorgane?) Geschlechtsproducte ansstossen sahı und die Stücke ganz unverselırt. aher ganz leer davon, fangen komnte. Die in der Tiefe zurückgebliebenen Kopftheile dagegen dürften walıscheinlich wicder nene Endstücke hervorsprossen lassen.

Die merkwïrdigste Erscheinung in der biologie des Palolowurmes ist sein ganz regelmässiges Auftreten in den Honaten October und November zur Zeit des letzten Mondviertels; nur zu diesen zwei Zeitpunkten im Jahre erscheint er an der Oberfliche auf den Korallenriffeu, und zwar ist der Noremberschwarm meist reichlicher, als der im October. Bisweilen ist sein Erscheinen an den einzelnen Inseln einer zusammengehörigen Gruppe anch verschieden; so tritt er nach Angabe des Herrn Dr. Krämer an der Insel Sawaii der Samoa-Gruppe besonders reichlich im October anf, während er bei Apia auf Upolu in der Regel im November häufiger ist. Ueberhaupt ist er manchmal im October an einer Stelle in Myriaden von Exemplaren vertreten und einen Monat später finden sich ebendaselbst nur wenige Exemplare, sowie ungekehrt.

Jedesmal erscheinen die Würmer in der Morgendümmerung am Tage vorher und am Tage des letzten Mondviertels selbst, einige Nachzügler zuweilen anch noch am Tage darauf. Da das Auftreten des Palolo ganz regelmässig so enge mit den Mondphasen verknüpft ist und er nur zu dem Zeitpunkte des letzten Mondviertels zur Oberfläche kommt, so ist es klar, dass er in jedem Jahre um mehrere Tage früher kommen würde, denn die Mondmonate fügen sich nicht dem Sonuenjahr. Erschiene der Palolo jedesmal nach 12 Mondmonaten (etwa 354 Tage) beim entsprechenden letrten IIondviertel, so käme er jedes folgende Jahr immer un etwa 11-12 Tage früher. Würde er 13 Mondmonate bis zu seinem Wiedererscheinen branchen, so würde er sich jeiles Jahr um etwa 18 Tage verspäten. In beiden Fällen würde seine Erscheinnugszeit in knrzer Frist aus den Monaten October und November heraustreten nnd er kömnte im Laufe der Jahre 211 jeder beliebigen Tahreszeit, in jedem heliebigen Monate anftreten; dieses ist aber, so lange man ihn kennt, nicht der Fall gewesen, vielmehr ist er stets nur in der Zeit von etwa dem 5. October bis gegen Ende November sichtbar geresen. Diese Thatsache brachte Whitmee auf den glücklichen Gedanken, den Erscheinungsmodus des Palolo nachzuspüren. Seine zum 'Theil allerdings lückenlıaften Beobachtungen erstrecken sich für die Samoa-Inseln anf den Zeitraum von 1861-1873, unter Berücksichtignng eines Datums von den FidschiInseln. An der Hand dieser Daten stellt Whitmee die sehr annehmbare Behauptung auf, dass ler Palolowum stets zwei Jahre hintereinander nach je 12 Mondmonaten erscheint, dass aher in jedem dritten Jahr ein Intervall von 13 Mondmonaten auftritt. Dieses stimmt mit den bekannten Erscheiunugsiaten des Wrumes überein und dabei überschreitet anch die Erscheinungszeit des Wurmes für längere Zeit nicht die Monate October und November. Derartige Intervalle vou 13 Honlmonaten sind nach Whitmee in den Jahren 186263, 1865/66, 186869 and 1871 72 eingetreten.

Wh it me e rechnet aber noch genaner. Wenn der Palolo nämlich zunächst 2 Jahre nach je 12 Mondmonaten, im 3. Jahre aber nach 13 Mondmonaten, also nach 3 Jahren zusammen in 37 Nondmonaten wielererscheint, so kommt 
er alle 3 Jahre noch immer um etwas mehr als "̈ 'lage frïher, da 3 mittlere Sonnenjahre über 3 Tage länger sind, als 37 Mondmonate. Würde hier nicht eine Correction eintreten, so würle die Erscheinungszeit des Palolo noch immer nach einer längeren Reihe von Jahren dic Monate October und November nicht mehr einhalten, sondern inmer frühzeitiger fallen. '/um Ausgleich dafür müsste nach Whitmees Rechmmg alle 28 his 29 Jahre ein Extra-Mondmnnat eingeschaltet werden: demuach würcle dam eine solche dreijührigo Palolopreriode zu dieser \%eit 1 Intervall von 12 und 2 vou je 13 Mlomimonaten umfassen. Eine solche Extra-Einschiebung von einem Mondmonat prophezeite Whitmee für 187374 und fand scine Vermuthung bestätigt, denn der Palolo zoigte sich 1874 erst nach Ablauf von 13 Mondmonaten am 31. October um 1. November.

Einfacher erklärt sich die Sache äbrigens in folgender Weise. Da die Mondphasen alle 19 Jahre fast genau zu derselben Sonnenzeit wiederkobren (Metonischer Cychus), so liegt es nahe, dass der Palolo alle 19 .Jahre zu demselben Datum erscheinen wird; dieses finde ich durch die Thatsachen bestätigt, denn 1874 beobachtete Whitmee den Palolo anf Samoa am 31. October unt 1. November: 19 Jahe später (1893) sammelte Dr. K r ämer das mir vorliegende Material ebenfalls am 31. Oetoher und 1. November.

An den Gilbert-Inselu soll der Palolo nach Pow ell stets in den Monaten Juni und Juli erscheinen.

Aus Ursachen unbekannter Natur tritt der Palolowm bisweilen auch in ganz anormaler Weise zu anderen Jahreszeiten auf; so soll er nach Whitmee gelegentlich, aber sehr selten auch im December bei Samoa vorkommen. Nach einer handschriftlichen Notiz vou Herrn P. Stoos in Lübeck blieb der Palolo an den Fidschi-Inseln im Jahre 1885 ganz ans, erschien dann aber ansser der Zeit Ende Januar 1886. Ueber ein weiteres abnormes Auftreten berichtet Powell, nach welchem der Palolo am 21. März 1881 bei Samoa erschien. Wie mir Herr Professor Goldstein, hier, freundlichst mittheilte, war am 15. März 1881 Vollmond; der Wurm ist also an einem Tage erschienen, als der Mond kurz vor dem letzten Viertel stand; er hat somit, wenn auch nicht die Jahreszeit, so docb wenigstens die Mondphase eingehalten.

Auf Samoa und den Tonga-Inselu heisst der Wurm Palolo, auf den FidschiInselı Mbalolo oder Balolo. Die Samoaner nennen den Wurm atch einen Fisch (i’a = ika in anderen polynesisehen Dialekten, und =ikan im Malayiscben). ,Pa“ bedeutet nach Turner soviel wie ,platzen", ,bersten"; , lolo" heisst, ,ölig" orler" ,fettig". Die Eingeborenen benennen die Monate nach dem Namen Palolo; so heisst auf den Fidschi-Inseln der October vula i mbalolo lailai (= kleiner Palolomonat), der November vula i mbalolo levu (= grosser Palolomonat), weil im letzteron der Palolo am reichlichsten auftritt. Die Samoancr nemen nach Whitmee die Jahreszeit, wann der Passatwind am Anfang des Sommers oder der Regenzeit von Südost nach Nordost umschlägt, vãi-palolo (d. h. Zeit des Palolo): die entgegengesetzte Jahreszeit, wann der Passat ron Nordost mach Südost wechselt. am Anfang der trockenen Jahreszeit, wird in ähnlicher Weise vãi to' clau genannt (d. h. Zeit des Umschlagens des Nordwindes). Diese Verbindung des Namens Palolo mit den Monaten und Jahreszeiten spricht wohl sicher dafür, dass sich 
die Erscheinungszeit des Palolo in Laufe langer Zeiträume ebensowenig geändert hat, wie die Jahreszeiten selbst. Die Bewohner der Gilbert-Inseln nemien den Wurm "Te Nmatamata" (d. h. der gleissende oder glänzende).

Der Palolowurm ist eine sehr begehrte Lieblingsspeise der Eingeborenen, anch manche dortige Europïer haben Geschmack daran gefunden. Das Erscheinen der 'Thiere auf den Korallenriften ist für die Samoaner und Fidschi-Insulaner ein Freudenfest. Jung und Alt rudert in der Morgendämmerung hinaus, um die werthvolle Gabe der Natur von den Booten aus mit Sieben und schön gefertigten Körben, oder aneh mit der blossen Hand einzuheimsen. Die Palolomasse wird entweder zum Theil gleich roh verzehrt oder in Brotfruchtbliitter gebunden und üher angezündeten Fonern gebacken. Händler kaufen an Ort und Stelle den Palolo auf, um andere Theile der Inseln damit zu versehen und Boten werden mit Palolo als Geschenk an ferner wohnenie Häuptlinge gesandt, in deren Gegend die Schwärme nicht erscheinen. Sein Geschmack soll nach Hood's Mittheilung an eine Auster erinnern. Die Fidschi-Insulaner haben den Aberglauben, dass nach dem Palolofang grössere Regengüsse auftreten müssen, um "die Fener, woran der Palolo geröstet ist, auszulöschen"; anderenfalls wird eine schlechte Yamswurzelernte erwartet.

Beiläufig gesagt ist übrigens die Zahl der zur șpeise dienenden höheren Würmer nicht gross: ausser dem Palolo wird nach Dr. Kr ämer noch ein grosser Regenwurm theilweise von den Samoanern gegessen und nach M'Intosh geniessen die Bewohner der Nenen Hebriden Borstenwürmer aus der Familie der Phyllodociden als Speise, welche sie A'oon nemnen. Von einem auf Amboina gegessenen Wurm wird weiter unten die Rede sein. In China sollen ferner Sipunculiden genossen werden.

Die ausserordentliche öconomische Wichtigkeit, welche der Palolo für die Insulaner besitzt, hat es natürlich zur Folge, dass die Eingeborenen sein Erscheinen mit grösster Genauigkeit beachten und sogar meist mit gutem Erfolge vorherberechnen. Sie achten nach Whitmee und Powell zuerst auf die Blüthezeit der scharlachrothen Blumen von Erythrina indica, eines Strauches aus der Familie der Papilionaceen (Aloalo genannt). Beginnen dann noch der Tavai (Rhus taitensis), der Lagaali (Aglaia edulis Asá Gray) und die Sisi (Eugenia sp.) zu blühen, so sehen die Eingeborenen nach dem Stande des Mondes; wemn derselbe dann in der Morgendämmerung tief ïber dem westlichen Horizont steht, so erwarten sio an 10. Tage darauf den Palolo. Meist ist ihre Rechnung richtig, doeh irren sie bisweilen, wann ein Intervall von 13 Mondmonaten seit dem vorigen Erscheinen des Palolo eintritt, um einen ganzen Monat. Von anderen wird dagegen auf das Untersinken gewisser Sternbilder unter den Horizont geachtet und daraus die Palolozeit berechnet. Hood berichtet, dass drei Tage vor dem Erscheinen des Palolo die "malio" (gewisse Landkrabben, Gecarcinus) sich in grossen Zügen aus dem Innern an die Meeresküste begehen, und diese Wanderung soll so sicher mit der Palolozeit zusammentrefien, dass die Eingeborenen hierdurch auf die drei Tage später auftretenden Paloloschwärme vorbereitet werden. Dieses eigenthümliche Zusammentreffen brachte $\mathrm{H}$ o od auf den abenteuerlichen Gedanken, dass die Palolobruchstücke der Laich dieser Krabben seien, eine Annahme, die 
aber weder bei den dortigen Furopäern noch kingeborenen Anklang fand, wie Hooll selbst sagt.

Als begleitenle Würmer des Palolo wird namentlich eine Noreis-lit angegeben: in dem Material ron Herrn Dr. Krämer fanden sich in der Palolomasse eine Anrahl Polychaeten aus den Gattungen Euphrosyne. lirione mnl Phyllodoce.

'Zum Schlusse sei noch auf' eine den Palolo-Auftreten gan\% älmliche Erscheinumg hingewiesen, auf welehe kd. vou Martens (Sitzber. l. Ges. naturf. Fremde zu Berlin, Jahrg. 1887 p. 17) zuerst aufmerksam gemacht hat, nämlich auf die Schildermng eines essbaren Wumes (Wawo) ron Amboina in dem Wrerke rou Georg Everharl li umplius ,I)' Amboinsche Rariteitlamer" etc., Amsterdam 1705. Ich will hier einen gekürzten Auszug aus seiner Beschreibung in freier Uebersetzung geben. Rumplitus beschreilut auf Seite 51 Il. seine "Vermiculi marini' Wawo" von Amboina wie folgt:

.,Es sind kleine Würmehen, kamm 1 Fnss lang, in der Dicke einige wie Segelgarm. die meisten wie gezwirnte Seide, in Klümpchen duch ënanler rrmischt, in welchen man immer einen grösseren. dickeren unl längeren sieht. als die anderen, wolchen man für die Mutter hält. Die meisten sind dunkelgrün, doch spielt darin auch etwas schmutzigweiss oder gelb, roth. braun und blan. Ihre rechte Gestalt kann man kamm erkennen, ausser lass sio wie ein verwirter Strang Garu durcheinander hängen und sofort in Stücke brechen. wenu man sie anrührt; weun man sie in Salzwasser bis zum anderen Tag stehen lässt, so kann man unter einem Vergrösserungsglas die folgende Gestalt daran crkennen; in jedem Ǩlumpen ist ein etwas grösserer Wurm, als die anderen, welchen man die Mutter nemut; er ist dick wie grobes Segelgarn und bisweilen wie ein lünner Fedcrkiel, bleichgelb oder weisslich; an dem Köpfchen kann man nur ¿ Hörnchen erkennen, wie sie die Schnecken baben, und an jeder Seite vier deutliche Füsschen, wie Raupen. Die anderen Füsschen sind sehr fein, wie Härchen, nnzählbar. und ziehen sich aus und ein. Die Kinder hängen rund um diese Mutter; in der Dicke sind sie wie feines Segelgarn oder gezwirnte Seide, und grünlich. einige eine Hand, andere $1^{1}$ a Fuss lang. Sie sind quer über len Leib gerippt, als ob sie ans vielen Gliedern beständen, doch sind sie so zart. dass sie gleich in Stücke zerbrechen, wenn man sie in die Hand nimmt; an den gekochten kann man die Glieder noch besser erkeunen. Wenn man sic des Abends, frisch aus dem Wasser geholt, besichtigt, kann man deutliche Zeichen ron Leben daran erkennen, aber man kann sic nicht bis zum nächsten Tag*e am Leben erhalten. Zeichen von Gesicht, Gehör und Geruch kann man anch daran bemerken, denn es scheint durch den Gesichtssinn zu geschehen, dass sie auf eine brennende Fackel oder Licht zuschiessen, doch wenn der Mond aufgeht, so verbergen sie sich wiederum. Das Gehör muss man ilınen zuschreiben, weil sie verjagt werden, wenu man grossen Lärm macht, und vom Gernch muss es kommen. dass sie so begierig nach schwangeren Framen und nach mit Geschwüren behafteten Beinen zuschwimmen.

"Dieses Gewïrm sieht man das ganze Jahr hindurch nicht, sondern allein am 2., 3. und 4. Abend nach dem vollen Mond, welcher cintritt, weun die Sonne 
in den Fischen steht, im Februar und März; alsdann muss man sie sofort nach Sonnenuntergang suchen mit angesteckten Fackeln, auf solchem Strand, wo grosse Klippen in der See stehen, die voll von Spalten und Rissen, aber glatt und nicht scharf sind; um diese sieht man die Würmer wimmeln und auf diejenigen zukommen, welche eine brennende Fackel im Boot haben; dann kann man sie mit ausgespannten Tüchern oder feinen Sieben schöpfen. Die ersten beiden Nüchte findet man sie um die Klippen, später aber etwas weiter fort in die See getrieben. Die Eingeborenen wïnschen, dass man beim Fang ruhig sein und das Boot ohne Lärm vorwärts treiben soll. - Am folgenden Vollmond sind die Würmchen schon grösser geworden, ungeführ strohhalmdick, ganz wie junge Tansendfüsse, grün, braun und weiss gemischt und daher etwas abscheulich, welche auch einen besonderen Namen haben und nicht für das echte "Wawo" gehalten werden. Am 5. Abend nach dem Vollmond verlieren sie sich und man kann sie das ganze Jahr hindurch nicht mehr sehen, ausser, wie gesagt, an dem folgenden Vollmond, zu welcher Zeit sie eine andere Gestalt und Namen haben. Der genannte Vollmond, wann der Mond in der Jungfrau und die Somne in den Fischen steht, ist die gewöhnliche Zeit des Wawo, doch geschieht es bisweilen, dass man sie auch etwas früher findet, nämlich bei dem Vollmond, wann die Sonne noch nicht in die Fische getreten ist. Das Wawo kommt auch nicht jährlich in gleicher Menge an die Oberfläche; denn wenn viele warme Regen vorangeben, kommt es reichlich, und man kann es alle 3 Abende nach einander schöpfen; aber wenu viele trockene und heisse Tage vorangehen, komnt es wenig und nur an einem Abend. Am Tage kanu man schon erkennen, ob es denselben Abend in die Höhe kommen wird, denn man sieht alsdann bei Tag schwarze Flecken im Seewasser, aucli hat man erfahren, dass in jedem Jahre hohes Wasser ist und immer höher als die tägliche Fluth, wenn das Wawo erscheint.

"Die gewöhnliche Meinung ist, dass das Gewürm ein Auswurf der genannten Kilippen ist; immer, wo solche Klippen fehlen, findet man das WTawo auch nicht. Das meiste wird gefangen in dem Amboinischen Golf, um den rothen Berg, an den drei Liasserschen Inseln, bei Latuhaloy und in Banda, als auch anf den Molukken.

"Vorläufig mag es "Vermiculi marini" heissen; der malayische Name ist unbekannt, weil es vielleicht in den Ländern nicht vorkommt; in gewöhnlichen Amboinisch heisst es Wawo und Wau, was man auch für Ternatisch hält. Auf Hitoe heisst es "Melatten", auf Leijtimor "Laur", auf den Uliazzers "Melattonno", in Banda „Oele". Weil es nun je nach den beiden Vollmonden zweierlei Art ist, so wird das erste und eigentliche, Wawo Kitsjil“ (= kleines Wawo), das andere oder grosse am folgenden Vollmond, Wawo bezaar" (= grosses Wawo) genannt. Die Bewohner von Hitoe unterscheiden es genauer und machen 3 Arten daraus, die erste heisst Melatten Salanay, das sind kleine Wïrmchen, wie ein Hanfen Faden aneinander hängend, welche am Vollmond im Januar vorkommen, wann die Somne in den Wasserniann tritt; doch weil es nicht alle Jahre an die Oberfläche kommt und es auch nur gering ist, wird es nicht gesammelt, sondern zur Nahrung für die Fische gelassen. Die zweite und eigentliche Sorte heisst Melatten Yan (d. h. Fisch-Melatten), als ob es nun schon zu lebenden Fischen oder kenntlichen 
Geschöpfen geworden wäre. Die dritte Sorte heisst Melatten Lalian (d. h. Tausenifuss-Wawo), weil es dann die Gestalt von Tausendfüssen bekommen hat. Dies kommt hervor zu dem folgenden Vollmond des April und wird zum Hssen für ungeeignet gehalten.

"Han macht viel Anfhebens von diesem Wawo in Amboina und in Banda, und diejenigen, welcho daran gewöhnt sind, machen davon eine grosse Leckerei, obwohl es beim Anschauen hässlich erscheint; es wird auf dreierlei Art zubereitet."

R umphius giebt nun in eingehender Weise zahlreiche Küchen-Recepte, wie das Wawo mit verschielenen Kräutern zusammen gekocht, gepökelt, geröstet, geräuchert und namentlich zu pikanten Brühen und Saucen verwendet wird. Die letztgenannte Wawo-Sorte soll bei Nacht in aer See mit hellem Licht lenchten, wesshalb sie um so mehr verabschent wird, weil sie diese Eigenschaft mit len 'Tausendfüssen gemein hat. Der Verfasser giebt dann die Daten für einige Jahre, wann das richtige Wawo gefangen ist:

„1684. Vollmond am 1. März. Das Wawo wurde am 2., 3. und 4. März gefangen ; es kam in reichlicher Menge ror: unter den Klippen, vom rothen Berg: bis nach Hative Kritsjil; man schöpft es, sowohl in dem Boot sitzend, als auch bis zur Mitte les Körpers in das Wasser gehend, während jemand eine brennende Fackel in der Hand lält, wozu die Eingeborenen eine schwangere Frau wählen, doch muss sie mit ler Fackel im Boot sitzen bleiben.

1655. Vollmond war am 20. März, als die Some in len Widder eintrat. Tor und nach dem Vollmond war sehr heisses Wetter, wesshalb nur wenig Wawo gesehen wurde, ausser am 22. März, wann sich das , Wawo-Jcan“* zeigte, = Fisch-Wawo, weil man es für die Fische lässt. Am 23. Mär\% wurde das echte gefangen, doch nur in kleiner Menge.

16S6. Vollmond war am 8. März. Wawo wurde am 11. gefangen, loch auch nur wenig wegen der vorhergegangenen Trockenheit.

165\%. Vollmond war am 27. Februar. Am 1. März hätte es erscheinen müssen, doch wurde nichts gesehen, ausser einigen schleimigen rothen Fäden, welche keine Gestalt hatten, indem wiedermm die rorhergehende 'Trockenheit die Ursache daron war.

1688. Vollmond war am 17. März. Am 19. und 20. März wurde wenig Wawo gefangen etc.

1690. Vollmond war am 27. März (im Widder): da es stilles Wetter mit wenig Regen war, hat man denselben Abend und die beiden folgenden das Wawo in reichlicher Menge bekommen.

1693. Am 24. März, am dritten Abend nach dem Vollmond (21. März) hat man begonnen, das Wawo zu fangen, vier Abende nach einander, in reichlich grosser Menge, denn um diese Zeit war stilles Wetter.

1694. Am 11. März, zwei 'Tage nach dem Tollmond (9. Mäı’z) in den Fischen, wurde das Wawo gefangen; es war schönes stilles Wetter. doch ist nicht viel rorgekommen." 
Aus den obigen, stellenweise allerdings recht unklaren Angaben von Rumphius sieht man, dass die Erscheinung des , Wawo" in selır vielen Punkten mit dem Palolo äbereinstimmt. Vielleicht handelt es sich um eine andere Wurm-Art, vielleicht anch um den richtigen Palolo. Auch das Wawo erscheint periodisch mit den Mondphasen und zwar, was $\mathrm{Rumphius}$ betont, immer nach dem Vollmond; mit demselben Rechte kann man aber sagen, dass es wenige Tage vor dem letzten Mondviertel erscheint, und hätte damit eine gewisse Uebereinstimmung mit dem Palolowurm. Die Jahreszeit ist allerdings eine ganz andere, aber anch bei den Gilbert-Inseln soll der richtige Palolo im Juni und Juli erscheinen, das Wawo bei Amboina im Februar und März. Handelt es sich in allen diesen Fällen um denselben Wurm, so würden vielleicht locale Verhältnisse sein Erscheinen zn verschiedener Jahreszeit beeinflussen.

Es ist merkwürdig, dass die Erscheinung des Wawo bei Amboina seit Rumplius ganz in Vergessenleit gerathen zu sein scheint, und dass man in den Berichten der dort gewesenen Europäer nichts mehr darüber findet. Jedenfalls scheint es der Mühe werth, diesen biologisch so interessanten Erscheinungen des Palolo und Wawo noch weiter nachzuspüren und die älteren Beobachtungen durch nene zu verbessern und zu ergänzen. 


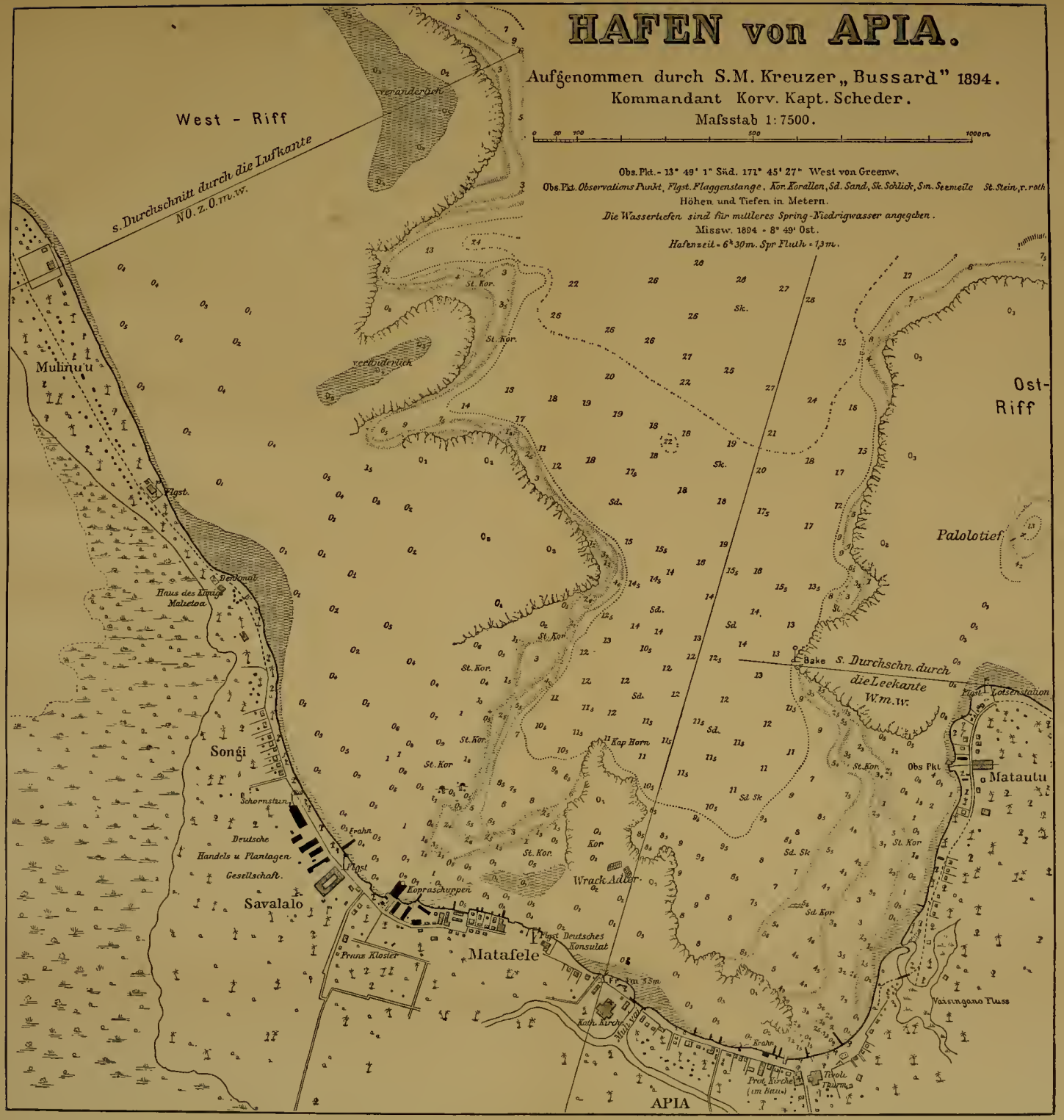


walle 722 
Verlag von Lipsius \& Tischer in Kiel und Leipzig.

Seit Herbst 1892 erscheinen:

Ergebnisse der in dem Atlantischen 0cean von Mitte Juli bis Anfang November 1889 ausgeführten

\section{Plankton-Expedition der Humboldt-Stiftung}

auf Grund von gemeinschaftlichen Untersuchungen einer Reihe von Fach-Forschern heransgegehen von Victor Hensen, l'rof. der Physiologie in Kiel.

Yon diesen monumentulen Trerke sind bis jetzt folgende Theile ersehienen:

Bd. I. Alth. A. Reisebeschreibung. Von (). K r ü m m el. Mit wissenschaltlichen Vorherichten. 30 II.

I. .. B. Methodik der Untersuchungen. Von V. Hensen. 24 II.

1. .. (. Geophysikalische Beobachtungen. Von (). K l ïmmel. (1) Il.

11. .. E. a. A. Thaliacea. Systemat. Bearb. von M. I'. A. Traustedt. 2 II.

II. .. F. a. B. Thaliacea. Vertheilung der Salpen. Ton $:$ Apstein. 7 II. 50 I'f.

II. . E. a. C. Thaliacea. Vertheilung der Doliolen. V́n A. $\overline{\text { Borgert. } 8}$ M. 60 Pf.

II. .. E. b. Pyrosomen. Ton O. Seeliger. $12 \mathrm{M}$

II. .. E. c. Appendicularien. Ton H. Lohnann. 30 M.

II. „ F. d. Gastropoden mit Ausschluss der Heteropoden und Pteropoden. Ton H. Simroth. 33 MI. 50 Pf.

II. .. F.e. Acephalen. Ton H. Simloth. 6 M.

II. .. G. a. Halobatiden. Ton Fr. Dahl. Halacarinen. Ton Dr. H. Lohmann. 16 II.

II. .. G. b. Decapoden und Schizopoden. Von A. Ortmann. 14 M.

II. .. G. c. Isopoden, Cumaceen und Stomatopoden. Von H. J. Hinsen. 14 M.

II. .. H. c. Pelagische Phyllodociden u. Typhloscoleciden. Von .J. Reibisch. 10 M.

II. .. H.f. Polycladen. Yon Marianne Plehn. 2 M.

II. .. H. g. Turbellaria acoela. Ton l. Böhmig. 6 M.

II. .. K. c. Die craspedoten Medusen. Vom O. Vaas. 14 II.

II. .. K. d. Die Akalephen. Ton K. Tanhöffon. 8 M.

.. IV. .. M. a. A. Peridineen, allgemeiner Theil. Von F. sebüt. 38 M.

IT. .. II. g. Die Bakterien des Meeres. Ton B. Fischer. 6 M.

Abonnenten anf das ganze Werk crhalten dasselbe 7.4 um $10 \%$ niedrigerem Vorzugspreise.

Ausfïhrlicher Prospelt steht gern zu Diensten. 


\title{
Wissenschaftliche Meeresuntersuchungen.
}

Herausgegeben ron der

Kommission zur wissenschaftlichen Untersuchung der deutschen Meere in Kiel und der Biologischen Anstalt auf Helgoland.

Neue Folge. Bd. I. Heft 1. Gr. 40. 404 Seiten mit 7 Taf. n. 41 Fig. im Text. II. 30. . I. .. 2. , $4^{0}$. XIII, 191 S., 71 Abb.. 8 Tab., 4 Taf. u. 1 Kt. M. 20.

.. II. . 1. Alt. 1. Gr. 4". 324 S.. 6 Tafeln u. 4 Figuren im Text. M. 25. . II. „. 1. „ 2. . $4^{0}$. Eirscheint März 1897.

\section{Jahresbericht der Kommission zur wissenschaftlichen Untersuchung der deutschen Meere.}

I. Jahrgang 1871. Nit 1 Seekarte n. 1 Tafel Abbildungen. Fol. (178 S.) M. 15. II.III. Jahrgang 1872, 1873. Nit 1 Seekarte. 16 Kupfertafeln und 9 Karten zur Fischerei-Statistik. Fol. (380 S.) M. 40.

IV.-VI. Jahrgang 1874, 1875, 1876. Mit 10 Tafeln und 1 graph. Darstellung. Fol. (294 und $2+$ S.) M. 36.

soxie die Fortsetzung davon unter dem Titel:

Bericht der Kommission zur wissenschaftlichen Untersuchung der deutschen Meere in Kiel.

Vierter Bericht für die Jahre 1877-1881. Fol. (382 S.) M. 49. Fünfter Bericht für die Jahre $1885-1886$. (158 S.) .. 25. Sechster Bericht für die Jahre 1887-1889 ,. 느.

Ergebnisse der Beobachtungsstationen an den deutschen Küsten. Jährlich 12 Hefte. Quer-Folio. Jahrgang 1873-1893. ì Jahrg. M. 12.

Atlas deutscher Meeresalgen ron Prof. Dr. Reinke in Kiel.

1. Heft 1889. Fol. ( $5+$ S. und $5+$ Taf.) M. 30. 2. Heft. Lfg. 1 und 2. 1891. Fol. (20 S. und 10 Taf.) M. 12 . 2. Heft, Lfg. 3-5, 1892. Fol. (15 S. und 15 Taf.) M. 18.

\section{Biologische Beobachtungen bei kinsticher Auf- zucht des Herings der westlichen Ostsee.}

\author{
Ton Dr. H. A. M e yer.
}

Im Anschluss an die Abhandlung VII im IV.-- VI. . Tahresberichte der Kommission zur wissenschaftlichen Untersuchung der deutschen Meere in Kiel. 8. (20 S.) M. 1.

Apstein, Dr. Carl, Das Suisswasserplankton. Methode und Resultate der quantitativen Cntersuchnng. Mit 113 Abbildumgen und vielen Tabellen. M. T.20.

Hensen, Victor. Professor in Kiel. Die Plankton-Expedition und Haeckel's Darwinismus. Ceber cinige Aufgaben und Ziele der bescheibenden Naturwissenschaften. Mit 12 Tafeln.

11. 3.---

Schütt, Dr. Franz. Analytische Plankton-Studien. Ziele und Methoden der PlanktonForschung.

M. 3.-.

- Das Pflanzenleben der Hochsee. Sonderabdruck ans Band I. A. der Erurebnisse der Plankton-Expedition der Humboldt-Stiftung. Mit einer Karte und zahlreichen Abhildungen im Text.

II. T.-. 





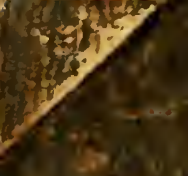

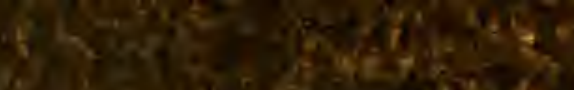

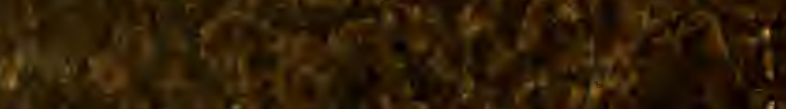

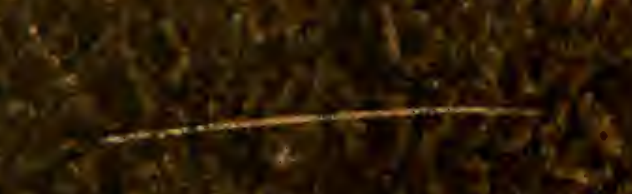

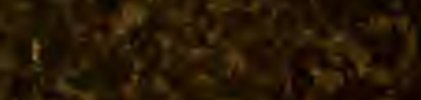

(i)

2.

a

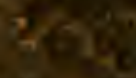

$\lim _{\rightarrow \rightarrow \infty} i \frac{10}{10}$

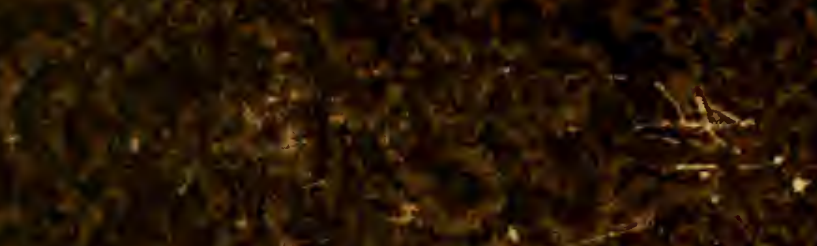

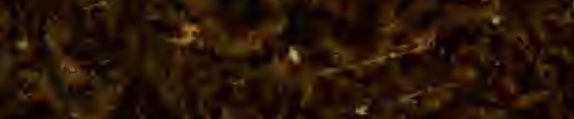

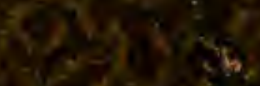

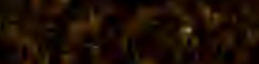

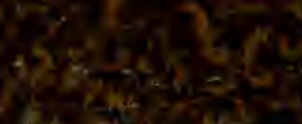
SW (4)

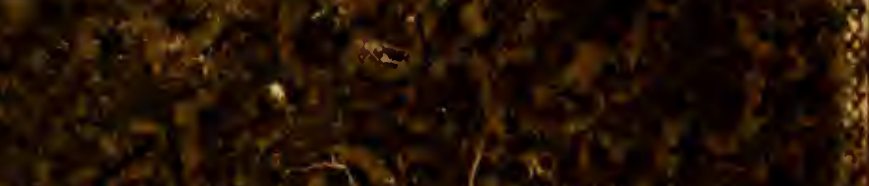
4.

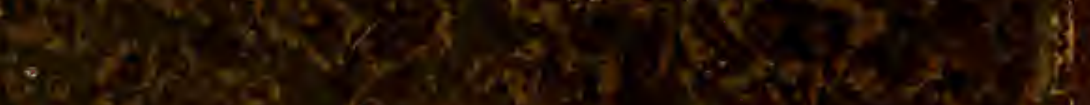

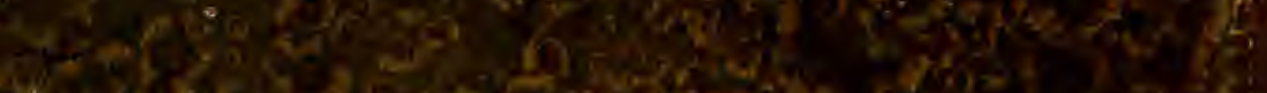

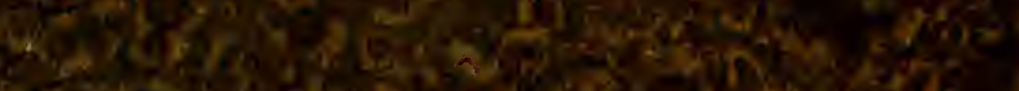

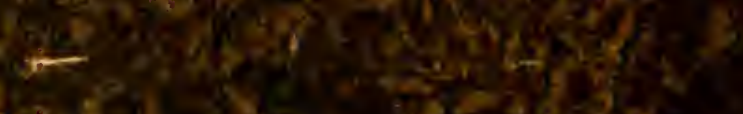
$\left(3-\frac{1}{2}\right.$

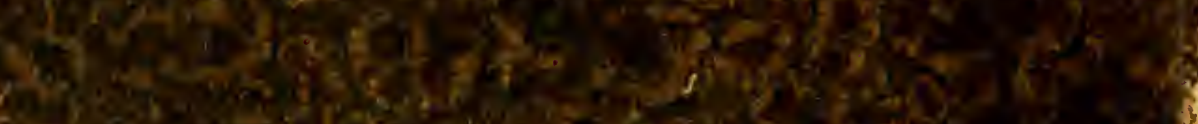

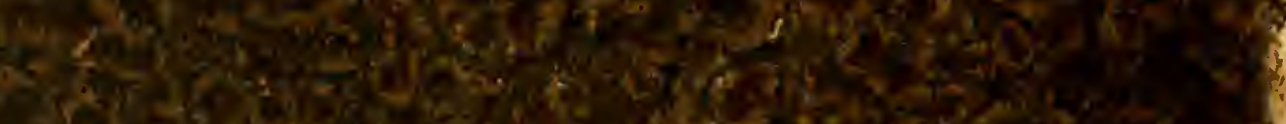

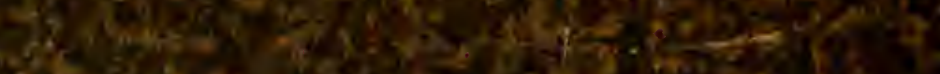

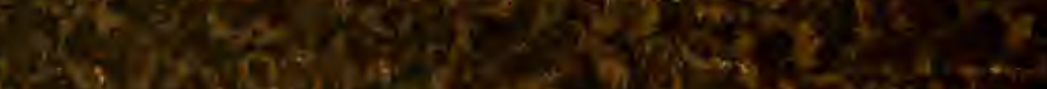

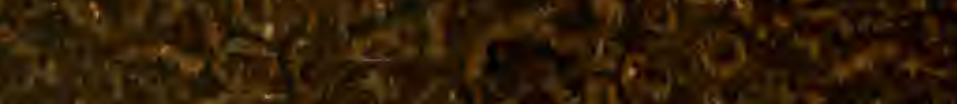
(3) 